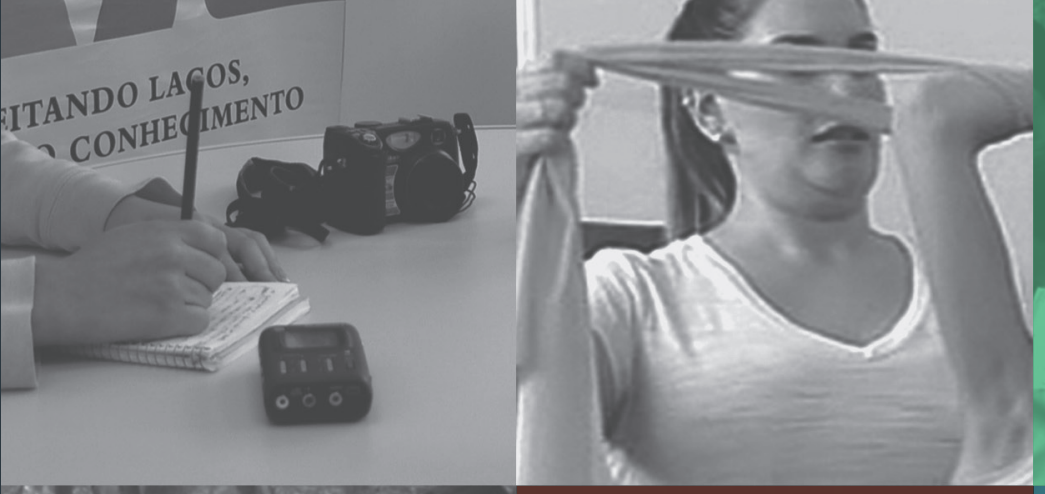

\title{
UFSEGar Pargeira
}

Programas de extensão para a cooperação com a sociedade 
Universidade Federal de São Carlos Pró-Reitoria de Extensão

\section{UFSCar Parceira}

Programas de extensão para

a cooperação com a sociedade

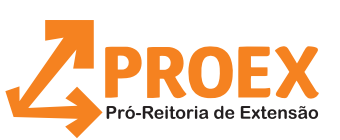




\section{UNIVERSIDADE FEDERAL DE SÃO CARLOS}

Reitor

Prof. Dr. Targino de Araújo Filho

Vice-Reitor

Prof. Dr. Adilson Jesus Aparecido de Oliveira

Pró-Reitora de Graduação

Profa. Dra. Claudia Raimundo Reyes

Pró-Reitora de Pós-Graduação

Profa. Dra. Débora Cristina Morato Pinto

Pró-Reitora de Pesquisa

Profa. Dra. Heloisa Sobreiro Selistre de Araújo

Pró-Reitora de Extensão

Profa. Dra. Claudia Maria Simões Martinez

Pró-Reitora de Administração

Edna Hércules Augusto

Pró-Reitor de Assuntos Comunitários e Estudantis

Geraldo Costa Dias Júnior

Pró-Reitor de Gestão de Pessoas

Prof. Dr. Mauro Rocha Côrtes

\section{Pró-Reitoria de Extensão}

Pró-Reitora de Extensão Profa. Dra. Cláudia Maria Simões Martinez

Pró-Reitor Adjunto de Extensão

Prof. Dr. Rodolfo Antônio de Figueiredo

Coordenador de Atividades de Extensão Prof. Dr. Fábio Gonçalves Pinto

Coordenadora de Projetos Especiais

Profa. Dra. Vera Alves Cepeda

Coordenador de Cultura

Prof. Dr. Wilson Alves-Bezerra

Coordenador de Cursos de Extensão

Prof. Dr. Murillo Rodrigo Petrucelli Homem

Coordenadora de Apoio a Eventos

Rosemeire Gallo Mecca

Núcleos de Extensão UFSCar-Sociedade

Núcleo UFSCar Escola

Prof. Dr. Anselmo João Calzolari Neto

Núcleo UFSCar Município

Prof. Dr. Bernardo Arantes do N. Teixeira

Núcleo UFSCar Saúde

Angélica Maria Adurens Cordeiro
Núcleo UFSCar Empresa

Profa. Dra. Marta Cristina Marjotta Maistro

Núcleo UFSCar Sindicato

Prof. Dr. Paulo Eduardo Gomes Bento

Núcleo. Educação, Tecnologia e Cultura

Profa. Dra. Teresa Mary Pires de Castro Melo

Pró-Reitoria de Extensão

UFSCar Parceira: Programas de extensão para a cooperação com a sociedade / Pró-Reitoria de Extensão. - São Carlos : PROEX, 2016.

$428 \mathrm{p}$

https://doi.org/10.4322/2016-ufscar-parceira

E-book

ISBN 978-85-66406-04-7

1. Extensão universitária. 2. Programas e projetos. 3. Interação UFSCar sociedade. 4. Interação universidade e sociedade. 5. PROEX. 6. UFSCar. I. Título. 


\section{Sumáríio}

V Apresentação

vi Prefácio

viii A Extensão Universitária na UFSCar - Um Histórico

11 Índice por Palavras-Chave

16 Índice por Coordenadores

20 Comunicação

$24 \quad$ Cultura

28 Direitos Humanos e Justiça

31 Educação

$51 \quad$ Meio Ambiente

60 Saúde

74 Tecnologia e Produção

95 Trabalho

98 Resumos 


\section{Apresentação}

No início do ano de 2016, último ano de nossa gestão à frente da Pró-Reitoria de Extensão da UFSCar, diante da constatação da riqueza das atividades de extensão desenvolvidas pelos extensionistas, sentimo-nos comprometidos em socializar e difundir um conjunto expressivo de projetos e ações de extensão presentes na UFSCar. Decidimos fazer isto com o objetivo de dar maior visibilidade aos Programas de Extensão desenvolvidos no âmbito dos quatro campi da UFSCar, a fim de fomentar parcerias, inspirando assim o título da presente publicação: UFSCar Parceira.

Decidimos o formato e o conteúdo da publicação, a partir de um profícuo debate com os coordenadores de área da PROEX, com a anuência do Conselho de Extensão da UFSCar, que aprovou no início de 2016 um aporte de recursos para investimentos na difusão e disseminação do conhecimento produzido no âmbito da extensão.

Considerando a modernização que permeia os processos interativos na atualidade, mediada pelo mundo virtual, e considerando ainda um cenário nacional de crise, esperamos que este instrumento virtualizado de interação entre a universidade e a sociedade, na forma de um e-book, favoreça a transferência de informações, propicie relações dialógicas na construção de propostas entre parceiros e a UFSCar e assim potencialize a geração de novos projetos e parcerias por meio de ações extensionistas.

Acreditamos que o alcance desta publicação possa atingir diversos pontos e regiões do nosso país e, quiçá, motivar parcerias internacionais mas, muito especialmente e, particularmente, apostamos nos possíveis e desejáveis impactos positivos que possa trazer aos municípios onde a UFSCar está inserida (Araras, Buri, São Carlos e Sorocaba) e nas suas respectivas regiões.

Esta publicação conta com um prefácio cuidadosamente redigido pelo Prof. Glaucius Oliva, com um capítulo que versa sobre o histórico da extensão e dos Programas na UFSCar redigido pelos Profs. Wilson Alves-Bezerra e Vera Alves Cepêda e ainda com a descrição de todos os 322 Programas de Extensão ativos, incluindo título, palavraschave, nome do coordenador e e-mail para contato. No título de cada Programa há um hiperlink que direciona o interessado para um banco de dados com informações detalhadas sobre o programa, na forma de um resumo.

Esperamos, a partir da ampla divulgação deste catálogo de programas para além da fronteira acadêmica, estimular a geração de novos projetos que venham a contribuir para a resolução de problemas sociais na direção de uma sociedade mais justa e igualitária.

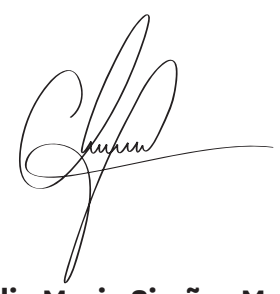

Claudia Maria Simões Martinez

Pró-Reitora de Extensão

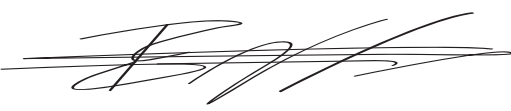

Rodolfo Antônio de Figueiredo

Pró-Reitor Adjunto de Extensão

Gestão 2012-2016 


\section{Prefácio}

Glaucius Oliva

A ciência e a universidade brasileira são muito jovens. Apenas no século XIX algumas escolas de medicina, direito e engenharia foram fundadas no Rio de Janeiro, Salvador, Recife, São Paulo e Minas Gerais e as primeiras universidades somente foram estabelecidas no início do século XX. inicialmente com a missão de formar profissionais para o desenvolvimento do país. A ciência estava restrita a alguns institutos de pesquisa especializados dedicados à saúde pública com a liderança de pioneiros, como Oswaldo Cruz, Carlos Chagas e Vital Brazil. A Academia Brasileira de Ciências (ABC), criada em 1916 e a Sociedade Brasileira para o Progresso da Ciência (SBPC), em 1948, tiveram papel fundamental para a inclusão da ciência na agenda nacional. Até o final da Segunda Guerra Mundial, o país tinha um pequeno número de Universidades e muito poucos grupos de pesquisa, a maioria concentrados no eixo Rio-São Paulo.

Em 1951 duas agências federais foram criadas, o Conselho Nacional de Pesquisa (CNPq) - com a missão de promover o desenvolvimento da ciência e tecnologia -, e a Campanha Nacional de Aperfeiçoamento de Pessoal de Nível Superior (CAPES) - com a missão de promover a capacitação especializada para o desenvolvimento do país.

No entanto, como resultado de grande esforço nacional, o Brasil adentra o século XXI tendo superado o desafio de estabelecer uma rede expressiva de instituições de ensino superior e a ela acoplado um sistema nacional de ciência e tecnologia que definitivamente inseriu o país no cenário global de produção e transmissão do saber. Nesta metade final do século XX, o compromisso central das universidades brasileiras foi a formação de profissionais qualificados para o país e também o estabelecimento de competências e infraestrutura para fazer ciência em todas as áreas do conhecimento.

Gradativamente ao longo deste período ampliou-se a demanda da sociedade brasileira pelo engajamento das suas universidades na solução direta dos problemas nacionais prementes, como saúde, educação básica, popularização da cultura e o desenvolvimento tecnológico com seus impactos econômicos e sociais. Estabeleceuse assim, inclusive nos estatutos universitários, o paradigma da tríplice missão universitária moderna, com a indissociabilidade entre o ensino, a pesquisa e a cultura e extensão. Incorporaram-se novas atividades ao cotidiano acadêmico, com o contato mais próximo com a sociedade, através de seus hospitais, museus, programas de extensão para a comunidade, a formação e reciclagem de professores, os centros de divulgação de ciências, os cursos de especialização e formação continuada, os programas e centros dedicados ao desenvolvimento de politicas publicas e os empreendimentos de inovação tecnológica em parceria com as empresas.

É fundamental observar que a crescente incorporação das atividades de cultura e extensão tem sido realizada sem qualquer prejuízo a todas as missões anteriormente assumidas pela Universidade, ao contrário, tornou-as mais vivas, arejadas e polinizadas pela constante interação com a sociedade.

No entanto, chegamos aos tempos atuais com o renovado desafio de consolidar a Educação, Ciência e Cultura como bens inalienáveis e estruturantes do futuro do país. O crescimento dos investimentos necessários à ampliação do acesso ao ensino superior e os crescentes custos da pesquisa científica moderna, tem gerado forte cobrança e em certa medida a incompreensão da sociedade como um todo e da classe política em particular, em relação à Universidade e suas missões.

Em grande parte a responsabilidade sobre o descaso social e politico em relação à Ciência \& Tecnologia cabe a nós mesmos, da comunidade cientifica e universitária, que temos demonstrado pouca capacidade em conquistar o apoio da sociedade para a convicção de que sem conhecimento não haverá crescimento econômico e social. $\mathrm{O}$ antigo contrato social entre Ciência e Sociedade, que operou com alguma eficiência no século XX, baseou-se numa relação de total confiança por parte da sociedade naquilo que os acadêmicos realizassem. No entanto, este panorama tem mudado, particularmente nas últimas décadas. Cada vez mais espera-se a adequada prestação 
de contas à sociedade, quanto às realizações e progressos em ensino, pesquisa e extensão. Nós, professores e pesquisadores, temos que, cada vez mais, de forma equilibrada e balanceada, adotar programas de pesquisa dirigidos à solução dos grandes problemas nacionais. As agências de fomento, que até a pouco tinham a função de atender à demanda qualificada e assim responder pela manutenção da ciência básica nas universidades e institutos de pesquisa, têm se transformado em instrumentos para a promoção das prioridades nacionais tecnológicas, econômicas e sociais, através dos programas dirigidos de financiamento de projetos. Assim, o novo contrato social entre Ciência e Sociedade, pressupõe um conhecimento chamado de "socialmente robusto". Não basta ser confiável, sob a óptica convencional científica. É necessário ser sensível a um espectro mais amplo de implicações sociais.

Para a Universidade brasileira, é questão de sobrevivência interagir permanentemente com a sociedade, de forma indissociável com a pesquisa e o ensino, por meio de programas de extensão universitária, bem como atividades e produtos culturais, dirigidos a todos os segmentos da sociedade, disponibilizando de forma rápida e eficiente o conhecimento e a prática gerados, fertilizando-se com as demandas e expectativas externas e assim consolidando sua relação com o povo brasileiro pelo cumprimento de sua missão educacional, científica e cultural.

Tendo a sociedade como objeto maior de sua atuação, esta obra demonstra que a UFSCar tem mudado o paradigma da extensão universitária como uma atividade de sentido único de dentro para fora de seus muros, isolada e independente, passando a encara-la de forma integrada a todas as suas outras missões, nutrindo-se das demandas externas como fonte de motivação para suas atividades de ensino e pesquisa, ao mesmo tempo em que cumpre seu papel de incorporação do conhecimento em todas as instâncias socioeconômicas, políticas e culturais, para o pleno desenvolvimento do país.

Compilar em um livro eletrônico o extenso espectro de atividades de cultura e extensão conduzidas pela UFSCar, de fácil acesso para informação e consulta pela comunidade interna e externa da universidade, foi mais um passo inovador da Pró-Reitoria de Extensão da UFSCar. No ano que celebra os 45 anos de sua fundação, a UFSCar brinda a comunidade com este portfolio exuberante de ações, projetos e programas de cultura e extensão, os quais contribuem de forma significativa para o estreitamento dos laços que unem a UFSCar à sociedade são-carlense, paulista e brasileira.

Glaucius Oliva é Professor Titular do Instituto de Física de São Carlos. É Membro Titular da Academia Brasileira de Ciências e Comendador da Ordem Nacional do Mérito Científico. Também é membro da TWAS (The World Academy of Sciences for the advancement of science in developing countries) e Fellow do Birkbeck College - University of London. Foi Diretor (2010) e Presidente (2011-2015) do Conselho Nacional e Desenvolvimento Científico e Tecnológico - CNPq, bem como fundador e membro do Governing Board do Global Research Council (GRC). 


\section{A Extensão Universitária na UFSCar -Um Histórico}

Wilson Alves-Bezerra e Vera Alves Cepêda

Refletir sobre a extensão universitária é tarefa complexa porque implica a pergunta sobre o projeto de universidade desejada, sobre sua finalidade e responsabilidade, sobre o tipo de relação que esta universidade propõe com o restante da sociedade. Refletir sobre a extensão hoje implica, também, avaliar o seu potencial como locus de produção do conhecimento e suas fronteiras com a realidade externa e a diversidade de agendas, problemas, focos, métodos e epistemes que envolvem a atividade científica. De forma sucinta, a extensão praticada hoje pelas universidades amplia a conexão com a realidade externa abrindo um estratégico canal de comunicação de dupla via: de um lado dissemina, aplica e submete ao teste prático suas inovações, conhecimento, expertise e produtos e, de outro lado, recebe informações sobre problemas e desafios que retroalimentam a cadeia de sua função fundamental - a de produzir conhecimento válido e destinado a seu tempo histórico. Desta forma, a extensão tem se caracterizado no período recente como uma fronteira, uma zona limítrofe de fortalecimento e inovação da produção acadêmica em forte diálogo com o contexto externo à universidade. E este processo aparece na experiência da UFSCar.

No campo da extensão universitária, a Universidade Federal de São Carlos tem se transformado muito ao longo de sua história. Em 1990, em vídeo institucional comemorativo aos 20 anos da universidade, com o lema 0 conhecimento como compromisso, ouve-se que "além do ensino, os docentes realizam uma significativa e diversificada atividade de pesquisa, com extenso trabalho de divulgação do conhecimento que produzem e sistematizam. Um dos compromissos permanentes da universidade foi e é a produção do conhecimento". Nesta colocação, nota-se a ênfase na produção do conhecimento, mais que em sua circulação. Tal posicionamento adiantava a necessidade de trilhar novos caminhos, pela via da trajetória da extensão que a própria universidade passou a fazer, a partir da transformadora década de 1990. Foi no cenário da fundação, em 1987, do Fórum dos Pró-Reitores de Extensão (FORPROEX), no contexto da redemocratização brasileira, que tal transformação se deu.

Consta na Política Nacional de Extensão Universitária formulada pelo FORPROEX, como diretrizes de atuação do campo extensionista brasileiro que:

Nunca é demais lembrar que a mera produção de conhecimento, por si só, não leva ao desenvolvimento sustentável e ético. Se o desenvolvimento econômico pode, eventualmente, ser promovido com boas teorias, tecnologias inovadoras e profissionais competentes, o desenvolvimento sustentável e humano requer mais que isso. Tecnologias, técnicas e teorias não são neutras. Por exemplo, as tecnologias e técnicas utilizadas na construção de moradias, no saneamento básico, no transporte urbano podem favorecer determinados grupos sociais em detrimento de outros; as teorias que orientam o desenho das políticas sociais são quase sempre ideologicamente enviesadas, e a escolha de um desenho ou outro envolve valores imponderáveis, não redutíveis a cálculos precisos. (Política Nacional de Extensão Universitária, 2012: 35)

Em seus princípios, a Política Nacional de Extensão Universitária já revoluciona ao reconhecer como lócus de conhecimento não mais apenas o que a academia produz, mas o diálogo que esta estabelece com o restante da sociedade e, ademais, os conhecimentos que nela pode reconhecer e sistematizar. O Fórum dos Pró Reitores de Extensão fixa ainda cinco princípios básicos da extensão universitária: 
1. Interação Dialógica; 2. Interdisciplinariedade e interprofissionalidade; 3. Indissociabilidade EnsinoPesquisa-Extensão; 4. Impacto na Formação do Estudante; 5. Impacto e Transformação Social. (Política Nacional de Extensão Universitária, 2012: 46)

Se os princípios da extensão encontram-se atualmente tão claramente formulados, é preciso considerar que na década de 1990, ano acima evocado a partir do vídeo institucional, o mesmo não se dava. Foi pouco a pouco que se estabeleceu a reflexão de que era preciso aumentar a relação da universidade com o restante da sociedade, através da extensão universitária - sempre em articulação com a pesquisa e com o ensino. Tais princípios permitiram à UFSCar minorar aquilo que pesquisadores da área apontaram como um desequilíbrio histórico: “Nos primeiros 20 anos da UFSCar (...) a extensão, embora existisse, era uma atividade ainda incipiente”. (Souza, 2007: 88). Assim, em 1995, a UFSCar criou os Núcleos de Extensão, com a missão de "captar demandas da sociedade e realizar seu encaminhamento para a comunidade interna da UFSCar analisando e viabilizando parcerias.” (PROEX, 2016: 111).

Os Núcleos de Extensão inicialmente implantados foram UFSCar-Cidadania, UFSCar-Empresa, UFSCar-Escola, UFSCar-Município, UFSCar-Saúde, UFSCar-Sindicato e mais recentemente o Núcleo Educação, Tecnologia e Cultura. Suas funções consistem em ampliar a integração entre universidade e sociedade e também funcionar como elemento catalisador, provocador e dinamizador das atividades de extensão e de grupos extensionistas internos à universidade em eixos de articulação interdisciplinar e multidisciplinar. Desta forma, os núcleos intensificam a realização de programas, projetos e atividades de cunho social, em rede interna e externa, em forte contato com a agenda de pesquisas existentes nas diversas áreas da produção acadêmica da UFSCar. Esses núcleos buscam atender as demandas da sociedade, contribuindo para a resolução dos problemas dos diferentes segmentos sociais e, de outro modo, colocam em contato a produção acadêmica interna em interação com o contexto externo.

A extensão universitária organiza-se, na UFSCar, a partir de Programas de Extensão. Atualmente, segundo o Regimento da Extensão Universitária desta universidade,

O Programa de Extensão constitui um conjunto de projetos e atividades de extensão, desenvolvidos junto à comunidade e reunidos por afinidade, conforme as linhas de atuação ou áreas de conhecimento de um departamento acadêmico, centro ou unidade multidisciplinar de ensino, pesquisa e extensão, podendo envolver outros setores. (Resolução COEX 03/2016, Cap. 2, art 10)

Os documentos sobre os Programas de Extensão da UFSCar apontam como suas funções o fomento de projetos institucionais multi e interdisciplinares e a integração entre professores, alunos e técnicos das diferentes áreas de conhecimento de forma a obter uma relação mais orgânica da UFSCar com a sociedade. A partir do ano de 1999 a UFSCar conferiu aos programas de extensão um caráter protagônico, não só como elemento propiciador de maior visibilidade do potencial extensionista da instituição, mas principalmente, como elemento estimulador da forma de se praticar a extensão, vinculando-a indissociavelmente ao ensino e à pesquisa.

É notável o crescimento da extensão nos últimos anos, atestada pelos dados que apresentamos a seguir:

\section{Quantitativo de Programas de Extensão na UFSCar: Evolução no Período 1999-2016}

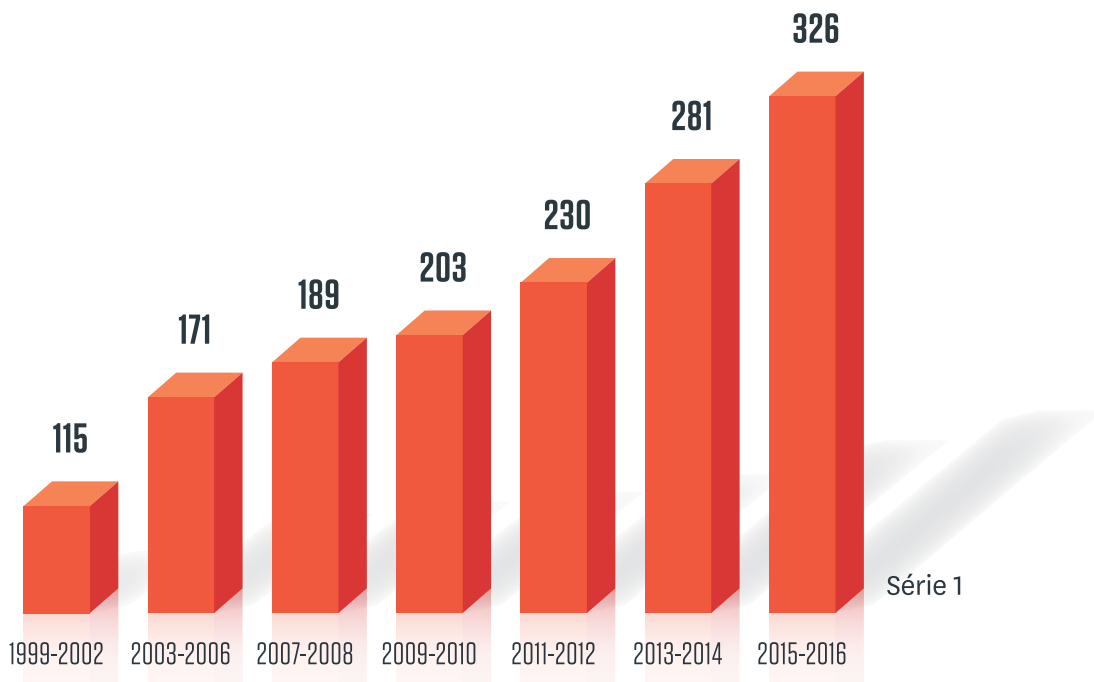

Crescimento do número de programas de extensão no período 1999-2016. Fonte: PROEX/UFSCar 
Nota-se, pelos dados acima, que ao longo dos últimos 15 anos, o número de programas de extensão praticamente triplicou. Cada um dos programas reúne um conjunto numeroso de projetos, os quais, por sua vez, mobilizam uma equipe de professores, técnicos e estudantes de graduação e pós-graduação da universidade e de fora dela.

A presente publicação organiza-se a partir dos programas de extensão ativos na universidade. É a forma de oferecer aos leitores - sejam eles pesquisadores, extensionistas ou possíveis parceiros - um mapeamento fiel do estado atual da extensão universitária em nossa universidade.

Além disso, os mais de 320 programas de extensão aqui presentes, organizados nas oito áreas temáticas estabelecidas pelo Fórum de Pró-Reitores de Extensão, oferecem uma mostra das possibilidades de potencias parcerias entre universidade e sociedade. Estabelecer pontes entre a UFSCar e a sociedade civil é particularmente salutar num momento político e histórico tão complexo como o atual, no qual o papel e os princípios da universidade pública, gratuita, de qualidade e comprometida com a transformação social, devem ser reafirmados e postos em prática no cotidiano.

Cabe reafirmar tal papel da universidade brasileira, fazendo reverberarem as palavras do português Boaventura de Souza Santos em 2004:

A área da extensão vai ter no futuro próximo um significado muito especial. No momento em que o capitalismo global pretende funcionalizar a universidade e, de facto, transformá-la numa vasta agência de extensão ao seu serviço, a reforma da universidade deve conferir uma nova centralidade às atividades de extensão (com implicações no curriculum e nas carreiras dos docentes) e concebê-las de modo alternativo ao capitalismo global, atribuindo às universidades uma participação activa na construção da coesão social, no aprofundamento da democracia, na luta contra a exclusão social e a degradação ambiental, na defesa da diversidade cultural (SANTOS, 2004:73)

Para finalizar, reafirmamos que a extensão na UFSCar tornou-se um elemento importante de sua atividade acadêmica, nos mais diversos campos do saber e tornou também a universidade mais complexa, mais comprometida socialmente e na vanguarda das transformações de seu entorno. Por isso é que, mais do que produzir conhecimento, a UFSCar quer ser sua parceira, para juntos enfrentarmos os desafios de nosso tempo, com conhecimento, comprometimento e pluralidade de ideias.

\section{REFERÊNCIAS BIBLIOGRÁFICAS}

FORPROEX. Política Nacional de Extensão Universitária, 2012

PROEX. Resolução COEX 03/2016. Dia 17 de março em 2016. Disponível em: Acessado em 05 out. 2016.

PROEX. Relatório de gestão do exercício 2012-2016. São Carlos: UFSCar, 2016.

SANTOS, Boaventura de Souza (2004). A universidade no século XXI: para uma reforma democrática e emancipatória da universidade. São Paulo: Cortez.

SOUZA, Marcos Lopes de (2007). Atividade curricular de integração entre ensino, pesquisa e extensão (ACIEPE): anseios, conjunturas e contornos de inovações curriculares em movimento. São Carlos: Tese de doutorado em Ciências Humanas, UFSCar.

Wilson Alves-Bezerra é Coordenador de Cultura, na Pró-Reitoria de Extensão da Universidade Federal de São Carlos. Doutor em Letras pela UERJ, é autor de livros de ensaio, poesia e de algumas traduções de literatura hispano-americana. É professor da UFSCar desde 2004, onde atua na graduação em Letras e na pós-graduação em Estudos de Literatura.

Vera Alves Cepêda é Coordenadora de Projetos Especiais, na Pró-Reitoria de Extensão da Universidade Federal de São Carlos. Doutora em Ciência Política pela USP, é professora do Departamento de Ciências Sociais da UFSCar e também atua no Programa de Pós-Graduação em Ciência Política. Desenvolve trabalhos e pesquisas no campo do pensamento político e social brasileiro. 


\section{$\overline{\text { Inditibe por }}$}

\section{Palavras-Ehave}

\section{COMO UTILIZAR ESSE MATERIAL}

Abaixo apresentamos um índice das palavras-chave que foram usadas para descrever todos os 322 Programas de Extensão ativos.

Clique sobre o número a frente da palavra-chave para acessar os resumos e outras informações de cada programa. No topo da página de cada resumo você encontra um link para retornar para o ponto de onde partiu ou para o início do índice.

A

ação afirmativa $\underline{203}$

ação e representações política 220

acessibilidade 132, 133, 219

acompanhamento 266

aconselhamento genético 274

adequação ambiental $\underline{393}$

administração $\underline{367}$

adulto $\underline{276}$

agrícola 379,383

agricultura $\underline{423}$

agricultura familiar 170, 334

agroecologia $225,246, \underline{253}$

agroindústria 354

agronegócio $\underline{186}$

agropecuária 234

agrotóxicos 226

alfabetização 135, 222

alfabetização científica $\underline{201}$

alimentos 268

ambiental 185,404

ambiente $\underline{338}$

analgesia $\underline{\underline{279}}$

análise de fármacos 376

análise de regressão $\underline{195}$

análise do comportamento $\underline{147}$

análise e projeto $\underline{413}$

análises cromatográficas $\underline{386}$

anatomia humana 137

aperfeiçoamento $\underline{157}, \underline{180}$

aplicação $\underline{405}$

apoio a consultas e análises g $\underline{399}$

apoio matricial 270

apoio tecnológico 332

aprendizagem 168, 209

aprendizagem de adultos 138 aquicultura sustentável 241

aquisição de leitura $\underline{222}$

aramar 252

araras 114

áreas degradadas $\underline{244}$

arte $\underline{114}$

assessoria tecnocienciometrica $\underline{141}$

assistência 271

assistência integral à saúde $\underline{297}$

assistência terminal 300

associações $\underline{107}$

atenção a grupos de pessoas com

necessidades especiais $\underline{147}, \underline{188}, \underline{219}, \underline{274}$,

282, 300,301

atenção ao indivíduo 147

atenção à saúde $\underline{274}$

atenção hospitalar $\underline{308}$

atenção integral $\underline{160}$

atenção integral à criança $\underline{266}, \underline{268}, \underline{270}, \underline{273}$,

$$
\text { 296, } 297
$$

atenção integral à mulher $\underline{291}, \underline{307}, \underline{316}$

atenção integral à saúde de adultos $\underline{100}, \underline{262}$

$264, \underline{275}, 277,281,283,290,294, \underline{306}, \underline{309}$,

$310,315,322$

atenção integral à terceira idade $\underline{213}, \underline{289}, \underline{314}$,

$\underline{317}$

atenção primária à saúde $\underline{298}$

atendimento 267,312

atendimento eletrônico 371

atividade humana 112

atividades $\underline{336}, \underline{341}, \underline{370}$

atividades complementares $\underline{326,402}$

atraso de desenvolvimento $\underline{187}$

audiovisual 106

autismo 147

automação 416,418

autoria 154 avaliação $\underline{187}$

avaliação respiratória $\underline{294}$

aves $\underline{400}$

avifauna $\underline{252}$

\section{B}

bacias hidrográficas $\underline{224}$

banco de dados $\underline{328}$

bases de dados científicas 141

baterias $\underline{392}$

bebês $\underline{266}$

bem estar $\underline{120}$

bibliometria 372

biblioteca 142

biodiversidade $\underline{231}$

bioensaios 192

biogeoquímica $\underline{404}$

bioindicadores $\underline{227}, \underline{259}$

biologia 102,240

biologia molecular $\underline{339}, \underline{340}$

biologia sintética $\underline{360}$

biologia vegetal $\underline{254}$

biomassa 408

biometria 199

bioprocessos 250

bioquímica $\underline{339}, \underline{340}$

biosensores 227

biotecnologia $\underline{227}, \underline{339}$

bovinocultura 341

brasil áfrica $\underline{124}$

\section{G}

cana-de-açúcar $\underline{346}, \underline{351}, \underline{364}$ canavieira 354 
capacitação 254, 292, 343, 358, 359, 373

capacitação de gestores de políticas públicas

$115,128,248$

caracterização 344,421

caracterização de materiais $\underline{378}$

cardiologia 262

cardiovascular $\underline{288}$

cavernas $\underline{229}$

ciclos de vida $\underline{308}$

cidadania $\underline{128}, \underline{135}, \underline{286}, \underline{318}$

cidades inteligentes $\underline{105}$

ciência $\underline{144}, \underline{145}, \underline{215}$

ciências agrárias $\underline{214}$

ciências sociais 220

cientista 215

cinema e vídeo $\underline{106}$

cirrose hepática $\underline{310}$

citrus 351

código florestal $\underline{394}$

cognição 317

colaboração $\underline{217}, \underline{375}$

comportamento de solos 249

comportamento simbólico $\underline{\underline{136}}$

compósitos 348

computação $\underline{143}, \underline{330}, \underline{355}, \underline{362}$

computação ubíqua $\underline{325}$

comunicação $\underline{100}, \underline{102}, \underline{103}, \underline{104}, \underline{105}, \underline{106}, \underline{107}$,

$108, \underline{109}, 110, \underline{114}, \underline{122}$

Comunicação 101

comunicação científica $\underline{145}$

comunicação escrita e eletrônica 101, 102, 118, 155

comunicação social 101

comunidade 113

conceitos $\underline{368}$

concreto armado 355

concreto pré-moldado $\underline{398}$

conhecimento 150, 166

conhecimento científico $\underline{156}$

conhecimento impreciso $\underline{417}$

conhecimento tecnológico $\underline{156}$

conscientização $\underline{275}$

conservação 229, 231

construção 108

construção civil 397

construção de material didático $\underline{201}$

construção industrializada $\underline{398}$

consultoria 378,415

controle $\underline{356}$

conversores de energia 349

cooperação interinstitucional $\underline{120}, \underline{134}, \underline{195}$,

$251,258,305,312,313,328,371,376,377,392$,

$\underline{395}, \underline{405}$

cooperação internacional $\underline{375}$

cooperativas 425

corpo e movimento 149

corpo humano 137

corrosão $\underline{392}$

criança 172, 291, 296

criatividade $\underline{143}$

crítica 174

cronicidade 281

cuidado 301

cuidado de saúde 325

cuidado em saúde $\underline{264}, \underline{265}$

cuidado integral 273

cuidados paliativos $\underline{300}$

cultura $\underline{112}, \underline{113}, \underline{114}, \underline{115}, \underline{116}, \underline{117}, \underline{118}, \underline{119}, \underline{120}, \underline{121}$

$\underline{122}, \underline{136}, \underline{167}$

cultura e identidade $\underline{220}$

cultura e memória social 117, 121, 189

cultura e trabalho $\underline{115}$

cursos $\underline{236}$

cursos de curta duração $\underline{357}$

D

deficiência $\underline{188}$

demências $\underline{314}$

democratização $\underline{150}$

democratização do conhecimento $\underline{\underline{209}}$

dermatologia $\underline{267}$

desenvolvimento $\underline{151}, \underline{153}, \underline{185}, \underline{208}, \underline{233}, \underline{295}, \underline{345}$

desenvolvimento de materiais $\underline{415}$

desenvolvimento de métodos $\underline{386}$

desenvolvimento de produtos $\underline{331}$

desenvolvimento de projetos $\underline{386}$

desenvolvimento de software $\underline{327}, \underline{363}, \underline{374}$

desenvolvimento do sistema de saúde $\underline{261}, \underline{263}$,

$\underline{265}, \underline{276}, \underline{278}, \underline{285}, \underline{288}, \underline{303}, \underline{304}, \underline{318}, \underline{319}, \underline{320}$

desenvolvimento econômico 164

desenvolvimento infantil $\underline{216}$

desenvolvimento profissional 139

desenvolvimento rural 146, 151, 153, 186, 225,

$\underline{234}, \underline{242}, \underline{246}, \underline{249}, \underline{334}, \underline{337}, \underline{338}, \underline{341}, \underline{346}$,

$347, \underline{351}, 352, \underline{354}, \underline{356}, \underline{379}, \underline{383}, \underline{394}, \underline{400}$

desenvolvimento sustentável $\underline{243}, \underline{255}$

desenvolvimento urbano $\underline{126}, \underline{164}, \underline{233}, \underline{239}, 333$

$\underline{355}, 366, \underline{301}$

desigualdades $\underline{126}$

desigualdades sociais $\underline{129}$

desporto $\underline{120}$

diabetes mellitus $\underline{\mathbf{2 8 3}}$

diagnose $\underline{356}$

diferença 126

difusão do conhecimento $\underline{326}, \underline{402}$

digital $\underline{154}$

direito ambiental $\underline{255}$

direitos de grupos sociais $\underline{122}, \underline{125}, \underline{127}, \underline{129}, \underline{150}$,

$\underline{158}, \underline{159}, \underline{203}, \underline{205}$

direitos humanos $\underline{158}, \underline{162}$

direitos humanos e justiça $\underline{124}, \underline{125}, \underline{126}, \underline{127}$

$\underline{128}, \underline{129}$

direitos sociais $\underline{161}$

discurso $\underline{107}$

disfunção física $\underline{306}$

disfunções físicas $\underline{313}$

disseminação dos conhecimentos $\underline{357}$

divulgação $\underline{178}$

divulgação científica $\underline{101}, \underline{102}, \underline{110}, \underline{145}, \underline{155}, \underline{169}$

doença hepática gordurosa $\underline{310}$

doenças crônicas $\underline{282}$

doenças de plantas $\underline{356}$

doenças tropicais $\underline{409}$

doméstica 311

dor $\underline{279}, \underline{300}$

E

ecologia $\underline{236}, \underline{238}$

ecologia da paisagem $\underline{235}, \underline{242}$

economia 208

economia aplicada $\underline{186}$

economia empresarial $\underline{367}$

economia e sociologia $\underline{214}$

ecossistemas 232

ecossistemas tropicais $\underline{251}$ educação 124, 127, 131, 132, 133, 134, 135, 136, 137 , $138,139,140,141,142,143,144,145,146,147$, $148,149,150,151,152,153,154,155,156,157$, $158,159,160,161,162,163,164,165,166,167$, $168,169,170,171,172,173,174,175,176,177$, $178,179,180,181,182,183,184,185,186,187$, $188,189,190,191,192,193,194,195,196,197$, $\underline{198}, \underline{199}, \underline{200}, \underline{201}, \underline{202}, \underline{203}, \underline{204}, \underline{205}, 206$, $\underline{207}, \underline{208}, \underline{209}, \underline{210}, \underline{211}, \underline{212}, \underline{213}, 214, \underline{215}, \underline{216}$, 217, 218, 219, 220, 221, 222, 285, 297, 301, 302, $303,316,324,357,405,412$

educação a distancia $\underline{207}, \underline{212}$

educação a distância $\underline{\underline{179}}$

educação à distância $\underline{207}, \underline{212}, \underline{412}$

educação ambiental $185,192,229,230,236$,

$\underline{237}, \underline{253}, \underline{254}, \underline{257}, \underline{339}, \underline{344}, \underline{381}, \underline{393}, \underline{404}$ educação básica $\underline{210}$

educação continuada $\underline{103}, \underline{104}, \underline{107}, \underline{116}, \underline{124}$,

$131,138,139,140,142,143,144,149,154,157$, $163,165,167,168,169,172,174,175,176,178$, $179,181,182,190,198,199,201,202,204,208$, $209,217,218,240,247,269,292,326,358$,

$\underline{359}, \underline{367}, \underline{368}, \underline{419}$

educação de jovens e adultos $\underline{137}$

educação de surdos $\underline{103}$

educação em saúde $\underline{138}, \underline{265}, \underline{298}, \underline{325}$

educação escolar e não escolar 202

educação especial $\underline{132}, \underline{133}, \underline{160}, \underline{161}, \underline{162}, \underline{171}$,

187, 191, 206, 210

educação física $\underline{149}$

educação inclusiva $\underline{110}, \underline{210}$

educação infantil $\underline{173}, \underline{211}, \underline{216}$

educação médica $\underline{279}$

educação musical $\underline{134}$

educação no campo 159

educação nutricional $\underline{268}$

educação para a cidadania $\underline{165}$

educação profissional $\underline{108}, \underline{112}, \underline{136}, \underline{152}, \underline{156}$,

$177, \underline{180}, \underline{183}, \underline{184}, \underline{194}, \underline{200}, \underline{214}, \underline{235}, \underline{238}, \underline{293}$,

$\underline{295}, \underline{329}, \underline{330}, \underline{335}, \underline{357}, \underline{363}, \underline{424}, \underline{427}$

educadoras $\underline{237}$

eletroquímica $\underline{141}$

emissão de gases 251

empreendimentos $\underline{369}$

empreendorismo 197, 324

endocrinologia 309

engenharia $\underline{333}, \underline{361}$

engenharia elétrica $\underline{326}, \underline{413}$

engenharia mecânica $\underline{402}$

ensino 137, 168, 180, 240, 271, 275

ensino-aprendizagem $\underline{167}$

ensino básico 131

ensino da libras $\underline{104}$

ensino de ciências 101

ensino de filosofia $\underline{176}$

ensino de música $\underline{119}$

ensino de química $\underline{169}$

ensino fundamental $\underline{135}, \underline{148}, \underline{215}$

ensino informatizado $\underline{222}$

ensino superior $\underline{132}, \underline{203}$

entomologia $\underline{146}$

entretenimento 120

envelhecimento $\underline{\underline{315}}$

envelhecimento ativo-saudável 289

envelhecimento saudável $\underline{317}$

equilíbrio emocional $\underline{428}$

ergonomia $\underline{391}, \underline{424}$

escolarização 171

espaço compartilhado $\underline{198}$

espanhol $\underline{167}$

especial 177

espectroanalítica $\underline{377}$ 
espectroscopia raman 376

esporte $\underline{113}, \underline{193}, \underline{286}, \underline{287}, \underline{302}$

estatística 214

estilos de linguagens 363

estrangeiros $\underline{194}$

estratégia $\underline{418}$

estrutural 344

estruturas 397

estruturas pré-fabricadas $\underline{398}$

estudos $\underline{172}, \underline{173}, \underline{365}$

eventos 109, 236

evolução 102

evolução de software 327

exercício 287

extensão $\underline{280}$

fauna $\underline{230}$

fermentações 350

fertilidade $\underline{337}$

filosofia 174

filosofia na escola 176

física 178

físico-química 421

fisiologia $\underline{259}, \underline{287}$

fisiologia vegetal $\underline{146}$

fisioterapia $278,288,308$

fisioterapia geriátrica $\underline{213}$

fisioterapia respiratória $\underline{294}$

fitopatologia $\underline{146}$

florestas 408

formação 112, 175, 180, 181, 188, 206, 269, 353

formação continuada $\underline{131}, \underline{140}, \underline{176}, \underline{179}, \underline{210}, \underline{211}$, $\underline{240}, \underline{335}$

formação de professores $\underline{139}, \underline{148}, \underline{149}, \underline{198}$

formação de psicólogos $\underline{148}$

formação docente 165

formação inicial 140, 211

formação jurídica 165

formação professores $\underline{154}$

fórmula sae 406

\section{G}

gameficação $\underline{219}$

gastrointestinal $\underline{273}$

genética $\underline{360}$

genética da conservação 241

genética forense $\underline{241}$

genética médica $\underline{274}$

genômica 360

geociências $\underline{239}$

geografia 218

geoprocessamento $\underline{235}, \underline{242}, \underline{368}$

geotecnia $\underline{239}, \underline{365}$

gerenciamento $\underline{387}$

gerontologia $\underline{289}, \underline{303}, \underline{305}$

gestão 184, 197, 263, 289, 305, 367

gestão ambiental $\underline{231}, \underline{243}, \underline{248}, \underline{255}, \underline{256}, \underline{258}$

gestão de recursos naturais $\underline{170}, \underline{224}, \underline{226}, \underline{228}$,

$\underline{230}, \underline{231}, \underline{232}, \underline{241}, \underline{243}, \underline{244}, \underline{245}, \underline{252}, \underline{253}, \underline{255}$,

256, $, 393, \underline{408}$

gestão de resíduos 253

gestão empresarial $\underline{370}$

gestão e política pública 115

gestão tecnológica 392

graduação $\underline{347}$

graduação em química 335

grupo de estudos $\underline{186}$
H

habilidades sociais $\underline{100}$

hepatite b 290

hepatite $\mathrm{c} \underline{\underline{290}}$

hepatites virais $290, \underline{310}$

hepatite viral $\underline{277}$

herbicidas $\underline{338}$

hibridos 348

higiene $\underline{424}$

história 174

hormônios 309

hospitais e clínicas universitárias $\underline{271}$ 272, 279,

299, 308

humanização 160, 193, 307, 371

I

ictiofauna 252

idoso 213

igualdade de direitos $\underline{205}$

imagens e vídeos biomédicos 342

impacto ambiental $\underline{\underline{245}}$

impactos 228

incentivo à leitura $\underline{166}, \underline{222}$

inclusão 206

inclusão social 156

incubação 369

incubadora 425

indicadores $\underline{258}$

indicadores de c\&t 372

indústria $\underline{329}, \underline{383}$

infância 172, 266

infectologia 272, 301

informação 117, 184, 189, 190

infraestrutura tecnológica 105

infravermelho 407

iniciação à docência $\underline{198}$

inovação 324

inovação tecnológica 105, 141, 221, $\underline{227}, \underline{250}$,

$259,325,327,331,332,336,340,342,343$,

$345,348,350,353,361,362,364,365,369$,

$370,372,373,374,378,380,382,384,385$,

$386,387,388,389,390,391,396,397,398$,

$399,402,403,406,407,409,410,411,414$.

$415,416,417,418,420,421$

insetos aquáticos 238

instituições culturais $\underline{115}$

instrumentação $\underline{261}$

integração $\underline{113}, \underline{234}$

integração de sistemas $\underline{246}$

integradas 336

integralidade 262

inteligência artificial 410, 411

inteligência competitiva $\underline{372}$

inteligência computacional $\underline{417}$

interativo 106

interdisciplinar $\underline{262}, \underline{272}, \underline{293}$

interface humano computador 371

interfaces homem-máquina $\underline{219}$

internet das coisas 374

intervenção precoce $\underline{187}, \underline{191}$

inventário 199

in vitro 347

L

laboratório 247, 295

lagoa do sino 151, 153

lazer 193

lazer e saúde $\underline{113}, \underline{193}, \underline{287}, \underline{302}$ leite 341

letramento $\underline{118,135}$

letramento científico 110

letras 181

levantamento de dados $\underline{195}$

libras 104, 107, 133

liga $\underline{296}$

liga acadêmica 299

língua estrangeira: espanhol $\underline{183}$

língua estrangeira: inglês 183

linguagem $\underline{136}, \underline{182}$

linguagens $\underline{118}$

linguagens de programação 363

linguagens e aprendizagem $\underline{212}$

língua materna: português 183

linguistica $\underline{182}$

linhas de cuidado em saúde 322

linux $\underline{330}$

literatura 116

literaturas de língua portuguesa $\underline{116}$

livraria $\underline{166}$

livro 142

logística 395

lusofonia 116

M

macroinvertebrados 232

manejo 230, 244, 352

manutenção de software 327

mapeamento de solos $\underline{249}$

matemática 157

materiais $345,353,389$

materiais polímericos $\underline{378}$

maturidade 293

mecanização $\underline{379}$

medelagem 192

medicina 204

medidas sócio-educativas 158

meio ambiente $\underline{170}, \underline{201}, \underline{224}, \underline{225}, \underline{226}, \underline{227}, \underline{228}$,

$229,230,231,232,233,234,235,236,237,238$,

$\underline{239}, \underline{240}, \underline{241}, \underline{242}, \underline{243}, \underline{244}, \underline{245}, \underline{246}, \underline{247}$,

$\underline{248}, \underline{249}, \underline{250}, \underline{251}, \underline{252}, \underline{253}, \underline{254}, \underline{255}, \underline{256}$,

$257,258,259$

memória 117

mercado de trabalho 164

metabologia $\underline{283}, \underline{309}$

metais nano-estruturados 388

metais vítreos $\underline{388}$

metodologias ativas de aprendizagem $\underline{138}$

métodos quantitativos 358

microbiologia $\underline{250}, \underline{383}$

microbiológico 350

microestrutura 36

microorganismos 340

mídia 106

mídia comunitária 114

mineração 328

minimização $\underline{381}$

modelagem $\underline{389}$

modelos lineares generalizados $\underline{195}$

monitoramento ambiental 245

morfologia 259

motricidade humana 284

movimentos sociais $\underline{159}, \underline{426}$

multiculturalismo 118

multidisciplinar $\underline{299}, 401$

multimidia 384

multiprofissional 283, 307

música 134

musical 163

música popular $\underline{119}$ 
nascentes $\underline{224}$

natação 302

natureza $\underline{\underline{218}}$

negócios $\underline{403}$

neurologia comportamental $\underline{314}$

novos materiais $\underline{388}$

núcleo $\underline{382}$

nui 375

nutrição $\underline{400}$

0

observatório $\underline{196}$

operacional $\underline{385}$

operações $\underline{358}, \underline{395}$

organizações populares $\underline{220}, \underline{425}$

orientação $\underline{128}$

P

participação social $\underline{171}$

parto 307

patrimônio institucional 121

pediatria $\underline{296}$

peixes 228,400

performance musical 119

perícias ambientais $\underline{256}$

permacultura 246

perspectivas profissionais $\underline{335}$

pesquisa $271,384,385$

pesquisa em educação 155

pessoas com deficiência $\underline{171}$

piezoelétricos 349

plâncton 247

planejamento 199, 387

planejamento ambiental 235

plasticidade do sistema nervoso central $\underline{313}$

polinização 226

política pública 151, 161, $\underline{162}$

políticas 200,304

políticas públicas $\underline{128}, \underline{129}, \underline{248}$

pólos tecnológicos $\underline{349}, \underline{360}, \underline{390}, \underline{413}$

português 194

práticas $\underline{269}$

práticas educativas 217

práticas pedagógicas 202

práticas tradutórias em libras 104

pré-escolares 191

preparo de amostras 377

prestacao de serviços 415

prevenção $216,275,278,282,312$

prevenção e promoção de saúde $\underline{317}$

prevenção e tratamento $\underline{277}$

privação de liberdade $\underline{158}$

processamento 382

processamento de imagem 411

processamento língua natural $\underline{411}$

processos 353

processos formativos $\underline{202}$

processos organizativos $\underline{426}$

produção $\underline{380}$

produção agrícola 226

produção artístico-cultural $\underline{112}$

produção cultural e artística na área de

fotografia 106

produção cultural e artística na área de música

e dança 119

produção de materiais $\underline{103}$ produção e difusão de material educativo 110 ,

$$
145
$$

produção florestal 394

produtividade $\underline{108}$

produtividade e qualidade $\underline{359}$

produto florestal não-madeireiro 257

produtores $\underline{324}$

produtos 329

produtos naturais 409

professores $\underline{139}, \underline{175}, \underline{191}$

programa nacional hepatite $\underline{277}$

projetos mecânicos 331

promoção da saúde $\underline{315}$

promoção de saúde $\underline{282}$

promoção do desenvolvimento 216

propriedade intelectual $\underline{396}$

protocolos de avaliação 245

psicanálise $\underline{264}, \underline{280}, \underline{313}$

psicodiagnóstico 261

psicologia 427

psicologia organizacional $\underline{427}$

psicossomática 320

psicoterapia $\underline{264}, \underline{280}$

psiquiatria 321

psiquiátrica $\underline{319}$

publicações $\underline{166}$

\section{0}

qualidade de vida $\underline{281}, \underline{428}$

questão agrária $\underline{423}, \underline{426}$

quilombola 127

quimiometria $\underline{376}, \underline{377}$

R

raciocínio 417

racionalização 397

racismo 129

reabilitação $\underline{278}, \underline{306}$

reabilitação pulmonar 294

recém-nascido 291

reciclagem 381

recuperação 254

recursos ambientais 408

recursos hidricos 248

recursos técnicos 133

rede de sementes florestais 257

redes sociais de suporte $\underline{125}$

relações étnico-raciais 124,205

repertórios acadêmicos 152

resistência à fitopatógenos 380

restauração ecológica 244

restauração florestal $\underline{393}, \underline{394}$

revista eletrônica 155

revitalização geriátrica $\underline{213}$

rmn 407

robótica 405

\section{$\S$}

saberes populares $\underline{169}$

saneamento 250

saude 302

saúde $204,261,262,263,264,265,266,267$,

$268,269,270,271,272,273,274,275,276,277$,

$\underline{278}, \underline{279}, \underline{280}, \underline{281}, \underline{282}, \underline{283}, \underline{284}, \underline{285}, \underline{286}$,

$\underline{287}, \underline{288}, \underline{289}, 290,291,292,293,294,295$,

296, 297, 299, 300, 301, 302, 303, 304, 305,

$306,307,308,309,310,311,312,313,314,315$,

$316,317,318,319,320,321,322$
Saúde 298

saúde adolescente $\underline{270}$

saúde coletiva 265

saúde da criança $\underline{270}, \underline{273}, \underline{297}$

saúde da família $\underline{267}, \underline{280}, \underline{284}, \underline{286}, \underline{298}, \underline{311}, \underline{321}$

saúde da família e comunidade 298

saúde da mulher $\underline{316}$

saúde do idoso 315

saúde do trabalhador $\underline{428}$

saúde e segurança no trabalho 428

saúde mental $\underline{281}, \underline{299}, \underline{319}, \underline{321}$

saúde reprodutiva 316

segurança $\underline{366}$

seletividade $\underline{338}$

sementes florestais 257

simulação $\underline{292}, \underline{391}$

simulação computacional 331, 389

sinais biomédicos $\underline{342}$

síntese 409

sistema de apoio à decisão $\underline{395}$

sistemas alimentares 334

sistemas computacionais 416

sistemas de apoio à decisão $\underline{410}$

sistemas de controle 416

sistemas de produção $\underline{359}$

sistemas de telecomunicações 419

sistemas elétricos de potência $\underline{413}$

sistemas estruturais 355

sistemas inteligentes $\underline{410}$

sistema único de saúde 322

situações produtivas 391

smart cities $\underline{374}$

social 109,401

sociedade $\underline{190}, \underline{218}$

sociologia 126

software livre $\underline{330}$

software para a área médica $\underline{342}$

solo 337,352

solo agrícola e florestal 251

subjetividade 144

sucroenergia $\underline{364}$

suprimento 414

sustentabilidade $\underline{197}, \underline{234}, \underline{237}, \underline{243}, \underline{258}, \underline{334}$

sustentabilidade ambiental 256

sustentável $\underline{401}, \underline{423}$

$\mathrm{T}$

taxonomia 238

técnica participatória $\underline{242}$

tecnologia 103, 122, 190, 221, 292, 303, 305, 348,

$\underline{362}, \underline{364}, \underline{365}, \underline{373}, \underline{414}, \underline{419}, \underline{420}, \underline{421}$

tecnologia da informação 399

tecnologia educacional $\underline{207}, \underline{212}$

tecnologia e produção 153, 324, 325, 326, 327,

$\underline{328}, 329,330,331,332,333,334, \underline{335}, 336,337$,

$338,339,340,341,342,343,344,345,346$,

$347,348,349,350,351,352,353,354,355$,

$356,357,358,359,360,361,362,363,364$,

$\underline{365}, \underline{366}, \underline{367}, \underline{368}, \underline{369}, \underline{370}, \underline{371}, \underline{372}, \underline{373}$,

$374,375,376,377,378,379,380,381,382$,

$383,384,385,386,387,388,389,390,391$,

$392,393,394,395,396,397,398,399,400$,

$\underline{401}, \underline{402}, \underline{403}, \underline{404}, \underline{405}, \underline{406}, \underline{407}, \underline{408}, \underline{409}$,

$\underline{410}, \underline{411}, \underline{412}, \underline{413}, \underline{414}, \underline{415}, \underline{416}, \underline{417}, \underline{418}, \underline{419}$,

420, 421

tecnologia e sociedade $\underline{145}$

tecnologias $\underline{418}$

tecnologias da informação e comunicação 105

tecnológica $\underline{343}$

tecnológico 412

teoria da atividade $\underline{140}$ 
terapia ocupacional 306, 321 terapia ocupacional social $\underline{125}$ território 127

território e comunidade 125

tics 179

trabalhadores rurais 159

trabalho $\underline{188}, \underline{263}, \underline{423}, \underline{424}, \underline{425}, \underline{426}, \underline{427}, \underline{428}$

trabalho em equipe 322

tráfego 366

transdutores ultrassonicos 349

transferência 221, $\underline{420}$

transferência de tecnologia $\underline{390}, \underline{396}$

trânsito 366

transportes $\underline{333}$

transtornos cognitivos 314

tratamento clinico $\underline{267}$ treinamento 419

treinamento e capacitação 390

turismo $\underline{109}, \underline{196}$

tutoria 207

U

ufscar 121

ultravioleta $\underline{407}$

unidades $\underline{403}$

universidade-escola 217

urbano 233

urgência $\underline{312}$

uso da terra $\underline{232}$
V

variedades $\underline{346}, \underline{380}$

veículos automotores 406

veículos de competição $\underline{406}$

vidros $\underline{332}$

Vigotsky 173

violência 311

visual analitics $\underline{375}$

visualização $\underline{328}$

vitaminas e minerais 268

7

zoneamento agrícola $\underline{249}$ 


\section{$\overline{\text { Inditirepor }}$ Boordenadores}

\section{COMO UTILIZAR ESSE MATERIAL}

Abaixo apresentamos o índice de coordenadores dos 322 Programas de Extensão ativos.

Clique sobre o número a frente do nome para acessar os resumos e outras informações de cada programa. No topo da página de cada resumo você encontra um link para retornar para o ponto de onde partiu ou para o início do índice.

A

Ademar da Silva $\quad 183$

Adilson Jesus Aparecido de Oliveira $\underline{101}$

Adriana Estela Sanjuan Montebello 214

Adriana Garcia Goncalves 160

Adriana Mattar Maamari 176

Adriana Sanches Garcia de Araujo $\quad \underline{308}$

Alberto Carvalho Peret $\underline{228}$

Alberto Luciano Carmassi $\underline{170}, \underline{245}$

Alessandra dos Santos Penha 244

Alexandre Alvaro $\quad 369$

Alexandre Lopes Gomes $\quad \underline{208}$

Alfredo Seiiti Urashima 356

Aline Maria de Medeiros Rodrigues Reali $\quad \underline{139}, \underline{179}$

Alissandra Nazareth de Carvalho $\underline{113}$

Ana Claudia de Oliveira $\quad \underline{204}, \underline{277}, \underline{310}$

Ana Claudia Lessinger $\underline{102}$

Ana Lucia Cortegoso $\underline{425}$

Ana Lucia Rossito Aiello 187

Ana Lucia Vitale Torkomian $\quad 396$

Ana Paula de Oliveira Amaral Mello 2

Ana Silvia Couto de Abreu 154

Anderson Ferreira da Cunha $\underline{340}$

Andrea Aparecida Contini $\underline{273}$

Andrea Braga Moruzzi 211

Andrea Rodrigues Ferro 164

Andre Coimbra Felix Cardoso $\underline{197}$

Andre Cordeiro Alves dos Santos $\underline{248}$

André Farias de Moura $\quad \underline{110}$

Anete Abramowicz $\quad \underline{172}$

Angela Merice de Oliveira Leal $\underline{283}$
Antonio Aparecido Mozeto $\underline{404}$

Antonio Carlos dos Santos $\underline{420}$

Antonio Celso de Noronha Goyos $\quad$ 147, 188

Antonio Gilberto Ferreira $\underline{407}$

Aparecida Maria Catai $\underline{288}$

Archimedes Azevedo Raia Junior 366

Arlene Goncalves Correa $\underline{409}$

Aryane Santos Nogueira $\underline{103}$

B

Bento Vidal de Moura Negrini $\quad 270,271$ Bernardino Geraldo Alves Souto $\underline{269}$ Bernardo Arantes do Nascimento Teixeira 381

\section{C}

Caio Marcio Paranhos da Silva $\quad \underline{378}$

Camila Carneiro Dias Rigolin 145

Camila Hofling $\underline{181}$

Carla Maria Ramos Germano $\underline{297}$

Carla Regina Silva $\underline{112}$

Carlos Augusto de Sousa Martins Filho 256, $\underline{393}$

Carlos Ventura D Alkaine $\underline{392}$

Carmen Lucia Brancaglion Passos $155, \underline{175}$

Carolina Maria Pozzi de Castro $\underline{233}$

Cassia Regina Rodrigues $\underline{264}$

Cecilia Candolo 195

Celso Luiz Aparecido Conti $\underline{200}$

Celso Maran de Oliveira $\underline{255}$

Cesar Augusto Camillo Teixeira $\quad \underline{412}$ 
Cesar Augusto Cavalheiro Marcondes $\quad 399$

Claudia Raimundo Reyes $\underline{135}$

Claudio Roberto Thiersch $\underline{199}$

Claudio Shyinti Kiminami $\underline{\underline{388}}$

Corinne Arrouvel $\quad 302$

Cristina Broglia Feitosa de Lacerda $\quad \underline{210}$

\section{D}

Dalva Maria da Silva Matos $\underline{236}$

Daniel Marinho Cezar da Cruz $\underline{306}$

Daniel Ribeiro Silva Mill $\quad 212$

Danilo Rolim Dias de Aguiar $\underline{367}$

Debora Gusmão Melo 274

Deisy Das Gracas de Souza $\quad 222$

Denise de Freitas 201

Denise de Paula Martins de Abreu e Lima 207

Dijnane Fernanda Vedovatto Iza $\quad \underline{149}$

Dileia Aparecida Martins Briega $\underline{133}$

Doris Lieth Nunes Peçanha $\underline{320}$

Ducinei Garcia 178

\section{E}

Edenir Rodrigues Pereira Filho $\quad \underline{377}$

Edgar Dutra Zanotto $\underline{332}$

Edilson Reis Rodrigues Kato $\underline{416}$

Ednaldo Brigante Pizzolato $\underline{371}$

Elenice Maria Cammarosano Onofre 158

Eliana Cardoso Leite $\quad 231$

Eliane da Silva Grazziano $\quad \underline{428}$

Eliane Hercules Augusto Navarro $\quad \underline{168}$

Elizabeth Joan Barham $\underline{427}$

Eloisa Tudella $\underline{266}$

Elson Longo da Silva $\underline{421}$

Elton Fabiano Sitta 335

Eniceia Goncalves Mendes $\underline{177}$

Erica Pugliesi $\underline{253}$

Erich Kellner 387

Ernesto Antonio Urquieta Gonzalez $\quad \underline{353}$

Estefano Vizconde Veraszto $\underline{209}$

Estevam Rafael Hruschka Junior $\underline{410}$

Esther Angelica Luiz Ferreira $\quad \underline{300}$

\section{$F$}

Fabiana Cia 191

Fabio de Lima Leite $\underline{215}$

Fabio Fernandes Neves $\quad 312$

Fabio Molina da Silva 414

Fatima Conceicao Marquez Pina Rodrigues $\quad 257$

Fernando Cesar Sala $\quad \underline{380}$

Fernando Donizete Alves $\underline{202}$

Fernando Henrique Martins Portelinha $\quad \underline{365}$

Fernando Stanzione Galizia 134

Flavio Henrique da Silva 339

Flavio Yukio Watanabe 402

Francisco de Assis Carvalho do Vale 314

Francis de Morais Franco Nunes 360

Frederico Yuri Hanai $\underline{258}$
Gabriel de Santis Feltran $\underline{126}$

Georgina Carolina de Oliveira Faneco Maniakas $144, \underline{318}$

Geovani Gurgel Aciole da Silva $\underline{265}$

Glauco Henrique de Sousa Mendes $\underline{359}$

Guilherme Aris Parsekian 397

H

Haydee Torres de Oliveira $\underline{237}$ Heber Lombardi de Carvalho $\quad \underline{153}$ Helena de Medeiros Caseli 411 Helio Crestana Guardia $\quad 374$ Heloisa de Arruda Camargo $\quad \underline{417}$ Hermann Paulo Hoffmann $\underline{346}$ Hermes Senger $\underline{105}$ Heros Augusto Santos Lobo $\underline{120}$ Humberto Sadanobu Hirakawa $\underline{307}$ Hylio Lagana Fernandes $\underline{180}$

\section{I}

leda Regina Lopes Del Ciampo $\underline{296}$ Ilza Zenker Leme Joly $\quad \underline{163}$ Iolanda Cristina Silveira Duarte $\quad \underline{250}$ Irineu Bianchini Junior $\underline{192}$

J

Jair Borges Barbosa Neto $\underline{299}$ Jamile Claro de Castro Bussadori 291 Janaina Braga do Carmo 251 Jane Maria Faulstich de Paiva $\quad \underline{348}$ Jean Carlos Cardoso $\quad \underline{234}$ Joao Alberto Camarotto $\underline{403}$ Joao Angelo Fantini $\quad 280$ João Carlos Massarolo $\underline{106}$ Joao Virgilio Tagliavini $\underline{165}$ Jorge José Correa Lopes $\underline{350}$ Jorge Vicente Valentim $\underline{116}$ Jose Antonio Eiras $\underline{349}$ Jose Antonio Salvador $\quad \underline{157}$ Jose Benaque Rubert $\underline{406}$ Jose Carlos Casagrande $\underline{337}$ Jose Carlos Paliari 108 Jose Carlos Pizolato Junior $\underline{419}$ José de Anchieta Rodrigues $\underline{361}$ Jose Eduardo Dos Santos $\underline{185}$ Jose Eduardo Marques Baioni $\quad \underline{174}$ Jose Geanini Peres 352 Jose Geraldo Vidal Vieira $\quad \underline{395}$ Jose Mansur Assaf $\underline{221}$ Jose Mauro Santana da Silva 408 Jose Rubens Rebelatto $\underline{213}$ Joyce do Rosario Martins $\underline{309}$ Jozivaldo Prudencio Gomes de Morais $324, \underline{341}$ Juliane Aparecida de Paula Perez Campos $\underline{171}$ Juliano Costa Goncalves $\underline{243}$ Julio Cesar Coelho de Rose 136 Julio Cesar Garavello $\quad \underline{252}$ Julio Cesar Pereira $\quad 358$ 
Junia Coutinho Anacleto 375

K

Katia Regina Moreno Caiado $\quad \underline{162}$

Kelly Cristina Tonello Polli $\underline{224}$

L

Leandro Innocentini Lopes de Faria $\quad \underline{372}$

Lee Tseng Sheng Gerald 347

Lidia Maria Marson Postalli $\underline{152}$

Ligia Maria Silva e Souza $\underline{142}$

Livia Maria Fusari 238

Lourdes de Fatima Bezerra Carril $\underline{127}$

Lucia Helena Seron $\quad \underline{268}$

Luciana Aparecida Martinez Zaina $\quad \underline{143}, \underline{363}$

Luciana de Souza Gracioso $\quad \underline{121}, \underline{189}$

Luciana Thie Seki Dias $\quad \underline{400}$

Lucimar Retto da Silva de Avo $\quad 282$

Luis Carlos Trevelin $\quad 384$

Luiz Andre Neves de Brito $\quad \underline{118}$

Luiz Antonio Correia Margarido $\underline{423}$

Luiz Antonio Pessan $\underline{382}$

Luiz Bezerra Neto $\quad 159$

Luiz Fernando de Oriani e Paulillo $\underline{151}$

Luiz Fernando Takase 137

Luiz Goncalves Junior $\underline{284}, \underline{286}$

Luzmara Curcino Ferreira $\underline{182}$

M

Marcela Xavier Ribeiro $\quad \underline{328}$

Marcelo de Araujo Ferreira $\quad \underline{398}$

Marcel Okamoto Tanaka $\underline{232}$

Marcia Niituma Ogata $\underline{322}$

Marcilene Dantas Ferreira $\underline{239}$

Marcos Antonio Garcia Ferreira 333

Marcos Antonio Sanches Vieira 351

Marcos Arduin 254

Marcos Hortes Nisihara Chagas $\quad 317$

Marcus Vinicius Batista Nascimento 107

Maria Aparecida Mello $\underline{173}$

Maria Cristina Comunian Ferraz $\quad 156$

Maria Cristina Innocentini Hayashi $\underline{117}$

Maria da Graca Gama Melão $\quad 247$

Maria de Jesus Dutra dos Reis 281

Maria do Carmo de Sousa $\underline{140}, \underline{198}$

Maria Elina Bichuette $\underline{229}$

Maria Ines Rauter Mancuso $\quad 128$

Maria Leonor Ribeiro Casimiro Lopes Assad 249

Maria Lucia Teixeira Machado $\quad 304$

Mariana de Almeida Prado Faga $\underline{298}$

Maria Stella Coutinho de Alcantara Gil $\quad \underline{216}$

Maria Teresa Mendes Ribeiro Borges $\underline{354}$

Maria Virginia Urso Guimaraes $\underline{240}$

Maria Waldenez de Oliveira $\quad \underline{285}$

Marilia Goncalves $\quad \underline{261}$

Mario Otavio Batalha $\underline{370}$

Marisa Narciso Fernandes $\underline{259}$

Maristela Schiabel Adler $\underline{267}$
Marta Cristina Marjotta Maistro $\quad \underline{114}, \underline{186}$

Meliza Goi Roscani 275

Miguel Angel Aires Borras $\quad \underline{390}$

Murillo Rodrigo Petrucelli Homem $\quad \underline{219}$

N

Naaman Francisco Nogueira Silva 334

Nelson Guedes de Alcantara $\quad \underline{345}$

Nelson Viana 194

Neusa de Fatima Mariano $\quad 218$

Nilton Luiz Menegon $\quad 391, \underline{424}$

0

Octavio Antonio Valsechi $\underline{364}$

Orides Morandin Junior 418

Osmar Ogashawara $\underline{326}$

Oswaldo Mario Serra Truzzi $\quad 166$

P

Patricia Andrea Monquero $3 \underline{338}$

Patricia Domingues de Freitas 241

Patricia Driusso $\underline{278}$

Paulo Waldir Tardioli $\underline{329}$

Petronilha Beatriz Gonçalves e Silva $\underline{205}$

0

Quezia Bezerra Cass $\underline{386}$

B

Rachel de Faria Brino $\quad 311$

Raquel de Lima Camargo Giordano $\underline{\underline{373}}$

Regimar Carla Machado Ranzani $\underline{292}$

Regina Helena Vitale Torkomian Joaquim $\underline{\underline{295}}$

Reinaldo Morabito Neto $\quad \underline{385}$

Renata Evangelista de Oliveira $\underline{225}$

Renata Prenstteter Gama 217

Renata Sebastiani 131

Renato Lajarim Carneiro $\quad \underline{376}$

Ricardo Augusto Gorne Viani $\quad 394$

Ricardo Augusto Souza Fernandes $\underline{413}$

Ricardo Jose Ferrari $\underline{342}$

Rita de Cassia Lana $\underline{115}$

Roberta Averna Valente Botezelli Tolini $\quad 242$

Roberta Cornelio Ferreira Nocelli $\underline{226}$

Roberto Antonio Martins $\underline{336}$

Roberto Chust Carvalho $\quad 355$

Rodrigo Alves Ferreira $\underline{316}$

Rodrigo Bezerra de Menezes Reiff $\quad 279$

Rodrigo Bresciani Canto $\quad \underline{389}$

Rogerio Aparecido Sa Ramalho $\quad 190$

Rogerio Hartung Toppa 235

Romeu Cardozo Rocha Filho $\underline{141}$

Rosana Batista Monteiro 129

Rosana Mattioli $\underline{313}$

Rosa Yokota 167

Roseli Esquerdo Lopes $\underline{125}$ 
Roseli Rodrigues de Mello $\underline{150}$ Rosely Moralez de Figueiredo $\underline{276}$ Rosemeire Aparecida Scopinho $\quad 426$ Rosemeire de Araujo Rangni $\underline{206}$ Rosimeire Maria Orlando $132, \underline{161}$ Rubismar Stolf $\underline{379}$

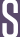

Sandra Abib $\quad \underline{343}$

Sandra Regina Ceccato Antonini 383

Sergio Antonio Rohm $\underline{368}$

Sergio Donizetti Zorzo $\quad \underline{362}$

Sergio Eduardo de Andrade Perez $\underline{287}$

Sergio Henrique Evangelista 331

Sergio Luiz Brasileiro Lopes $\underline{262}$

Sigrid de Sousa Dos Santos $\underline{272}, \underline{301}$

Silvana Gama Florencio Chacha 290

Silvia Carla da Silva Andre 315

Sofia Cristina lost Pavarini 293

Sonia Regina Zerbetto $\quad 319$

\section{T}

Tania Maria Santana de Rose $\quad \underline{148}$

Tatiana de Figueiredo Pereira Alves Taveira Pazelli 405

Tatiane Cosentino Rodrigues 124

Telma Darn 109, 196

Teresa Mary Pires de Castro Melo $\underline{122}$

Thais dos Guimaraes Alvim Nunes 119

Thelma Simoes Matsukura 321

Tiago da Silva Alexandre 303

Tiemi Christine Sakata $\quad 330$
Tomaz Toshimi Ishikawa $\quad 357, \underline{415}$

V

Vadim Viviani 227

Valeria Amorim Pires di Lorenzo $\quad \underline{294}$

Valeria Vernaschi Lima 138

Valter Roberto Silverio $\quad \underline{203}$

Valter Vieira de Camargo $\quad \underline{327}$

Vanessa Regina de Oliveira Martins 104

Vania Aparecida Gurian Varoto $\underline{305}$

Vera Alves Cepeda 220

Vivian Aline Mininel $\quad \underline{263}$

Vlamir Jose Rocha 230

\section{W}

Waldemar Marques Junior $\underline{193}$ Waldir Cintra de Jesus Junior $\underline{146}$

Walter Jose Botta Filho 344

Walter Ruggeri Waldman 169

Wanda Aparecida Machado Hoffmann $\quad 184$ Wanderley Lopes de Souza $\quad \underline{325}$

Wilson Jose Alves Pedro $\quad 289$

y

Yeda Regina Venturini $\underline{401}$

Z

Zilda Aparecida Pereira Del Prette $\underline{100}$ 


\section{Bomunibaดtão}

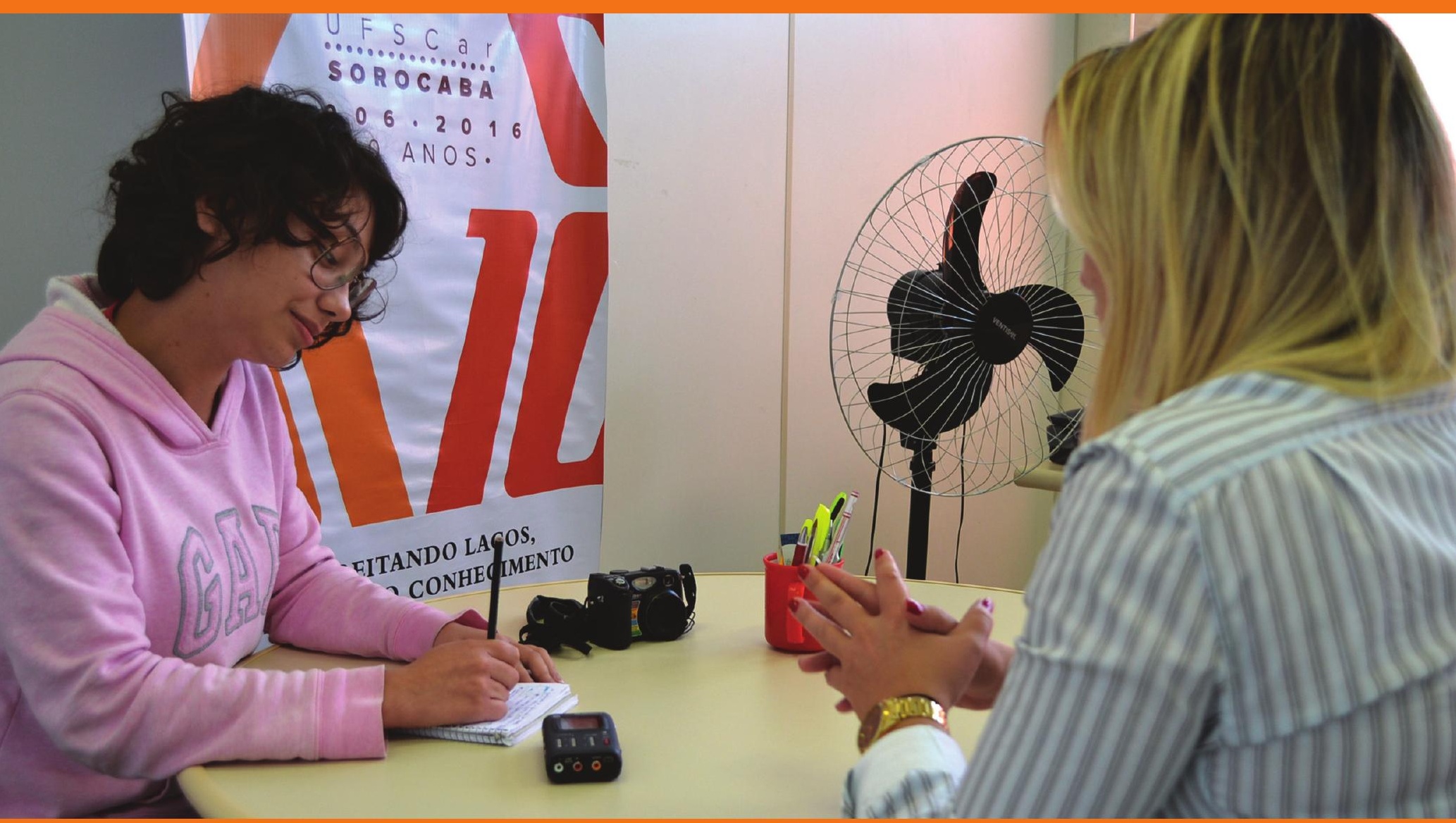

Entrevista na UFSCar - Sorocaba.

Foto: João Eduardo Justi. 


$\begin{array}{ll}\text { TÍTULO } & \text { Avaliação e Promoção de Habilidades Sociais e Relações } \\ & \text { Interpessoais } \\ \text { COORDENAÇÃo } & \text { Zilda Aparecida Pereira Del Prette } \\ \text { SETOR } & \text { Departamento de Psicologia } \\ \text { CONTATO } & \text { dpsic@ufscar.br } \\ \text { PALAVRAS-CHAVE } & \text { habilidades sociais; comunicação; atenção integral à saúde de adultos } \\ \text { DATA INÍCIO } & \text { 8/2/2001 }\end{array}$

Título Disseminação do Conhecimento Científico e Tecnológico na
UFSCar

COORDENAÇÃo Adilson Jesus Aparecido de Oliveira

SETOR Departamento de Física

CONTATO dfchefe@ufscar.br

PALAVRAS-CHAVE divulgação científica; ensino de ciências; comunicação social; comunicação; comunicação escrita e eletrônica

DATA INÍCIO 17/4/2007

$\begin{array}{ll}\text { TÍtULO } & \text { Divulgação Científica em Biologia } \\ \text { COORDENAÇÃo } & \text { Ana Claudia Lessinger } \\ \text { SETOR } & \text { Departamento de Biologia } \\ \text { CONTATO } & \text { dbio@ufscar.br } \\ \text { PALAVRAS-CHAVE } & \begin{array}{l}\text { divulgação científica; biologia; evolução; comunicação; comunicação escrita e } \\ \text { eletrônica }\end{array} \\ \text { DATA INÍCIO } & 20 / 1 / 2016\end{array}$

TíTULO

Educação de Surdos e Tecnologias: Reflexões e Ações de Formação

COORDENAÇÃo Aryane Santos Nogueira

SETOR Departamento de Psicologia

CONTATO dpsic@ufscar.br

PALAVRAS-CHAVE educação de surdos; tecnologia; produção de materiais; comunicação; educação continuada

DATA INÍCIO 5 5/9/2016

$\begin{array}{ll}\text { TíTULO } & \text { Ensino de Libras (Língua Brasileira de Sinais) e Formação } \\ & \text { Continuada para o uso Desta Língua em Diversos Contextos } \\ & \text { Sociais } \\ \text { COORDENAÇÃo } & \text { Vanessa Regina de Oliveira Martins } \\ \text { SETOR } & \text { Departamento de Psicologia } \\ \text { CONTATO } & \text { dpsic@ufscar.br } \\ \text { PALAVRAS-CHAVE } & \begin{array}{l}\text { ensino da libras; libras; práticas tradutórias em libras; comunicação; educação } \\ \text { continuada }\end{array} \\ \text { DATA INÍCIO } & \text { 10/9/2015 }\end{array}$


TítULo

COORDENAÇÃO

SETOR

CONTATO

PALAVRAS-CHAVE

DATA INÍCIO
Estudos, Pesquisa e Desenvolvimento de Tecnologias para Cidades Inteligentes

Hermes Senger

Departamento de Computação

dc@ufscar.br

cidades inteligentes; tecnologias da informação e comunicação; infraestrutura tecnológica; comunicação; inovação tecnológica

$15 / 3 / 2016$

$\begin{array}{ll}\text { TÍTULO } & \text { GEMInIS UFSCar } \\ \text { COORDENAÇÃo } & \text { João Carlos Massarolo } \\ \text { SETOR } & \text { Departamento de Artes e Comunicação } \\ \text { CONTATO } & \text { dac@ufscar.br } \\ \text { PALAVRAS-CHAVE } & \begin{array}{l}\text { mídia; audiovisual; interativo; comunicação; produção cultural e artística na área de } \\ \text { fotografia, cinema e vídeo }\end{array} \\ \text { DATA INÍ́CIO } & \text { 5/6/2013 }\end{array}$

$\begin{array}{ll}\text { TíTULO } & \text { Libras em Uso: Discurso, Ensino, Tradução e Interpretação } \\ & \text { em Ações de Formação com as Comunidades Surdas } \\ \text { COORDENAÇÃo } & \text { Marcus Vinicius Batista Nascimento } \\ \text { SETOR } & \text { Departamento de Psicologia } \\ \text { CONTATO } & \text { dpsic@ufscar.br } \\ \text { PALAVRAS-CHAVE } & \text { libras; discurso; associações; comunicação; educação continuada } \\ \text { DATA INÍCIO } & \text { 1/12/2015 }\end{array}$

TítuLo

Melhoria da Qualidade e Produtividade na Construção Civil

COORDENAÇÃO

Jose Carlos Paliari

SETOR

Departamento de Engenharia Civil

CONTATO

deciv@ufscar.br

PALAVRAS-CHAVE

produtividade; construção; comunicação; educação profissional

DATA INÍCIO

$1 / 1 / 2002$

$\begin{array}{ll}\text { TÍTULO } & \text { Núcleo de Eventos UFSCar Sorocaba } \\ \text { COORDENAÇÃo } & \text { Telma Darn } \\ \text { SETOR } & \text { Departamento de Geografia, Turismo e Humanidades } \\ \text { CONTATO } & \text { dgth@ufscar.br } \\ \text { PALAVRAS-CHAVE } & \text { eventos; comunicação; social; comunicação; turismo } \\ \text { DATA INÍCIO } & \text { 22/11/2006 }\end{array}$


TíTULO

COORDENAÇÃO

SETOR

CONTATO

PALAVRAS-CHAVE

DATA INÍCIO

\section{Núcleo Ouroboros de Divulgação Científica}

André Farias de Moura

Departamento de Química

dqchefe@ufscar.br

divulgação científica; letramento científico; educação inclusiva; comunicação; produção e difusão de material educativo

$13 / 4 / 2011$ 


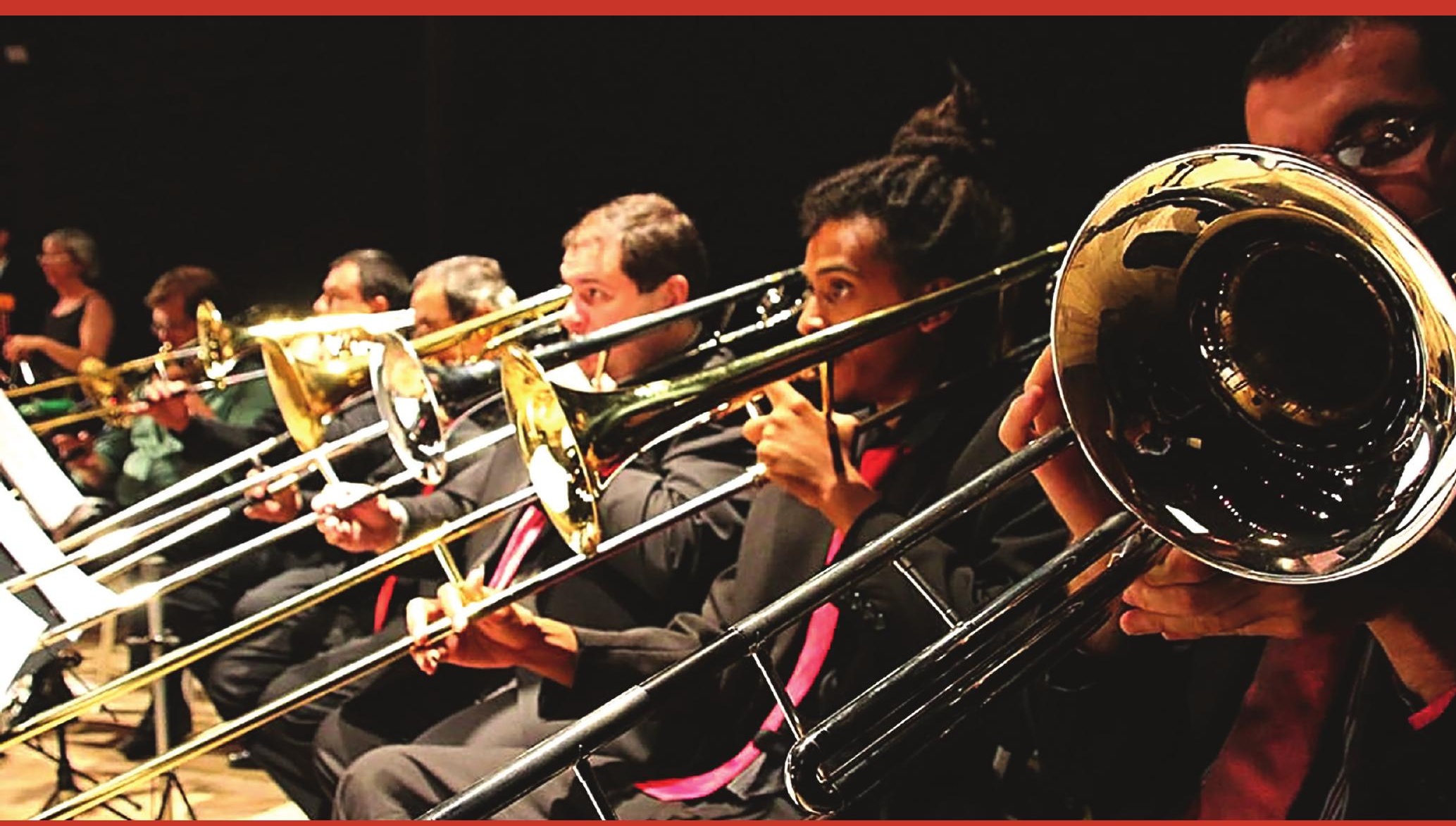

Apresentação da Orquestra Experimental da UFSCar.

Foto: Vinicius Sampaio. 
TíTULO

COORDENAÇÃO

SETOR

CONTATO

PALAVRAS-CHAVE

DATA INÍCIO

TíTULO

COORDENAÇÃO

SETOR

CONTATO

PALAVRAS-CHAVE

DATA INÍCIO
Atividade Humana, Produção Artístico-Cultural e Terapia Ocupacional

Carla Regina Silva

Departamento de Terapia Ocupacional

chdto@ufscar.br

atividade humana; produção artístico-cultural; formação; cultura; educação profissional

$3 / 10 / 2012$

$\begin{array}{ll}\text { TÍTULO } & \text { Comunicação, Arte e Cultura em Araras } \\ \text { COORDENAÇÃo } & \text { Marta Cristina Marjotta Maistro } \\ \text { SETOR } & \text { Centro de Ciências Agrárias } \\ \text { CONTATO } & \text { ccadir@cca.ufscar.br } \\ \text { PALAVRAS-CHAVE } & \text { comunicação; arte; araras; cultura; mídia comunitária } \\ \text { DATA INÍCIO } & 5 / 6 / 2013\end{array}$

TítULO

Espaços Públicos, Cidadania e Cultura - Gestão, Desenvolvimento de Ações e Qualificação de Agentes Sociais

COORDENAÇÃO

SETOR

CONTATO

PALAVRAS-CHAVE

DATA INÍCIO

\section{Bolha Cultural}

Alissandra Nazareth de Carvalho

Departamento de Geografia, Turismo e Humanidades

dgth@ufscar.br

cultura; integração; comunidade; cultura; esporte, lazer e saúde

$22 / 11 / 2006$ Rita de Cassia Lana

Departamento de Geografia, Turismo e Humanidades

dgth@ufscar.br

gestão e política pública; instituições culturais; cultura e trabalho; cultura; capacitação de gestores de políticas públicas

$12 / 4 / 2012$

TítULo

Formação e Educação Continuada em Literaturas de Língua Portuguesa

COORDENAÇÃO Jorge Vicente Valentim

SETOR

Departamento de Letras

CONTATO

dl@ufscar.br

PALAVRAS-CHAVE

DATA INÍCIO

literatura; lusofonia; literaturas de língua portuguesa; cultura; educação continuada 20/11/2009 


$\begin{array}{ll}\text { TÍTULO } & \text { Informação, Arquivo e Memória } \\ \text { COORDENAÇÃo } & \text { Maria Cristina Innocentini Hayashi } \\ \text { SETOR } & \text { Departamento de Ciência da Informação } \\ \text { CONTATO } & \text { dci@ufscar.br } \\ \text { PALAVRAS-CHAVE } & \text { informação; memória; cultura; cultura e memória social } \\ \text { DATA INÍCIO } & 1 / 1 / 2000\end{array}$

$\begin{array}{ll}\text { TíTULO } & \text { Letramentos Múltiplos e Multiculturais } \\ \text { COORDENAÇÃo } & \text { Luiz Andre Neves de Brito } \\ \text { SETOR } & \text { Departamento de Letras } \\ \text { CONTATO } & \text { dl@ufscar.br } \\ \text { PALAVRAS-CHAVE } & \text { letramento; multiculturalismo; linguagens; cultura; comunicação escrita e eletrônica } \\ \text { DATA INÍCIO } & 9 / 1 / 2013\end{array}$

$\begin{array}{ll}\text { TÍTULO } & \text { Música Popular: História, Performance e Ensino } \\ \text { COORDENAÇÃo } & \text { Thais dos Guimaraes Alvim Nunes } \\ \text { SETOR } & \text { Departamento de Artes e Comunicação } \\ \text { CONTATO } & \text { dac@ufscar.br } \\ \text { PALAVRAS-CHAVE } & \begin{array}{l}\text { música popular; ensino de música; performance musical; cultura; produção cultural } \\ \text { e artística na área de música e dança }\end{array} \\ \text { DATA INÍ́cIO } & \text { 1/12/2015 }\end{array}$

$\begin{array}{ll}\text { TÍTULO } & \text { Núcleo de Atividades de Lazer, Esporte e Cidadania - NALEC } \\ \text { COORDENAÇÃO } & \text { Heros Augusto Santos Lobo } \\ \text { SETOR } & \text { Departamento de Geografia, Turismo e Humanidades } \\ \text { CONTATO } & \text { dgth@ufscar.br } \\ \text { PALAVRAS-CHAVE } & \text { entretenimento; desporto; bem estar; cultura; cooperação interinstitucional } \\ \text { DATA INÍCIO } & 28 / 3 / 2016\end{array}$

Título Programa de Preservação da Memória da UFSCar

COORDENAÇÃo Luciana de Souza Gracioso

SETOR Departamento de Ciência da Informação

CONTATO dci@ufscar.br

PALAVRAS-CHAVE patrimônio institucional; UFSCar; cultura; cultura; cultura e memória social

DATA INÍCIO 5/5/2015 
TítULO

COORDENAÇÃo

SETOR

CONTATO

PALAVRAS-CHAVE

DATA INÍCIO

\section{Tecnologia, Cultura e Sociedade}

Teresa Mary Pires de Castro Melo

Departamento de Ciências Humanas e Educação

dche@ufscar.br

tecnologia; cultura; comunicação; cultura; direitos de grupos sociais $14 / 3 / 2014$ 


\section{Direitos Humanos}

\section{e Justiça}

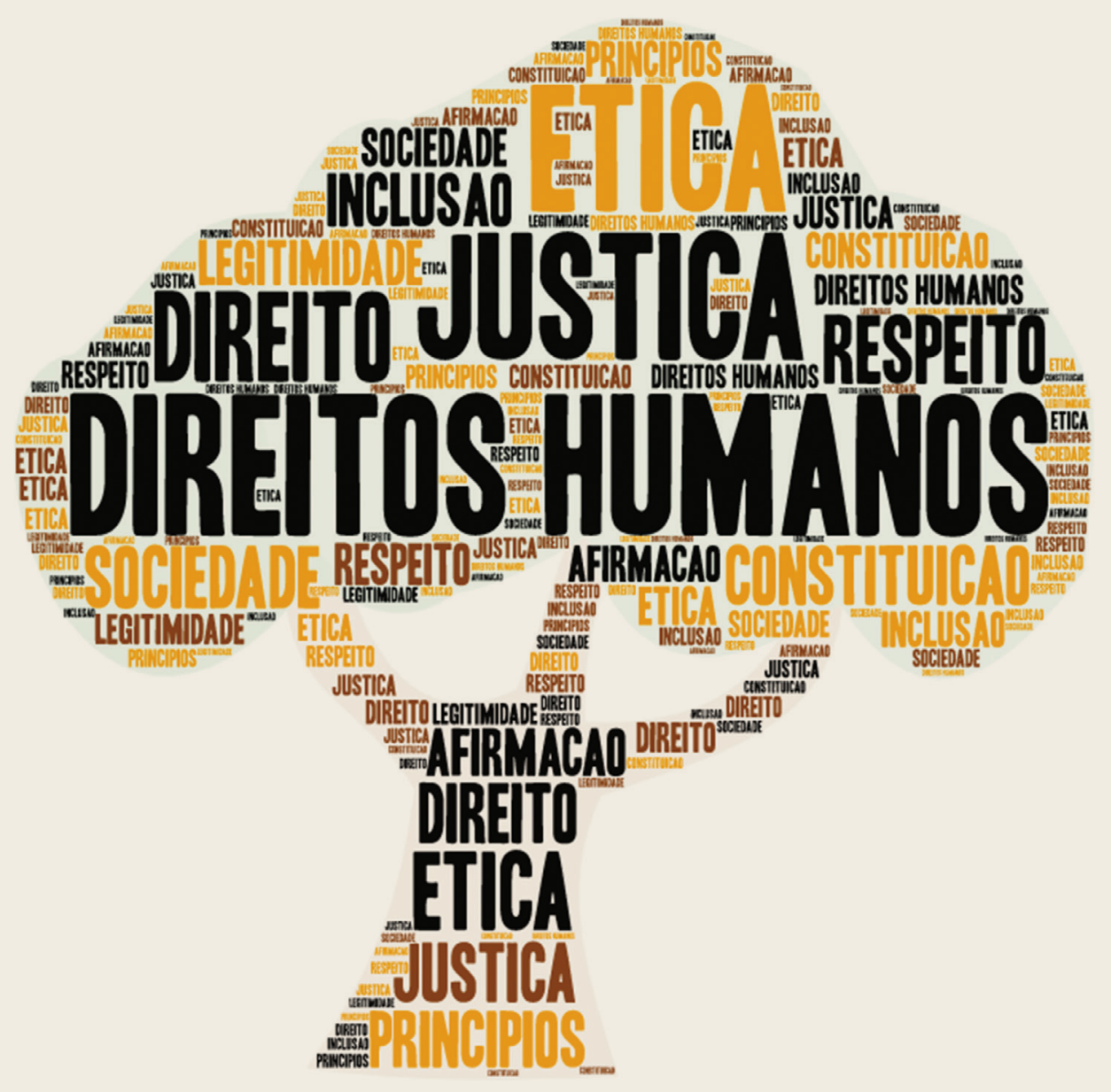

Ilustração: João Vitor Costa de Brito e Mateus Limeira. 


$\begin{array}{ll}\text { TítULO } & \text { Educação das Relações Étnico-Raciais } \\ \text { COORDENAÇÃo } & \text { Tatiane Cosentino Rodrigues } \\ \text { SETOR } & \text { Departamento de Teorias e Práticas Pedagógicas } \\ \text { CONTATO } & \text { dtpp@ufscar.br } \\ \text { PALAVRAS-CHAVE } & \begin{array}{l}\text { educação; relações étnico-raciais; Brasil África; direitos humanos e justiça; } \\ \text { educação continuada }\end{array}\end{array}$

DATA INÍCIO 28/3/2014

$\begin{array}{ll}\text { TÍTULO } & \text { METUIA - Terapia Ocupacional Social } \\ \text { COORDENAÇÃo } & \text { Roseli Esquerdo Lopes } \\ \text { SETOR } & \text { Departamento de Terapia Ocupacional } \\ \text { CONTATO } & \text { chdto@ufscar.br } \\ \text { PALAVRAS-CHAVE } & \begin{array}{l}\text { terapia ocupacional social; redes sociais de suporte; território e comunidade; } \\ \text { direitos humanos e justiça; direitos de grupos sociais } \\ \text { DATA INÍ́CIO }\end{array} \\ \end{array}$

$\begin{array}{ll}\text { TítULO } & \text { Nas Margens: Diălogos em Sociologia Urbana, Desigualdades } \\ & \text { e Diferença } \\ \text { COORDENAÇÃo } & \text { Gabriel de Santis Feltran } \\ \text { SETOR } & \text { Departamento de Sociologia } \\ \text { CONTATO } & \text { ds@ufscar.br } \\ \text { PALAVRAS-CHAVE } & \begin{array}{l}\text { sociologia; desigualdades; diferença; direitos humanos e justiça; desenvolvimento } \\ \text { urbano } \\ \text { DATA INÍCIO }\end{array} \\ \end{array}$

$\begin{array}{ll}\text { TÍTULO } & \text { Observatório Quilombola Evamariô } \\ \text { COORDENAÇÃo } & \text { Lourdes de Fatima Bezerra Carril } \\ \text { SETOR } & \text { Departamento de Geografia, Turismo e Humanidades } \\ \text { CONTATO } & \text { dgth@ufscar.br } \\ \text { PALAVRAS-CHAVE } & \text { território; educação; quilombola; direitos humanos e justiça; direitos de grupos } \\ & \text { sociais } \\ \text { DATA INÍCIO } & 5 / 9 / 2016\end{array}$

$\begin{array}{ll}\text { TítUlo } & \text { Orientação e Avaliação de Políticas Públicas para a } \\ & \text { Construção da Cidadania } 2 \\ \text { COORDENAÇÃo } & \text { Maria Ines Rauter Mancuso } \\ \text { SETOR } & \text { Departamento de Sociologia } \\ \text { CONTATO } & \text { ds@ufscar.br } \\ \text { PALAVRAS-CHAVE } & \begin{array}{l}\text { orientação; políticas públicas; cidadania; direitos humanos e justiça; capacitação de } \\ \text { gestores de políticas públicas }\end{array}\end{array}$

DATA INÍCIO

$13 / 4 / 2000$ 
TítULo

COORDENAÇÃO

SETOR

CONTATO

PALAVRAS-CHAVE

DATA INÍCIO
Relações Étnico-Raciais em Educação, Saúde e

Territorialidades

\section{Rosana Batista Monteiro}

Departamento de Ciências Humanas e Educação

dche@ufscar.br

racismo; políticas públicas; desigualdades sociais; direitos humanos e justiça; direitos de grupos sociais

$30 / 5 / 2014$ 
4

\section{Eduraßão}

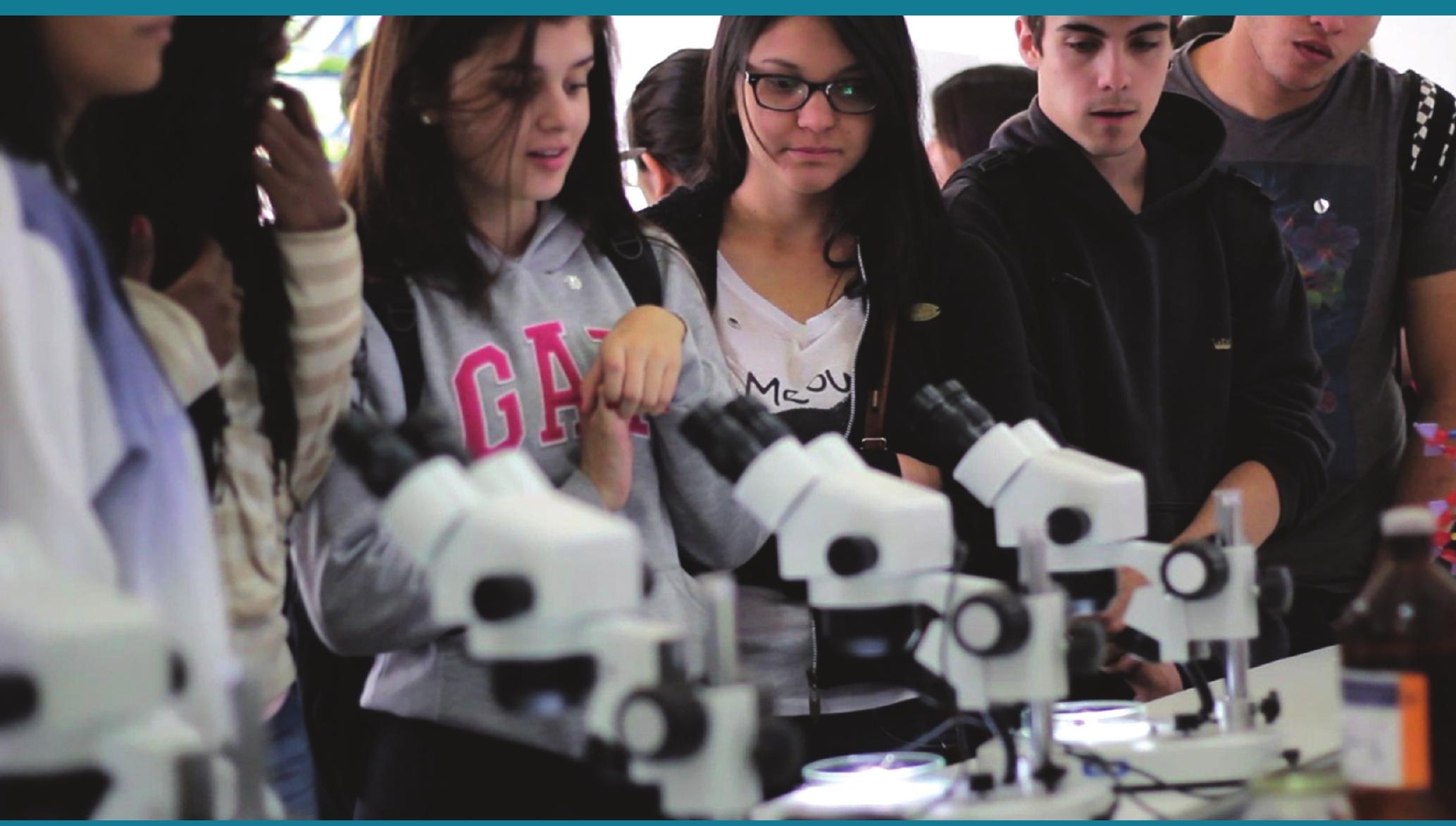

Projeto Porteiras Abertas - Campus Lagoa do Sino.

Foto: Tiago Santi. 
TíTULO

COORDENAÇÃo

SETOR

CONTATO

PALAVRAS-CHAVE

DATA INÍCIO

TítULo

COORDENAÇÃO

SETOR

CONTATO

PALAVRAS-CHAVE

DATA INÍCIO

TítULo

TítULO

COORDENAÇÃO

SETOR

CONTATO

PALAVRAS-CHAVE

DATA INÍCIO

COORDENAÇÃO

SETOR

CONTATO

PALAVRAS-CHAVE

DATA INÍCIO
A Produção do Conhecimento na Universidade: Contribuições para a Formação Inicial e Continuada de Professores

Renata Sebastiani

Departamento de Ciências da Natureza, Matemática e Educação

dcnme@cca.ufscar.br

educação; ensino básico; formação continuada; educação; educação continuada $1 / 9 / 2014$

\section{Acessibilidade é Direito}

Rosimeire Maria Orlando

Departamento de Psicologia

dpsic@ufscar.br

educação especial; acessibilidade; ensino superior; educação; educação especial

$21 / 6 / 2016$

Acessibilidade e Língua Brasileira de Sinais: Dos Processos Formativos Vivenciados na Educação Básica aos Recursos e Técnicas para Acesso na Educação Superior

\section{Dileia Aparecida Martins Briega}

Departamento de Psicologia

dpsic@ufscar.br

acessibilidade; libras; recursos técnicos; educação; educação especial

$20 / 1 / 2016$

\section{Ações e Reflexões em Educação e Educação Musical}

Fernando Stanzione Galizia

Departamento de Metodologia de Ensino

deme@ufscar.br

educação; educação musical; música; educação; cooperação interinstitucional

$31 / 8 / 2011$

$\begin{array}{ll}\text { TÍTULO } & \text { Alfabetização: Saberes e Cidadania } \\ \text { COORDENAÇÃo } & \text { Claudia Raimundo Reyes } \\ \text { SETOR } & \text { Departamento de Teorias e Práticas Pedagógicas } \\ \text { CONTATO } & \text { dtpp@ufscar.br } \\ \text { PALAVRAS-CHAVE } & \text { alfabetização; cidadania; letramento; educação; ensino fundamental } \\ \text { DATA INÍCIO } & \text { 29/2/2008 }\end{array}$


TíTULO

COORDENAÇÃO

SETOR

CONTATO

PALAVRAS-CHAVE

DATA INÍCIO

TítULo

COORDENAÇÃO

SETOR

CONTATO

PALAVRAS-CHAVE

DATA INÍCIO

Análise Comportamental da Cultura, Linguagem e

Comportamento Simbólico - CLICS

Julio Cesar Coelho de Rose

Departamento de Psicologia

dpsic@ufscar.br

comportamento simbólico; linguagem; cultura; educação; educação profissional $28 / 3 / 2016$
Anatomia Humana: Pesquisa, Ensino e Divulgação Científica

Luiz Fernando Takase

Departamento de Morfologia e Patologia

dmp@ufscar.br

anatomia humana; ensino; corpo humano; educação; educação de jovens e adultos

$5 / 4 / 2013$
TíTULO

COORDENAÇÃO

SETOR

CONTATO

PALAVRAS-CHAVE

DATA INÍCIO

TíTulo

Apoio à Formação Educacional e Político-Gerencial de Profissionais de Saúde

Valeria Vernaschi Lima

Departamento de Medicina

dmed@ufscar.br

aprendizagem de adultos; metodologias ativas de aprendizagem; educação em saúde; educação; educação continuada

$10 / 9 / 2007$

Aprendizagem e Desenvolvimento Profissional da Docência: Formação de Professores da Educação Básica e Outros Agentes Educacionais

COORDENAÇÃO Aline Maria de Medeiros Rodrigues Reali

SETOR

Departamento de Metodologia de Ensino

CONTATO

deme@ufscar.br

PALAVRAS-CHAVE

formação de professores; desenvolvimento profissional; professores; educação; educação continuada

DATA INÍCIO

$24 / 9 / 2008$

TíTULO

Atividade de Ensino: Expressão da Unidade Teoria e Prática na Formação de Professores

COORDENAÇÃo Maria do Carmo de Sousa

SETOR

CONTATO

deme@ufscar.br

PALAVRAS-CHAVE

teoria da atividade; formação inicial; formação continuada; educação; educação continuada

DATA INÍCIO

$22 / 4 / 2009$ 
TítULo

COORDENAÇÃO

SETOR

CONTATO

PALAVRAS-CHAVE

DATA INÍCIO

$\begin{array}{ll}\text { TÍTULO } & \text { Biblioteca Comunitária } \\ \text { COORDENAÇÃo } & \text { Ligia Maria Silva e Souza } \\ \text { SETOR } & \text { Biblioteca Comunitária } \\ \text { CONTATO } & \text { bco@ufscar.br } \\ \text { PALAVRAS-CHAVE } & \text { biblioteca; livro; educação; educação continuada } \\ \text { DATA INÍ́CIO } & \text { 12/7/1999 }\end{array}$

Atividades de Assessoria e Desenvolvimento de Projetos do Laboratório de Pesquisas em Eletroquímica

Romeu Cardozo Rocha Filho

Departamento de Química

dqchefe@ufscar.br

eletroquímica; bases de dados científicas; assessoria tecnocienciometrica; educação; inovação tecnológica

$26 / 6 / 2013$

$\begin{array}{ll}\text { TÍTULO } & \text { C2Y! - Computing for You! } \\ \text { COORDENAÇÃo } & \text { Luciana Aparecida Martinez Zaina } \\ \text { SETOR } & \text { Departamento de Computação } \\ \text { CONTATO } & \text { dcomp@ufscar.br } \\ \text { PALAVRAS-CHAVE } & \text { computação; criatividade; educação; educação; educação continuada } \\ \text { DATA INÍCIO } & 28 / 3 / 2016\end{array}$

$\begin{array}{ll}\text { TítULO } & \text { Ciência e Subjetividade } \\ \text { COORDENAÇÃo } & \text { Georgina Carolina de Oliveira Faneco Maniakas } \\ \text { SETOR } & \text { Departamento de Psicologia } \\ \text { CONTATO } & \text { dpsic@ufscar.br } \\ \text { PALAVRAS-CHAVE } & \text { ciência; subjetividade; educação; educação continuada } \\ \text { DATA INÍCIO } & \text { 19/11/2004 }\end{array}$

$\begin{array}{ll}\text { TÍTULO } & \text { Ciência, Tecnologia e Sociedade (CTS) } \\ \text { COORDENAÇÃo } & \text { Camila Carneiro Dias Rigolin } \\ \text { SETOR } & \text { Departamento de Ciência da Informação } \\ \text { CONTATO } & \text { dci@ufscar.br } \\ \text { PALAVRAS-CHAVE } & \begin{array}{l}\text { ciência, tecnologia e sociedade; divulgação científica; comunicação científica; } \\ \text { educação; produção e difusão de material educativo }\end{array}\end{array}$

DATA INÍCIO

$14 / 3 / 2012$ 

dos Principais Problemas Bióticos e Abióticos Agrícolas da Comunidade Territorial Lagoa Do Sino

COORDENAÇÃo Waldir Cintra de Jesus Junior

SETOR

Centro de Ciências da Natureza

CONTATO

diretorccn@ufscar.br

PALAVRAS-CHAVE entomologia; fitopatologia; fisiologia vegetal; educação; desenvolvimento rural

DATA INÍCIO

$11 / 6 / 2015$

TíTULO

Consultoria e Prestação de Serviços para Atendimento na Área de Deficiência Intelectual e Autismo: Institucional e Individual

COORDENAÇÃo Antonio Celso de Noronha Goyos

SETOR

Departamento de Psicologia

CONTATO

dpsic@ufscar.br

PALAVRAS-CHAVE

atenção ao indivíduo; autismo ; análise do comportamento; educação; atenção a grupos de pessoas com necessidades especiais

DATA INÍCIO 24/4/2013

TÍTULO

\section{Contribuições da Psicologia para o Contexto Escolar Público}

COORDENAÇÃo

Tania Maria Santana de Rose

SETOR

Departamento de Psicologia

CONTATO

dpsic@ufscar.br

PALAVRAS-CHAVE

formação de psicólogos; formação de professores; ensino fundamental; educação; ensino fundamental

DATA INÍ́CIO

$14 / 3 / 2014$

TíTULO

\section{Corpo em Educação}

COORDENAÇÃO

Dijnane Fernanda Vedovatto Iza

SETOR

Departamento de Metodologia de Ensino

CONTATO

deme@ufscar.br

PALAVRAS-CHAVE

formação de professores; educação física; corpo e movimento; educação; educação continuada

DATA INÍCIO 30/9/2013

TíTULO

\section{Democratização do Conhecimento e do Acesso À Educação}

COORDENAÇÃO

Roseli Rodrigues de Mello

SETOR

Departamento de Teorias e Práticas Pedagógicas

CONTATO

dtpp@ufscar.br

PALAVRAS-CHAVE

democratização; conhecimento; educação; direitos de grupos sociais

DATA INÍCIO

$1 / 9 / 2002$ 
TítULo

COORDENAÇÃO

SETOR

CONTATO

PALAVRAS-CHAVE

DATA INÍCIO

TíTULO

COORDENAÇÃO

SETOR

CONTATO

PALAVRAS-CHAVE

DATA INÍCIO

\section{Desenvolvimento de Repertórios Acadêmicos}

Lidia Maria Marson Postalli

Departamento de Psicologia

dpsic@ufscar.br

repertórios acadêmicos; educação; educação profissional

$1 / 1 / 2001$

\section{Título \\ Desenvolvimento Territorial Sustentável na Região do Campus Lagoa do Sino da UFSCar Suportado pelas Atividades de Extensão, Ensino e Pesquisa \\ COORDENAÇÃO \\ Heber Lombardi de Carvalho \\ SETOR \\ Centro de Ciências da Natureza \\ CONTATO \\ diretorccn@ufscar.br \\ PALAVRAS-CHAVE desenvolvimento; lagoa do sino; tecnologia e produção; educação; desenvolvimento rural \\ DATA INÍCIO \\ $16 / 9 / 2016$}

$\begin{array}{ll}\text { TÍTULO } & \text { Discursos na Rede } \\ \text { COORDENAÇÃo } & \text { Ana Silvia Couto de Abreu } \\ \text { SETOR } & \text { Departamento de Metodologia de Ensino } \\ \text { CONTATO } & \text { deme@ufscar.br } \\ \text { PALAVRAS-CHAVE } & \text { formação professores; autoria; digital; educação; educação continuada } \\ \text { DATA INÍCIO } & 8 / 12 / 2008\end{array}$

TÍTULO

\section{Divulgação Científica em Educação}

COORDENAÇÃo

Carmen Lucia Brancaglion Passos

SETOR

Programa de Pós-Graduação em Educação

CONTATO

PALAVRAS-CHAVE secppge@ufscar.br

divulgação científica; pesquisa em educação; revista eletrônica; educação; comunicação escrita e eletrônica

DATA INÍCIO

$5 / 11 / 2012$ 


$\begin{array}{ll}\text { TíTULO } & \text { Divulgação Científica, Comunicação e Inclusão Social } \\ \text { COORDENAÇÃo } & \text { Maria Cristina Comunian Ferraz } \\ \text { SETOR } & \text { Departamento de Ciência da Informação } \\ \text { CONTATO } & \text { dci@ufscar.br } \\ \text { PALAVRAS-CHAVE } & \begin{array}{l}\text { conhecimento científico; conhecimento tecnológico; inclusão social; educação; } \\ \text { educação profissional }\end{array} \\ \text { DATA INÍCIO } & 8 / 2 / 2008\end{array}$

$\begin{array}{ll}\text { TÍTULO } & \text { Educação Continuada } \\ \text { COORDENAÇÃo } & \text { Jose Antonio Salvador } \\ \text { SETOR } & \text { Departamento de Matemática } \\ \text { CONTATO } & \text { dmchefe@ufscar.br } \\ \text { PALAVRAS-CHAVE } & \begin{array}{l}\text { educação continuada; aperfeiçoamento; matemática; educação; educação } \\ \text { continuada }\end{array} \\ \text { DATA INÍCIO } & 6 / 11 / 2003\end{array}$

$\begin{array}{ll}\text { TÍtULO } & \text { Educação de Jovens e Adultos Privados de Liberdade } \\ \text { COORDENAÇÃo } & \text { Elenice Maria Cammarosano Onofre } \\ \text { SETOR } & \text { Departamento de Teorias e Práticas Pedagógicas } \\ \text { CONTATO } & \text { dtpp@ufscar.br } \\ \text { PALAVRAS-CHAVE } & \begin{array}{l}\text { privação de liberdade; medidas sócio-educativas; direitos humanos; educação; } \\ \text { direitos de grupos sociais }\end{array}\end{array}$

DATA INÍCIO 22/4/2009

$\begin{array}{ll}\text { TítULO } & \text { Educação do Campo } \\ \text { COORDENAÇÃo } & \text { Luiz Bezerra Neto } \\ \text { SETOR } & \text { Departamento de Educação } \\ \text { CONTATO } & \text { secded@ufscar.br } \\ \text { PALAVRAS-CHAVE } & \begin{array}{l}\text { educação no campo; movimentos sociais; trabalhadores rurais; educação; direitos } \\ \text { de grupos sociais }\end{array} \\ \text { DATA INÍCIO } & \text { 17/10/2011 }\end{array}$

$\begin{array}{ll}\text { TÍTULO } & \text { Educação Especial e Humanização nos Serviços de Saúde: } \\ & \text { Pesquisa e Intervenção } \\ \text { COORDENAÇÃo } & \text { Adriana Garcia Goncalves } \\ \text { SETOR } & \text { Departamento de Psicologia } \\ \text { CONTATO } & \text { dpsic@ufscar.br } \\ \text { PALAVRAS-CHAVE } & \text { educação especial; humanização; atenção integral; educação; educação especial } \\ \text { DATA INÍCIO } & \text { 8/11/2013 }\end{array}$


TítULo

COORDENAÇÃO

SETOR

CONTATO

PALAVRAS-CHAVE

DATA INÍCIO

TítULo

COORDENAÇÃO

SETOR

CONTATO

PALAVRAS-CHAVE

DATA INÍCIO

\section{Educação Especial: Direito a Educação}

Katia Regina Moreno Caiado

Departamento de Ciências Humanas e Educação

dche@ufscar.br

educação especial; política pública; direitos humanos; educação; educação especial $4 / 6 / 2013$

$\begin{array}{ll}\text { TíTULO } & \text { Educação Musical na UFSCar } \\ \text { COORDENAÇÃo } & \text { Ilza Zenker Leme Joly } \\ \text { SETOR } & \text { Departamento de Artes e Comunicação } \\ \text { CONTATO } & \text { dac@ufscar.br } \\ \text { PALAVRAS-CHAVE } & \text { educação; musical; educação; educação continuada } \\ \text { DATA INÍCIO } & 9 / 8 / 1999\end{array}$

TíTULO

Educação, Trabalho e Desenvolvimento Econômico e Social

COORDENAÇÃO

Andrea Rodrigues Ferro

SETOR

Departamento de Economia

CONTATO

deco@ufscar.br

PALAVRAS-CHAVE

educação; mercado de trabalho; desenvolvimento econômico; educação; desenvolvimento urbano

DATA INÍCIO

$17 / 10 / 2011$

$\begin{array}{ll}\text { TítULO } & \text { Educar Direito } \\ \text { COORDENAÇÃo } & \text { Joao Virgilio Tagliavini } \\ \text { SETOR } & \text { Departamento de Educação } \\ \text { CONTATO } & \text { secded@ufscar.br } \\ \text { PALAVRAS-CHAVE } & \text { formação jurídica; formação docente; educação para a cidadania; educação; } \\ & \text { educação continuada }\end{array}$

DATA INÍCIO

27/3/2013 
TítULo

COORDENAÇÃO

SETOR

CONTATO

PALAVRAS-CHAVE

DATA INÍCIO

TítULo

COORDENAÇÃO

SETOR

CONTATO

PALAVRAS-CHAVE

DATA INÍCIO

EdUFSCar - Livros, Materiais Didáticos e Atividades de Divulgação do Conhecimento

Oswaldo Mario Serra Truzzi

Departamento de Engenharia de Produção

dep@ufscar.br

conhecimento; publicações; livraria; educação; incentivo à leitura

$29 / 11 / 2013$

\section{Ensino/Aprendizagem de Língua Espanhola}

Rosa Yokota

Departamento de Letras

dl@ufscar.br

espanhol; cultura; ensino-aprendizagem; educação; educação continuada

$17 / 3 / 2009$

$\begin{array}{ll}\text { TÍTULO } & \text { Ensino/Aprendizagem de Língua Inglesa } \\ \text { COORDENAÇÃo } & \text { Eliane Hercules Augusto Navarro } \\ \text { SETOR } & \text { Departamento de Letras } \\ \text { CONTATO } & \text { dl@ufscar.br } \\ \text { PALAVRAS-CHAVE } & \text { ensino; aprendizagem; educação; educação continuada } \\ \text { DATA INÍCIO } & 1 / 1 / 1999\end{array}$

TÍTULO

\section{Ensino de Química e Divulgação Científica}

COORDENAÇÃO Walter Ruggeri Waldman

SETOR

Departamento de Física, Química e Matemática

CONTATO

dfqm@ufscar.br

PALAVRAS-CHAVE

ensino de química; divulgação científica; saberes populares; educação; educação continuada

DATA INÍCIO

$5 / 11 / 2012$

TíTULO

Ensino, Pesquisa e Desenvolvimento Sustentável no Território Lagoa do Sino

COORDENAÇÃO Alberto Luciano Carmassi

SETOR

Centro de Ciências da Natureza

CONTATO

diretorccn@ufscar.br

PALAVRAS-CHAVE

educação; meio ambiente; agricultura familiar; educação; gestão de recursos naturais

DATA INÍCIO

$17 / 9 / 2014$ 
TítULo

COORDENAÇÃO

SETOR

CONTATO

PALAVRAS-CHAVE

DATA INÍCIO

TítULo

COORDENAÇÃO

SETOR

CONTATO

PALAVRAS-CHAVE

DATA INÍCIO
Escolarização, Trabalho e Participação Social da Pessoa com Deficiência

Juliane Aparecida de Paula Perez Campos

Departamento de Psicologia

dpsic@ufscar.br

escolarização; pessoas com deficiência; participação social; educação; educação especial

$24 / 4 / 2013$

$\begin{array}{ll}\text { TÍTULO } & \text { Estudos sobre a Escola de Vigotsky } \\ \text { COORDENAÇÃo } & \text { Maria Aparecida Mello } \\ \text { SETOR } & \text { Departamento de Teorias e Práticas Pedagógicas } \\ \text { CONTATO } & \text { dtpp@ufscar.br } \\ \text { PALAVRAS-CHAVE } & \text { estudos; Vigotsky; educação; educação infantil } \\ \text { DATA INÍ́cIO } & 21 / 10 / 2004\end{array}$

Estudos sobre a Criança e a Infância - História da Educação Infantil e Formação Continuada de Professores de Educação Infantil e de Outros Agentes Educacionais

Anete Abramowicz

Departamento de Teorias e Práticas Pedagógicas

dtpp@ufscar.br

estudos; criança; infância; educação; educação continuada

27/8/1999

$\begin{array}{ll}\text { TítUlo } & \text { Filosofia: Perspectivas e Contemporaneidade } \\ \text { COORDENAÇÃo } & \text { Jose Eduardo Marques Baioni } \\ \text { SETOR } & \text { Departamento de Filosofia e Metodologia da Ciência } \\ \text { CONTATO } & \text { dfmc@ufscar.br } \\ \text { PALAVRAS-CHAVE } & \text { filosofia; história; crítica; educação; educação continuada } \\ \text { DATA INÍCIO } & 23 / 5 / 2012\end{array}$

TítULo

Formação Compartilhada de Professores que Ensinam Matemática na Educação Básica

COORDENAÇÃo Carmen Lucia Brancaglion Passos

SETOR

Departamento de Metodologia de Ensino

CONTATO

deme@ufscar.br

PALAVRAS-CHAVE formação; professores; educação; educação continuada

DATA INÍCIO

$1 / 1 / 2003$ 
TítULo

COORDENAÇÃO

SETOR

CONTATO

PALAVRAS-CHAVE

DATA INÍCIO

TíTULO

COORDENAÇÃO

SETOR

CONTATO

PALAVRAS-CHAVE

DATA INÍCIO
Formação Continuada de Professores de Filosofia da

\section{Educação Básica}

Adriana Mattar Maamari

Departamento de Metodologia de Ensino

deme@ufscar.br

ensino de filosofia; formação continuada; filosofia na escola; educação; educação continuada

29/11/2013

$\begin{array}{ll}\text { TíTULO } & \text { Formação de Professores e Divulgação Científica } \\ \text { COORDENAÇÃo } & \text { Ducinei Garcia } \\ \text { SETOR } & \text { Departamento de Física } \\ \text { CONTATO } & \text { dfchefe@ufscar.br } \\ \text { PALAVRAS-CHAVE } & \text { física; divulgação; educação; educação continuada } \\ \text { DATA INÍCIO } & 1 / 1 / 2005\end{array}$

\section{Formação Continuada em Educação Especial}

Eniceia Goncalves Mendes

Departamento de Psicologia

dpsic@ufscar.br

educação; especial; educação; educação profissional

$29 / 6 / 2000$

$\begin{array}{ll}\text { TítULO } & \text { Formação de Profissionais em EaD } \\ \text { COORDENAÇÃo } & \text { Aline Maria de Medeiros Rodrigues Reali } \\ \text { SETOR } & \text { Secretaria Geral de Educação a Distância } \\ \text { CONTATO } & \text { sead@ufscar.br } \\ \text { PALAVRAS-CHAVE } & \text { educação a distância; formação continuada; tics; educação; educação continuada } \\ \text { DATA INÍCIO } & 28 / 4 / 2011\end{array}$

TítULO

\section{Formação e Aperfeiçoamento de Educadores}

COORDENAÇÃo Hylio Lagana Fernandes

SETOR Departamento de Ciências Humanas e Educação

CONTATO

PALAVRAS-CHAVE

dche@ufscar.br

DATA INÍCIO

aperfeiçoamento; ensino; formação; educação; educação profissional

$15 / 9 / 2006$ 


$\begin{array}{ll}\text { TíTULO } & \text { Formação e Educação Continuada em Letras } \\ \text { COORDENAÇÃo } & \text { Camila Hofling } \\ \text { SETOR } & \text { Coordenação do Curso de Licenciatura em Letras } \\ \text { CONTATO } & \text { ccl@ufscar.br } \\ \text { PALAVRAS-CHAVE } & \text { educação continuada; formação; letras; educação; educação continuada } \\ \text { DATA INÍCIO } & 7 / 1 / 2015\end{array}$

$\begin{array}{ll}\text { TÍTULO } & \text { Formação e Educação Continuada em Linguística } \\ \text { COORDENAÇÃo } & \text { Luzmara Curcino Ferreira } \\ \text { SETOR } & \text { Departamento de Letras } \\ \text { CONTATO } & \text { dl@ufscar.br } \\ \text { PALAVRAS-CHAVE } & \text { linguistica; linguagem; educação; educação; educação continuada } \\ \text { DATA INÍ́CIO } & 9 / 9 / 2013\end{array}$

$\begin{array}{ll}\text { TÍTULO } & \text { Formação Inicial e Continuada de Professores de Línguas } \\ \text { COORDENAÇÃo } & \text { Ademar da Silva } \\ \text { SETOR } & \text { Departamento de Metodologia de Ensino } \\ \text { CONTATO } & \text { deme@ufscar.br } \\ \text { PALAVRAS-CHAVE } & \begin{array}{l}\text { língua estrangeira: inglês; língua estrangeira: espanhol; língua materna: português; } \\ \text { educação; educação profissional }\end{array} \\ \text { DATA INÍCIO } & \text { 14/12/2012 }\end{array}$

$\begin{array}{ll}\text { TÍTULO } & \text { Gestão da Informação e do Conhecimento } \\ \text { COORDENAÇÃo } & \text { Wanda Aparecida Machado Hoffmann } \\ \text { SETOR } & \text { Departamento de Ciência da Informação } \\ \text { CONTATO } & \text { dci@ufscar.br } \\ \text { PALAVRAS-CHAVE } & \text { gestão; informação; educação; educação profissional } \\ \text { DATA INÍCIO } & 16 / 8 / 1999\end{array}$

\begin{tabular}{ll}
\hline TítULO & Gestão e Planejamento Ambiental - Conservação de Recursos \\
& Naturais para um Desenvolvimento Sustentado \\
COORDENAÇÃo & Jose Eduardo Dos Santos \\
SETOR & Departamento de Ciências Ambientais \\
CONTATO & dcam@ufscar.br \\
PALAVRAS-CHAVE & ambiental; desenvolvimento; educação; educação ambiental \\
DATA INÍCIO & $6 / 7 / 2001$
\end{tabular}




$\begin{array}{ll}\text { TítUlo } & \text { Grupo de Estudos do Agronegócio (GEAgro) } \\ \text { COORDENAÇÃo } & \text { Marta Cristina Marjotta Maistro } \\ \text { SETOR } & \text { Departamento de Tecnologia Agroindustrial e Socioeconomia Rural } \\ \text { CONTATO } & \text { secdtai@cca.ufscar.br } \\ \text { PALAVRAS-CHAVE } & \begin{array}{l}\text { agronegócio; economia aplicada; grupo de estudos; educação; desenvolvimento } \\ \text { rural }\end{array} \\ \text { DATA INÍCIO } & 13 / 4 / 2011\end{array}$

$\begin{array}{ll}\text { TÍTULO } & \text { Identificação e Intervenção Precoce Domiciliar de Crianças } \\ & \text { com TGD (Transtorno Global do Desenvolvimento) } \\ \text { COORDENAÇÃo } & \text { Ana Lucia Rossito Aiello } \\ \text { SETOR } & \text { Departamento de Psicologia } \\ \text { CONTATO } & \text { dpsic@ufscar.br } \\ \text { PALAVRAS-CHAVE } & \text { atraso de desenvolvimento; intervenção precoce; avaliação; educação; educação } \\ & \text { especial } \\ \text { DATA INÍCIO } & 22 / 4 / 2009\end{array}$

$\begin{array}{ll}\text { TítULO } & \text { Inclusão Social do Deficiente Mental Através do Trabalho } \\ \text { COORDENAÇÃo } & \text { Antonio Celso de Noronha Goyos } \\ \text { SETOR } & \text { Departamento de Psicologia } \\ \text { CONTATO } & \text { dpsic@ufscar.br } \\ \text { PALAVRAS-CHAVE } & \begin{array}{l}\text { formação; trabalho; deficiência; educação; atenção a grupos de pessoas com } \\ \text { necessidades especiais } \\ \text { DATA INÍ́CIO }\end{array} \\ \end{array}$

$\begin{array}{ll}\text { TÍTULO } & \text { Informação para Educação } \\ \text { COORDENAÇÃo } & \text { Luciana de Souza Gracioso } \\ \text { SETOR } & \text { Departamento de Ciência da Informação } \\ \text { CONTATO } & \text { dci@ufscar.br } \\ \text { PALAVRAS-CHAVE } & \text { informação; educação; educação; cultura e memória social } \\ \text { DATA INÍ́CIO } & \text { 1/1/1999 }\end{array}$

Título Informação, Tecnologia e Sociedade

COORDENAÇÃO

Rogerio Aparecido Sa Ramalho

SETOR

Departamento de Ciência da Informação

CONTATO

dci@ufscar.br

PALAVRAS-CHAVE

informação; tecnologia; sociedade; educação; educação continuada

DATA INÍCIO

$10 / 9 / 2015$ 
TíTULO

COORDENAÇÃO

SETOR

CONTATO

PALAVRAS-CHAVE

DATA INÍCIO
Intervenção Precoce e Educação Inclusiva

Fabiana Cia

Departamento de Psicologia

dpsic@ufscar.br

intervenção precoce; pré-escolares; professores; educação; educação especial $17 / 10 / 2011$
TÍTULO

COORDENAÇÃo

SETOR

CONTATO

PALAVRAS-CHAVE

DATA INÍCIO

\section{Laboratório de Bioensaios e Modelagem Matemática}

Irineu Bianchini Junior

Departamento de Hidrobiologia

secdhb@ufscar.br

bioensaios; medelagem; educação; educação ambiental

$16 / 9 / 1999$
TÍTULO

COORDENAÇÃO

SETOR

CONTATO

PALAVRAS-CHAVE

DATA INÍCIO

TíTULO

COORDENAÇÃO

SETOR

CONTATO

PALAVRAS-CHAVE

DATA INÍCIO

\section{Linguiística Aplicada: Português Para Estrangeiros}

Nelson Viana

Departamento de Letras

dl@ufscar.br

português; estrangeiros; educação; educação profissional

$1 / 1 / 2000$
TítULO

COORDENAÇÃO

SETOR

CONTATO

PALAVRAS-CHAVE

DATA INÍCIO

\section{Modelagem Estatística Aplicada e Levantamento de Dados}

Cecilia Candolo

Departamento de Estatística

deschefe@ufscar.br

análise de regressão; modelos lineares generalizados; levantamento de dados; educação; cooperação interinstitucional

$4 / 1 / 2013$ 
TÍTULO

COORDENAÇÃO

SETOR

CONTATO

PALAVRAS-CHAVE

DATA INÍCIO

TÍTULo

COORDENAÇÃO

SETOR

CONTATO

PALAVRAS-CHAVE

DATA INÍCIO

$\begin{array}{ll}\text { TíTULO } & \text { PIBID-UFSCar: Espaço de Formação Compartilhada entre } \\ & \text { Professores da Educação Básica e Licenciandos } \\ \text { COORDENAÇÃo } & \text { Maria do Carmo de Sousa } \\ \text { SETOR } & \begin{array}{l}\text { Departamento de Metodologia de Ensino } \\ \text { CONTATO }\end{array} \\ \text { deme@ufscar.br } \\ \text { PALAVRAS-CHAVE } & \begin{array}{l}\text { iniciação à docência; formação de professores; espaço compartilhado; educação; } \\ \text { educação continuada }\end{array}\end{array}$

DATA INÍCIO

16/11/2011
Observatório do Turismo do Estado de São Paulo - OTURESP

Telma Darn

Departamento de Geografia, Turismo e Humanidades

dgth@ufscar.br

observatório; turismo; educação; turismo

$5 / 11 / 2012$
PEGASUS - Programa de Educação e Gestão para o Acesso à

\section{Sustentabilidade}

Andre Coimbra Felix Cardoso

Departamento de Administração

dadm@ufscar.br

sustentabilidade; educação; gestão; educação; empreendorismo

$28 / 4 / 2011$

$\begin{array}{ll}\text { TÍTULO } & \text { Planejamento Florestal } \\ \text { COORDENAÇÃo } & \text { Claudio Roberto Thiersch } \\ \text { SETOR } & \text { Departamento de Ciências Ambientais - Sorocaba } \\ \text { CONTATO } & \text { dca@ufscar.br } \\ \text { PALAVRAS-CHAVE } & \text { biometria; inventário; planejamento; educação; educação continuada } \\ \text { DATA INÍCIO } & \text { 29/4/2011 }\end{array}$

TítULo

COORDENAÇÃO

Políticas Públicas e Gestão da Educação

SETOR

Celso Luiz Aparecido Conti

CONTATO

Departamento de Educação

secded@ufscar.br

PALAVRAS-CHAVE

DATA INÍCIO

políticas; educação; educação; educação profissional

$1 / 1 / 2002$ 
TíTULO

COORDENAÇÃO

SETOR

CONTATO

PALAVRAS-CHAVE

DATA INÍCIO

TítuLo

SETOR

CONTATO

PALAVRAS-CHAVE

DATA INÍCIO

TítuLo

SETOR

CONTATO

PALAVRAS-CHAVE

DATA INÍCIO

\section{Popularização da Educação em Ciências}

Denise de Freitas

Departamento de Metodologia de Ensino

deme@ufscar.br

alfabetização científica; construção de material didático; meio ambiente; educação; educação continuada

$21 / 9 / 2009$

\section{Práticas Pedagógicas e Processos Formativos na Educação Escolar e Não Escolar: Estudo, Produção e Divulgação de Conhecimentos e Saberes}

Fernando Donizete Alves

Departamento de Educação Física e Motricidade Humana

defmh@ufscar.br

práticas pedagógicas; processos formativos; educação escolar e não escolar; educação; educação continuada

$5 / 11 / 2012$

TítULo

\section{Programa de Educação Continuada em Saúde}

COORDENAÇÃo Ana Claudia de Oliveira

SETOR

Departamento de Medicina

CONTATO

dmed@ufscar.br

PALAVRAS-CHAVE educação continuada; saúde; medicina; educação; educação continuada

DATA INÍCIO $24 / 4 / 2013$

TíTULO

\section{Programa de Educação das Relações Étnico-Raciais da}

\section{UFSCar}

COORDENAÇÃO

SETOR

CONTATO

PALAVRAS-CHAVE

DATA INÍCIO
Petronilha Beatriz Goncalves e Silva

Departamento de Teoria e Práticas Pedagógicas

dtpp@ufscar.br

educação; relações étnico-raciais; igualdade de direitos; educação; direitos de grupos sociais

$14 / 3 / 2014$ 
TíTULO

COORDENAÇÃO

SETOR

CONTATO

PALAVRAS-CHAVE

DATA INÍCIO
Programa de Educação Especial: Formação e Inclusão

Rosemeire de Araujo Rangni

Departamento de Psicologia

dpsic@ufscar.br

educação especial; formação; inclusão; educação; educação especial

$27 / 9 / 2013$
Título

COORDENAÇÃO

SETOR

CONTATO

PALAVRAS-CHAVE

DATA INÍCIO
Programa de Educação Superior UAB-UFSCar (Universidade Aberta do Brasil)

Denise de Paula Martins de Abreu e Lima

Gabinete da Reitoria

reitoria@ufscar.br

educação a distancia; tecnologia educacional; tutoria; educação; educação à distância

$2 / 8 / 2007$
TÍTULO

COORDENAÇÃO

SETOR

CONTATO

PALAVRAS-CHAVE

DATA INÍCIO

\section{Programa de Estudos Avançados em Desenvolvimento e}

\section{Economia - PEADE}

Alexandre Lopes Gomes

Departamento de Economia

deco@ufscar.br

educação; economia; desenvolvimento; educação; educação continuada

$19 / 4 / 2012$

TíTULO

Programa de Extensão para a Democratização do

Conhecimento: Comunicação entre Universidade, Comunidade e Escola

COORDENAÇÃO

Estefano Vizconde Veraszto

SETOR

Departamento de Ciências da Natureza, Matemática e Educação

CONTATO

dcnme@cca.ufscar.br

PALAVRAS-CHAVE

aprendizagem; educação continuada; democratização do conhecimento; educação; educação continuada

DATA INÍCIO

9/9/2013

TíTULO

Programa de Formação Continuada em Educação Especial a Profissionais de Redes Municipais de Ensino

COORDENAÇÃo Cristina Broglia Feitosa de Lacerda

SETOR

Departamento de Psicologia

CONTATO

dpsic@ufscar.br

PALAVRAS-CHAVE

educação inclusiva; educação básica; formação continuada; educação; educação especial

DATA INÍCIO

$22 / 4 / 2009$ 
TÍTULO

COORDENAÇÃO

SETOR

CONTATO

PALAVRAS-CHAVE

DATA INÍCIO
Programa de Formação em Educação Infantil da UAC

Andrea Braga Moruzzi

Unidade de Atendimento a Criança

uac@ufscar.br

educação infantil; formação inicial; formação continuada; educação; educação infantil

$24 / 7 / 2014$

$\begin{array}{ll}\text { TÍTULO } & \text { Programa de Inovação em Educação, Tecnologias e } \\ & \text { Linguagens (EaD-UFSCar) } \\ \text { COORDENAÇÃo } & \text { Daniel Ribeiro Silva Mill } \\ \text { SETOR } & \text { Secretaria Geral de Educação a Distância } \\ \text { CONTATO } & \text { sead@ufscar.br } \\ \text { PALAVRAS-CHAVE } & \text { educação a distancia; tecnologia educacional; linguagens e aprendizagem; } \\ & \text { educação; educação à distância } \\ \text { DATA INÍCIO } & 3 / 9 / 2013\end{array}$

$\begin{array}{ll}\text { TÍTULO } & \text { Programa de Revitalização Geriátrica } \\ \text { COORDENAÇÃo } & \text { Jose Rubens Rebelatto } \\ \text { SETOR } & \text { Departamento de Fisioterapia } \\ \text { CONTATO } & \text { dfisio@ufscar.br } \\ \text { PALAVRAS-CHAVE } & \begin{array}{l}\text { revitalização geriátrica; idoso; fisioterapia geriátrica; educação; atenção integral à } \\ \text { terceira idade }\end{array} \\ \text { DATA INÍCIO } & 26 / 11 / 2008\end{array}$

$\begin{array}{ll}\text { TÍTULO } & \text { Programa em Socioeconomia e Estatística Aplicada } \\ \text { COORDENAÇÃo } & \text { Adriana Estela Sanjuan Montebello } \\ \text { SETOR } & \text { Departamento de Tecnologia Agroindustrial e Socioeconomia Rural } \\ \text { CONTATO } & \text { secdtai@cca.ufscar.br } \\ \text { PALAVRAS-CHAVE } & \begin{array}{l}\text { ciências agrárias; economia e sociologia; estatística; educação; educação } \\ \text { profissional }\end{array}\end{array}$

DATA INÍCIO 28/3/2014

$\begin{array}{ll}\text { TÍTULO } & \text { Programa Futuro Cientista (PFC) } \\ \text { COORDENAÇÃo } & \text { Fabio de Lima Leite } \\ \text { SETOR } & \text { Departamento de Física, Química e Matemática } \\ \text { CONTATO } & \text { dfqm@ufscar.br } \\ \text { PALAVRAS-CHAVE } & \text { cientista; ensino fundamental; ciência; educação; ensino fundamental } \\ \text { DATA INÍCIO } & \text { 23/11/2009 }\end{array}$


TítULo

COORDENAÇÃO

SETOR

CONTATO

PALAVRAS-CHAVE

DATA INÍCIO

TíTULO

COORDENAÇÃO

SETOR

CONTATO

PALAVRAS-CHAVE

DATA INÍCIO
Pro-Infância: Programa de Promoção do Desenvolvimento Infantil

Maria Stella Coutinho de Alcantara Gil

Departamento de Psicologia

dpsic@ufscar.br

desenvolvimento infantil; prevenção; promoção do desenvolvimento; educação; educação infantil

$14 / 3 / 2014$
TíTULO

COORDENAÇÃO

SETOR

CONTATO

PALAVRAS-CHAVE

DATA INÍCIO

\section{Rede Colaborativa de Práticas Educativas em Matemática}

Renata Prenstteter Gama

Departamento de Metodologia de Ensino

deme@ufscar.br

universidade-escola; colaboração; práticas educativas; educação; educação continuada

$29 / 11 / 2013$
TÍTULO

COORDENAÇÃO

SETOR

CONTATO

PALAVRAS-CHAVE

DATA INÍCIO

\section{Reflexões Geográficas}

Neusa de Fatima Mariano

Departamento de Geografia, Turismo e Humanidades

dgth@ufscar.br

geografia; natureza; sociedade; educação; educação continuada

$18 / 4 / 2011$

$\begin{array}{ll}\text { TÍTULO } & \text { Temas em Antropologia e Ciência Política } \\ \text { COORDENAÇÃo } & \text { Vera Alves Cepeda } \\ \text { SETOR } & \begin{array}{l}\text { Departamento de Ciências Sociais } \\ \text { d-dcso@ufscar.br } \\ \text { CONTATO }\end{array} \\ \text { PALAVRAS-CHAVE } & \begin{array}{l}\text { ação e representações política; cultura e identidade; ciências sociais; educação; } \\ \text { organizações populares }\end{array} \\ \text { DATA INÍCIO } & 5 / 11 / 2012\end{array}$

\section{Tecnologias para Acessibilidade}

Murillo Rodrigo Petrucelli Homem

Departamento de Computação

dcomp@ufscar.br

acessibilidade; gameficação; interfaces homem-máquina; educação; atenção a grupos de pessoas com necessidades especiais

$28 / 4 / 2014$

$5 / 11 / 2012$ 
TíTULo

COORDENAÇÃO

SETOR

CONTATO

PALAVRAS-CHAVE

DATA INÍCIO

TítULo

SETOR

CONTATO

PALAVRAS-CHAVE

DATA INÍCIO
Transferência de Conhecimento, Tecnologia e Equipamentos para o Ensino de Engenharia Química

Jose Mansur Assaf

Departamento de Engenharia Química

deqchefe@ufscar.br

transferência; tecnologia; educação; inovação tecnológica

$21 / 6 / 2000$

Unidade de Iniciação à Leitura para Atendimento a Escolares de Risco

Deisy Das Gracas de Souza

Departamento de Psicologia

dpsic@ufscar.br

aquisição de leitura; alfabetização; ensino informatizado; educação; incentivo à leitura

$17 / 4 / 2007$ 


\section{Meio Ambiente}

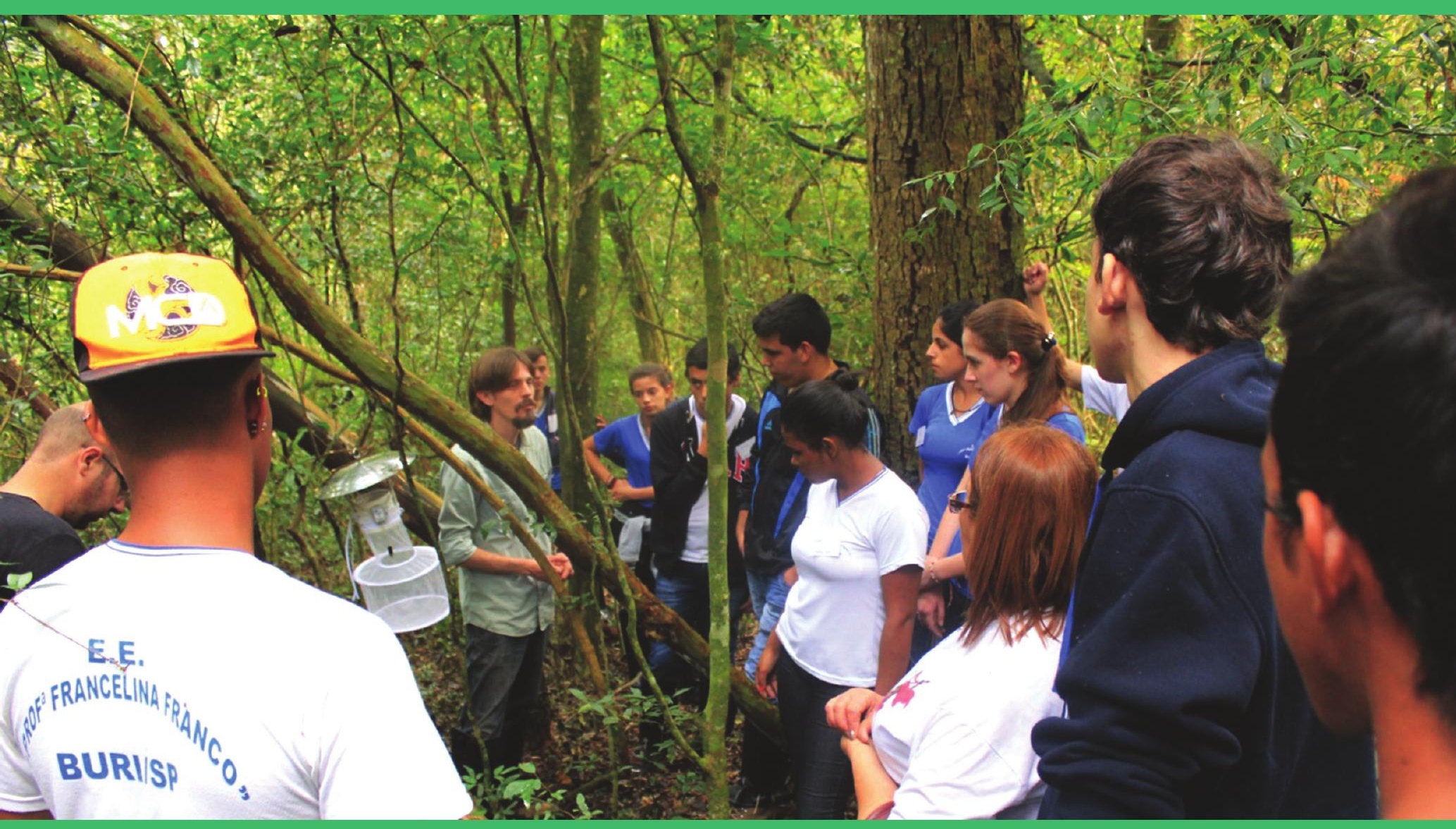

Atividade Dia de Campo na Fazenda Floresta - Campus Lagoa do Sino.

Foto: Tiago Santi. 


TÍTULO
COORDENAÇÃo
SETOR
CONTATO

PALAVRAS-CHAVE

DATA INÍCIO

\section{A Bacia Hidrográfica como Unidade de Planejamento}

Kelly Cristina Tonello Polli

Departamento de Ciências Ambientais - Sorocaba

dca@ufscar.br

nascentes; meio ambiente; bacias hidrográficas; meio ambiente; gestão de recursos naturais

$26 / 10 / 2010$
TÍTULO

COORDENAÇÃO

SETOR

CONTATO

PALAVRAS-CHAVE

DATA INÍCIO

TítULo

COORDENAÇÃo

SETOR

CONTATO

PALAVRAS-CHAVE

DATA INÍCIO

$\begin{array}{ll}\text { TíTULO } & \text { Atividades em Biotecnologia Ambiental } \\ \text { COORDENAÇÃO } & \text { Vadim Viviani } \\ \text { SETOR } & \text { Departamento de Física, Química e Matemática } \\ \text { CONTATO } & \text { dfqm@ufscar.br }\end{array}$

PALAVRAS-CHAVE

DATA INÍCIO

\section{As abelhas e os Serviços Ambientais}

Roberta Cornelio Ferreira Nocelli

Departamento de Ciências da Natureza, Matemática e Educação

dcnme@cca.ufscar.br

polinização; produção agrícola; agrotóxicos; meio ambiente; gestão de recursos naturais

$24 / 4 / 2013$

$\begin{array}{ll}\text { TÍTULO } & \text { Avaliações de Impactos em Populações de Peixes } \\ \text { COORDENAÇÃo } & \text { Alberto Carvalho Peret } \\ \text { SETOR } & \text { Departamento de Hidrobiologia } \\ \text { CONTATO } & \text { secdhb@ufscar.br } \\ \text { PALAVRAS-CHAVE } & \text { impactos; peixes; meio ambiente; gestão de recursos naturais } \\ \text { DATA INÍCIO } & 1 / 1 / 2002\end{array}$


TÍTULO

COORDENAÇÃO

SETOR

CONTATO

PALAVRAS-CHAVE

DATA INÍCIO
Cavernas Brasileiras - Conservação e Diversidade

Maria Elina Bichuette

Departamento de Ecologia e Biologia Evolutiva

secdebe@ufscar.br

cavernas; conservação; educação ambiental; meio ambiente; educação ambiental $21 / 9 / 2011$
TÍTULO

COORDENAÇÃo

SETOR

CONTATO

PALAVRAS-CHAVE

DATA INÍCIO

\section{Conservação, Biologia e Manejo de Animais Silvestres}

Vlamir Jose Rocha

Departamento de Ciências da Natureza, Matemática e Educação

dcnme@cca.ufscar.br

fauna; manejo; educação ambiental; meio ambiente; gestão de recursos naturais $14 / 3 / 2014$

$\begin{array}{ll}\text { TítULO } & \text { Conservação da Natureza e Gestão Ambiental } \\ \text { COORDENAÇÃo } & \text { Eliana Cardoso Leite } \\ \text { SETOR } & \text { Departamento de Ciências Ambientais } \\ \text { CONTATO } & \text { dca@ufscar.br } \\ \text { PALAVRAS-CHAVE } & \begin{array}{l}\text { conservação; gestão ambiental; biodiversidade; meio ambiente; gestão de recursos } \\ \text { naturais }\end{array} \\ \text { DATA INÍ́CIO } & 22 / 9 / 2011\end{array}$

$\begin{array}{ll}\text { TíTULO } & \text { Conservação de Ecossistemas } \\ \text { COORDENAÇÃO } & \text { Marcel Okamoto Tanaka } \\ \text { SETOR } & \text { Departamento de Ciências Ambientais } \\ \text { CONTATO } & \text { dcam@ufscar.br } \\ \text { PALAVRAS-CHAVE } & \begin{array}{l}\text { ecossistemas; macroinvertebrados; uso da terra; meio ambiente; gestão de recursos } \\ \text { naturais }\end{array}\end{array}$

DATA INÍCIO

$24 / 8 / 2007$

$\begin{array}{ll}\text { TítULO } & \text { Desenvolvimento Urbano e Regional e Habitação Social } \\ \text { COORDENAÇÃo } & \text { Carolina Maria Pozzi de Castro } \\ \text { SETOR } & \text { Departamento de Engenharia Civil } \\ \text { CONTATO } & \text { deciv@ufscar.br } \\ \text { PALAVRAS-CHAVE } & \text { desenvolvimento; urbano; meio ambiente; desenvolvimento urbano } \\ \text { DATA INÍ́CIO } & 14 / 1 / 2000\end{array}$


TítULo

COORDENAÇÃO

SETOR

CONTATO

PALAVRAS-CHAVE

DATA INÍCIO

TítULO

COORDENAÇÃo

SETOR

CONTATO

PALAVRAS-CHAVE

DATA INÍCIO

$\begin{array}{ll}\text { TÍTULO } & \text { Ecologia e Conservação } \\ \text { COORDENAÇÃo } & \text { Dalva Maria da Silva Matos } \\ \text { SETOR } & \text { Departamento de Hidrobiologia } \\ \text { CONTATO } & \text { secdhb@ufscar.br } \\ \text { PALAVRAS-CHAVE } & \text { cursos; eventos; ecologia; meio ambiente; educação ambiental } \\ \text { DATA INÍCIO } & 16 / 11 / 2011\end{array}$

TíTULO

COORDENAÇÃO

SETOR

CONTATO

PALAVRAS-CHAVE

DATA INÍCIO

\section{Educação Ambiental}

Haydee Torres de Oliveira

Departamento de Ciências Ambientais

dcam@ufscar.br

educação ambiental; sustentabilidade; educadoras; meio ambiente; educação ambiental

$27 / 9 / 2005$

\section{Ecologia da Paisagem e Conservação}

Hartung Toppa

dca@ufscar.br

geoprocessamento; planejamento ambiental; ecologia da paisagem; meio ambiente; educação profissional

$30 / 5 / 2014$

$\begin{array}{ll}\text { TítULO } & \text { Entomologia Aquática } \\ \text { COORDENAÇÃo } & \text { Livia Maria Fusari } \\ \text { SETOR } & \text { Departamento de Hidrobiologia } \\ \text { CONTATO } & \text { secdhb@ufscar.br } \\ \text { PALAVRAS-CHAVE } & \text { insetos aquáticos; taxonomia; ecologia; meio ambiente; educação profissional } \\ \text { DATA INÍCIO } & 28 / 5 / 2010\end{array}$

TÍTULO 
TítULo

COORDENAÇÃO

SETOR

CONTATO

PALAVRAS-CHAVE

DATA INÍCIO

TítuLo

SETOR

CONTATO

PALAVRAS-CHAVE

DATA INÍCIO

TítULo

COORDENAÇÃO

SETOR

CONTATO

PALAVRAS-CHAVE

DATA INÍCIO

TítuLo

COORDENAÇÃO

SETOR

CONTATO

PALAVRAS-CHAVE

DATA INÍCIO
Estudos, Pesquisas, Ensino, Consultoria, Assessoria e Divulgação em Geociências, Geotecnia e Meio Ambiente

Marcilene Dantas Ferreira

Departamento de Engenharia Civil

deciv@ufscar.br

meio ambiente; geotecnia; geociências; meio ambiente; desenvolvimento urbano $4 / 6 / 2013$
Formação Profissional Inicial, Continuada, Treinamento e Prestação de Serviço na Área de Ciências Naturais

Maria Virginia Urso Guimaraes

Departamento de Biologia

dbio@ufscar.br

biologia; formação continuada; ensino; meio ambiente; educação continuada

$4 / 6 / 2013$

\section{Genética Aplicada à Conservação Animal}

Patricia Domingues de Freitas

Departamento de Genética e Evolução

dge@ufscar.br

genética da conservação; genética forense; aquicultura sustentável; meio ambiente; gestão de recursos naturais

$3 / 10 / 2014$

Geotecnologias Aplicadas ao Planejamento e Conservação de Paisagens

Roberta Averna Valente Botezelli Tolini

Departamento de Ciências Ambientais

dca@ufscar.br

geoprocessamento; ecologia da paisagem; técnica participatória; meio ambiente; desenvolvimento rural

$1 / 12 / 2015$

TíTULo

Gestão e Análise Ambiental: PET AMBIENTAL

COORDENAÇÃO

Juliano Costa Goncalves

SETOR

Departamento de Ciências Ambientais

CONTATO

dcam@ufscar.br

PALAVRAS-CHAVE

gestão ambiental; sustentabilidade; desenvolvimento sustentável; meio ambiente; gestão de recursos naturais

DATA INÍCIO

20/3/2014 
TíTULO

COORDENAÇÃO

SETOR

CONTATO

PALAVRAS-CHAVE

DATA INÍCIO

TítULO

COORDENAÇÃO

SETOR

CONTATO

PALAVRAS-CHAVE

DATA INÍCIO

TíTULO

Integrando Ações em Ensino-Pesquisa-Extensão: Coletivo de Estudos e Práticas em Permacultura - Pés Vermelhos (CPPV)

COORDENAÇÃO

SETOR

CONTATO

PALAVRAS-CHAVE

DATA INÍCIO

Ana Paula de Oliveira Amaral Mello

Departamento de Desenvolvimento Rural

ddr@cca.ufscar.br

permacultura; integração de sistemas; agroecologia; meio ambiente; desenvolvimento rural

$10 / 9 / 2015$

$\begin{array}{ll}\text { TÍTULO } & \text { Laboratório de Plâncton DHb } \\ \text { COORDENAÇÃo } & \text { Maria da Graca Gama Melão } \\ \text { SETOR } & \text { Departamento de Hidrobiologia } \\ \text { CONTATO } & \text { secdhb@ufscar.br } \\ \text { PALAVRAS-CHAVE } & \text { laboratório; plâncton; meio ambiente; educação continuada } \\ \text { DATA INÍCIO } & 1 / 8 / 2000\end{array}$


TítULo

COORDENAÇÃO

SETOR

CONTATO

PALAVRAS-CHAVE

DATA INÍCIO

TítULo

SETOR

CONTATO

PALAVRAS-CHAVE

DATA INÍ́cIO

TítuLo

COORDENAÇÃO

SETOR

CONTATO

PALAVRAS-CHAVE

DATA INÍCIO
Observatório do Comitê de Bacia do Rio Sorocaba e Médio Tietê

Andre Cordeiro Alves dos Santos

Departamento de Biologia

dbio@ufscar.br

recursos hidricos; gestão ambiental; políticas públicas; meio ambiente; capacitação de gestores de políticas públicas

9/4/2012

\section{Pesquisa e Desenvolvimento em Alternativas de Manejo de}

Solos Tropicais

Maria Leonor Ribeiro Casimiro Lopes Assad

Departamento de Recursos Naturais e Proteção Ambiental

secdrnpa@cca.ufscar.br

mapeamento de solos; zoneamento agrícola; comportamento de solos; meio ambiente; desenvolvimento rural

$15 / 4 / 2011$

TíTULO

Pesquisa, Ensino, Consultoria e Análises de Solo, Gases do Efeito Estufa e Biogeoquímica de Ecossistemas Tropicais

COORDENAÇÃO

SETOR

CONTATO

PALAVRAS-CHAVE

DATA INÍCIO

\section{Pesquisa, Ensino e Consultoria em Microbiologia Ambiental} Iolanda Cristina Silveira Duarte

Departamento de Biologia

dbio@ufscar.br

microbiologia; saneamento; bioprocessos; meio ambiente; inovação tecnológica $20 / 11 / 2009$

\section{TíTULo \\ Plano de Monitoramento da Ictiofauna e Avifauna dos Ambientes Aquáticos e Fragmentos Vegetais da Área do Centro Experimental de Aramar \\ COORDENAÇÃO \\ SETOR \\ CONTATO \\ PALAVRAS-CHAVE \\ DATA INÍCIO \\ Julio Cesar Garavello \\ Departamento de Ecologia e Biologia Evolutiva \\ secdebe@ufscar.br \\ ictiofauna; avifauna; aramar; meio ambiente; gestão de recursos naturais \\ $4 / 1 / 2013$}

Janaina Braga do Carmo

Departamento de Ciências Ambientais - Sorocaba

dca@ufscar.br

ecossistemas tropicais; emissão de gases; solo agrícola e florestal; meio ambiente; cooperação interinstitucional

$24 / 10 / 2011$ 
TítULo

COORDENAÇÃO

SETOR

CONTATO

PALAVRAS-CHAVE

DATA INÍCIO
Programa de Atividades de Extensão da Secretaria Geral de Gestão Ambiental e Sustentabilidade (SGAS)

Erica Pugliesi

Departamento de Ciências Ambientais

dcam@ufscar.br

gestão de resíduos; educação ambiental; agroecologia; meio ambiente; gestão de recursos naturais

20/7/2009
TÍTULO

COORDENAÇÃo

SETOR

CONTATO

PALAVRAS-CHAVE

DATA INÍCIO

\section{Programa de Extensão em Biologia Vegetal}

Marcos Arduin

Departamento de Botânica

db@ufscar.br

biologia vegetal; capacitação; recuperação; meio ambiente; educação ambiental $11 / 8 / 2005$

$\begin{array}{ll}\text { TÍTULO } & \text { Programa de Extensão em Direito Ambiental } \\ \text { COORDENAÇÃo } & \text { Celso Maran de Oliveira } \\ \text { SETOR } & \text { Departamento de Ciências Ambientais } \\ \text { CONTATO } & \text { dcam@ufscar.br } \\ \text { PALAVRAS-CHAVE } & \begin{array}{l}\text { direito ambiental; gestão ambiental; desenvolvimento sustentável; meio ambiente; } \\ \text { gestão de recursos naturais }\end{array} \\ \text { DATA INÍ́CIO } & 24 / 4 / 2013\end{array}$

\begin{tabular}{|c|c|}
\hline Título & $\begin{array}{l}\text { Programa de Extensão em Perícias e Sustentabilidade } \\
\text { Ambiental }\end{array}$ \\
\hline COORDENAÇÃO & Carlos Augusto de Sousa Martins Filho \\
\hline SETOR & Departamento de Ciências Ambientais \\
\hline CONTATO & dcam@ufscar.br \\
\hline PALAVRAS-CHAVE & $\begin{array}{l}\text { perícias ambientais; gestão ambiental; sustentabilidade ambiental; meio ambiente; } \\
\text { gestão de recursos naturais }\end{array}$ \\
\hline ATA INÍCIO & 9/1/2013 \\
\hline
\end{tabular}

$\begin{array}{ll}\text { TÍTULO } & \text { Rede de Sementes Florestais } \\ \text { COORDENAÇÃO } & \text { Fatima Conceicao Marquez Pina Rodrigues } \\ \text { SETOR } & \text { Departamento de Ciências Ambientais - Sorocaba } \\ \text { CONTATO } & \text { dca@ufscar.br } \\ \text { PALAVRAS-CHAVE } & \begin{array}{l}\text { sementes florestais; rede de sementes florestais; produto florestal não-madeireiro; } \\ \text { meio ambiente; educação ambiental }\end{array}\end{array}$

DATA INÍCIO

$11 / 4 / 2007$ 
TíTULO

COORDENAÇÃo

SETOR

CONTATO

PALAVRAS-CHAVE

DATA INÍCIO

Sustentabilidade e Gestão Ambiental

Frederico Yuri Hanai

Departamento de Ciências Ambientais

dcam@ufscar.br

gestão ambiental; sustentabilidade; indicadores; meio ambiente; cooperação interinstitucional

$3 / 10 / 2012$

$\begin{array}{ll}\text { TíTULO } & \text { Zoofisiologia e Bioquímica Comparativa } \\ \text { COORDENAÇÃo } & \text { Marisa Narciso Fernandes } \\ \text { SETOR } & \text { Departamento de Ciências Fisiológicas } \\ \text { CONTATO } & \text { dcf@ufscar.br } \\ \text { PALAVRAS-CHAVE } & \text { bioindicadores; morfologia; fisiologia; meio ambiente; inovação tecnológica } \\ \text { DATA INÍCIO } & 25 / 5 / 2006\end{array}$


Frame do vídeo USE - 10 anos de história. Direção: Débora Burini.

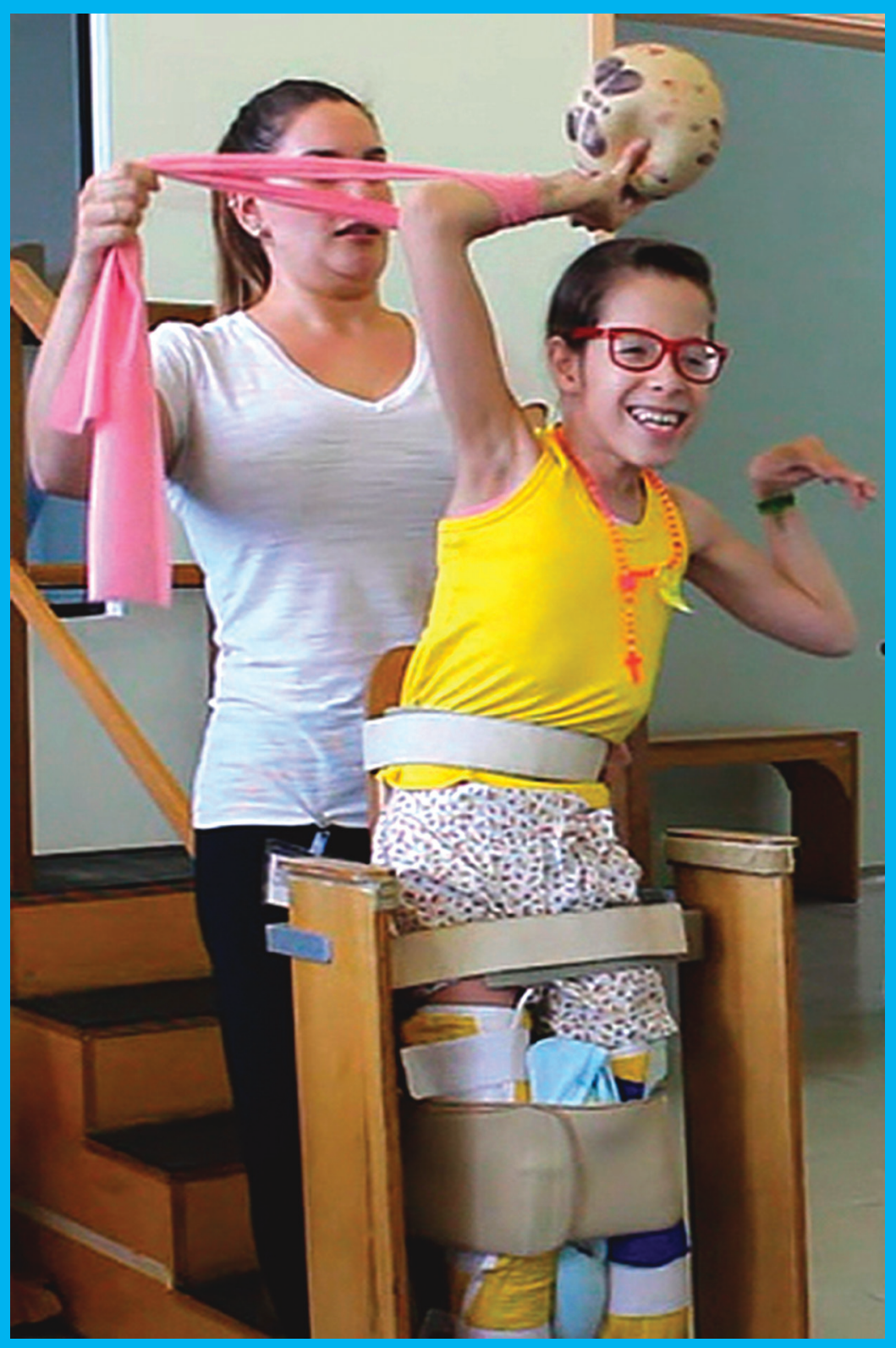

OUTUBRO 2016 


$\begin{array}{ll}\text { TítUlo } & \text { A Avaliação Psicológica como Recurso Técnico da Psicologia } \\ & \text { Aplicada: Instrumentação, Diagnóstico e Intervenção } \\ \text { COORDENAÇÃo } & \text { Marilia Goncalves } \\ \text { SETOR } & \text { Departamento de Psicologia } \\ \text { CONTATO } & \text { dpsic@ufscar.br } \\ \text { PALAVRAS-CHAVE } & \text { psicodiagnóstico; instrumentação; saúde; desenvolvimento do sistema de saúde } \\ \text { DATA INÍCIO } & \text { 29/10/2003 }\end{array}$

$\begin{array}{ll}\text { TÍTULO } & \text { Abordagem Interdisciplinar em Cardiologia } \\ \text { COORDENAÇÃo } & \text { Sergio Luiz Brasileiro Lopes } \\ \text { SETOR } & \text { Departamento de Medicina } \\ \text { CONTATO } & \text { dmed@ufscar.br } \\ \text { PALAVRAS-CHAVE } & \begin{array}{l}\text { integralidade; interdisciplinar; cardiologia; saúde; atenção integral à saúde de } \\ \text { adultos }\end{array} \\ \text { DATA INÍ́CIO } & 5 / 11 / 2012\end{array}$

TÍTULO

Ações de Integração em Gestão, Formação, Saúde e Trabalho

COORDENAÇÃO

Vivian Aline Mininel

SETOR

Departamento de Enfermagem

CONTATO

denf@ufscar.br

PALAVRAS-CHAVE

saúde; trabalho; gestão; saúde; desenvolvimento do sistema de saúde

DATA INÍCIO

9/9/2016

\begin{tabular}{|c|c|}
\hline TítUlo & Ações e Investigações em Processos Psicanalíticos \\
\hline COORDENAÇÃO & Cassia Regina Rodrigues \\
\hline SETOR & Departamento de Medicina \\
\hline CONTATO & dmed@ufscar.br \\
\hline PALAVRAS-CHAVE & $\begin{array}{l}\text { psicanálise; psicoterapia; cuidado em saúde; saúde; atenção integral à saúde de } \\
\text { adultos }\end{array}$ \\
\hline DATA INÍCIO & $31 / 5 / 2016$ \\
\hline TítUlo & Ações em Saúde Coletiva \\
\hline COORDENAÇÃO & Geovani Gurgel Aciole da Silva \\
\hline SETOR & Departamento de Medicina \\
\hline CONTATO & dmed@ufscar.br \\
\hline PALAVRAS-CHAVE & $\begin{array}{l}\text { cuidado em saúde; educação em saúde; saúde coletiva; saúde; desenvolvimento do } \\
\text { sistema de saúde }\end{array}$ \\
\hline DATA INÍCIO & $17 / 4 / 2007$ \\
\hline
\end{tabular}


Título

COORDENAÇÃO

SETOR

CONTATO

PALAVRAS-CHAVE

DATA INÍCIO

TítULo

COORDENAÇÃO

SETOR

CONTATO

PALAVRAS-CHAVE

DATA INÍCIO

$\begin{array}{ll}\text { TÍTULO } & \text { Análise de Alimentos voltada à Educação Nutricional } \\ \text { COORDENAÇÃo } & \text { Lucia Helena Seron } \\ \text { SETOR } & \text { Departamento de Química } \\ \text { CONTATO } & \text { dqchefe@ufscar.br } \\ \text { PALAVRAS-CHAVE } & \begin{array}{l}\text { alimentos; vitaminas e minerais; educação nutricional; saúde; atenção integral à } \\ \text { criança }\end{array} \\ \text { DATA INÍCIO } & 14 / 12 / 2012\end{array}$

DATA INÍCIO

TítULO

Apoio à Rede Escola de Cuidados à Saúde do Município de São Carlos

COORDENAÇÃO

SETOR

CONTATO

PALAVRAS-CHAVE

DATA INÍCIO

Bernardino Geraldo Alves Souto

Departamento de Medicina

dmed@ufscar.br

saúde; práticas; formação; saúde; educação continuada

9/10/2006

$\begin{array}{ll}\text { TítULO } & \text { Apoio Matricial em Atenção à Saúde da Criança e do } \\ & \text { Adolescente } \\ \text { COORDENAÇÃo } & \text { Bento Vidal de Moura Negrini } \\ \text { SETOR } & \text { Departamento de Medicina } \\ \text { CONTATO } & \text { dmed@ufscar.br } \\ \text { PALAVRAS-CHAVE } & \begin{array}{l}\text { saúde da criança; saúde adolescente; apoio matricial; saúde; atenção integral à } \\ \text { criança }\end{array} \\ \text { DATA INÍCIO } & 5 / 11 / 2012\end{array}$


TíTULO

COORDENAÇÃO

SETOR

CONTATO

PALAVRAS-CHAVE

DATA INÍCIO
Assessoria Técnica Junto ao Hospital Escola Municipal (HEM)

Bento Vidal de Moura Negrini

Departamento de Medicina

dmed@ufscar.br

ensino; assistência; pesquisa; saúde; hospitais e clínicas universitárias

$9 / 1 / 2013$
Título

COORDENAÇÃO

SETOR

CONTATO

PALAVRAS-CHAVE

DATA INÍCIO

\section{Assistência, Ensino e Pesquisa em Moléstias Infecciosas e} Parasitárias

Sigrid de Sousa Dos Santos

Departamento de Medicina

dmed@ufscar.br

infectologia; interdisciplinar; saúde; saúde; hospitais e clínicas universitárias

$5 / 10 / 2010$

$\begin{array}{ll}\text { TÍTULO } & \text { Atenção à Saúde da Criança com Patologias } \\ & \text { Gastroenterológicas, Hepáticas e Nutricionais } \\ \text { COORDENAÇÃo } & \text { Andrea Aparecida Contini } \\ \text { SETOR } & \text { Departamento de Medicina } \\ \text { CONTATO } & \text { dmed@ufscar.br } \\ \text { PALAVRAS-CHAVE } & \text { saúde da criança; gastrointestinal; cuidado integral; saúde; atenção integral à } \\ & \text { criança } \\ \text { DATA INÍCIO } & 24 / 4 / 2013\end{array}$

TÍTULO

Atenção à Saúde em Genética Médica

COORDENAÇÃO

Debora Gusmão Melo

SETOR

Departamento de Medicina

CONTATO

dmed@ufscar.br

PALAVRAS-CHAVE

genética médica; atenção à saúde; aconselhamento genético; saúde; atenção a grupos de pessoas com necessidades especiais

DATA INÍCIO $\quad$ 5/6/2013

$\begin{array}{ll}\text { TítULO } & \text { Atenção em Educação e Saúde Cardiovascular na Cidade de } \\ & \text { São Carlos } \\ \text { COORDENAÇÃo } & \text { Meliza Goi Roscani } \\ \text { SETOR } & \text { Departamento de Medicina } \\ \text { CONTATO } & \text { dmed@ufscar.br } \\ \text { PALAVRAS-CHAVE } & \text { prevenção; conscientização; ensino; saúde; atenção integral à saúde de adultos } \\ \text { DATA INÍCIO } & 24 / 7 / 2014\end{array}$


TítULo

COORDENAÇÃO

SETOR

CONTATO

PALAVRAS-CHAVE

DATA INÍCIO

COORDENAÇÃO

SETOR

CONTATO

PALAVRAS-CHAVE

DATA INÍCIO
Atenção Integral à Saúde do Adulto - Ações Educativas, Cuidativas, Gerenciais e de Pesquisa

Rosely Moralez de Figueiredo

Departamento de Enfermagem

denf@ufscar.br

saúde; adulto; saúde; desenvolvimento do sistema de saúde

$1 / 1 / 2003$

$\begin{array}{ll}\text { TÍTULO } & \text { Avaliação e Intervenção Fisioterapêutica } \\ \text { COORDENAÇÃo } & \text { Patricia Driusso } \\ \text { SETOR } & \text { Departamento de Fisioterapia } \\ \text { CONTATO } & \text { dfisio@ufscar.br } \\ \text { PALAVRAS-CHAVE } & \text { fisioterapia; reabilitação; prevenção; saúde; desenvolvimento do sistema de saúde } \\ \text { DATA INÍCIO } & 4 / 1 / 2012\end{array}$

Atendimento Integral ao Portador de Hepatite Viral a partir da Implantação do Programa Nacional de Hepatites Virais (PNHV SUS/2002)

Ana Claudia de Oliveira

Departamento de Medicina

dmed@ufscar.br

hepatite viral; prevenção e tratamento; programa nacional hepatite; saúde; atenção integral à saúde de adultos

$28 / 4 / 2014$

$\begin{array}{ll}\text { TÍTULO } & \text { Change Pain } \\ \text { COORDENAÇÃo } & \text { Rodrigo Bezerra de Menezes Reiff } \\ \text { SETOR } & \text { Departamento de Medicina } \\ \text { CONTATO } & \text { dmed@ufscar.br } \\ \text { PALAVRAS-CHAVE } & \text { dor; analgesia; educação médica; saúde; hospitais e clínicas universitárias } \\ \text { DATA INÍCIO } & \text { 5/9/2016 }\end{array}$

TÍTULO

Clínica Psicanalítica Contemporânea

COORDENAÇÃo

Joao Angelo Fantini

SETOR

Departamento de Psicologia

CONTATO

dpsic@ufscar.br

PALAVRAS-CHAVE

psicoterapia; psicanálise; extensão; saúde; saúde da família

DATA INÍCIO

$1 / 1 / 2006$ 
TítULo

COORDENAÇÃO

SETOR

CONTATO

PALAVRAS-CHAVE

DATA INÍCIO

TítULo

SETOR

CONTATO

PALAVRAS-CHAVE

DATA INÍCIO

\section{Diabetes Mellitus e Metabologia}

TÍTULO

COORDENAÇÃO

SETOR

CONTATO

PALAVRAS-CHAVE

DATA INÍCIO

Angela Merice de Oliveira Leal

Departamento de Medicina

dmed@ufscar.br

diabetes mellitus; metabologia; multiprofissional; saúde; atenção integral à saúde de adultos

$1 / 2 / 2011$

$\begin{array}{ll}\text { TÍTULO } & \text { Divulgação e Atualização na Área de Motricidade Humana } \\ \text { COORDENAÇÃo } & \text { Luiz Goncalves Junior } \\ \text { SETOR } & \text { Departamento de Educação Física e Motricidade Humana } \\ \text { CONTATO } & \text { defmh@ufscar.br } \\ \text { PALAVRAS-CHAVE } & \text { motricidade humana; saúde; saúde da família } \\ \text { DATA INÍCIO } & 1 / 2 / 2005\end{array}$

TítULO

COORDENAÇÃo Maria Waldenez de Oliveira

SETOR

CONTATO

PALAVRAS-CHAVE

DATA INÍCIO

\section{Educação em Saúde}

Departamento de Metodologia de Ensino

deme@ufscar.br

educação; saúde; saúde; desenvolvimento do sistema de saúde

$1 / 1 / 1999$ 
TÍTULO

COORDENAÇÃO

SETOR

CONTATO

PALAVRAS-CHAVE

DATA INÍCIO

\section{Esporte para a Cidadania}

Luiz Goncalves Junior

Departamento de Educação Física e Motricidade Humana

defmh@ufscar.br

esporte; cidadania; saúde; saúde da família

$16 / 9 / 1999$

$\begin{array}{ll}\text { TÍTULO } & \text { Fisiologia do Exercício } \\ \text { COORDENAÇÃo } & \text { Sergio Eduardo de Andrade Perez } \\ \text { SETOR } & \text { Departamento de Ciências Fisiológicas } \\ \text { CONTATO } & \text { dcf@ufscar.br } \\ \text { PALAVRAS-CHAVE } & \text { fisiologia; exercício; saúde; esporte, lazer e saúde } \\ \text { DATA INÍ́CIO } & 1 / 1 / 2001\end{array}$

$\begin{array}{ll}\text { TÍTULO } & \text { Fisioterapia Cardiovascular } \\ \text { COORDENAÇÃo } & \text { Aparecida Maria Catai } \\ \text { SETOR } & \text { Departamento de Fisioterapia } \\ \text { CONTATO } & \text { dfisio@ufscar.br } \\ \text { PALAVRAS-CHAVE } & \text { fisioterapia; cardiovascular; saúde; desenvolvimento do sistema de saúde } \\ \text { DATA INÍCIO } & 28 / 1 / 2000\end{array}$

TítULO

Gerontologia: Gestão da Velhice Saudável

COORDENAÇÃo Wilson Jose Alves Pedro

SETOR

Departamento de Gerontologia

CONTATO

dgero.secretaria@ufscar.br

PALAVRAS-CHAVE

gerontologia; gestão; envelhecimento ativo-saudável; saúde; atenção integral à terceira idade

DATA INÍCIO 6/4/2010

$\begin{array}{ll}\text { TítULO } & \text { Hepatites Virais em São Carlos } \\ \text { COORDENAÇÃo } & \text { Silvana Gama Florencio Chacha } \\ \text { SETOR } & \text { Departamento de Medicina } \\ \text { CONTATO } & \text { dmed@ufscar.br } \\ \text { PALAVRAS-CHAVE } & \text { hepatite c; hepatite b; hepatites virais; saúde; atenção integral à saúde de adultos } \\ \text { DATA INÍCIO } & 29 / 4 / 2016\end{array}$


TítULo

COORDENAÇÃO

SETOR

CONTATO

PALAVRAS-CHAVE

DATA INÍCIO

TítULo

Integração de Ações Educativas e de Pesquisa em Urgências e Emergências, Cuidados Críticos e Cardiovasculares

COORDENAÇÃo Regimar Carla Machado Ranzani

SETOR

CONTATO

PALAVRAS-CHAVE

DATA INÍCIO

TítULo

COORDENAÇÃO

SETOR

CONTATO

PALAVRAS-CHAVE

DATA INÍCIO

Departamento de Enfermagem

denf@ufscar.br

capacitação; tecnologia; simulação; saúde; educação continuada

$11 / 6 / 2015$

\section{Interdisciplinar de Pesquisa e Extensão na Maturidade}

Sofia Cristina lost Pavarini

Departamento de Gerontologia

dgero.secretaria@ufscar.br

interdisciplinar; maturidade; saúde; educação profissional

$1 / 1 / 1999$

$\begin{array}{ll}\text { TÍTULO } & \text { Intervenção Fisioterapêutica no Paciente Pneumopata } \\ \text { COORDENAÇÃo } & \text { Valeria Amorim Pires di Lorenzo } \\ \text { SETOR } & \text { Departamento de Fisioterapia } \\ \text { CONTATO } & \text { dfisio@ufscar.br } \\ \text { PALAVRAS-CHAVE } & \text { fisioterapia respiratória; reabilitação pulmonar; avaliação respiratória; saúde; } \\ & \text { atenção integral à saúde de adultos }\end{array}$

DATA INÍCIO

$21 / 5 / 2008$

$\begin{array}{ll}\text { TíTULO } & \text { Laborató rio de Atividades e Desenvolvimento - LAD/DTO } \\ \text { COORDENAÇÃO } & \text { Regina Helena Vitale Torkomian Joaquim } \\ \text { SETOR } & \text { Departamento de Terapia Ocupacional } \\ \text { CONTATO } & \text { chdto@ufscar.br } \\ \text { PALAVRAS-CHAVE } & \text { laboratório; desenvolvimento; saúde; educação profissional } \\ \text { DATA INÍCIO } & 1 / 8 / 1999\end{array}$


TÍTULO

COORDENAÇÃO

SETOR

CONTATO

PALAVRAS-CHAVE

DATA INÍCIO

TÍTULO

COORDENAÇÃO

SETOR

CONTATO

PALAVRAS-CHAVE

DATA INÍCIO
LAEP - Liga Acadêmica de Atividades Pediátricas

leda Regina Lopes Del Ciampo

Departamento de Medicina

dmed@ufscar.br

liga; pediatria; criança; saúde; atenção integral à criança

$31 / 5 / 2016$

\section{Liga Acadêmica de Especialidades de Especialidades}

\section{Pediátricas}

Carla Maria Ramos Germano

Departamento de Medicina

dmed@ufscar.br

saúde da criança; assistência integral à saúde; educação; saúde; atenção integral à criança

$14 / 3 / 2014$

TÍTULO

\section{COORDENAÇÃO}

SETOR

CONTATO

PALAVRAS-CHAVE

DATA INÍCIO

TítULO

COORDENAÇÃo

SETOR

CONTATO

PALAVRAS-CHAVE

DATA INÍCIO

Título

COORDENAÇÃo

SETOR

CONTATO

PALAVRAS-CHAVE

DATA INÍCIO

\section{Liga Acadêmica de Medicina de Família e Comunidade}

Mariana de Almeida Prado Faga

Departamento de Medicina

dmed@ufscar.br

saúde da família e comunidade; atenção primária à saúde; educação em saúde; saúde; saúde da família

$13 / 9 / 2016$

\section{Liga Acadêmica de Saúde Mental}

Jair Borges Barbosa Neto

Departamento de Medicina

dmed@ufscar.br

liga acadêmica; saúde mental; multidisciplinar; saúde; hospitais e clínicas universitárias

$28 / 3 / 2016$

Liga Acadêmica de Terapia Antálgica e Cuidados Paliativos (LATACP)

Esther Angelica Luiz Ferreira

Departamento de Medicina

dmed@ufscar.br

dor; cuidados paliativos; assistência terminal; saúde; atenção a grupos de pessoas com necessidades especiais

$13 / 9 / 2016$ 
TíTULO

COORDENAÇÃO

SETOR

CONTATO

PALAVRAS-CHAVE

DATA INÍCIO

\section{Liga de Infectologia da UFSCar}

Sigrid de Sousa Dos Santos

Departamento de Medicina

dmed@ufscar.br

infectologia; cuidado; educação; saúde; atenção a grupos de pessoas com necessidades especiais

$9 / 3 / 2015$

$\begin{array}{ll}\text { TÍTULO } & \text { Natação para Servidores e Alunos da UFSCar } \\ \text { COORDENAÇÃo } & \text { Corinne Arrouvel } \\ \text { SETOR } & \text { Departamento de Física, Química e Matemática } \\ \text { CONTATO } & \text { dfqm@ufscar.br } \\ \text { PALAVRAS-CHAVE } & \text { natação; saude; educação; saúde; esporte, lazer e saúde } \\ \text { DATA INÍCIO } & 28 / 6 / 2013\end{array}$

$\begin{array}{ll}\text { TítUlo } & \text { Núcleo de Apoio Tecnológico e Educacional em Gerontologia } \\ & (\text { NATEG) } \\ \text { COORDENAÇÃo } & \text { Tiago da Silva Alexandre } \\ \text { SETOR } & \text { Departamento de Gerontologia } \\ \text { CONTATO } & \text { dgero.secretaria@ufscar.br } \\ \text { PALAVRAS-CHAVE } & \text { tecnologia; educação; gerontologia; saúde; desenvolvimento do sistema de saúde } \\ \text { DATA INÍ́CIO } & 28 / 3 / 2016\end{array}$

$\begin{array}{ll}\text { TítULo } & \text { Políticas e Práticas em Saúde } \\ \text { COORDENAÇÃo } & \text { Maria Lucia Teixeira Machado } \\ \text { SETOR } & \text { Departamento de Enfermagem } \\ \text { CONTATO } & \text { denf@ufscar.br } \\ \text { PALAVRAS-CHAVE } & \text { políticas; saúde; saúde; desenvolvimento do sistema de saúde } \\ \text { DATA INÍCIO } & \text { 1/1/2003 }\end{array}$

TíTULo

PRO-GERONTO: Processos e Produtos em Gerontologia

COORDENAÇÃo

Vania Aparecida Gurian Varoto

SETOR

Departamento de Gerontologia

CONTATO

dgero.secretaria@ufscar.br

PALAVRAS-CHAVE

gerontologia; gestão; tecnologia; saúde; cooperação interinstitucional

DATA INÍCIO

$28 / 4 / 2011$ 
TítULo

COORDENAÇÃO

SETOR

CONTATO

PALAVRAS-CHAVE

DATA INÍCIO

TíTULO

COORDENAÇÃO

SETOR

CONTATO

PALAVRAS-CHAVE

DATA INÍCIO
Programa de Ação e Investigação em Terapia Ocupacional na Disfunção Física do Adulto

Daniel Marinho Cezar da Cruz

Departamento de Terapia Ocupacional

chdto@ufscar.br

terapia ocupacional; disfunção física; reabilitação; saúde; atenção integral à saúde de adultos

$21 / 7 / 2009$

$\begin{array}{ll}\text { TÍTULO } & \text { Programa de Assistência Fisioterapêutica Hospitalar } \\ \text { COORDENAÇÃo } & \text { Adriana Sanches Garcia de Araujo } \\ \text { SETOR } & \text { Departamento de Fisioterapia } \\ \text { CONTATO } & \text { dfisio@ufscar.br } \\ \text { PALAVRAS-CHAVE } & \text { fisioterapia; atenção hospitalar; ciclos de vida; saúde; hospitais e clínicas } \\ & \begin{array}{l}\text { universitárias } \\ \text { DATA INÍ́CIO }\end{array} \\ \text { 13/4/2011 }\end{array}$

\begin{tabular}{|c|c|}
\hline Título & $\begin{array}{l}\text { Programa de Atendimento em Endocrinologia e Metabologia } \\
\text { da Unidade de Saúde-Escola }\end{array}$ \\
\hline COORDENAÇÃO & Joyce do Rosario Martins \\
\hline SETOR & Departamento de Medicina \\
\hline CONTATO & dmed@ufscar.br \\
\hline PALAVRAS-CHAVE & $\begin{array}{l}\text { endocrinologia; metabologia; hormônios; saúde; atenção integral à saúde de } \\
\text { adultos }\end{array}$ \\
\hline DATA INÍCIO & $7 / 4 / 2010$ \\
\hline
\end{tabular}

Programa de Apoio ao Parto Saudável

Humberto Sadanobu Hirakawa

Departamento de Medicina

dmed@ufscar.br

parto; humanização; multiprofissional; saúde; atenção integral à mulher

$6 / 4 / 2010$

$\begin{array}{ll}\text { TíTULO } & \text { Programa de Atendimento Integral ao Portador de } \\ & \text { Hepatopatia Crônica } \\ \text { COORDENAÇÃO } & \text { Ana Claudia de Oliveira } \\ \text { SETOR } & \text { Departamento de Medicina } \\ \text { CONTATO } & \text { dmed@ufscar.br } \\ \text { PALAVRAS-CHAVE } & \begin{array}{l}\text { hepatites virais; doença hepática gordurosa; cirrose hepática; saúde; atenção } \\ \text { integral à saúde de adultos }\end{array} \\ \text { DATA INÍCIO } & \text { 14/11/2008 }\end{array}$

DATA INÍCIO

$14 / 11 / 2008$ 
TítULo

COORDENAÇÃO

SETOR

CONTATO

PALAVRAS-CHAVE

DATA INÍCIO

TítULo

COORDENAÇÃO

SETOR

CONTATO

PALAVRAS-CHAVE

DATA INÍCIO

Programa de Extensão em Medicina de Urgência

Fabio Fernandes Neves

Departamento de Medicina

dmed@ufscar.br

urgência; atendimento; prevenção; saúde; cooperação interinstitucional

$22 / 4 / 2009$

\section{TíTULO \\ Programa de Extensão Psicanálise e Disfunções Físicas \\ COORDENAÇÃO \\ Rosana Mattioli \\ SETOR \\ Departamento de Fisioterapia \\ CONTATO \\ dfisio@ufscar.br \\ PALAVRAS-CHAVE psicanálise; disfunções físicas; plasticidade do sistema nervoso central; saúde; cooperação interinstitucional}

DATA INÍCIO

$5 / 12 / 2014$

TítULO

COORDENAÇÃO

SETOR

CONTATO

PALAVRAS-CHAVE

DATA INÍ́cIO

TíTULO

Promoção à Saúde do Idoso: A Busca pelo Envelhecimento Saudável na Atenção Básica

COORDENAÇÃO

SETOR

CONTATO

PALAVRAS-CHAVE

DATA INÍCIO

\section{Programa de Neurologia Cognitiva e Comportamental da UFSCar}

Departamento de Medicina

dmed@ufscar.br

neurologia comportamental; demências; transtornos cognitivos; saúde; atenção integral à terceira idade

20/7/2009
Francisco de Assis Carvalho do Vale

Silvia Carla da Silva Andre

Departamento de Enfermagem

denf@ufscar.br

envelhecimento; saúde do idoso; promoção da saúde; saúde; atenção integral à saúde de adultos

$29 / 4 / 2016$ 
TítULo

COORDENAÇÃO

SETOR

CONTATO

PALAVRAS-CHAVE

DATA INÍCIO

TítULO

COORDENAÇÃO

SETOR

CONTATO

PALAVRAS-CHAVE

DATA INÍCIO

\section{ProViVe - Programa Viva Bem a Velhice}

Marcos Hortes Nisihara Chagas

Departamento de Gerontologia

dgero.secretaria@ufscar.br

envelhecimento saudável; cognição; prevenção e promoção de saúde; saúde; atenção integral à terceira idade

10/9/2015

$\begin{array}{ll}\text { TÍTULO } & \text { Saúde Mental e Cidadania } \\ \text { COORDENAÇÃo } & \text { Georgina Carolina de Oliveira Faneco Maniakas } \\ \text { SETOR } & \text { Departamento de Psicologia } \\ \text { CONTATO } & \text { dpsic@ufscar.br } \\ \text { PALAVRAS-CHAVE } & \text { saúde; cidadania; saúde; desenvolvimento do sistema de saúde } \\ \text { DATA INÍCIO } & 1 / 1 / 2002\end{array}$

$\begin{array}{ll}\text { TíTULO } & \text { Saúde Mental no Contexto da Reforma Psiquiátrica } \\ \text { COORDENAÇÃo } & \text { Sonia Regina Zerbetto } \\ \text { SETOR } & \text { Departamento de Enfermagem } \\ \text { CONTATO } & \text { denf@ufscar.br } \\ \text { PALAVRAS-CHAVE } & \text { saúde mental; psiquiátrica; saúde; desenvolvimento do sistema de saúde } \\ \text { DATA INÍCIO } & 1 / 1 / 2004\end{array}$

$\begin{array}{ll}\text { TÍTULO } & \text { Saúdle Psicossomática } \\ \text { COORDENAÇÃo } & \text { Doris Lieth Nunes Peçanha } \\ \text { SETOR } & \text { Departamento de Psicologia } \\ \text { CONTATO } & \text { dpsic@ufscar.br } \\ \text { PALAVRAS-CHAVE } & \text { saúde; psicossomática; saúde; desenvolvimento do sistema de saúde } \\ \text { DATA INÍ́CIO } & 1 / 1 / 2001\end{array}$


TítULo

Terapia Ocupacional em Saúde Mental do Laboratório de Saúde Mental do DTO

COORDENAÇÃo Thelma Simoes Matsukura

SETOR

Departamento de Terapia Ocupacional

CONTATO

chdto@ufscar.br

PALAVRAS-CHAVE

DATA INÍCIO

2/8/1999

\section{TíTULO \\ COORDENAÇÃO \\ SETOR \\ CONTATO}

PALAVRAS-CHAVE

DATA INÍCIO

\section{Unidade Saúde Escola}

Marcia Niituma Ogata

Departamento de Enfermagem

denf@ufscar.br

sistema único de saúde; linhas de cuidado em saúde; trabalho em equipe; saúde; atenção integral à saúde de adultos

$6 / 4 / 2010$ 


\section{Ternologiae Produpão}

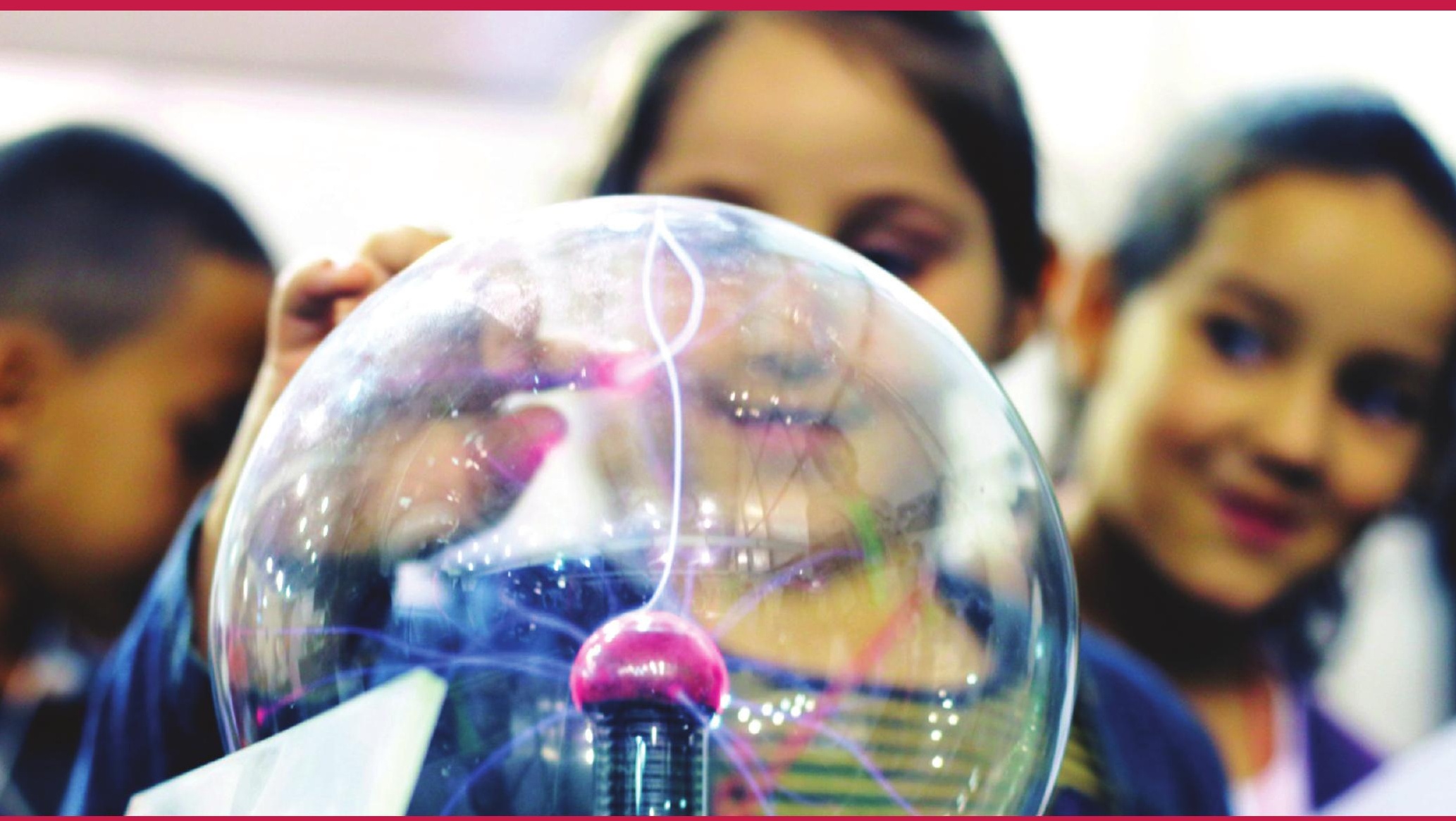

$67^{\mathrm{a}}$ Reunião Anual da SBPC - Campus São Carlos.

Foto: Rogério Gianlorenzo. 
TíTULO

COORDENAÇÃO

SETOR

CONTATO

PALAVRAS-CHAVE

DATA INÍCIO

TíTULO

COORDENAÇÃO

SETOR

CONTATO

PALAVRAS-CHAVE

DATA INÍCIO

\begin{tabular}{|c|c|}
\hline Título & $\begin{array}{l}\text { Análise, Modelagem, Simulação, Projeto e Controle de } \\
\text { Sistemas Dinâmicos }\end{array}$ \\
\hline COORDENAÇÃO & Osmar Ogashawara \\
\hline TOR & Centro de Ciências Exatas e de Tecnologia \\
\hline NTATO & ccetdir@ufscar.br \\
\hline PALAVRAS-CHAVE & $\begin{array}{l}\text { engenharia elétrica; atividades complementares; difusão do conhecimento; } \\
\text { tecnologia e produção; educação continuada }\end{array}$ \\
\hline A INícıO & 18/11/2011 \\
\hline
\end{tabular}

TítULo

Aplicação, Aprimoramento e Difusão de Técnicas Avançadas de Engenharia de Software

COORDENAÇÃO

Valter Vieira de Camargo

SETOR

CONTATO

PALAVRAS-CHAVE

DATA INÍCIO

Ações Educacionais e Tecnológicas para o Desenvolvimento da Região de Leme

Jozivaldo Prudencio Gomes de Morais

Departamento de Biotecnologia e Produção Vegetal e Animal

stela@cca.ufscar.br

produtores; inovação; educação; tecnologia e produção; empreendorismo

$16 / 9 / 2016$

Ambientes de Computação Ubíqua na Saúde (ACUS)

Wanderley Lopes de Souza

Departamento de Computação

dc@ufscar.br

computação ubíqua; educação em saúde; cuidado de saúde; tecnologia e produção; inovação tecnológica

$28 / 4 / 2014$

Departamento de Computação

dc@ufscar.br

desenvolvimento de software; manutenção de software; evolução de software; tecnologia e produção; inovação tecnológica

$17 / 10 / 2011$

TíTULO

Aplicações de Mineração, Visualização e Gerenciamento de Dados

COORDENAÇÃo

Marcela Xavier Ribeiro

SETOR

Departamento de Computação

CONTATO

PALAVRAS-CHAVE

dc@ufscar.br

banco de dados; visualização; mineração; tecnologia e produção; cooperação interinstitucional

DATA INÍCIO

$28 / 3 / 2016$ 
TíTULO

Apoio ao Desenvolvimento de Produtos, Processos e à Formação de Pessoal para a Indústria Química e Áreas

\section{Correlatas}

COORDENAÇÃO

Paulo Waldir Tardioli

SETOR

CONTATO

PALAVRAS-CHAVE

DATA INÍCIO
Departamento de Engenharia Química

deqchefe@ufscar.br

produtos; indústria; tecnologia e produção; educação profissional

$1 / 10 / 2001$
TíTULO

COORDENAÇÃO

SETOR

CONTATO

PALAVRAS-CHAVE

DATA INÍCIO

TíTULO

COORDENAÇÃO

SETOR

CONTATO

PALAVRAS-CHAVE

DATA INÍCIO

TíTULO

COORDENAÇÃO

SETOR

CONTATO

PALAVRAS-CHAVE

DATA INÍCIO

\section{Apoio Tecnológico e Educacional ao Desenvolvimento de} Projetos Mecânicos

Sergio Henrique Evangelista

Departamento de Engenharia Mecânica

demec@ufscar.br

projetos mecânicos; desenvolvimento de produtos; simulação computacional; tecnologia e produção; inovação tecnológica

$24 / 10 / 2014$
TÍTULO

COORDENAÇÃO

SETOR

CONTATO

PALAVRAS-CHAVE

DATA INÍCIO

\section{Apoio Tecnológico e Educacional em Vidros e Materiais Afins}

Edgar Dutra Zanotto

Departamento de Engenharia de Materiais

demachef@ufscar.br

apoio tecnológico; vidros; tecnologia e produção; inovação tecnológica

$8 / 8 / 2000$

\section{Assessoria e Consultoria a Pessoas ou Instituições Públicas} ou Privadas em Estudos Relacionados à Engenharia de Transportes

Marcos Antonio Garcia Ferreira

Departamento de Engenharia Civil

deciv@ufscar.br

engenharia; transportes; tecnologia e produção; desenvolvimento urbano

$1 / 1 / 1999$ 
TítULo

COORDENAÇÃO

SETOR

CONTATO

PALAVRAS-CHAVE

DATA INÍCIO

TíTULO

COORDENAÇÃO

SETOR

CONTATO

PALAVRAS-CHAVE

DATA INÍCIO
Atividades Agrícolas e Agroindustriais para o Desenvolvimento Sustentável do Território Lagoa do Sino

Naaman Francisco Nogueira Silva

Centro de Ciências da Natureza

diretorccn@ufscar.br

sustentabilidade; agricultura familiar; sistemas alimentares; tecnologia e produção; desenvolvimento rural

$23 / 6 / 2016$
TíTULO

COORDENAÇÃO

SETOR

CONTATO

PALAVRAS-CHAVE

DATA INÍCIO
Atividades de Divulgação de Ciência e Tecnologia na Química

Elton Fabiano Sitta

Departamento de Química

dqchefe@ufscar.br

graduação em química; perspectivas profissionais; formação continuada; tecnologia e produção; educação profissional

$5 / 12 / 2014$
Título

COORDENAÇÃO

SETOR

CONTATO

PALAVRAS-CHAVE

DATA INÍCIO

\section{Atividades Integradas de Extensão do GEPEQ - Grupo de Estudo e Pesquisa em Qualidade}

Roberto Antonio Martins

Departamento de Engenharia de Produção

dep@ufscar.br

atividades; integradas; tecnologia e produção; inovação tecnológica

$14 / 1 / 2000$
TÍTULO

COORDENAÇÃO

SETOR

CONTATO

PALAVRAS-CHAVE

DATA INÍCIO

\section{Avaliação da Fertilidade do Solo}

Jose Carlos Casagrande

Departamento de Recursos Naturais e Proteção Ambiental

secdrnpa@cca.ufscar.br

fertilidade; solo; tecnologia e produção; desenvolvimento rural

$1 / 1 / 1999$

\section{Avaliação de Herbicidas em Plantas e no Ambiente}

Patricia Andrea Monquero

Departamento de Recursos Naturais e Proteção Ambiental

secdrnpa@cca.ufscar.br

herbicidas; seletividade; ambiente; tecnologia e produção; desenvolvimento rural

$6 / 4 / 2006$ 
TíTULO

COORDENAÇÃO

SETOR

CONTATO

PALAVRAS-CHAVE

DATA INÍCIO
Bioquímica e Biologia Molecular Aplicadas à Biotecnologia

Flavio Henrique da Silva

Departamento de Genética e Evolução

dge@ufscar.br

bioquímica; biologia molecular; biotecnologia; tecnologia e produção; educação ambiental

$1 / 1 / 2006$
TítULO

COORDENAÇÃO

SETOR

CONTATO

PALAVRAS-CHAVE

DATA INÍCIO

TítULo

COORDENAÇÃO

SETOR

CONTATO

PALAVRAS-CHAVE

DATA INÍCIO

TíTULo

COORDENAÇÃO

SETOR

CONTATO

PALAVRAS-CHAVE

DATA INÍCIO

\section{Bioquímica e Biologia Molecular de Microorganismos}

Anderson Ferreira da Cunha

Departamento de Genética e Evolução

dge@ufscar.br

microorganismos; biologia molecular; bioquímica; tecnologia e produção; inovação tecnológica

$30 / 7 / 2010$

\section{Bovinocultura}

Jozivaldo Prudencio Gomes de Morais

Departamento de Biotecnologia e Produção Vegetal e Animal

stela@cca.ufscar.br

bovinocultura; leite; atividades; tecnologia e produção; desenvolvimento rural

$6 / 6 / 2006$

Capacitação Tecnológica de Estudantes e Profissionais para a Utilização e Desenvolvimento de Software Aplicado à Área de Processamento, Análise e Manipulação de Imagens e Vídeos

\section{Biomédicos}

Ricardo Jose Ferrari

Departamento de Computação

dc@ufscar.br

imagens e vídeos biomédicos; software para a área médica; sinais biomédicos; tecnologia e produção; inovação tecnológica

$14 / 12 / 2012$

TíTULO

COORDENAÇÃO

SETOR

CONTATO

PALAVRAS-CHAVE

DATA INÍCIO

\section{Capacitação Tecnológica}

Sandra Abib

Departamento de Computação

dc@ufscar.br

capacitação; tecnológica; tecnologia e produção; inovação tecnológica

$15 / 3 / 2000$ 
TíTULO

COORDENAÇÃO

SETOR

CONTATO

PALAVRAS-CHAVE

DATA INÍCIO

TÍTULO

COORDENAÇÃO

SETOR

CONTATO

PALAVRAS-CHAVE

DATA INÍCIO

$\begin{array}{ll}\text { TítULO } & \begin{array}{l}\text { Cooperação Técnico-Científica na Área de Melhoramento } \\ \text { Genético da Cana-de-Açúcar }\end{array} \\ \text { COORDENAÇÃo } & \text { Hermann Paulo Hoffmann } \\ \text { SETOR } & \text { Departamento de Biotecnologia e Produção Vegetal e Animal } \\ \text { CONTATO } & \text { stela@cca.ufscar.br } \\ \text { PALAVRAS-CHAVE } & \text { cana-de-açúcar; variedades; tecnologia e produção; desenvolvimento rural } \\ \text { DATA INÍCIO } & \text { 13/7/1999 }\end{array}$

\section{Caracterização Estrutural dos Materiais}

Walter Jose Botta Filho

Departamento de Engenharia de Materiais

demachef@ufscar.br

caracterização; estrutural; tecnologia e produção; educação ambiental

$1 / 1 / 2005$

\section{Centro de Caracterização e Desenvolvimento de Materiais} (CCDM)

Nelson Guedes de Alcantara

Departamento de Engenharia de Materiais

demachef@ufscar.br

materiais; desenvolvimento; tecnologia e produção; inovação tecnológica

$1 / 1 / 2000$

$\begin{array}{ll}\text { TÍTULO } & \text { Cultura de Tecidos de Plantas } \\ \text { COORDENAÇÃo } & \text { Lee Tseng Sheng Gerald } \\ \text { SETOR } & \text { Departamento de Biotecnologia e Produção Vegetal e Animal } \\ \text { CONTATO } & \text { stela@cca.ufscar.br } \\ \text { PALAVRAS-CHAVE } & \text { in vitro; graduação; tecnologia e produção; desenvolvimento rural } \\ \text { DATA INÍCIO } & 8 / 8 / 2000\end{array}$

TítULo

Desenvolvimento de Atividades Relacionadas a Materiais Compósitos, Híbridos e Tecnologias Aplicáveis nas Áreas Aeronáutica, Náutica e de Geração de Energia a partir de Fontes Alternativas

COORDENAÇÃO

Jane Maria Faulstich de Paiva

SETOR

Departamento de Engenharia de Produção - Sorocaba

CONTATO

PALAVRAS-CHAVE

DATA INÍCIO

deps@ufscar.br

tecnologia; compósitos; híbridos; tecnologia e produção; inovação tecnológica

$30 / 5 / 2007$ 
TíTULO

COORDENAÇÃO

SETOR

CONTATO

PALAVRAS-CHAVE

DATA INÍ́CIO

TíTULO

Desenvolvimento de Processos, Produtos e Controles Químico, Microbiológico, Matéria-Prima e de Qualidade, Aplicado à Agroindústria de Fermentações

COORDENAÇÃO

SETOR

CONTATO

PALAVRAS-CHAVE

DATA INÍCIO
Desenvolvimento de Materiais e Dispositivos (Sensores, Ataudores e Transdutores) Piezoelétricos

Jose Antonio Eiras

Departamento de Física

dfchefe@ufscar.br

piezoelétricos; transdutores ultrassonicos; conversores de energia; tecnologia e produção; pólos tecnológicos

$19 / 4 / 2012$
Jorge José Correa Lopes

Departamento de Tecnologia Agroindustrial e Socioeconomia Rural secdtai@cca.ufscar.br

fermentações; microbiológico; tecnologia e produção; inovação tecnológica $7 / 5 / 2004$

$\begin{array}{ll}\text { TÍTULO } & \begin{array}{l}\text { Desenvolvimento de Técnicas, Produtos e Serviços } \\ \text { Controle Fitossanitário e Cultural em Cana-de-Açúca }\end{array} \\ \text { COORDENAÇÃo } & \text { Marcos Antonio Sanches Vieira } \\ \text { SETOR } & \text { Departamento de Biotecnologia e Produção Vegetal e Animal } \\ \text { CONTATO } & \text { stela@cca.ufscar.br } \\ \text { PALAVRAS-CHAVE } & \text { cana-de-açúcar; citrus; tecnologia e produção; desenvolvimento rural } \\ \text { DATA INÍCIO } & 21 / 6 / 2000\end{array}$

TítULO

Desenvolvimento de Técnicas, Produtos e Serviços para o Manejo da Água no Sistema Solo Planta

COORDENAÇÃO

SETOR

CONTATO

PALAVRAS-CHAVE

DATA INÍCIO

Jose Geanini Peres

Departamento de Recursos Naturais e Proteção Ambiental

secdrnpa@cca.ufscar.br

manejo; solo; tecnologia e produção; desenvolvimento rural

$1 / 9 / 2000$

TítULO

Desenvolvimento de Tecnologia em Materiais e Processos

COORDENAÇÃO

Ernesto Antonio Urquieta Gonzalez

SETOR

Departamento de Engenharia Química

CONTATO

deqchefe@ufscar.br

PALAVRAS-CHAVE

DATA INÍCIO

materiais; processos; formação; tecnologia e produção; inovação tecnológica $30 / 8 / 2006$ 
TítULo

COORDENAÇÃO

SETOR

CONTATO

PALAVRAS-CHAVE

DATA INÍCIO

TítULO

Desenvolvimento, Análise, Produção e Divulgação de Ferramentas para Projetos de Sistemas Estruturais de Concreto Armado e Protendido
Desenvolvimento e Controle da Qualidade na Agroindústria Canavieira (DCQAC)

Maria Teresa Mendes Ribeiro Borges

Departamento de Tecnologia Agroindustrial e Socioeconomia Rural

secdtai@cca.ufscar.br

agroindústria; canavieira; tecnologia e produção; desenvolvimento rural

$16 / 9 / 1999$
COORDENAÇÃO

SETOR

CONTATO

PALAVRAS-CHAVE

DATA INÍ́CIO

TíTULO

COORDENAÇÃO

SETOR

CONTATO

PALAVRAS-CHAVE

DATA INÍCIO

Roberto Chust Carvalho

Departamento de Engenharia Civil

deciv@ufscar.br

sistemas estruturais; concreto armado; computação; tecnologia e produção; desenvolvimento urbano

$31 / 3 / 2011$

\section{Diagnose e Controle de Doenças de Plantas}

Alfredo Seiiti Urashima

Departamento de Biotecnologia e Produção Vegetal e Animal

stela@cca.ufscar.br

diagnose; doenças de plantas; controle; tecnologia e produção; desenvolvimento rural

$28 / 3 / 2006$
TíTULO

COORDENAÇÃO

SETOR

CONTATO

PALAVRAS-CHAVE

DATA INÍCIO

TíTULO

COORDENAÇÃO

SETOR

CONTATO

PALAVRAS-CHAVE

DATA INÍCIO
Difusão do Conhecimento e Formação Educacional na Área de Engenharia de Materiais

Tomaz Toshimi Ishikawa

Departamento de Engenharia de Materiais

demachef@ufscar.br

educação; cursos de curta duração; disseminação dos conhecimentos; tecnologia e produção; educação profissional

$28 / 7 / 2008$ 
TíTULo

COORDENAÇÃO

SETOR

CONTATO

PALAVRAS-CHAVE

DATA INÍCIO

TíTULO

COORDENAÇÃO

SETOR

CONTATO

PALAVRAS-CHAVE

DATA INÍCIO
Difusão e Aplicações de Métodos para Gestão e Melhoria da Produtividade e da Qualidade de Sistemas de Produção

Glauco Henrique de Sousa Mendes

Departamento de Engenharia de Produção

dep@ufscar.br

sistemas de produção; capacitação; produtividade e qualidade; tecnologia e produção; educação continuada

$28 / 4 / 2009$
Título

COORDENAÇÃO

SETOR

CONTATO

PALAVRAS-CHAVE

DATA INÍCIO

\section{Do DNA à Biologia Sintética}

Francis de Morais Franco Nunes

Departamento de Genética e Evolução

dge@ufscar.br

genética; genômica; biologia sintética; tecnologia e produção; pólos tecnológicos $28 / 4 / 2014$

\section{Engenharia de Microestrutura de Materiais}

José de Anchieta Rodrigues

Departamento de Engenharia de Materiais

demachef@ufscar.br

microestrutura; engenharia; tecnologia e produção; inovação tecnológica

$10 / 3 / 2000$

\section{TíTulo Engenharia para a Web: Metodologias, Técnicas e Processos para o Desenvolvimento de Sistemas de Software para a Web com Qualidade}

COORDENAÇÃo Sergio Donizetti Zorzo

SETOR

Departamento de Computação

CONTATO

dc@ufscar.br

PALAVRAS-CHAVE tecnologia; computação; tecnologia e produção; inovação tecnológica

DATA INÍCIO

$1 / 5 / 2000$

TítULo

\section{Estudo de Linguagens de Programação de Computadores}

COORDENAÇÃO

SETOR

CONTATO

PALAVRAS-CHAVE

DATA INÍCIO
Luciana Aparecida Martinez Zaina

Departamento de Computação

dcomp@ufscar.br

linguagens de programação; desenvolvimento de software; estilos de linguagens; tecnologia e produção; educação profissional

$28 / 7 / 2009$ 


$\begin{array}{ll}\text { TÍTULO } & \text { Estudos do Setor Sucroenergético } \\ \text { COORDENAÇÃo } & \text { Octavio Antonio Valsechi } \\ \text { SETOR } & \text { Departamento de Tecnologia Agroindustrial e Socioeconomia Rural } \\ \text { CONTATO } & \text { secdtai@cca.ufscar.br } \\ \text { PALAVRAS-CHAVE } & \begin{array}{l}\text { sucroenergia; cana-de-açúcar; tecnologia; tecnologia e produção; inovação } \\ \text { tecnológica }\end{array} \\ \text { DATA INÍ́CIO } & 22 / 12 / 2011\end{array}$

\section{Título Estudos, Desenvolvimentos e Caracterização de Materiais Geotécnicos}

COORDENAÇÃO Fernando Henrique Martins Portelinha

SETOR Departamento de Engenharia Civil

CONTATO deciv@ufscar.br

PALAVRAS-CHAVE geotecnia; estudos; tecnologia; tecnologia e produção; inovação tecnológica

DATA INÍCIO 1/12/2015

$\begin{array}{ll}\text { TÍTULO } & \text { Estudos, Pesquisas, Ensino, Consultoria e Assessoria em } \\ & \text { Engenharia e Segurança de Tráfego } \\ \text { COORDENAÇÃo } & \text { Archimedes Azevedo Raia Junior } \\ \text { SETOR } & \text { Departamento de Engenharia Civil } \\ \text { CONTATO } & \text { deciv@ufscar.br } \\ \text { PALAVRAS-CHAVE } & \text { trânsito; tráfego; segurança; tecnologia e produção; desenvolvimento urbano } \\ \text { DATA INÍ́CIO } & \text { 18/7/2007 }\end{array}$

TÍTULO

Formação de Profissionais em Gestão de Negócios

COORDENAÇÃo Danilo Rolim Dias de Aguiar

SETOR Departamento de Economia

CONTATO deco@ufscar.br

PALAVRAS-CHAVE gestão; administração; economia empresarial; tecnologia e produção; educação continuada

DATA INÍCIO 2/5/2007

$\begin{array}{ll}\text { TÍTULO } & \text { Geoprocessamento } \\ \text { COORDENAÇÃO } & \text { Sergio Antonio Rohm } \\ \text { SETOR } & \text { Departamento de Engenharia Civil } \\ \text { CONTATO } & \text { deciv@ufscar.br } \\ \text { PALAVRAS-CHAVE } & \text { geoprocessamento; conceitos; tecnologia e produção; educação continuada } \\ \text { DATA INÍCIO } & 13 / 4 / 2000\end{array}$


Gestão da Criação, Treinamento, Incubação, Pesquisa e Desenvolvimento e Inovação (PeDel) e Transferência de Tecnologia de Empreendimentos de Base Tecnológica

COORDENAÇÃO

SETOR

CONTATO

PALAVRAS-CHAVE

DATA INÍCIO
Alexandre Alvaro

Departamento de Computação

dcomp@ufscar.br

empreendimentos; incubação; inovação tecnológica; tecnologia e produção; inovação tecnológica

$20 / 2 / 2013$

$\begin{array}{ll}\text { TÍTULO } & \text { Gestão Empresarial e Estudos Econômicos Aplicados aos } \\ & \text { Sistemas Agroindustriais } \\ \text { COORDENAÇÃo } & \text { Mario Otavio Batalha } \\ \text { SETOR } & \text { Departamento de Engenharia de Produção } \\ \text { CONTATO } & \text { dep@ufscar.br } \\ \text { PALAVRAS-CHAVE } & \text { atividades; gestão empresarial; tecnologia e produção; inovação tecnológica } \\ \text { DATA INÍCIO } & 1 / 11 / 2000\end{array}$

TítULO

TítULo

COORDENAÇÃO

SETOR

CONTATO

PALAVRAS-CHAVE

DATA INÍCIO

IAHoMaq: Interfaces Avançadas entre Homens e Máquinas

Ednaldo Brigante Pizzolato

Departamento de Computação

dc@ufscar.br

humanização; atendimento eletrônico; interface humano computador; tecnologia e produção; cooperação interinstitucional

$16 / 5 / 2011$

\begin{tabular}{|c|c|}
\hline Título & Informação, Ciência e Tecnologia \\
\hline COORDENAÇÃO & Leandro Innocentini Lopes de Faria \\
\hline SETOR & Departamento de Ciência da Informação \\
\hline CONTATO & dci@ufscar.br \\
\hline PALAVRAS-CHAVE & $\begin{array}{l}\text { indicadores de c\&t; inteligência competitiva; bibliometria; tecnologia e produção; } \\
\text { inovação tecnológica }\end{array}$ \\
\hline DATA INÍCIO & 29/4/2016 \\
\hline TítuLo & $\begin{array}{l}\text { Inovação Tecnológica e Capacitação de Pessoal em Processos } \\
\text { Biotecnológicos }\end{array}$ \\
\hline COORDENAÇÃO & Raquel de Lima Camargo Giordano \\
\hline SETOR & Departamento de Engenharia Química \\
\hline CONTATO & deqchefe@ufscar.br \\
\hline PALAVRAS-ChAVE & tecnologia; capacitação; tecnologia e produção; inovação tecnológica \\
\hline DATA INÍcIO & $1 / 1 / 2003$ \\
\hline
\end{tabular}

$$
16 / 5 / 2011
$$




$\begin{array}{ll}\text { TÍTULO } & \text { Internet das Coisas } \\ \text { COORDENAÇÃO } & \text { Helio Crestana Guardia } \\ \text { SETOR } & \text { Departamento de Computação } \\ \text { CONTATO } & \text { dc@ufscar.br } \\ \text { PALAVRAS-CHAVE } & \text { internet das coisas; smart cities; desenvolvimento de software; tecnologia e } \\ & \text { produção; inovação tecnológica } \\ \text { DATA INÍCIO } & 24 / 7 / 2014\end{array}$

TítULo

Investigação de Novos Paradigmas de Interação Considerando NUI (Natural User Interfaces)

COORDENAÇÃo Junia Coutinho Anacleto

SETOR Departamento de Computação

CONTATO dc@ufscar.br

PALAVRAS-CHAVE NUI; visual analitics; colaboração; tecnologia e produção; cooperação internacional DATA INÍCIO $5 / 1 / 2012$

$\begin{array}{ll}\text { TÍTULO } & \text { Laboratório de Caracterização de Fármacos e Quimiometria } \\ & \text { Aplicada } \\ \text { COORDENAÇÃO } & \text { Renato Lajarim Carneiro } \\ \text { SETOR } & \text { Departamento de Química } \\ \text { CONTATO } & \text { dqchefe@ufscar.br } \\ \text { PALAVRAS-CHAVE } & \text { quimiometria; análise de fármacos; espectroscopia raman; tecnologia e produção; } \\ & \text { cooperação interinstitucional } \\ \text { DATA INÍCIO } & 5 / 11 / 2012\end{array}$

TÍTULO

Laboratório de Espectroanalítica, Preparo de Amostras e Quimiometria

COORDENAÇÃO

Edenir Rodrigues Pereira Filho

SETOR

Departamento de Química

CONTATO

dqchefe@ufscar.br

PALAVRAS-CHAVE

espectroanalítica; preparo de amostras; quimiometria; tecnologia e produção; cooperação interinstitucional

DATA INÍCIO

$9 / 3 / 2015$

$\begin{array}{ll}\text { TítULO } & \text { Laboratório de Polímeros - Soluções para a Comunidade de } \\ & \text { Polímeros } \\ \text { COORDENAÇÃo } & \text { Caio Marcio Paranhos da Silva } \\ \text { SETOR } & \text { Departamento de Química } \\ \text { CONTATO } & \text { dqchefe@ufscar.br } \\ \text { PALAVRAS-CHAVE } & \begin{array}{l}\text { materiais polímericos; consultoria; caracterização de materiais; tecnologia e } \\ \text { produção; inovação tecnológica }\end{array} \\ \text { DATA INÍCIO } & 22 / 4 / 2013\end{array}$




$\begin{array}{ll}\text { TítULO } & \text { Mecanização Agrícola no Manejo Solo-Planta } \\ \text { COORDENAÇÃo } & \text { Rubismar Stolf } \\ \text { SETOR } & \text { Departamento de Recursos Naturais e Proteção Ambiental } \\ \text { CONTATO } & \text { secdrnpa@cca.ufscar.br } \\ \text { PALAVRAS-CHAVE } & \text { mecanização; agrícola; tecnologia e produção; desenvolvimento rural } \\ \text { DATA INÍCIO } & 1 / 1 / 2004\end{array}$

$\begin{array}{ll}\text { TÍTULO } & \text { Melhoramento Genético de Hortaliças } \\ \text { COORDENAÇÃo } & \text { Fernando Cesar Sala } \\ \text { SETOR } & \text { Departamento de Biotecnologia e Produção Vegetal e Animal } \\ \text { CONTATO } & \text { stela@cca.ufscar.br } \\ \text { PALAVRAS-CHAVE } & \begin{array}{l}\text { variedades; produção; resistência à fitopatógenos; tecnologia e produção; inovação } \\ \text { tecnológica }\end{array} \\ \text { DATA INÍCIO } & \text { 1/2/2011 }\end{array}$

$\begin{array}{ll}\text { TíTULO } & \text { Minimização e Reciclagem de Resíduos } \\ \text { COORDENAÇÃo } & \text { Bernardo Arantes do Nascimento Teixeira } \\ \text { SETOR } & \text { Departamento de Engenharia Civil } \\ \text { CONTATO } & \text { deciv@ufscar.br } \\ \text { PALAVRAS-CHAVE } & \text { minimização; reciclagem; tecnologia e produção; educação ambiental } \\ \text { DATA INÍCIO } & \text { 1/4/2000 }\end{array}$

$\begin{array}{ll}\text { TítUlo } & \text { Núcleo de Reologia e Processamento de Polímeros do DEMa/ } \\ & \text { NRPP/DEMa } \\ \text { COORDENAÇÃo } & \text { Luiz Antonio Pessan } \\ \text { SETOR } & \text { Departamento de Engenharia de Materiais } \\ \text { CONTATO } & \text { demachef@ufscar.br } \\ \text { PALAVRAS-CHAVE } & \text { núcleo; processamento; tecnologia e produção; inovação tecnológica } \\ \text { DATA INÍCIO } & \text { 18/11/1999 }\end{array}$

$\begin{array}{ll}\text { TítULO } & \text { Pesquisa e Desenvolvimento em Microbiologia Agrícola e } \\ & \text { Molecular } \\ \text { COORDENAÇÃO } & \text { Sandra Regina Ceccato Antonini } \\ \text { SETOR } & \text { Departamento de Tecnologia Agroindustrial e Socioeconomia Rural } \\ \text { CONTATO } & \text { secdtai@cca.ufscar.br } \\ \text { PALAVRAS-CHAVE } & \text { microbiologia; indústria; agrícola; tecnologia e produção; desenvolvimento rural } \\ \text { DATA INÍCIO } & \text { 1/9/2014 }\end{array}$


TíTULO

COORDENAÇÃO

SETOR

CONTATO

PALAVRAS-CHAVE

DATA INÍCIO

$\begin{array}{ll}\text { TÍTULO } & \text { Pesquisa Operacional Aplicada } \\ \text { COORDENAÇÃo } & \text { Reinaldo Morabito Neto } \\ \text { SETOR } & \text { Departamento de Engenharia de Produção } \\ \text { CONTATO } & \text { dep@ufscar.br } \\ \text { PALAVRAS-CHAVE } & \text { pesquisa; operacional; tecnologia e produção; inovação tecnológica } \\ \text { DATA INÍ́CIO } & 11 / 10 / 2000\end{array}$

\section{Pesquisa e Tecnologia em Sistemas Multimidia Distribuídos}

Luis Carlos Trevelin

Departamento de Computação

dc@ufscar.br

pesquisa; multimidia; tecnologia e produção; inovação tecnológica

$6 / 8 / 2004$

$\begin{array}{ll}\text { TÍTULO } & \text { Pesquisas e Análises Cromatográficas } \\ \text { COORDENAÇÃo } & \text { Quezia Bezerra Cass } \\ \text { SETOR } & \text { Departamento de Química } \\ \text { CONTATO } & \text { dqchefe@ufscar.br } \\ \text { PALAVRAS-CHAVE } & \begin{array}{l}\text { desenvolvimento de métodos; análises cromatográficas; desenvolvimento de } \\ \text { projetos; tecnologia e produção; inovação tecnológica }\end{array}\end{array}$

DATA INÍ́CIO

$28 / 3 / 2016$

$\begin{array}{ll}\text { TÍTULO } & \text { Planejamento e Gerenciamento de Sistemas Hidráulicos, } \\ & \text { Sanitários e Ambientais } \\ \text { COORDENAÇÃo } & \text { Erich Kellner } \\ \text { SETOR } & \text { Departamento de Engenharia Civil } \\ \text { CONTATO } & \text { deciv@ufscar.br } \\ \text { PALAVRAS-CHAVE } & \text { planejamento; gerenciamento; tecnologia e produção; inovação tecnológica } \\ \text { DATA INÍCIO } & 2 / 8 / 1999\end{array}$

$\begin{array}{ll}\text { TíTULO } & \text { Programa de Apoio Tecnológico e Educacional em Metais } \\ & \text { Vítreos e Nano-estruturados } \\ \text { COORDENAÇÃO } & \text { Claudio Shyinti Kiminami } \\ \text { SETOR } & \text { Departamento de Engenharia de Materiais } \\ \text { CONTATO } & \text { demachef@ufscar.br } \\ \text { PALAVRAS-CHAVE } & \begin{array}{l}\text { metais vítreos; metais nano-estruturados; novos materiais; tecnologia e produção; } \\ \text { inovação tecnológica }\end{array} \\ \text { DATA INÍCIO } & \text { 18/7/2007 }\end{array}$

DATA INÍCIO

$18 / 7 / 2007$ 
TítULo

Programa de Apoio Tecnológico e Educacional em Simulação Computacional Aplicada aos Materiais de Engenharia e seus Processos de Transformação

COORDENAÇÃO

Rodrigo Bresciani Canto

SETOR

CONTATO

PALAVRAS-CHAVE

DATA INÍCIO

Departamento de Engenharia de Materiais

demachef@ufscar.br

simulação computacional; materiais; modelagem; tecnologia e produção; inovação tecnológica

$30 / 5 / 2014$
TítULo

Programa de Desenvolvimento e Transferência de Tecnologia para o Aperfeiçoamento de Setores Produtivos

COORDENAÇÃo

SETOR

CONTATO

PALAVRAS-CHAVE

DATA INÍCIO

Miguel Angel Aires Borras

Departamento de Engenharia de Produção - Sorocaba

deps@ufscar.br

inovação tecnológica; transferência de tecnologia; treinamento e capacitação; tecnologia e produção; pólos tecnológicos

$13 / 5 / 2011$
TíTULO

Programa de Ensino, Pesquisa e Extensão do Laboratório de Ergonomia, Simulação e Projeto de Situações Produtivas PSPLab/DEP/UFSCar

COORDENAÇÃo Nilton Luiz Menegon

SETOR

CONTATO

PALAVRAS-CHAVE

DATA INÍCIO

Departamento de Engenharia de Produção

dep@ufscar.br

situações produtivas; simulação; ergonomia; tecnologia e produção; inovação tecnológica

$13 / 9 / 2016$

\section{TíTULo \\ Programa de Extensão do Grupo de Eletroquímica e Polímeros DQ-UFSCar \\ COORDENAÇÃO \\ SETOR \\ CONTATO \\ PALAVRAS-CHAVE \\ Carlos Ventura D Alkaine \\ Departamento de Química \\ dqchefe@ufscar.br \\ corrosão; baterias; gestão tecnológica; tecnologia e produção; cooperação interinstitucional}

DATA INÍCIO
$13 / 4 / 2011$ 
TíTULO

COORDENAÇÃO

SETOR

CONTATO

PALAVRAS-CHAVE

DATA INÍCIO

\section{Programa de Extensão em Adequação Ambiental}

Carlos Augusto de Sousa Martins Filho

Departamento de Ciências Ambientais

dcam@ufscar.br

restauração florestal; adequação ambiental; educação ambiental; tecnologia e produção; gestão de recursos naturais

9/1/2013
TítULO

COORDENAÇÃO

SETOR

CONTATO

PALAVRAS-CHAVE

DATA INÍCIO

TíTULO

COORDENAÇÃO

SETOR

CONTATO

PALAVRAS-CHAVE

DATA INÍCIO

Título

Programa de Inovação Tecnológica, Propriedade Intelectual

e Transferência de Tecnologia da Agência de Inovação da UFSCar

COORDENAÇÃO

SETOR

CONTATO

PALAVRAS-CHAVE

DATA INÍCIO

Ana Lucia Vitale Torkomian

Agência de Inovação da UFSCar

inovacao@ufscar.br

inovação tecnológica; propriedade intelectual; transferência de tecnologia; tecnologia e produção; inovação tecnológica

9/1/2013

TíTULo

Programa de Melhoria Tecnica da Área de Sistemas Estruturais e Construtivos

COORDENAÇÃO Guilherme Aris Parsekian

SETOR

Departamento de Engenharia Civil

CONTATO

PALAVRAS-CHAVE

deciv@ufscar.br

estruturas; construção civil; racionalização; tecnologia e produção; inovação tecnológica

DATA INÍCIO

$22 / 4 / 2009$ 
TítULo

Programa do NETPRE para Integração Pesquisa-ProjetoProdução no Desenvolvimento da Construção Industrializada de Concreto no Brasil

COORDENAÇÃo Marcelo de Araujo Ferreira

SETOR

CONTATO

PALAVRAS-CHAVE

DATA INÍCIO

deciv@ufscar.br

concreto pré-moldado; estruturas pré-fabricadas; construção industrializada; tecnologia e produção; inovação tecnológica

$17 / 7 / 2009$
TítULo

Programa em Desenvolvimento, Inovação e Difusão em Tecnologias da Informação e Comunicação (TIC)

COORDENAÇÃO

SETOR

CONTATO

PALAVRAS-CHAVE

DATA INÍCIO

$28 / 4 / 2011$

$\begin{array}{ll}\text { TítULO } & \text { Programa Produção em Monogástricos } \\ \text { COORDENAÇÃo } & \text { Luciana Thie Seki Dias } \\ \text { SETOR } & \text { Departamento de Biotecnologia e Produção Vegetal e Animal } \\ \text { CONTATO } & \text { stela@cca.ufscar.br } \\ \text { PALAVRAS-CHAVE } & \text { aves; peixes; nutrição; tecnologia e produção; desenvolvimento rural } \\ \text { DATA INÍCIO } & 5 / 11 / 2012\end{array}$

TíTULO

Projeto PROMUS - Promovendo Mudanças - "Mentes

Pensantes, Criativas e de Boa Vontade, Unidas no

Desenvolvimento de Projeto Inovador e Auto-Sustentável

Aplicado a Sociedades Desfavorecidas"

$\begin{array}{ll}\text { COORDENAÇÃO } & \text { Yeda Regina Venturini } \\ \text { SETOR } & \text { Departamento de Computação } \\ \text { CONTATO } & \text { dcomp@ufscar.br } \\ \text { PALAVRAS-CHAVE } & \begin{array}{l}\text { social; sustentável; multidisciplinar; tecnologia e produção; desenvolvimento } \\ \text { urbano }\end{array}\end{array}$

DATA INÍCIO

$13 / 5 / 2011$ 
TíTULO

COORDENAÇÃO

SETOR

CONTATO

PALAVRAS-CHAVE

DATA INÍCIO
Projeto, Modelagem e Simulação de Sistemas Mecânicos

Flavio Yukio Watanabe

Centro de Ciências Exatas e de Tecnologia

ccetdir@ufscar.br

engenharia mecânica; atividades complementares; difusão do conhecimento; tecnologia e produção; inovação tecnológica

$17 / 10 / 2011$
TítULO

COORDENAÇÃO

SETOR

CONTATO

PALAVRAS-CHAVE

DATA INÍCIO

\section{Projetos de Unidades Industriais e de Negócios}

Joao Alberto Camarotto

Departamento de Engenharia de Produção

dep@ufscar.br

unidades; negócios; tecnologia e produção; inovação tecnológica

$21 / 6 / 2000$

\section{TíTULo \\ Química e Biogeoquímica Ambiental do Laboratório de Biogeoquímica Ambiental do Departamento de Química da UFSCar \\ COORDENAÇÃo Antonio Aparecido Mozeto \\ SETOR \\ Departamento de Química \\ CONTATO \\ dqchefe@ufscar.br \\ PALAVRAS-CHAVE biogeoquímica; ambiental; tecnologia e produção; educação ambiental \\ DATA INÍCIO \\ 20/10/1998}

\section{TítUlo Robótica}

COORDENAÇÃo Tatiana de Figueiredo Pereira Alves Taveira Pazelli

SETOR Departamento de Engenharia Elétrica

CONTATO

dee@ufscar.br

PALAVRAS-CHAVE robótica; educação; aplicação; tecnologia e produção; cooperação interinstitucional

DATA INÍCIO $29 / 4 / 2016$

$\begin{array}{ll}\text { TÍTULO } & \text { Route UFSCar } \\ \text { COORDENAÇÃo } & \text { Jose Benaque Rubert } \\ \text { SETOR } & \text { Departamento de Engenharia Mecânica } \\ \text { CONTATO } & \begin{array}{l}\text { demec@ufscar.br } \\ \text { fórmula sae; veículos automotores; veículos de competição; tecnologia e produção; } \\ \text { PALAVRAS-CHAVE }\end{array} \\ \text { inovação tecnológica } \\ \text { DATA INÍCIO } & 24 / 7 / 2014\end{array}$

DATA INÍCIO

$24 / 7 / 2014$ 
TítULo

COORDENAÇÃO

SETOR

CONTATO

PALAVRAS-CHAVE

DATA INÍCIO

TítULo

COORDENAÇÃO

SETOR

CONTATO

PALAVRAS-CHAVE

DATA INÍCIO

$\begin{array}{ll}\text { TítULO } & \text { Síntese e Avaliação da Atividade Biológica de Produtos } \\ & \text { Naturais e Análogos } \\ \text { COORDENAÇÃo } & \text { Arlene Goncalves Correa } \\ \text { SETOR } & \text { Departamento de Química } \\ \text { CONTATO } & \text { dqchefe@ufscar.br } \\ \text { PALAVRAS-CHAVE } & \text { síntese; produtos naturais; doenças tropicais; tecnologia e produção; inovação } \\ & \text { tecnológica } \\ \text { DATA INÍCIO } & 4 / 7 / 2011\end{array}$

Serviço de Análise do Laboratório de Ressonância Magnética Nuclear do DQ-UFSCar

Antonio Gilberto Ferreira

Departamento de Química

dqchefe@ufscar.br

RMN; infravermelho; ultravioleta; tecnologia e produção; inovação tecnológica

$31 / 7 / 2014$

\section{Silvicultura e Recursos Florestais}

Jose Mauro Santana da Silva

Departamento de Ciências Ambientais - Sorocaba

dca@ufscar.br

florestas; biomassa; recursos ambientais; tecnologia e produção; gestão de recursos naturais

$30 / 9 / 2013$
TíTULO

COORDENAÇÃO

SETOR

CONTATO

PALAVRAS-CHAVE

DATA INÍCIO

TíTULo

COORDENAÇÃo

SETOR

CONTATO

PALAVRAS-CHAVE

DATA INÍCIO

\section{Sistemas Computacionais Inteligentes}

Estevam Rafael Hruschka Junior

Departamento de Computação

dc@ufscar.br

sistemas inteligentes; inteligência artificial; sistemas de apoio à decisão; tecnologia e produção; inovação tecnológica

$28 / 4 / 2011$

\section{Sistemas Computacionais Inteligentes Aplicados para Obtenção de Conhecimento Online}

Helena de Medeiros Caseli

Departamento de Computação

dc@ufscar.br

inteligência artificial; processamento língua natural; processamento de imagem; tecnologia e produção; inovação tecnológica

$5 / 12 / 2014$ 
TíTULO

COORDENAÇÃO

SETOR

CONTATO

PALAVRAS-CHAVE

DATA INÍCIO

\section{Suporte Tecnológico em Educação a Distância}

Cesar Augusto Camillo Teixeira

Departamento de Computação

dc@ufscar.br

tecnológico; educação; tecnologia e produção; educação à distância

$14 / 3 / 2001$
Título

COORDENAÇÃo

SETOR

CONTATO

PALAVRAS-CHAVE

DATA INÍCIO
Técnicas de Análise, Diagnóstico e Projetos para Sistemas Elétricos de Potência

Ricardo Augusto Souza Fernandes

Centro de Ciências Exatas e de Tecnologia

ccetdir@ufscar.br

engenharia elétrica; sistemas elétricos de potência; análise e projeto; tecnologia e produção; pólos tecnológicos

$14 / 3 / 2014$
Título

COORDENAÇÃO

SETOR

CONTATO

PALAVRAS-CHAVE

DATA INÍCIO
Tecnologia de Informação, Programação de Operações e

\section{Cadeia de Suprimento}

Fabio Molina da Silva

Departamento de Engenharia de Produção

dep@ufscar.br

tecnologia; suprimento; tecnologia e produção; inovação tecnológica

$1 / 1 / 2003$
TíTulo

COORDENAÇÃO

SETOR

CONTATO

PALAVRAS-CHAVE

DATA INÍCIO

TÍTULO

COORDENAÇÃO

SETOR

CONTATO

PALAVRAS-CHAVE

DATA INÍCIO

\section{Tecnologia e Desenvolvimento de Materiais}

Tomaz Toshimi Ishikawa

Departamento de Engenharia de Materiais

demachef@ufscar.br

consultoria; desenvolvimento de materiais; prestacao de serviços; tecnologia e produção; inovação tecnológica

$28 / 7 / 2008$

\section{Tecnologias e Aplicações de Automação Industrial}

Edilson Reis Rodrigues Kato

Departamento de Computação

dc@ufscar.br

automação; sistemas computacionais; sistemas de controle; tecnologia e produção; inovação tecnológica

$1 / 12 / 2011$ 
TíTULO

COORDENAÇÃO

SETOR

CONTATO

PALAVRAS-CHAVE

DATA INÍCIO
Tecnologias e Aplicações de Inteligência Computacional

Heloisa de Arruda Camargo

Departamento de Computação

dc@ufscar.br

inteligência computacional; conhecimento impreciso; raciocínio; tecnologia e produção; inovação tecnológica

$13 / 4 / 2011$
TítULO

COORDENAÇÃO

SETOR

CONTATO

PALAVRAS-CHAVE

DATA INÍCIO

\section{Tecnologias e Estratégias de Automação}

Orides Morandin Junior

Departamento de Computação

dc@ufscar.br

estratégia; automação; tecnologias; tecnologia e produção; inovação tecnológica

$27 / 10 / 2006$

$\begin{array}{ll}\text { TÍTULO } & \text { Tecnologias, Treinamentos e Aplicações em } \\ & \text { Telecomunicações } \\ \text { COORDENAÇÃo } & \text { Jose Carlos Pizolato Junior } \\ \text { SETOR } & \text { Centro de Ciências Exatas e de Tecnologia } \\ \text { CONTATO } & \begin{array}{l}\text { ccetdir@ufscar.br } \\ \text { PALAVRAS-CHAVE }\end{array} \\ & \begin{array}{l}\text { treinamento; tecnologia; sistemas de telecomunicações; tecnologia e produção; } \\ \text { educação continuada }\end{array}\end{array}$

DATA INÍCIO

19/4/2012

\section{TEC-SHARE: Transferência de Tecnologia no Ensino de Computação}

COORDENAÇÃO

Antonio Carlos dos Santos

SETOR

Departamento de Computação

CONTATO

dc@ufscar.br

PALAVRAS-CHAVE

DATA INÍCIO

$1 / 1 / 2002$

$\begin{array}{ll}\text { TÍTULO } & \text { Testes e Análises Técnicas, Físico-Químicas e Analíticas de } \\ & \text { Materiais e seus Componentes } \\ \text { COORDENAÇÃo } & \text { Elson Longo da Silva } \\ \text { SETOR } & \text { Departamento de Química } \\ \text { CONTATO } & \text { dqchefe@ufscar.br } \\ \text { PALAVRAS-CHAVE } & \begin{array}{l}\text { caracterização; físico-química; tecnologia; tecnologia e produção; inovação } \\ \text { tecnológica }\end{array} \\ \text { DATA INÍ́CIO } & 11 / 6 / 2015\end{array}$


8

\section{Trabalho}

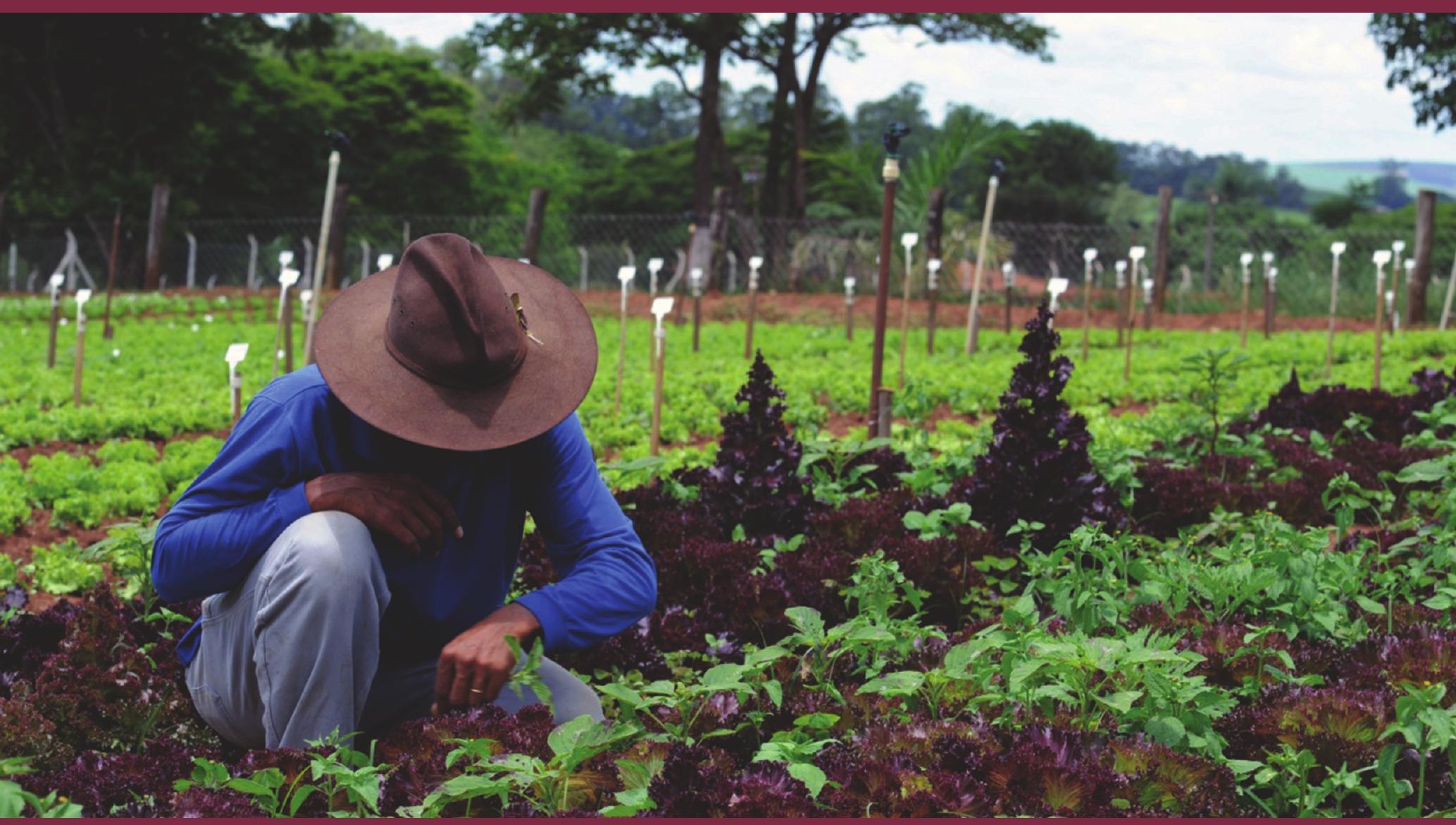

UFSCar Campus Araras, 2012.

Foto: Cain Rodrigues. 


$\begin{array}{ll}\text { TítULO } & \text { Agricultura Sustentável (Antes Denominado Tecnologia } \\ & \text { Apropriada para Agricultura Familiar) } \\ \text { COORDENAÇÃO } & \text { Luiz Antonio Correia Margarido } \\ \text { SETOR } & \text { Departamento de Tecnologia Agroindustrial e Socioeconomia Rural } \\ \text { CONTATO } & \text { secdtai@cca.ufscar.br } \\ \text { PALAVRAS-CHAVE } & \text { agricultura; sustentável; trabalho; questão agrária } \\ \text { DATA INÍCIO } & 1 / 5 / 1999\end{array}$

Título
Ergonomia, Segurança, Higiene e Projeto do Trabalho.
Ergonomia e Projetação do Trabalho

COORDENAÇÃo Nilton Luiz Menegon

SETOR Departamento de Engenharia de Produção

CONTATO dep@ufscar.br

PALAVRAS-CHAVE ergonomia; higiene; trabalho; educação profissional

DATA INÍCIO $\quad 1 / 1 / 2001$

$\begin{array}{ll}\text { TÍTULO } & \text { Incubadora Regional de Cooperativas Populares - INCOOP } \\ \text { COORDENAÇÃo } & \text { Ana Lucia Cortegoso } \\ \text { SETOR } & \text { Departamento de Psicologia } \\ \text { CONTATO } & \text { dpsic@ufscar.br } \\ \text { PALAVRAS-CHAVE } & \text { incubadora; cooperativas; trabalho; organizações populares } \\ \text { DATA INÍ́CIO } & \text { 10/3/2000 }\end{array}$

$\begin{array}{ll}\text { TÍTULO } & \text { Processo Organizativo e Gestão de Assentamentos Rurais e } \\ & \text { Comunidades Tradicionais } \\ \text { COORDENAÇÃO } & \text { Rosemeire Aparecida Scopinho } \\ \text { SETOR } & \text { Departamento de Psicologia } \\ \text { CONTATO } & \text { dpsic@ufscar.br } \\ \text { PALAVRAS-CHAVE } & \text { trabalho; processos organizativos; movimentos sociais; trabalho; questão agrária } \\ \text { DATA INÍCIO } & \text { 13/9/2016 }\end{array}$

$\begin{array}{ll}\text { TítULO } & \text { Psi-Sistemas: Serviço em Psicologia Organizacional } \\ \text { COORDENAÇÃo } & \text { Elizabeth Joan Barham } \\ \text { SETOR } & \text { Departamento de Psicologia } \\ \text { CONTATO } & \text { dpsic@ufscar.br } \\ \text { PALAVRAS-CHAVE } & \text { psicologia; psicologia organizacional; trabalho; educação profissional } \\ \text { DATA INÍCIO } & \text { 1/1/2001 }\end{array}$


TíTULO

COORDENAÇÃo

SETOR

CONTATO

PALAVRAS-CHAVE

DATA INÍCIO
Qualidade de vida na UFSCar

Eliane da Silva Grazziano

Departamento de Terapia Ocupacional

denf@ufscar.br

qualidade de vida; saúde do trabalhador; equilíbrio emocional; trabalho; saúde e segurança no trabalho

$11 / 4 / 2007$ 


\section{Resumas}




\section{Bomunibaดtão}

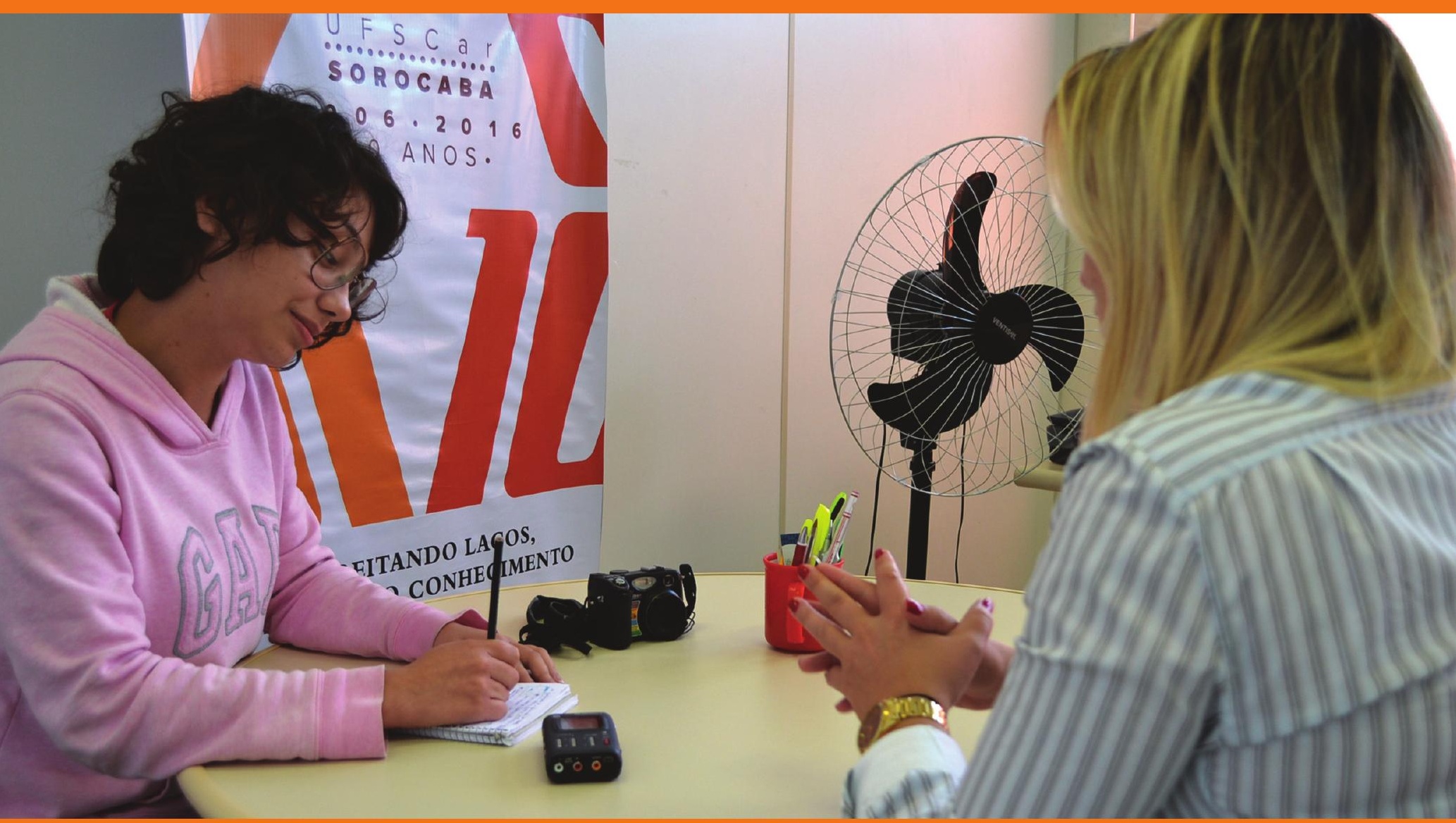

Entrevista na UFSCar - Sorocaba.

Foto: João Eduardo Justi. 
Avaliação e Promoção de Habilidades Sociais e Relações Interpessoais

\begin{tabular}{ll} 
COORDENAÇÃO & Zilda Aparecida Pereira Del Prette \\
\hline SETOR & Departamento de Psicologia \\
\hline CONTATO & dpsic@ufscar.br \\
\hline
\end{tabular}

RESUMO Aperfeiçoamento de instrumentos e procedimentos de avaliação de habilidades sociais, competência social e relações interpessoais em geral.

PALAVRAS-CHAVE habilidades sociais; comunicação; atenção integral à saúde de adultos

DATA INÍCIO $\quad 8 / 2 / 2001$


Título

\section{Disseminação do Conhecimento Científico e Tecnológico na UFSCar}

\begin{tabular}{ll} 
COORDENAÇÃO & Adilson Jesus Aparecido de Oliveira \\
SETOR & Departamento de Física \\
\hline CONTATO & dfchefe@ufscar.br
\end{tabular}

RESUMO A Coordenadoria de Comunicação Social (CCS) da UFSCar tem atuado fortemente na promoção e apoio de iniciativas de divulgação científica na UFSCar. Em 2006, a aprovação pelo CNPq do projeto "Laboratório Aberto de Interatividade Disseminação do Conhecimento Científico e Tecnológico” - elaborado pela CCS em parceria com o coordenador do projeto, e com a participação de docentes dos departamentos de Artes e Comunicação, Química, Computação e Metodologia de Ensino - representou o amadurecimento dessas iniciativas e colocou a necessidade de caracterização institucional destas como atividades de extensão, visando seu enriquecimento enquanto espaços também para o desenvolvimento de atividades de ensino e pesquisa.

PALAVRAS-CHAVE divulgação científica; ensino de ciências; comunicação social; Comunicação; comunicação escrita e eletrônica 
тítuı Divulgação Científica em Biologia

\begin{tabular}{ll} 
COORDENAÇÃo & Ana Claudia Lessinger \\
\hline SETOR & Departamento de Biologia \\
\hline CONTATO & dbio@ufscar.br \\
\hline RESUMO & $\begin{array}{l}\text { Agências de financiamento de projetos de pesquisa têm exigido dos pesquisadores } \\
\text { o uso de estratégias de comunicação para tornar o conhecimento produzido pela } \\
\text { academia acessível ao público não especializado. Esta questão pode ser formalizada } \\
\text { e atendida institucionalmente por atividades de extensão associadas à divulgação } \\
\text { de conhecimentos produzidos pelos grupos de pesquisa do Departamento de } \\
\text { Biologia. Além disso, este programa abriga o compromisso de democratizar o acesso } \\
\text { ao conhecimento científico produzido na área de Biologia a diferentes setores da } \\
\text { sociedade via estratégias de divulgação-científica com o objetivo de habilitar o } \\
\text { público-alvo a reconhecer, participar e formar opiniões relacionadas ao tema com } \\
\text { autonomia. }\end{array}$ \\
\end{tabular}


TíTULO

\section{Educação de Surdos e Tecnologias: Reflexões e Ações de Formação}

\begin{tabular}{|c|c|}
\hline COORDEI & Aryane Santos Nogueira \\
\hline SETOR & Departamento de Psicologia \\
\hline CONTATO & dpsic@ufscar.br \\
\hline RESUMO & $\begin{array}{l}\text { Este programa tem por objetivo articular questões relacionadas à educação de } \\
\text { surdos e às potencialidades das tecnologias digitais, considerando a necessidade } \\
\text { de desenvolvimento de estratégias diferenciadas para a educação de surdos e a } \\
\text { imprescindibilidade em garantir e incentivar a democratização do saber em seus } \\
\text { diversos contextos. Tem como referencial teórico base a educação bilíngue para } \\
\text { surdos e a comunicação e a produção de significados que se dá por meio dos vários } \\
\text { recursos semióticos e linguísticos, em diferentes modalidades, e que estão em } \\
\text { interação nas plataformas digitais. }\end{array}$ \\
\hline
\end{tabular}

PALAVRAS-CHAVE educação de surdos; tecnologia; produção de materiais; comunicação; educação continuada 
Título

\section{Ensino de Libras (Língua Brasileira de Sinais) e Formação Continuada para o Uso Desta Língua em Diversos Contextos Sociais}

\begin{tabular}{ll} 
COORDENAÇÃo & Vanessa Regina de Oliveira Martins \\
\hline SETOR & Departamento de Psicologia \\
\hline CONTATO & dpsic@ufscar.br \\
\hline RESUMO & $\begin{array}{l}\text { Com a disseminação da língua de sinais em diversos espaços sociais, por } \\
\text { meio da ação legal e do direito linguístico das pessoas surdas, promovida pelo } \\
\text { Decreto 5.626/05, muitas pessoas tem se interessado e necessitado, em sua } \\
\text { atuação profissional, aprender Libras (Língua Brasileira de Sinais). Deste modo, } \\
\text { este programa prevê a oferta de cursos de Libras (módulos I, II, III, IV e V), bem } \\
\text { como formação para o uso desta língua em diversos contextos: escolas, espaços } \\
\text { comunitários, empresas, entre outros. Assim, o programa abrange atividades de } \\
\text { extensão e de ensino, desde o aprendizado inicial da língua à estratégias tradutórias } \\
\text { mais avançadas de pessoas que já conhecem este idioma. }\end{array}$ \\
\hline PALAVRAS-CHAVE & $\begin{array}{l}\text { ensino da libras; libras; práticas tradutórias em libras; comunicação; } \\
\text { educação continuada }\end{array}$ \\
\hline DATA INÍCIO & \begin{tabular}{l} 
10/9/2015 \\
\hline
\end{tabular}
\end{tabular}


TítULO

\section{Estudos, Pesquisa e Desenvolvimento de Tecnologias para Cidades Inteligentes}

\begin{tabular}{ll} 
COORDENAÇÃO & Hermes Senger \\
\hline SETOR & Departamento de Computação \\
\hline CONTATO & dc@ufscar.br \\
\hline
\end{tabular}

RESUMO Este programa tem por finalidade desenvolver pesquisas, estudos e projetos sobre o tema cidades inteligentes. Poderão ser abordados aspectos relacionados com os seguintes temas: infraestutura e serviços para cidades digitais; desenvolvimento e aplicação de tecnologias que melhorem a qualidade de vida nas cidades (cidades inteligentes); tecnologias da informação e comunicação para a melhoria da qualidade de vida nas cidades; tecnologias da informação e comunicação para melhoria da mobilidade urbana; coleta, transmissão, processamento e armazenamento de informações e dados aplicados a cidades inteligentes; infraestrutura tecnológica para cidades inteligentes.

PALAVRAS-CHAVE cidades inteligentes; tecnologias da informação e comunicação; infraestrutura tecnológica; comunicação; inovação tecnológica 
título GeMInIS UFSCar

COORDENAÇÃo João Carlos Massarolo

SETOR Departamento de Artes e Comunicação

CONTATO dac@ufscar.br

RESUMO Este programa de extensão pretende criar e desenvolver canais de comunicação para a divulgação junto à socidedade do conhecimento produzido pelo Grupo de Estudos sobre Mídias Interativas em Imagem e Som (GEMInIS UFSCar). As atividades de extensão do grupo, criado em 2002, certificado pelo CNPq e vinculado ao Programa de Pós-Graduação em Imagem e Som (PPGIS), objetivam a transferência de conhecimento para o campo social, por meio de ações que envolvem parcerias externas, palestras, encontros, conferências, seminários, colóquios, cursos, workshops, publicações (livros, artigos, anais de eventos e periódico), utilizando blogs, sites, redes sociais, entre outras mídias.

PALAVRAS-CHAVE mídia; audiovisual; interativo; comunicação; produção cultural e artística na área de fotografia, cinema e vídeo 
TítULO

\section{Libras em Uso: Discurso, Ensino, Tradução e Interpretação em Ações de Formação com as Comunidades Surdas}

\begin{tabular}{|c|c|}
\hline COORDEN & Marcus Vinicius Batista Nascimento \\
\hline SETOR & Departamento de Psicologia \\
\hline CONTATO & dpsic@ufscar.br \\
\hline RESUMO & $\begin{array}{l}\text { Este programa tem por objetivo promover ações de formação com as comunidades } \\
\text { surdas, considerando surdos e ouvintes usuários da Língua Brasileira de Sinais } \\
\text { (Libras), em associações de surdos, associações de tradutores e intérpretes de } \\
\text { Libras, escolas da rede pública e outros espaços para pensar o ensino, a tradução, } \\
\text { a interpretação e quaisquer outros usos que se fazem da Libras a partir de uma } \\
\text { perspectiva discursiva que desdobre em práticas pedagógicas, tradutórias e } \\
\text { interpretativas efetivas que considerem os sujeitos envolvidos nas interações com } \\
\text { esta língua em diferentes contextos sociais. }\end{array}$ \\
\hline
\end{tabular}

PALAVRAS-CHAVE libras; discurso; associações; comunicação; educação continuada 
TítuLo

\section{Melhoria da Qualidade e Produtividade na Construção Civil}

\begin{tabular}{ll} 
COORDENAÇÃO & Jose Carlos Paliari \\
SETOR & Departamento de Engenharia Civil \\
\hline
\end{tabular}

CONTATO deciv@ufscar.br

RESUMO São objetivos deste programa disseminar a aplicação dos resultados práticos mais recentes da pesquisa acadêmica, no campo de atuação dos docentes do DECiv; estreitar a relação entre os docentes do DECiv e o setor produtivo, bem como a sociedade em geral, no sentido de contribuir para a melhoria dos processos. Há parcerias com empresas construtoras, indústrias de materiais e componentes para construção civil, empresas de projetos, prefeituras municipais, Poder Judiciário, empresas de planejamento de empreendimentos, usuários de edificações, entre outros. produtividade; construção; comunicação; educação profissional 
Título Núcleo de Eventos UFSCar Sorocaba

COORDENAÇÃo Telma Darn

SETOR Departamento de Geografia, Turismo e Humanidades

CONTATO dgth@ufscar.br

RESUMO O presente programa surgiu a partir das várias demandas de eventos ocorridas desde a implantação da UFSCar Sorocaba como por exemplo Calourada, visita do Presidente da República, visita do Ministro do Turismo, Workshop, entre outros. A criação de um Núcleo de Eventos atenderá não só as demandas já existentes, como também, poderá atuar na captação e criação de novos eventos.

PALAVRAS-CHAVE eventos; comunicação; social; comunicação; turismo

DATA INÍCIO 2 22/11/2006 
Título Núcleo Ouroboros de Divulgação Científica

COORDENAÇÃo André Farias de Moura

SETOR Departamento de Química

CONTATO dqchefe@ufscar.br

RESUMO O programa Núcleo Ouroboros de Divulgação Científica surge para reunir todos os projetos em andamento desde 2005 relacionados às montagens teatrais do grupo Ouroboros do Departamento de Química da UFSCar, bem como os projetos de realidade virtual e aumentada, jogos interativos, programas e sistemas em plataforma Linux, atividades de divulgação científica para crianças, teatro e ilustrações científicas para a comunidade, bem como festivais e eventos promovidos pelo Núcleo como o Ciência em Cena e o I Festival Ouroboros de teatro e divulgação científica. Além do mais, oficinas de ciências, projetos de ciência inclusivos para pessoas com deficiência visual e auditiva, produção literária, exposições e mostras também farão parte desse programa.

PALAVRAS-CHAVE divulgação científica; letramento científico; educação inclusiva; comunicação; produção e difusão de material educativo

DATA INÍCIO

$13 / 4 / 2011$ 


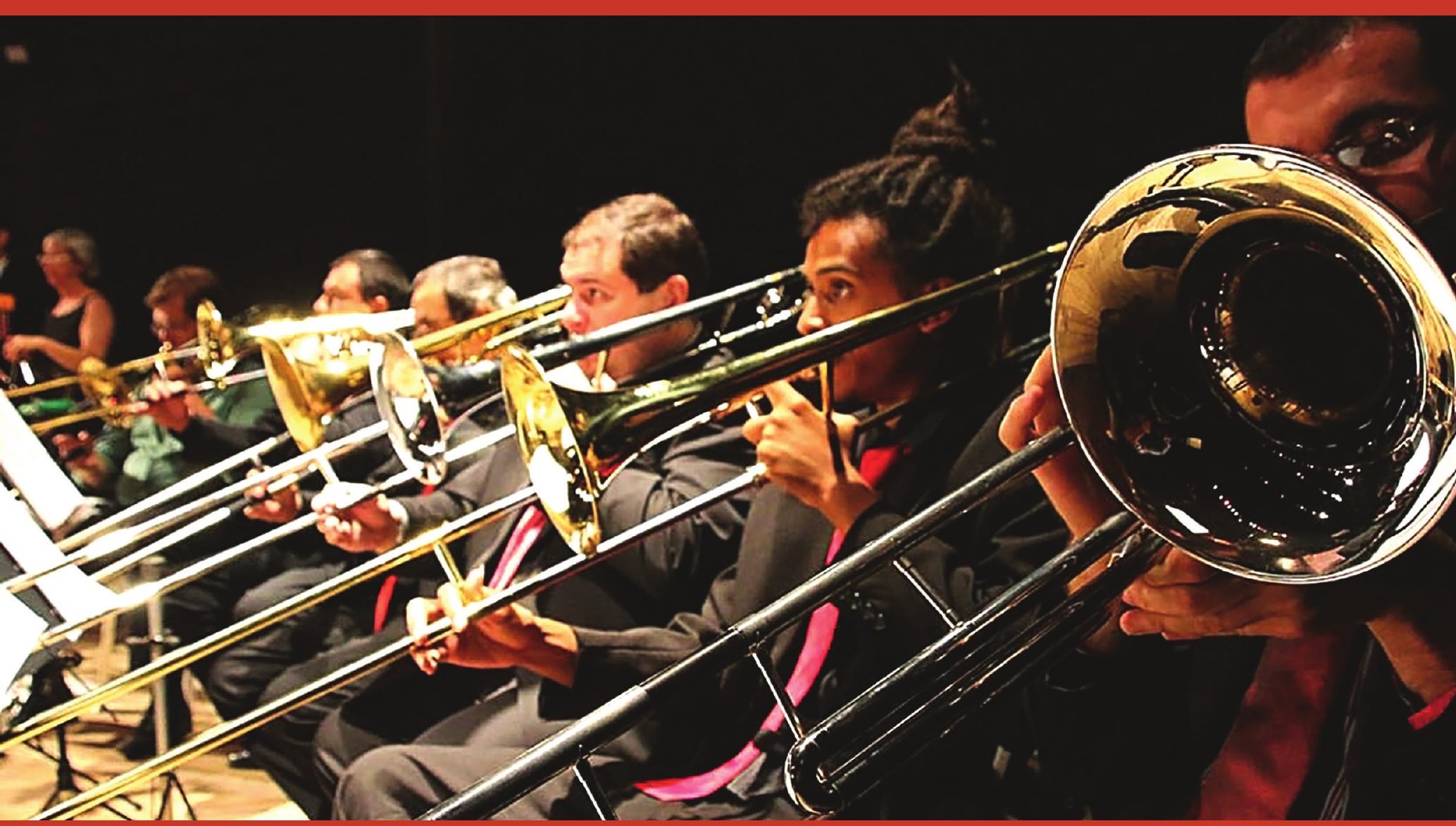

Apresentação da Orquestra Experimental da UFSCar.

Foto: Vinicius Sampaio. 
Título

\section{Atividade Humana, Produção Artístico-Cultural e Terapia Ocupacional}

\begin{tabular}{ll} 
COORDENAÇÃo & Carla Regina Silva \\
\hline SETOR & Departamento de Terapia Ocupacional \\
\hline CONTATO & chdto@ufscar.br
\end{tabular}

RESUMO Este programa pauta-se na indissociabilidade entre ensino, pesquisa e extensão e pretende abarcar distintas atividades que promovam a formação, a investigação e a intervenção acerca das atividades humanas, tecnologias e dos recursos na Terapia Ocupacional. As atividades desenvolvidas devem apresentar proposições entre dois eixos de trabalho: o primeiro refere-se à integração entre práticas e conhecimentos produzidos sobre as atividades e os recursos, promovendo diferentes possibilidades às populações-alvo da Terapia Ocupacional; o segundo está voltado para a formação em espaços de criação ética-estética-política que fomentem a capacitação dos estudantes do instrumental diversificado possível de ser utilizado na Terapia Ocupacional.

PALAVRAS-CHAVE atividade humana; produção artístico-cultural; formação; cultura; educação profissional 
Título Bolha Cultural

COORDENAÇão Alissandra Nazareth de Carvalho

SETOR Departamento de Geografia, Turismo e Humanidades

CONTATO dgth@ufscar.br

RESUMO O programa visa difundir e estimular manifestações artísticas e culturais, através de um espaço cultural interativo e que permita a inserção e integração de todos, sociedade e academia. 


\section{título Comunicação, Arte e Cultura em Araras}

\begin{tabular}{|c|c|}
\hline COORDENAÇÃO & Marta Cristina Marjotta Maistro \\
\hline SETOR & Centro de Ciências Agrárias \\
\hline CONTATO & ccadir@cca.ufscar.br \\
\hline RESUMO & $\begin{array}{l}\text { O programa visa articular ações das áreas de comunicação, informação, cultura, } \\
\text { arquitetura e arte em torno da promoção cultural do Centro de Ciências Agrárias } \\
\text { (CCA) da UFSCar. A relevância do programa está pautada no vasto campo de } \\
\text { pesquisa que podem representar as edificações remanescentes da Fazenda Santa } \\
\text { Escolástica (onde foi instalado o extinto Instituto do Açúcar e do Álcool e que veio } \\
\text { a abrigar o campus da UFSCar em 1990) para várias áreas do conhecimento, na } \\
\text { necessidade do estabelecimento de um ambiente cultural no campus de Araras e na } \\
\text { criação de espaços adequados para fins de eventos culturais e artísticos no local, } \\
\text { hoje inexistentes. As atividades de comunicação e cultura têm se mostrado cada } \\
\text { vez mais essenciais para a formação dos alunos e para a integração da Universidade } \\
\text { com a população local. }\end{array}$ \\
\hline
\end{tabular}

PALAVRAS-CHAVE Comunicação; arte; araras; cultura; mídia comunitária

DATA INÍCIO $\quad 5 / 6 / 2013$




\section{TíTULo \\ Espaços Públicos, Cidadania e Cultura \\ - Gestão, Desenvolvimento de Ações e Qualificação de Agentes Sociais}

\begin{tabular}{ll} 
COORDENAÇÃo & Rita de Cassia Lana \\
\hline SETOR & Departamento de Geografia, Turismo e Humanidades \\
\hline CONTATO & dgth@ufscar.br \\
\hline RESUMO & $\begin{array}{l}\text { O programa justifica-se pelo entendimento de que a dimensão do espaço público } \\
\text { constitui-se por elementos sócio-econômicos, políticos, fisico-culturais, etc.; } \\
\text { assim, comporta reflexões críticas e saberes multidisciplinares que estimulem } \\
\text { outros modos de compreensão e interferência crítica na realidade brasileira. Neste } \\
\text { sentido, o programa visa permitir a realização de ações do corpo docente e técnico- } \\
\text { administrativo do DGTH, além de especialistas convidados, para que se articulem } \\
\text { membros da comunidade acadêmica da UFSCar e da sociedade de forma ampla. }\end{array}$ \\
\hline
\end{tabular}


Título

Formação e Educação Continuada em Literaturas de Língua Portuguesa

\begin{tabular}{ll} 
COORDENAÇÃO & Jorge Vicente Valentim \\
\hline SETOR & Departamento de Letras
\end{tabular}

CONTATO dl@ufscar.br

RESUMO O programa tem como objetivo proporcionar atividades de extensão específicas da área de literaturas de língua portuguesa (Brasil, Portugal e África). Em virtude do crescente interesse discente em pesquisa e extensão, ligadas a temas dos estudos literários, a área propõe um espaço de execução e consolidação de suas respectivas atividades.

PALAVRAS-CHAVE literatura; lusofonia; literaturas de língua portuguesa; cultura; educação continuada 
Tírulo Informação, Arquivo e Memória

\begin{tabular}{ll} 
COORDENAÇÃo & Maria Cristina Innocentini Hayashi \\
\hline SETOR & Departamento de Ciência da Informação \\
\hline CONTATO & dci@ufscar.br \\
\hline RESUMO & $\begin{array}{l}\text { Identificação, organização, conservação e preservação de acervos documentais } \\
\text { históricos; construção de fontes de informação e pesquisa histórica, visando o } \\
\text { resgate e disseminação da cultura e memória social. }\end{array}$ \\
\hline PALAVRAS-CHAVE & informação; memória; cultura; cultura e memória social \\
\hline DATA INÍ́CIO & $1 / 1 / 2000$
\end{tabular}




\section{Título Letramentos Múltiplos e Multiculturais}

COORDENAÇão Luiz Andre Neves de Brito

SETOR Departamento de Letras

CONTATO dl@ufscar.br

RESUMO Este programa visa fornecer subsídio a diversas atividades de extensão que já vêm sendo oferecidas, tais como: ACIEPE "Letramentos Múltiplos”; Atividades de Extensão "Estudo de Língua Portuguesa na modalidade acadêmica”, "Inglês para Graduandos Indígenas”, “Tradução Literária”; Atividade Artístico- Cultural "Caxiri na Cuia”; dentre outras atividades que possam vir a ser oferecidas dentro da temática.

PALAVRAS-CHAVE letramento; multiculturalismo; linguagens; cultura; comunicação escrita e eletrônica DATA INÍCIO 9/1/2013 


\section{Título Música Popular: História, Performance e}

\section{Ensino}

$\begin{array}{ll}\text { COORDENAÇÃo } & \text { Thais dos Guimaraes Alvim Nunes } \\ \text { SETOR } & \text { Departamento de Artes e Comunicação }\end{array}$

CONTATO dac@ufscar.br

RESUMO O programa de extensão destina-se a abrigar projetos, planos e atividades ligados à música popular, oferecidos tanto à comunidade interna quanto externa da universidade. Seus principais objetivos consistem em divulgar o repertório, contribuir para a formação de cantores e instrumentistas e propiciar espaço de reflexão estética, histórica e performática sobre a música popular. Entende-se que o ensino desse repertório, bem como a reflexão crítica sobre ele ainda ocupa um espaço marginal nas universidades brasileiras, a despeito da grande relevância que essa música passou a ter ao longo de sua história. Nesse sentido, a UFSCar poderia contribuir no sentido de suprir, ao menos em âmbito local, essas carências, uma vez que já possui um corpo de docentes com formação nessa área.

PALAVRAS-CHAVE música popular; ensino de música; performance musical; cultura; produção cultural e artística na área de música e dança 
Título

\section{Núcleo de Atividades de Lazer, Esporte e Cidadania - NALEC}

\begin{tabular}{ll} 
COORDENAÇÃo & Heros Augusto Santos Lobo \\
\hline SETOR & Departamento de Geografia, Turismo e Humanidades
\end{tabular}

CONTATO dgth@ufscar.br

RESUMO O NALEC tem como princípio norteador a geração e articulação de atividades e projetos que proporcionem oportunidades de atividades de lazer e de cunho esportivo, envolvendo a UFSCar, o poder público e a sociedade civil organizada. O objetivo geral é fomentar e democratizar o acesso às práticas de lazer e esportiva, visando tanto o caráter recreativo quanto o formativo educacional. As justificativas do NALEC se embasam na possibilidade de promoção de aspectos fundamentais para uma sociedade equilibrada, tais como: a inclusão social, a saúde física e mental, a conscientização de princípios sócio-educativos (cooperação, emancipação, participação, regionalismo) e a melhora do condicionamento físico. 


\title{
TíTULO \\ Programa de Preservação da Memória da UFSCar
}

$\begin{array}{ll}\text { COORDENAÇÃo } & \text { Luciana de Souza Gracioso } \\ \text { SETOR } & \text { Departamento de Ciência da Informação }\end{array}$

CONTATO dci@ufscar.br

RESUMO

\begin{abstract}
A relevância consiste em reunir e possibilitar uma melhor articulação entre os diversos grupos que promovem as atividades de extensão no campo da memória entendendo que esta é uma área interdisciplinar por natureza. Configura-se como área estratégica para a Universidade uma vez que seu quadro de docentes e funcionários tem se renovado e ampliado. A preservação da memória institucional permite o auto conhecimento institucional e também o conhecimento mútuo entre os campi sobre seu patrimônio material e imaterial, alarga a compreensão da sociedade sobre a Universidade, sua história, sua missão e sua função social. 0 programa, ao promover, acolher e sistematizar diferentes propostas no âmbito da memória, contribuirá para o efetivo estabelecimento de políticas de preservação da memória e cultura institucional. o programa fomenta a identificação, organização, divulgação e a popularização, em diferentes esferas, do patrimônio material (acervos, coleções, produção cientifica) e imaterial (as histórias orais, a cultura e os saberes institucionalizado). O acesso a esses conteúdos pode atrair a comunidade para a Universidade e ao mesmo tempo sugerir um sentimento de pertencimento da sociedade em relacao as ações da Universidade.
\end{abstract}


tírulo Tecnologia, Cultura e Sociedade

COORDENAÇão Teresa Mary Pires de Castro Melo

SETOR Departamento de Ciências Humanas e Educação

CONTATO dche@ufscar.br

RESUMO A proposta do presente Programa vem contemplar uma área da Extensão que reúna atividades relativas às relações entre sociedade, cultura e tecnologias, entendendo que os processos e linguagens tecnológicas contribuem para as elaborações das realidades sociais e suas decorrentes culturas e por elas são elaborados. 


\section{Direitos Humanos}

\section{e Justiça}

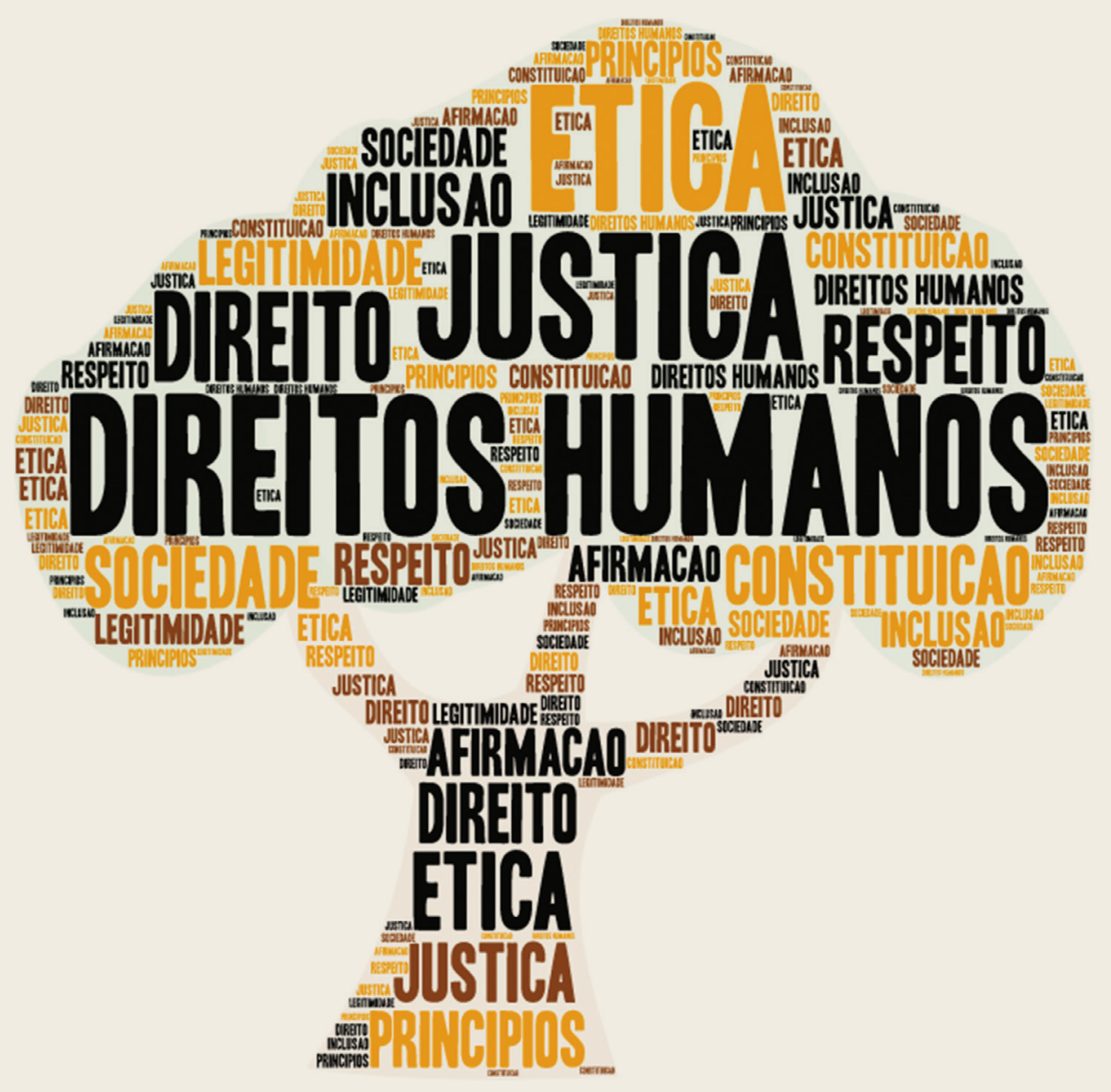

Ilustração: João Vitor Costa de Brito e Mateus Limeira. 
TíTuLo Educação das Relações Étnico-Raciais

COORDENAÇÃo Tatiane Cosentino Rodrigues

SETOR Departamento de Teorias e Práticas Pedagógicas

CONTATO dtpp@ufscar.br

RESUMO O programa tem como objetivo promover ações de formação continuada de profissionais de educação, produção e difusão de materiais sobre o ensino de história e cultura afro-brasileira e africana, como preveem os documentos normativos para a educação das relações étnico-raciais, Diretrizes Curriculares para a educação das relações étnico-raciais, para o ensino de história e cultura afro-brasileira e aficana e o plano nacional de implementação destas Diretrizes Curriculares.

PALAVRAS-CHAVE I educação; relações étnico-raciais; brasil áfrica; direitos humanos e justiça; educação continuada 
Título METUIA - Terapia Ocupacional Social

COORDENAÇÃo Roseli Esquerdo Lopes

SETOR Departamento de Terapia Ocupacional

CONTATO chdo@ufscar.br

RESUMO O Projeto METUIA - Grupo interinstitucional de estudos, formação e ações pela cidadania de crianças, adolescentes, jovens e adultos em processos de ruptura das redes sociais de suporte - tem sido importante articulador de ações e reflexões acerca da terapia ocupacional social. Criado em 1998 por docentes da Pontifícia Universidade Católica de Campinas, da Universidade Federal de São Carlos (UFSCar) e da Universidade de São Paulo (USP), sua proposta tem sido a de desenvolver projetos no âmbito do ensino, da pesquisa e da extensão em terapia ocupacional social. Em 1999, foram criados os Núcleos USP/UFSCar e Campinas do Projeto METUIA e, em 2004, o Núcleo UFSCar do METUIA. Atualmente, existem quatro núcleos do METUIA - Terapia Ocupacional Social, no Brasil: os núcleos das Universidades Federais de São Carlos (em São Carlos/SP), de São Paulo (em Santos/ SP) e do Espírito Santo (em Vitória/ES) e o da Universidade de São Paulo (em São Paulo/SP). Uma face importante das atividades é o programa de intervenção de terapia ocupacional em suas interconexões com a esfera social; esta intervenção se dá em espaços públicos, espaços comunitários e instituições sociais, envolvendo populações em processo de ruptura de redes sociais de suporte. Trabalha-se na construção de bases para a elaboração de programas terapêutico-ocupacionais na área social, bem como na sua experimentação prática, constituídos a partir de uma apreensão aprofundada dos sujeitos, individuais e coletivos, aos quais é direcionada a ação.

PALAVRAS-CHAVE T Terapia ocupacional social; redes sociais de suporte; território e comunidade; direitos humanos e justiça; direitos de grupos sociais 


\section{тіт́то Nas Margens: Diálogos em Sociologia} Urbana, Desigualdades e Diferença

\begin{tabular}{|c|c|}
\hline COORDEN & Gabriel de Santis Feltran \\
\hline SETOR & Departamento de Sociologia \\
\hline CONTATO & ds@ufscar.br \\
\hline RESUMO & $\begin{array}{l}\text { As desigualdades e diferenças têm sido centrais para pensar dilemas políticos } \\
\text { e sociais contemporâneos. Há, no entanto, um descompasso notável entre a } \\
\text { reflexão acadêmica sobre essas temáticas, concentrada nas Ciências Humanas, e } \\
\text { a formação dos profissionais de ação direta junto às populações mais privadas de } \\
\text { direitos. O presente programa visa a formentar esse diálogo de saberes, integrando } \\
\text { as atividades de Ensino, Pesquisa e Extensão promovidas pelos docentes do } \\
\text { Departamento de Sociologia, através da proposição de encontros de formação entre } \\
\text { os saberes acadêmicos e de profissionais que atuam diretamente junto a populações } \\
\text { social, econômica ou politicamente desfavorecidas. }\end{array}$ \\
\hline
\end{tabular}

PALAVRAS-CHAVE Sociologia; desigualdades; diferença; direitos humanos e justiça; desenvolvimento urbano 
тітuцо Observatório Quilombola Evamariô

COORDENAÇÃo Lourdes de Fatima Bezerra Carril

SETOR Departamento de Geografia, Turismo e Humanidades

CONTATO dgth@ufscar.br

RESUMO Constituição do Observatório Quilombola Evamariô, vinculado ao Curso de Licenciatura em Geografia, na UFSCar, numa plataforma online, com apoio institucional. Disponibilizar publicamente os resultados das pesquisas, situação atual; a construção de dados e indicadores sócio-econômicos e territoriais, georreferenciados, dos quilombos da região. Considera-se fundamental apreender a realidade sócio-territorial e cultural dos quilombos da Região Metropolitana de Sorocaba e contribuir à compreensão da formação da sociedade brasileira, combater o racismo, apoiar direitos e uma pedagogia crítica voltada à educação quilombola.

PALAVRAS-CHAVE Território; educação; quilombola; direitos humanos e justiça; direitos de grupos sociais 


\section{Orientação e Avaliação de Políticas Públicas para a Construção da Cidadania 2}

\begin{tabular}{ll} 
COORDENAÇÃO & Maria Ines Rauter Mancuso \\
SETOR & Departamento de Sociologia \\
\hline CONTATO & ds@ufscar.br
\end{tabular}

RESUMO Estimular projetos que criem ou contribuam para criar condições para o pleno exercício da cidadania; e que visem a produção e sistematização de conhecimentos para a definição e implementação de políticas públicas.

PALAVRAS-CHAVE orientação; políticas públicas; cidadania; direitos humanos e justiça; capacitação de gestores de políticas públicas 


\section{Tírulo Relações Étnico-raciais em Educação, Saúde e Territorialidades}

COORDENAÇÃo Rosana Batista Monteiro

SETOR Departamento de Ciências Humanas e Educação

CONTATO dche@ufscar.br

RESUMO O Programa “Relações étnico-raciais em Educação, Saúde e Territorialidades” articula a necessidade da universidade envolver-se com a avaliação e acompanhamento de programas e políticas públicas relacionadas ao combate do racismo na sociedade brasileira. A partir da pesquisa acadêmica objetiva-se propor ações articuladas que promovam a implementação efetiva do conjunto de políticas relacionadas aos direitos humanos e justiça, como, por exemplo, as ações afirmativas, delimitadas nos últimos anos. Tendo em vista o público-alvo, os objetivos específicos referem-se à proposição de atividades relacionadas a promoção da igualdade étnica e racial no âmbito da educação, da saúde e da cidadania e justiça (território).

PALAVRAS-CHAVE racismo; políticas públicas; desigualdades sociais; direitos humanos e justiça; direitos de grupos sociais 
4

\section{Eduraßão}

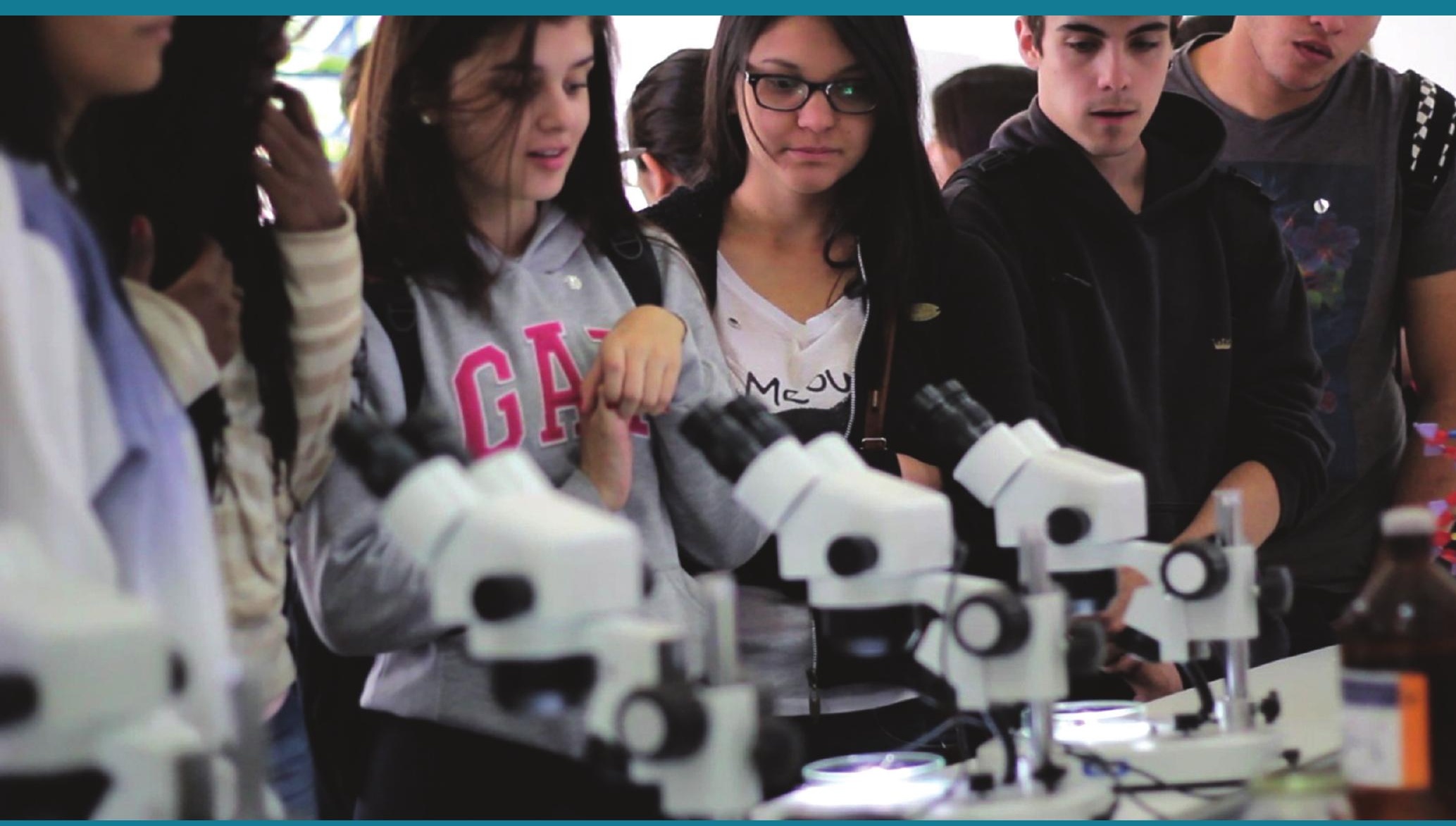

Projeto Porteiras Abertas - Campus Lagoa do Sino.

Foto: Tiago Santi. 
TítuLo

\section{A Produção do Conhecimento na Universidade: Contribuições para a Formação Inicial e Continuada de Professores}

\begin{tabular}{ll} 
COORDENAÇÃo & Renata Sebastiani \\
\hline SETOR & Departamento de Ciências da Natureza, Matemática e Educação \\
\hline CONTATO & denme@cca.ufscar.br \\
\hline RESUMO & $\begin{array}{l}\text { A popularização da ciência envolve um processo contínuo de produção e divulgação } \\
\text { do conhecimento científico. Se por um lado a universidade é um dos principais } \\
\\
\text { centros de produção do conhecimento, por outro lado está diretamente envolvida } \\
\text { na formação de professores, tornando-se assim um ambiente propício para a } \\
\text { relação entre esses dois eventos. } \\
\text { O presente programa tem como objetivo favorecer a implantação de projetos } \\
\text { relacionados à produção de conhecimento e sua consequente contribuição para a } \\
\text { formação de professores. Através desse programa pretende-se também favorecer } \\
\text { a discussão sobre dificuldades e necessidades de docentes do Ensino Básico e a } \\
\text { aproximação entre a comunidade e a universidade. }\end{array}$ \\
\end{tabular}

PALAVRAS-CHAVE educação; ensino básico; formação continuada; educação; educação continuada 


\section{Educațão}

título Acessibilidade é Direito

COORDENAÇÃo Rosimeire Maria Orlando

SETOR Departamento de Psicologia

CONTATO dpsic@ufscar.br

RESUMO Por meio do Decreto 6949/2009 (BRASIL, 2009) o Brasil promulga a Convenção Internacional sobre os Direitos das Pessoas com Deficiência, e põe em destaque, a igualdade de oportunidades e à acessibilidade. Nesta direção, a Universidade Federal de São Carlos cria a Secretaria Geral de Ações Afirmativas, órgão de apoio administrativo vinculado à Reitoria,responsável pelo estabelecimento e implementação de políticas de ações afirmativas, diversidade e equidade e aprova sua estrutura. As ações de extensão deste Programa, em parceria com o Incluir - Núcleo de Acessibilidade da UFSCar, que compõe a Coordenadoria de Direitos Humanos e Inclusão, têm como objetivo promover ações de acessibilidade de estudantes da Educação Especial, matriculados na UFSCar.

PALAVRAS-CHAVE educação especial; acessibilidade; ensino superior; educação; educação especial 
TíTULO

\section{Acessibilidade e Língua Brasileira de Sinais: dos Processos Formativos Vivenciados na Educação Básica aos Recursos e Técnicas para Acesso na Educação Superior}

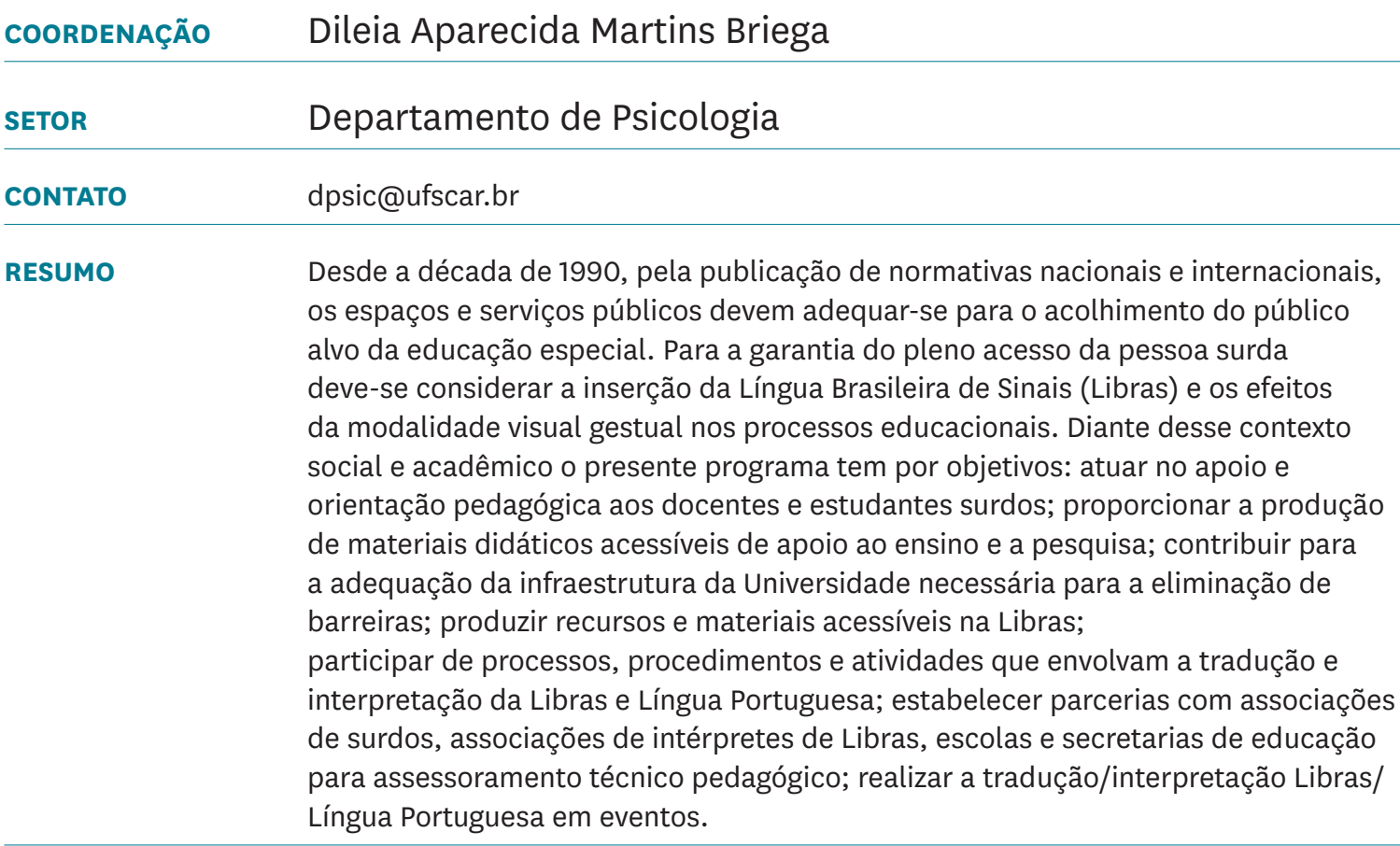




\section{Educacã̃o}

TítuLo

\section{Ações e Reflexões em Educação e Educação} Musical

\begin{tabular}{ll} 
COORDENAÇÃo & Fernando Stanzione Galizia \\
\hline SETOR & Departamento de Metodologia de Ensino
\end{tabular}

CONTATO deme@ufscar.br

RESUMO Este Programa de Extensão buscará abarcar e coordenar diversas ações/ atividades extensionistas em Educação e Educação Musical na UFSCar, respeitando as particularidades das linhas de atuação dos professores do Departamento de Metodologia de Ensino e possibilitando a realização de trabalhos interdepartamentais e interdisciplinares. O Programa foi criado com a intenção de estimular as ações extensionistas, bem como reflexões e produções acadêmicas sobre as mesmas dos professores da área de música/educação musical da UFSCar e de outras IES, com ou sem a participação de alunos de graduação. Por fim, os projetos a serem desenvolvidos no âmbito deste programa podem ter como foco a utilização de novas tecnologias em educação e música, em ações presenciais ou a distância.

PALAVRAS-CHAVE educação; educação musical; música; educação; cooperação interinstitucional 


\section{Educațão}

\begin{tabular}{|c|c|}
\hline TítuLo & Alfabetização: Saberes e Cidadania \\
\hline COORDENAÇÃO & Claudia Raimundo Reyes \\
\hline SETOR & Departamento de Teorias e Práticas Pedagógicas \\
\hline CONTATO & dtpp@ufscar.br \\
\hline RESUMO & $\begin{array}{l}\text { Resultados do Sistema Nacional de Avaliação da Educação Básica (SAEB), de } 2003 \text {, } \\
\text { demonstram que } 59 \% \text { os alunos da } 4 \text { a série do ensino fundamental apresentam } \\
\text { sérias limitações em seu aprendizado da leitura e da escrita, revelando ainda que o } \\
\text { trabalho desenvolvido nas escolas não tem sido suficiente para garantir às crianças } \\
\text { o direito de saber ler e escrever, para exercerem sua cidadania; motivo pelo qual } \\
\text { justificamos a necessidade de implantar um programa cujo objetivo é contribuir } \\
\text { com a melhoria da qualidade do ensino, tanto no que diz respeito à formação do } \\
\text { professor, quanto da aprendizagem do aluno. }\end{array}$ \\
\hline
\end{tabular}

alfabetização; cidadania; letramento; educação; ensino fundamental 
TíTULO

\section{Análise Comportamental da Cultura, Linguagem e Comportamento Simbólico - CLICS}

\begin{tabular}{|c|c|}
\hline SETOR & Departamento de Psicologia \\
\hline CONTATO & dpsic@ufscar.br \\
\hline RESUMO & $\begin{array}{l}\text { O Grupo de Pesquisa em Análise Comportamental da Cultura, Linguagem e } \\
\text { Comportamento simbólico desenvolve pesquisa com base no modelo de relações de } \\
\text { equivalência e molduras relacionais, que fornece uma abordagem comportamental } \\
\text { ao funcionamento simbólico. Este modelo permite uma abordagem integrada do } \\
\text { comportamento simbólico, linguagem e cultura. As atividades de pesquisa do grupo } \\
\text { têm despertado interesse entre estudantes de graduação e pós-graduação de várias } \\
\text { regiões do país. Assim, o Grupo de Pesquisa pretende desenvolver atividades de } \\
\text { divulgação e disseminação do conhecimento produzido, voltadas para estudantes } \\
\text { de graduação, pós-graduação e profissionais de psicologia e áreas afins. Entre as } \\
\text { atividades destacam-se a manutenção de um blog para divulgação do conhecimento } \\
\text { e a realização de cursos com a mesma finalidade. }\end{array}$ \\
\hline
\end{tabular}




\section{Educațão}

\section{TítULo \\ Anatomia Humana: Pesquisa, Ensino e Divulgação Científica}

COORDENAÇÃo Luiz Fernando Takase

SETOR Departamento de Morfologia e Patologia

CONTATO dmp@ufscar.br

RESUMO Neste programa serão desenvolvidas atividades de extensão relacionadas a pesquisa, ensino e divulgação da Anatomia Humana, disciplina fundamental para a formações de profissionais de todos os cursos das áreas Biológicas e da Saúde. Alunos do ensino fundamental, médio e técnico poderão ampliar seus conhecimentos sobre o corpo humano através de exposições teórico-práticas sobre os diversos sistemas orgânicos. A comunidade universitária (docentes, técnicos, alunos de graduação e pós-graduação) poderá ampliar e/ou aprofundar seus conhecimentos anatômicos através de palestras, discussões dirigidas, treinamentos e oficinas. anatomia humana; ensino; corpo humano; educação; educação de jovens e adultos 


\section{Educacã̃o}

Título

\section{Apoio à Formação Educacional e Político- Gerencial de Profissionais de Saúde}

\begin{tabular}{ll} 
COORDENAÇÃO & Valeria Vernaschi Lima \\
\hline SETOR & Departamento de Medicina \\
\hline CONTATO & dmed@ufscar.br \\
\hline RESUMO & $\begin{array}{l}\text { Visa atender à necessidade emergente de melhorar os processos de formação de } \\
\text { profissionais de Saúde, estimulada pelos Ministérios da Saúde e da Educação. }\end{array}$ \\
\hline PALAVRAS-CHAVE & $\begin{array}{l}\text { aprendizagem de adultos; metodologias ativas de aprendizagem; educação em saúde; } \\
\text { educação; educação continuada }\end{array}$ \\
\hline DATA INÍCIO & \begin{tabular}{l} 
10/9/2007 \\
\hline
\end{tabular}
\end{tabular}




\section{Educacẫo}

TítuLo

Aprendizagem e Desenvolvimento Profissional da Docência: Formação de Professores da Educação Básica e Outros Agentes Educacionais

\begin{tabular}{ll} 
COORDENAÇÃo & Aline Maria de Medeiros Rodrigues Reali \\
\hline SETOR & Departamento de Metodologia de Ensino \\
\hline CONTATO & deme@ufscar.br \\
\hline RESUMO & $\begin{array}{l}\text { Investigar e intervir junto a professores da educação básica e outros agentes } \\
\text { educacionais, por meio de ações presenciais e virtuais, visando a promoção de seu } \\
\text { desenvolvimento profissional. }\end{array}$ \\
\hline PALAVRAS-CHAVE & $\begin{array}{l}\text { formação de professores; desenvolvimento profissional; professores; educação; } \\
\text { educação continuada }\end{array}$ \\
\hline DATA INÍcIO & 24/9/2008 \\
\hline
\end{tabular}


TítuLo

Atividade De Ensino: Expressão da Unidade Teoria e Prática na Formação de Professores

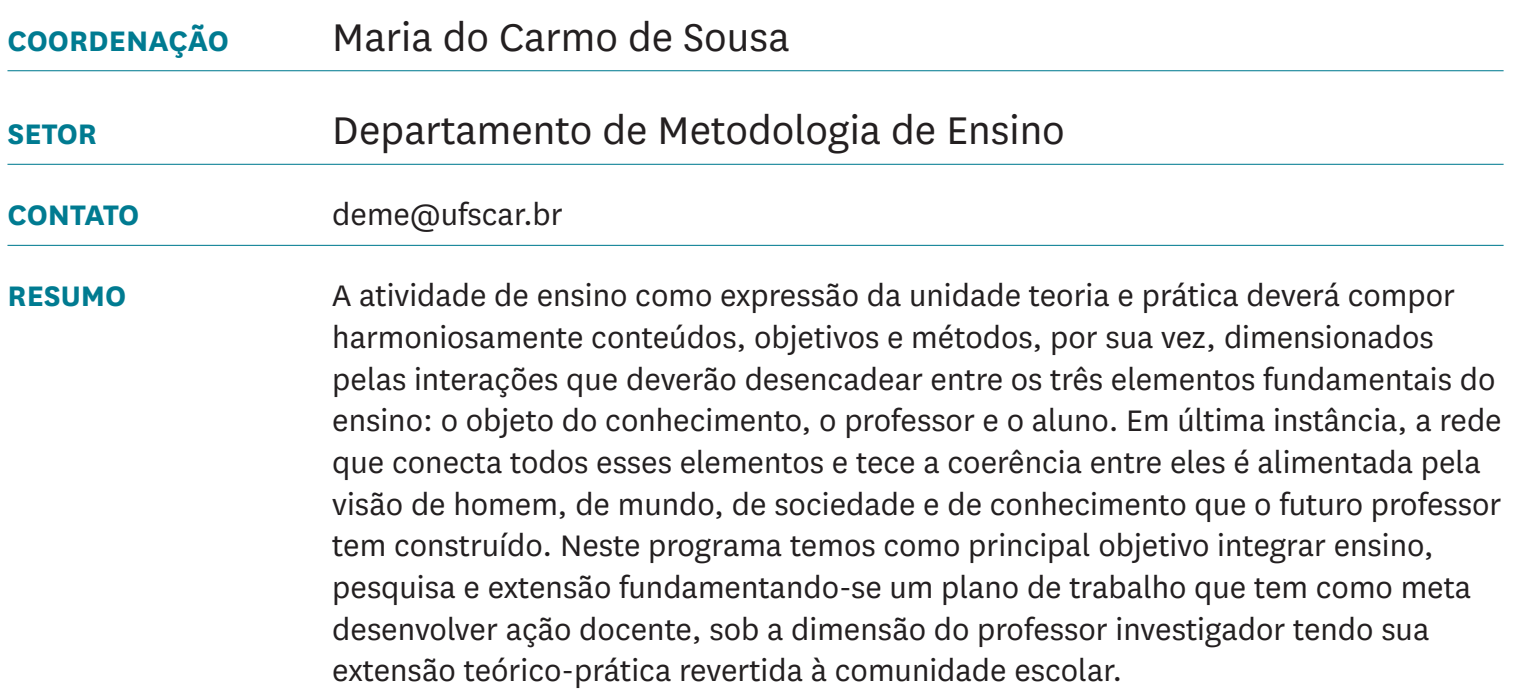

PALAVRAS-CHAVE teoria da atividade; formação inicial; formação continuada; educação; educação continuada 


\section{Educacẫo}

TíTULO

\section{Atividades de Assessoria e Desenvolvimento de Projetos do Laboratório de Pesquisas em Eletroquímica}

\begin{tabular}{ll} 
COORDENAÇÃo & Romeu Cardozo Rocha Filho \\
\hline SETOR & Departamento de Química \\
\hline CONTATO & dqchefe@ufscar.br \\
\hline RESUMO & $\begin{array}{l}\text { Os principais objetivos do programa são, sempre que demandado: realizar } \\
\text { assessorias nas áreas de Eletroquímica e de uso de bases de dados científicas } \\
\text { (Web of Knowledge, Scopus etc.); desenvolver projetos específicos na área de } \\
\text { Eletroquímica. }\end{array}$ \\
\hline PALAVRAS-CHAVE & $\begin{array}{l}\text { eletroquímica; bases de dados científicas; assessoria tecnocienciometrica; } \\
\text { educação; inovação tecnológica }\end{array}$ \\
\hline DATA INíCIO & $26 / 6 / 2013$ \\
\hline
\end{tabular}




\section{Educacã̃o}

\section{Título Biblioteca Comunitária}

\begin{tabular}{ll} 
COORDENAÇÃO & Ligia Maria Silva e Souza \\
\hline SETOR & Biblioteca Comunitária \\
\hline CONTATO & bco@ufscar.br \\
\hline RESUMO & $\begin{array}{l}\text { Objetivos: Promover a biblioteca, o livro e a leitura através de atividades que } \\
\text { conquistem pelo prazer e inovação; disponibilizar os recursos da BCo e da UFSCar, } \\
\text { buscando o envolvimento com a comunidade externa. }\end{array}$
\end{tabular}

PALAVRAS-CHAVE biblioteca; livro; educação; educação continuada

DATA INÍCIO 12/7/1999




\section{Educațão}

тітицо C2Y! - Computing for You!

COORDENAÇÃo Luciana Aparecida Martinez Zaina

SETOR Departamento de Computação

CONTATO dcomp@ufscar.br

RESUMO O presente programa tem por objetivo motivar a execução de atividades que disseminem para sociedade em geral a criatividade através do pensamento computacional. O estudo da Computação permite que diferentes habilidades cognitivas sejam desenvolvidas, tais como: raciocínio lógico-matemático, desenvolvimento da comunicação através de linguagens, visões gerais e particulares de conceitos diversos, estratégias para resolução de problemas, entre outros. Para atingir tal objetivo, serão oferecidos workshops, cursos, palestras e atividades voltadas à imersão de crianças e adultos ao mundo da Computação.

computação; criatividade; educação; educação; educação continuada 


\section{Educațão}

Tírulo Ciência e Subjetividade

COORDENAÇÃo Georgina Carolina de Oliveira Faneco Maniakas

SETOR Departamento de Psicologia

CONTATO dpsic@ufscar.br

RESUMO O programa objetiva: refletir sobre o estatuto e a prática da ciência na sociedade contemporânea, contemplando as dimensões objetiva e subjetiva implicadas no processo de construção do conhecimento; apresentar e publicar os produtos teóricos e/ou os desdobramentos práticos dessa atividade de extensão em congressos, simpósios, encontros, reuniões temáticas, entre outros.

PALAVRAS-CHAVE ciência; subjetividade; educação; educação continuada

DATA INÍCIO

$19 / 11 / 2004$ 


\section{Educațão}

Título Ciência, Tecnologia e Sociedade (CTS)

COORDENAÇÃo Camila Carneiro Dias Rigolin

SETOR Departamento de Ciência da Informação

CONTATO dci@ufscar.br

RESUMO A relevância social e acadêmica do programa relaciona-se à necessidade de oferecer às comunidades internas e externas, elementos conceituais do campo dos Estudos Sociais da Ciência e da Tecnologia que adquiram concretude no contexto da sociedade tecnocientífica e proporcionem a reflexão sobre a dinâmica da produção científica e tecnológica, a percepção pública da atividade tecnocientífica, a construção de políticas públicas de Ciência \& Tecnologia, o ensino de ciências e tecnologia, a pesquisa e o desenvolvimento, a sustentabilidade, a inovação, a responsabilidade social, a consciência sobre a produção e circulação de saberes, a cidadania e a democratização dos meios de produção.

PALAVRAS-CHAVE ciência, tecnologia e sociedade; divulgação científica; comunicação científica; educação; produção e difusão de material educativo 
TítuLo

\section{Clínica Fitossanitária para o Apoio à Identificação e Diagnose dos Principais Problemas Bióticos e Abióticos Agrícolas da Comunidade Territorial Lagoa do Sino}

\begin{tabular}{ll} 
COORDENAÇÃo & Waldir Cintra de Jesus Junior \\
\hline SETOR & Centro de Ciências da Natureza \\
\hline CONTATO & diretorccn@ufscar.br \\
\hline RESUMO & Clínicas para o apoio a produtores familiares são de extrema importância na busca \\
& por uma agricultura sustentável. Esta atividade trará ao produtor a possibilidade de \\
& O objetivo principal da clínica é se tornar referência regional quanto ao diagnóstico \\
& dos principais problemas bióticos (insetos, ácaros, fitopatógenos etc) e abióticos \\
& $\begin{array}{l}\text { (disfunções fisiológicas, fitoxicidade etc), assim como ter orientações sobre o } \\
\text { manejo do problema. A participação de discentes neste processo diagnóstico será } \\
\text { de extrema importância para a prática dos conhecimentos adquiridos em aula. }\end{array}$
\end{tabular}


TÍTULO

\section{Consultoria e Prestação de Serviços para Atendimento na Área de Deficiência Intelectual e Autismo: Institucional e Individual}

\begin{tabular}{ll} 
COORDENAÇÃO & Antonio Celso de Noronha Goyos \\
\hline SETOR & Departamento de Psicologia \\
\hline CONTATO & dpsic@ufscar.br
\end{tabular}

RESUMO

Proporcionar um campo de atuação para alunos e participantes envolvidos nos projetos de pesquisa e de prestação de serviços sob minha orientação; criar e tornar disponível conhecimentos que possam ser incorporados pela população individual e institucional envolvida no atendimento de pessoas com deficiência intelectual e autismo, através de pesquisas, atendimento clínico e educacional, consultorias, cursos, prestação de serviços, assessorias, palestras e divulgação científica. No âmbito social, o programa tem como meta principal melhorar a qualidade dos serviços educacionais e clínicos diretamente para o indivíduo com autismo e também os prestados a população que convive com estes indivíduos e das instituições prestadoras destes serviços. O programa visa atualizar o conhecimento sobre pesquisa e aplicação da tecnologia da análise comportamental gerada na área e fomentar intercâmbio acadêmico de modo a produzir projetos colaborativos de pesquisa. A ênfase do programa encontra-se em abordagens sobre o comportamento autista, mas apresenta também multidisciplinaridade envolvendo as áreas de educação, saúde, psicologia experimental, genética, medicina celular e molecular, educação física e educação especial. Pesquisadores e clínicos nacionais e internacionais participarão do programa. Consideramos o programa com importância tanto científica quanto social. A importância científica relaciona-se aos temas sobre pesquisa de ponta em desenvolvimento de linguagem e de comportamentos importantes para o desenvolvimento cognitivo e social de indivíduos com deficiência intelectual e autismo. A importância tecnológica e social é, a partir da pesquisa científica de ponta, tornar o conhecimento produzido por esta área disponível e aplicável nos setores que atendem esta população.

PALAVRAS-CHAVE $\quad$ atenção ao indivíduo; autismo ; análise do comportamento; educação; atenção a grupos de pessoas com necessidades especiais 
TítuLo

\section{Contribuições da Psicologia para o Contexto Escolar Público}

\begin{tabular}{ll} 
COORDENAÇÃo & Tania Maria Santana de Rose \\
\hline SETOR & Departamento de Psicologia \\
\hline CONTATO & dpsic@ufscar.br
\end{tabular}

RESUMO A proposta do presente Programa visa o alcance das seguintes metas: garantir a divulgação da produção do conhecimento produzido no âmbito do grupo de pesquisa Nucleo de Estudos de Motivação Acadêmica junto a professores em formação inicial e professores em serviço por meio da oferta de ACIEPES e assessorias a escolas conduzidas por estagiários do Curso de Psicologia e mestrandos e doutorandos do Programa de Pós-Graduação em Educação Especial; integrar um campo de formação de futuros psicológos para atuarem na área da Psicologia Escolar com a possibildade de experimentação e busca de compreensão do processo de implementação de práticas educativas inovadoras dirigidas para o encaminhamento de problemas reais do contexto escolar; garantir a prestação de serviços sistemáticos a escolas por meio da implementação de praticas inovadoras que visem possibilitar a participação de alunos da Educação Infantil e do Ensino Fundamental em vivências ou oportunidades de ensino dirigidas para o enriquecimento da formação dos alunos, bem como a melhoria do aproveitamento acadêmico e da relação estabelecida com a escola.

PALAVRAS-CHAVE formação de psicólogos; formação de professores; ensino fundamental; educação; ensino fundamental 


\section{Educațão}

\section{Tírulo Corpo em Educação}

COORDENAÇão Dijnane Fernanda Vedovatto Iza

SETOR Departamento de Metodologia de Ensino

CONTATO deme@ufscar.br

RESUMO O programa visa promover a formação inicial e continuada de professores, por meio de ações colaborativas entre licenciandos e professores atuantes na educação básica. 0 diálogo entre os diferentes saberes e a reflexão sobre as práticas educativas evidencia a relevância acadêmica e social desse programa, uma vez que colabora para a implementação de novas práticas pedagógicas que visam melhoria da qualidade de ensino na educação básica. A articulação entre ensino, pesquisa e extensão é o principal objetivo desse programa, que busca contribuir com a formação inicial e continuada de professores atuantes na realidade educacional.

PALAVRAS-CHAVE formação de professores; educação física; corpo e movimento; educação; educação continuada 


\section{Educacã̃o}

Título Democratização do Conhecimento e do Acesso à Educação

\begin{tabular}{ll} 
COORDENAÇÃo & Roseli Rodrigues de Mello \\
\hline SETOR & Departamento de Teorias e Práticas Pedagógicas \\
\hline CONTATO & dtpp@ufscar.br \\
\hline RESUMO & $\begin{array}{l}\text { Promover atividades educativas e culturais que possibilitem o acesso ao } \\
\text { conhecimento sistematizado. Promover projetos e atividades que estimulem a } \\
\text { participação em atividades culturais e educacionais, de pessoas e grupos que } \\
\text { sofrem exclusão social ou seu risco. Promover atividades de formação e outros } \\
\text { agentes educativos que estimulem açães profissionais voltadas para a superação } \\
\text { de exclusão escolar de segmentos que sofrem exclusão social. Desenvolver projetos } \\
\text { que contribuam para a produção de conhecimento sistematizado e escolarização } \\
\text { como via de construção de superação de exclusão social. }\end{array}$ \\
\hline
\end{tabular}




\section{TítuLo \\ Desenvolvimento de Atividades de Pesquisa, Ensino e Extensão da Fazenda Experimental Lagoa do Sino da UFSCar}

\begin{tabular}{ll} 
COORDENAÇÃo & Luiz Fernando de Oriani e Paulillo \\
\hline SETOR & Departamento de Engenharia de Produção \\
\hline CONTATO & dep@ufscar.br \\
\hline RESUMO & $\begin{array}{l}\text { Trata-se de um conjunto de atividades de ensino, pesquisa e extensão desenvolvida } \\
\text { ao longo do processo de construção do novo campus da Universidade Federal } \\
\text { de São Carlos na Fazenda Experimental Lagoa do Sino (Buri-SP), compreendendo } \\
\end{array}$ \\
$\begin{array}{l}\text { : produção e comercialização de alimentos; programas e políticas públicas de } \\
\text { segurança alimentar e de combate à miséria e à fome no Brasil; desenvolvimentos } \\
\text { de tecnologias de produção agrícola e de desenvolvimento sustentável; projetos de } \\
\text { capacitação e melhoria da agricultura familiar; programas educacionais e de apoio } \\
\text { para gestores públicos, agricultores e trabalhadores rurais. }\end{array}$
\end{tabular}

PALAVRAS-CHAVE desenvolvimento; lagoa do sino; política pública; educação; desenvolvimento rural

DATA INÍCIO $\quad$ 8/8/2011 


\section{Educacẫo}

título Desenvolvimento de Repertórios Acadêmicos

\begin{tabular}{ll} 
COORDENAÇÃo & Lidia Maria Marson Postalli \\
\hline SETOR & Departamento de Psicologia \\
\hline CONTATO & dpsic@ufscar.br \\
\hline RESUMO & $\begin{array}{l}\text { Tornar disponível, serviço de atendimento a indivíduos que necessitem corrigir } \\
\text { ou aperfeiçoar comportamento de estudos para comunidade interna e externa da } \\
\text { UFSCar. }\end{array}$ \\
\hline PALAVRAS-CHAVE & repertórios acadêmicos; educação; educação profissional \\
\hline DATA INÍCIO & \begin{tabular}{l}
$1 / 1 / 2001$ \\
\hline
\end{tabular}
\end{tabular}




\section{Desenvolvimento Territorial Sustentável na} Região do Campus Lagoa do Sino da UFSCar Suportado pelas Atividades de Extensão, Ensino e Pesquisa

\begin{tabular}{ll} 
COORDENAÇÃo & Heber Lombardi de Carvalho \\
\hline SETOR & Centro de Ciências da Natureza \\
\hline CONTATO & diretorccn@ufscar.br \\
\hline \multirow{2}{*}{ RESUMO } & $\begin{array}{l}\text { Atividades de ensino, pesquisa e extensão que serão direcionadas ao } \\
\text { desenvolvimento territorial sustentável, atreladas à continuidade do processo de } \\
\text { implantação do campus da Universidade Federal de São Carlos na Fazenda Lagoa } \\
\text { do Sino (Buri-SP), compreendendo : produção e comercialização de alimentos; } \\
\text { programas e políticas públicas de segurança alimentar e de combate à miséria } \\
\text { e à fome no Brasil; desenvolvimentos de tecnologias de produção agropecuária, } \\
\text { agroindustrial e de desenvolvimento sustentável; projetos de capacitação e melhoria } \\
\text { da agricultura familiar; programas educacionais e de apoio para gestores públicos, } \\
\text { agricultores e trabalhadores rurais. }\end{array}$ \\
\hline
\end{tabular}

PALAVRAS-CHAVE desenvolvimento; lagoa do sino; tecnologia e produção; educação; desenvolvimento rural 


\section{Educațão}

título Discursos na Rede

COORDEnAÇão Ana Silvia Couto de Abreu

SETOR Departamento de Metodologia de Ensino

CONTATO deme@ufscar.br

RESUMO O Programa pretende gerar reflexão e debate sobre os processos de autoria em tempos de Internet, a fim de melhor compreendermos os modos de formulação e circulação de discursos no espaço digital, bem como seus efeitos nas concepções e práticas de leitura e escrita no ambiente escolar. Em um momento em que muito se fala em abertura - conteúdo aberto, software livre, download de músicas, bibliotecas disponibilizadas na Internet - a autoria e os direitos autorais são, mais fortemente, postos em questão, o que traz consequências em nossos posicionamentos, enquanto leitores e autores, e enquanto formadores desses. Derivam daí debates e decisões pedagógicas sobre temas diversos, como por exemplo, a questão do plágio, tanto em seus aspectos linguísticos, discursivos, quanto em seus aspectos educacionais, éticos e legais.

PALAVRAS-CHAVE formação professores; autoria; digital; educação; educação continuada

DATA INÍCIO $8 / 12 / 2008$ 


\section{Educațão}

\section{Tírulo Divulgação Científica em Educação}

COORDENAÇÃo Carmen Lucia Brancaglion Passos

SETOR Programa de Pós-Graduação em Educação

CONTATO secppge@ufscar.br

RESUMO Divulgar, fazendo chegar a um número maior de pessoas, o conhecimento produzido em decorrência das pesquisas e vivências na área de Educação, é uma obrigação da instituição pública. Fazer isso com rigor científico e ao mesmo tempo com simplicidade, constitui-se em um desafio que esse programa está se propondo. O objetivo é a socialização do conhecimento gerado pela Ciência da Educação, um bem público e universal, contemplada em um processo amplo e coletivo, apresentada de diversas formas, por diferentes meios e linguagens e atingindo os mais variados públicos, nacional e internacionalmente.

PALAVRAS-CHAVE divulgação científica; pesquisa em educação; revista eletrônica; educação; comunicação escrita e eletrônica 


\section{Educacã̃o}

\section{tíruıo Divulgação Científica, Comunicação e Inclusão Social}

\begin{tabular}{ll} 
COORDENAÇÃo & Maria Cristina Comunian Ferraz \\
SETOR & Departamento de Ciência da Informação \\
\hline CONTATO & dci@ufscar.br \\
\hline RESUMO & $\begin{array}{l}\text { O presente programa de extensão, que se preocupa com a divulgação científica e } \\
\text { com o letramento em ciência e tecnologia, se apóia na Gestão do Conhecimento, } \\
\text { na Comunicação Social e no Marketing Social. Tem como objetivos: diagnosticar e } \\
\text { propor soluções para os problemas relacionados à comunicação da informação em } \\
\text { ciência e tecnologia; contribuir para a representação, recuperação e disseminação } \\
\text { do conhecimento produzido na UFSCar; fazer uso do conhecimento científico } \\
\text { como ferramenta de inclusão social; contribuir para os debates sobre temas } \\
\text { que permeiam atualmente as discussões nacionais sobre a proteção do trabalho } \\
\text { intelectual e sobre o uso sustentável da biodiversidade brasileira. }\end{array}$
\end{tabular}

PALAVRAS-CHAVE conhecimento científico; conhecimento tecnológico; inclusão social; educação; educação profissional 


\section{EduGațão}

Tíulo Educação Continuada

\begin{tabular}{ll} 
COORDENAÇÃO & Jose Antonio Salvador \\
\hline SETOR & Departamento de Matemática \\
\hline CONTATO & dmchefe@ufscar.br \\
\hline RESUMO & $\begin{array}{l}\text { O objetivo do programa é proporcionar atualização de técnicas matemáticas e } \\
\text { ferramentas computacionais para profissionais, bem como aperfeiçoamento de } \\
\text { alunos e professores. }\end{array}$
\end{tabular}

PALAVRAS-CHAVE ～educação continuada; aperfeiçoamento; matemática; educação; educação continuada

DATA INÍCIO

$6 / 11 / 2003$ 


\section{Educacã̃o}

\section{TítULo \\ Educação de Jovens e Adultos Privados de Liberdade}

\begin{tabular}{ll} 
COORDENAÇÃo & Elenice Maria Cammarosano Onofre \\
\hline SETOR & Departamento de Teorias e Práticas Pedagógicas \\
\hline CONTATO & dtpp@ufscar.br \\
\hline RESUMO & O programa tem sua justificativa acadêmica e social ancorada em políticas públicas \\
& voltadas para a educação de jovens e adultos em privação de liberdade. Os objetivos \\
& principais são: desencadear ações voltadas para a inclusão social de jovens autores \\
& de atos infracionais e adultos em privação de liberdade; promover discussões \\
& e debates com pesquisadores da temática; organizar eventos acadêmicos que \\
& contribuam no sentido de partilhar das políticas públicas nacionais voltadas para as \\
& ações afirmativas e inclusivas; inserção em espaços da comunidade voltados para o \\
& atendimento dessa população marginalizada, contribuindo de maneira efetiva para \\
& a sua reinserção social.
\end{tabular}

PALAVRAS-CHAVE privação de liberdade; medidas sócio-educativas; direitos humanos; educação; direitos de grupos sociais 


\section{Educacṭ̃o}

Titulo Educação do Campo

COORDENAÇÃo Luiz Bezerra Neto

SETOR Departamento de Educação

CONTATO secded@ufscar.br

RESUMO O programa tem por objetivo facilitar o oferecimento dos cursos sobre Educação do Campo, quer através do curso de Pedagogia da Terra, quer através do Programa Escola Ativa. Objetiva ainda, proporcionar um espaço de discussão sobre os estudos e pesquisas sobre a educação do campo nas relações com as práticas das camadas populares, os movimentos sociais e a luta pela terra.

PALAVRAS-CHAVE I educação no campo; movimentos sociais; trabalhadores rurais; educação; direitos de grupos sociais

DATA INÍCIO $17 / 10 / 2011$ 


\section{Educacã̃o}

\section{TítuLo \\ Educação Especial e Humanização nos Serviços de Saúde: Pesquisa e Intervenção}

$\begin{array}{ll}\text { COORDENAÇÃo } & \text { Adriana Garcia Goncalves } \\ \text { SETOR } & \text { Departamento de Psicologia }\end{array}$

CONTATO dpsic@ufscar.br

RESUMO A educação especial como modalidade transversal apresenta caráter interativo e interdisciplinar. Na saúde, humanizar requer uma prática que aprecia tanto os aspectos físicos, quanto os subjetivos e sociais presentes na relação entre profissionais e usuários. A presente proposta de programa tem como objetivos: possibilitar parceria entre educação especial e saúde para atender as necessidades educacionais de alunos e suas famílias; orientar os profissionais envolvidos e a família para atenção integral do aluno; atender alunos público alvo da educação especial em ambientes escolares e não escolares. 


\section{TíTULO \\ Educação Especial na Perspectiva Inclusiva: Direitos Sociais, Escolarização e Formação Docente}

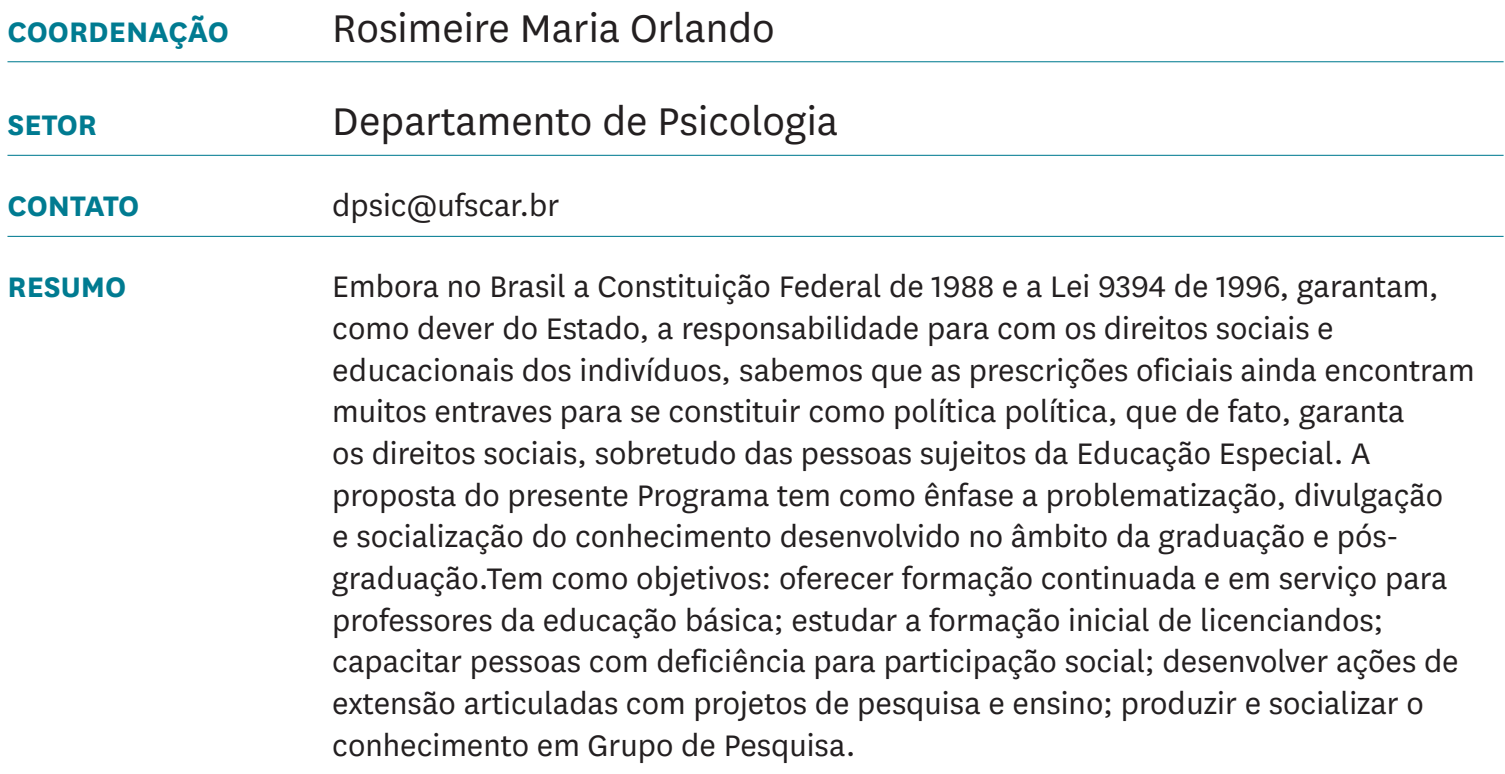




\section{Educațão}

Título Educação Especial: Direito a Educação

COORDEnAÇão Katia Regina Moreno Caiado

SETOR Departamento de Ciências Humanas e Educação

CONTATO dche@ufscar.br

RESUMO O direito à educação especial, garantido na legislação nacional, ainda tem muitos entraves para ser implementado como política pública. Se o número de matrículas de alunos da educação especial cresceu nas últimas décadas, é inegável que permanece longe da demanda, conforme dados do Censo do IBGE e do Censo Escolar. As ações de extensão deste Programa têm potencial para divulgação e socialização da produção do conhecimento e problematização do ensino de graduação e pós-graduação. Os objetivos do Programa são: oferecer formação continuada e em serviço para professores da educação básica; capacitar profissionais da educação que atuam com a educação especial; capacitar pessoas com deficiência para participação social e política; socializar o conhecimento produzido no grupo de pesquisa "Núcleo de Estudos e Pesquisas em Direito à Educação - Educação Especial”.

PALAVRAS-CHAVE educação especial; política pública; direitos humanos; educação; educação especial 


\section{Educațão}

Título Educação Musical na UFSCar

\begin{tabular}{ll} 
COORDENAÇÃo & Ilza Zenker Leme Joly \\
\hline SETOR & Departamento de Artes e Comunicação
\end{tabular}

CONTATO dac@ufscar.br

RESUMO São objetivos deste programa: desenvolver atividades educacionais musicais, ampliando possibilidades de ensino, pesquisa; promover cursos de extensão; divulgar conhecimento da área musical. 


\section{Educacã̃o}

\section{TítULo \\ Educação, Trabalho e Desenvolvimento Econômico e Social}

\begin{tabular}{|c|c|}
\hline COORDEN & Andrea Rodrigues Ferro \\
\hline SETOR & Departamento de Economia \\
\hline CONTATO & deco@ufscar.br \\
\hline RESUMO & $\begin{array}{l}\text { O objetivo deste programa é promover estudos, cursos e mini-cursos, palestras e } \\
\text { debates sobre educação e trabalho, suas inter-relações e suas implicações para } \\
\text { o desenvolvimento econômico e social. Sabe-se que a educação está, por um } \\
\text { lado, intimamente ligada ao desempenho dos indivíduos no mercado de trabalho, } \\
\text { tanto em termos de empregabilidade quanto em termos de salários - além de } \\
\text { aspectos mais subjetivos do desenvolvimento humano, como auto-estima e senso } \\
\text { de cidadania. Por outro lado, o nível de qualificação médio dos trabalhadores se } \\
\text { apresenta como uma variável central no desenvolvimento das forças produtivas } \\
\text { de um país. Desse modo, aprofundar os estudos sobre tais temas envolvendo } \\
\text { a sociedade, em especial gestores de políticas públicas e outros segmentos } \\
\text { organizados, contribui para a evolução econômica e social de cidades, estados e } \\
\text { países. }\end{array}$ \\
\hline
\end{tabular}




\section{Educațão}

título Educar Direito

\begin{tabular}{ll} 
COORDENAÇÃo & Joao Virgilio Tagliavini \\
\hline SETOR & Departamento de Educação \\
\hline CONTATO & secded@ufscar.br \\
\hline RESUMO & $\begin{array}{l}\text { O Brasil tem aproximadamente } 1.200 \text { cursos de Direito, sendo } 230 \text { deles no Estado } \\
\text { de São Paulo, atualmente com matrícula de mais de } 600 \text { mil bacharelandos. Diante } \\
\text { do comprovado insucesso do processo de ensino e aprendizagem do Direito, faz-se } \\
\text { necessário um trabalho contínuo de aperfeiçoamento dos projetos pedagógicos, das } \\
\text { práticas educacionais, da formação dos docentes para o ensino e dos estudantes } \\
\text { para a aprendizagem, além de estabelecer uma rede de contatos para a socialização } \\
\text { das experiências bem sucedidas. }\end{array}$
\end{tabular}

PALAVRAS-CHAVE formação jurídica; formação docente; educação para a cidadania; educação; educação continuada 
TíTULo

\section{EdUFSCar - Livros, Materiais Didáticos e Atividades de Divulgação do Conhecimento}

\begin{tabular}{ll} 
COORDENAÇÃo & Oswaldo Mario Serra Truzzi \\
\hline SETOR & Departamento de Engenharia de Produção \\
\hline CONTATO & dep@ufscar.br \\
\hline \multirow{2}{*}{ RESUMO } & O Programa envolve as atividades da Editora da UFSCar em 6 frentes, objetivando: \\
& divulgar a produção de conhecimento (em particular a produzida na UFSCar) por \\
& meio da publicação de livros e materiais didáticos, em formato impresso e digital; \\
& proporcionar a oferta de livros acadêmicos e de livros em geral para a comunidade \\
& da UFSCar e região por meio de sua livraria; assessorar potenciais autores no projeto \\
& de publicação; promover eventos, como feiras, lançamentos etc., relacionados à \\
& divulgação e venda de livros da EdUFSCar; à oferta de livros em geral em condições \\
& mais favoráveis; Paltex (Programa Ampliado de Livros Texto e materiais de \\
& instrução); divulgação e venda de livros e equipamentos na área da saúde; informar \\
& a comunidade da UFSCar e o público em geral das ações desenvolvidas pela \\
& EdUFSCar por meio de veículos variados na mídia e, em particular, pelo Informativo \\
& EdUFSCar.
\end{tabular}

PALAVRAS-CHAVE conhecimento; publicações; livraria; educação; incentivo à leitura 


\section{Educacã̃o}

\section{тітицо Ensino/Aprendizagem de Língua Espanhola}

COORDENAÇÃo Rosa Yokota

SETOR Departamento de Letras

CONTATO dl@ufscar.br

RESUMO O objetivo do programa é criar um espaço para a formação continuada de professores de língua espanhola em que a pesquisa e a prática docente se complementem. Ao mesmo tempo atender o público (externo e interno) interessado na língua e na cultura dos países hispano-falantes.

PALAVRAS-CHAVE espanhol; cultura; ensino-aprendizagem; educação; educação continuada

DATA INÍCIO 17/3/2009




\section{Educacṭ̃o}

Tiтuцо Ensino/Aprendizagem de Língua Inglesa

COORDENAÇÃo Eliane Hercules Augusto Navarro

SETOR Departamento de Letras

CONTATO dl@ufscar.br

RESUMO O programa objetiva criar uma intersecção entre pesquisa e o ensino da universidade com a realidade escolar, auxiliando dessa forma os professores de língua inglesa da rede pública a ter uma educação continuada. 


\section{Tíruı $\quad$ Ensino de Química e Divulgação Científica}

COORDENAÇÃo Walter Ruggeri Waldman

SETOR Departamento de Física, Química e Matemática

CONTATO dfqm@ufscar.br

RESUMO Neste programa serão desenvolvidas atividades de extensão relacionadas ao ensino de ciências, em especial mas não somente, na área de química. O público alvo vai desde a comunidade universitária à comunidade externa. A comunidade universitária, alunos de graduação e pós, docentes e técnicos, e a comunidade externa será atendida com palestras, cursos de extensão e atividades relacionadas a ensino de química e divulgação científica.

PALAVRAS-CHAVE ensino de química; divulgação científica; saberes populares; educação; educação continuada 
TíTULo

\section{Ensino, Pesquisa e Desenvolvimento Sustentável no Território Lagoa do Sino}

\begin{tabular}{ll} 
COORDENAÇÃo & Alberto Luciano Carmassi \\
\hline SETOR & Centro de Ciências da Natureza \\
\hline CONTATO & diretorccn@ufscar.br \\
\hline
\end{tabular}

RESUMO O Campus da UFSCar Lagoa do Sino está inserido no denominado Território Lagoa do Sino (TLS) que apresenta uma série de contrastes que justificam a criação do referido Programa de Extensão. Trata-se da região que atualmente possui um dos piores índices de desenvolvimento humano do estado de São Paulo, refletindo nas condições de saúde, educação, transporte e segurança da população. Dados referentes à atividade agrícola refletem uma população rural com média superior ao estado, sendo a agricultura familiar uma prática presente e que possui grande participação na produção agrícola estadual. A demanda de atividades de capacitação dos docentes das escolas públicas do ensino médio é uma realidade, visto a baixa taxa de professores com ensino superior em muitos municípios da região, além da taxa de matrícula no ensino superior ser quatro vezes menor que a média estadual, sendo um indicativo da formação desqualificada dos jovens concluintes do ensino médio. Ainda, a região encontra-se em uma importante bacia hidrográfica o que motiva a prática de atividades educacionais ambientais. Nesse sentido, projetos de extensão inseridos nesse programa devem favorecer o desenvolvimento territorial da agricultura familiar através da capacitação dos agricultores e desenvolver atividades que visem à produção orgânica para a segurança alimentar e o desenvolvimento territorial. Além disso, os projetos devem inserir discentes e docentes do ensino médio em atividades que objetivam a qualificação continuada e o desenvolvimento de projetos educacionais e/ou laboratoriais nas escolas.

PALAVRAS-CHAVE educação; meio ambiente; agricultura familiar; educação; gestão de recursos naturais 
TítuLo

\section{Escolarização, Trabalho e Participação Social da Pessoa com Deficiência}

\begin{tabular}{ll} 
COORDENAÇÃo & Juliane Aparecida de Paula Perez Campos \\
\hline SETOR & Departamento de Psicologia \\
\hline CONTATO & dpsic@ufscar.br \\
\hline RESUMO & O Brasil vivencia tempos de efervescência, no que diz respeito à luta pelos direitos \\
& sociais das pessoas com deficiência. O direito à educação é garantido na legislação \\
& nacional, entretanto ainda existem muitos obstáculos a serem enfrentados. As \\
& ações de extensão deste Programa têm potencial para divulgação e socialização \\
& da produção do conhecimento e problematização do ensino de graduação e \\
& pós-graduação. A presente proposta de Programa tem como objetivos, oferecer \\
formação continuada e em serviço para professores da educação básica; capacitar \\
pessoas com deficiência para o trabalho e participação social e política na \\
comunidade; socializar o conhecimento produzido no Grupo de Estudos e Pesquisas \\
sobre a Escolarização da Pessoa com Deficiência (GEPEPD).
\end{tabular}

PALAVRAS-CHAVE I escolarização; pessoas com deficiência; participação social; educação; educação especial 


\begin{tabular}{ll} 
Título & Estudos sobre a Criança e a Infância - \\
& História da Educação Infantil e Formação \\
& Continuada de Professores de Educação \\
& Infantil e de Outros Agentes Educacionais \\
\hline COORDENAÇão & Anete Abramowicz \\
\hline SETOR & Departamento de Teorias e Práticas Pedagógicas \\
\hline CONTATO & dtpp@ufscar.br \\
\hline RESUMO & $\begin{array}{l}\text { Continuar pesquisas, criar grupos de estudos, iniciar trabalhos de formação } \\
\text { continuada de professores de educação infantil em parceria com secretarias de } \\
\text { ensino. }\end{array}$ \\
\hline PALAVRAS-CHAVE & estudos; criança; infância; educação; educação continuada \\
\hline DATA INício & 27/8/1999
\end{tabular}




\section{Educacã̃o}

\begin{tabular}{|c|c|}
\hline Título & Estudos sobre a Escola de Vigotsky \\
\hline COORDENAÇÃO & Maria Aparecida Mello \\
\hline SETOR & Departamento de Teorias e Práticas Pedagógicas \\
\hline CONTATO & dtpp@ufscar.br \\
\hline RESUMO & $\begin{array}{l}\text { Este programa tem como principal eixo o desenvolvimento de estudos, pesquisa } \\
\text { e extensão na perspectiva teórica Histórico-Cultural de Vigotsky, nas áreas de } \\
\text { Educação Infantil, Educação Física, Pedagogia, Políticas de Ensino Superior e } \\
\text { Direito e Educação. Nele estão inseridas as atividades de pesquisa e extensão } \\
\text { desenvolvidas, primordialmente, em escolas públicas municipais, envolvendo alunos } \\
\text { de graduação, especialização, pós-graduação, ex-alunos de graduação e pós- } \\
\text { graduação, professores da rede pública municipal e gestores escolares. A intenção } \\
\text { desse programa é fortalecer a parceria entre a Universidade e Comunidade Externa. } \\
\text { O foco central dessa parceria é a troca e a integração dos saberes produzidos na } \\
\text { universidade e escola. A perspectiva teórica adotada nos projetos vai ao encontro } \\
\text { desse principal objetivo, uma vez que concebe o homem como produtor de sua } \\
\text { história e cultura e, nesse processo os tipos de relações entre os indivíduos são } \\
\text { imprescindíveis para a apropriação de conhecimentos e de aprendizagens. }\end{array}$ \\
\hline
\end{tabular}

estudos; Vigotsky; educação; educação infantil 


\section{Equcacã̃o}

TíTULo

\section{Filosofia: Perspectivas e Contemporaneidade}

\begin{tabular}{ll} 
COORDENAÇÃo & Jose Eduardo Marques Baioni \\
\hline SETOR & Departamento de Filosofia e Metodologia da Ciência \\
\hline RESUMO & dfmc@ufscar.br \\
& Tendo como pano de fundo a dispersão dos saberes em razão de sua crescente \\
& especialização e complexidade, o programa aqui proposto pretende articular os \\
& diversos momentos do ensino, formação e pesquisa em filosofia em torno de uma \\
& prática comum de crítica, reflexão e diálogo tanto das diferentes vertentes da \\
& filosofia entre si quanto destas com outras formas de saberes. o objetivo é, assim, \\
& aprimorar o ensino e a pesquisa de filosofia, aproximando, por um lado, os diversos \\
& agentes envolvidos na reflexão filosófica e, por outro, incentivando o diálogo \\
& da filosofia com outras formas de saberes (literatura, arte, psicanálise, cinema, \\
& antropologia, ciências exatas, história, para dar alguns exemplos). Para alcançar \\
& esse objetivo, pretende-se: apoiar a formação de grupos de pesquisa em nossa \\
& graduação e em nossa pós-graduação; incentivar o debate entre as diversas áreas \\
& de conhecimento e difundir para um público mais amplo as diferentes formas que a \\
& filosofia tem assumido, promovendo atividades de extensão. Alguns exemplos das \\
atividades propostas: ciclos de palestras, conferências, seminários de alunos de \\
graduacao e de alunos da pós-graduaçao e mini-cursos, ACIEPES, todos eles abertos \\
à comunidade acadêmica e ao público em geral).
\end{tabular}

PALAVRAS-CHAVE filosofia; história; crítica; educação; educação continuada 


\begin{tabular}{ll} 
Título & Formação Compartilhada de Professores \\
& $\begin{array}{l}\text { que Ensinam Matemática na Educação } \\
\text { Básica }\end{array}$ \\
\hline COORDENAÇÃo & Carmen Lucia Brancaglion Passos \\
\hline SETOR & Departamento de Metodologia de Ensino \\
\hline CONTATO & deme@ufscar.br \\
\hline RESUMO & $\begin{array}{l}\text { O programa visa a formação inicial e continuada de professores; implementa } \\
\text { experiências a partir de reflexões sobre a prática; cria e coordena grupo de estudos } \\
\text { e pesquisas, visando a produção dos trabalhos. }\end{array}$ \\
\hline PALAVRAS-CHAVE & formação; professores; educação; educação continuada \\
\hline DATA INÍcIo & \begin{tabular}{l}
$1 / 1 / 2003$ \\
\hline
\end{tabular}
\end{tabular}




\section{Educacã̃o}

\section{Tíulo Formação Continuada de Professores de Filosofia da Educação Básica}

\begin{tabular}{|c|c|}
\hline COORDEN & Adriana Mattar Maamari \\
\hline SETOR & Departamento de Metodologia de Ensino \\
\hline CONTATO & deme@ufscar.br \\
\hline RESUMO & $\begin{array}{l}\text { A disciplina de Filosofia foi suprimida da educação básica brasileira durante a } \\
\text { ditadura militar, através da lei 5692, de 1971, e somente em contexto recente, pela } \\
\text { Lei 11684, de junho de 2008, retorna ao ensino médio como disciplina obrigatória. } \\
\text { Este projeto, antes de tudo, visa consolidar e aprimorar a recente implantação da } \\
\text { disciplina nas escolas, por meio da problematização do ensino de Filosofia, em } \\
\text { ações compartilhadas que integrem licenciandos e professores de Filosofia. Estas } \\
\text { ações se darão no interior de escolas públicas da cidade de São Carlos de modo a } \\
\text { que professores iniciantes na atividade docente e profissionais que já lecionam na } \\
\text { Educação Básica possam obter desenvolvimento profissional. }\end{array}$ \\
\hline
\end{tabular}

PALAVRAS-CHAVE ensino de filosofia; formação continuada; filosofia na escola; educação; educação continuada 
Tívıঃ Formação Continuada em Educação

\section{Especial}

\begin{tabular}{ll} 
COORDENAÇÃO & Eniceia Goncalves Mendes \\
\hline SETOR & Departamento de Psicologia \\
\hline CONTATO & dpsic@ufscar.br
\end{tabular}

RESUMO

PALAVRAS-CHAVE educação; especial; educação; educação profissional

DATA INÍCIO 29/6/2000




\section{Educacã̃o}

\section{Título Formação de Professores e Divulgação Científica}

\begin{tabular}{ll} 
COORDENAÇÃo & Ducinei Garcia \\
\hline SETOR & Departamento de Física \\
\hline CONTATO & dfchefe@ufscar.br \\
\hline RESUMO & $\begin{array}{l}\text { O objetivo do Programa é oferecer Cursos de Educação Continuada para Professores } \\
\text { de Física e de Ciências do Ensino Fundamental, Médio e Superior, tanto para Rede } \\
\text { Pública quanto para Rede Privada além de desenvolver projetos envolvendo alunos } \\
\text { dos cursos de Bacharelado e Licenciatura em física da UFSCar. Outro ponto é o } \\
\text { desenvolvimento de material didático para as escolas de ensino fundamental e } \\
\text { médio e o desenvolvimento de cursos, palestras, workshops e eventos de divulgação } \\
\text { científica para professores e alunos. }\end{array}$ \\
\hline
\end{tabular}

PALAVRAS-CHAVE física; divulgação; educação; educação continuada

DATA INÍCIO

$1 / 1 / 2005$ 


\section{Educacã̃o}

Tírulo Formação de Profissionais em EaD

\begin{tabular}{ll} 
COORDENAÇÃo & Aline Maria de Medeiros Rodrigues Reali \\
\hline SETOR & Secretaria Geral de Educação a Distância \\
\hline CONTATO & sead@ufscar.br \\
\hline RESUMO & $\begin{array}{l}\text { Os cursos de formação continuada ofertados por meio deste Programa são } \\
\text { direcionados a profissionais que necessitam construir conhecimentos e atitudes } \\
\text { referentes aos diferentes papéis que desenvolvem na modalidade de educação a } \\
\text { distância. }\end{array}$ \\
\hline PALAVRAS-CHAVE & educação a distância; formação continuada; tics; educação; educação continuada \\
\hline DATA INÍCIO & 28/4/2011
\end{tabular}




\section{Educacã̃o}

Título Formação e Aperfeiçoamento de

\section{Educadores}

COORDENAÇÃo Hylio Lagana Fernandes

SETOR Departamento de Ciências Humanas e Educação

CONTATO dche@ufscar.br

RESUMO O programa objetiva a formação e aperfeiçoamento de educadores que atuam nos sistemas de ensino no âmbito regional que resulte na melhoria do ensino; busca ainda gerar conhecimentos e propostas sobre as redes de ensino, sua estrutura e funcionamento e os problemas que afetam o processo ensino-aprendizagem. aperfeiçoamento; ensino; formação; educação; educação profissional 


\section{Educacã̃o}

\section{Tírulo Formação e Educação Continuada em Letras}

COORdENAÇÃo Camila Hofling

SETOR Coordenação do Curso de Licenciatura em Letras

CONTATO ccl@ufscar.br

RESUMO O Programa Formação e Educação Continuada em Letras, idealizado por professores do departamento de Letras, tem como objetivo oferecer aos alunos e à comunidade acadêmica uma diversidade de enfoques de estudos sobre a linguagem. As modalidade de atividades a serem oferecidas neste programa serão seminários, Jornada de Letras, publicações acadêmicas, minicursos, revistas eletrônicas, entre outras. No que concerne a relevância acadêmica, os projetos a serem propostos neste programa são relevantes tanto para ampliar e legitimar a pesquisa no Departamento de Letras, como para projetar o trabalho desenvolvido no Departamento à comunidade. Quanto à relevância social, a ampliação das informações por meio destas atividades contribuem socialmente para a formação do estudante universitário e dos profissionais que atuam na área.

PALAVRAS-CHAVE educação continuada; formação; letras; educação; educação continuada 


\section{Educacã̃o}

TíTULo

\section{Formação e Educação Continuada em Linguística}

\begin{tabular}{ll} 
COORDENAÇÃo & Luzmara Curcino Ferreira \\
SETOR & Departamento de Letras \\
\hline
\end{tabular}

CONTATO dl@ufscar.br

RESUMO O programa tem como objetivo possibilitar a atuação da área de Linguística e Língua Portuguesa e do Programa de Pós-Graduação em Linguística junto à Comunidade em geral na difusão do conhecimento científico produzido na Universidade, na disseminação dos saberes relacionados à língua e à linguagem e no levantamento de problemáticas relacionadas a língua/linguagem que afetam a sociedade.

PALAVRAS-CHAVE linguistica; linguagem; educação; educação; educação continuada

DATA INÍCIO 9/9/2013




\section{Educacã̃o}

\section{Tíuı $\quad$ Formação Inicial e Continuada de Professores de Línguas}

$\begin{array}{ll}\text { COORDENAÇÃo } & \text { Ademar da Silva } \\ \text { SETOR } & \text { Departamento de Metodologia de Ensino }\end{array}$

CONTATO deme@ufscar.br

RESUMO O programa visa oferecer aos alunos de Estágio Supervisionado e Orientação para a Prática Profissional de Línguas (portuguesa, inglesa e espanhola) o contato prático com as várias abordagens de ensino/aprendizagem de línguas. Essa atividade de formação será feita por meio de atividades de ensino, análise e produção de materiais didáticos, em colaboração com membros da comunidade (professores e alunos da rede municipal/estadual de ensino; alunos e funcionários da UFSCar) que, também , beneficiar-se-ão com o intercâmbio. Essas duas frentes (alunos da graduação e comunidade) tornam esse programa relevante tanto acadêmica como socialmente. O investimento nos aspectos relacionados ao ensino/aprendizagem e formação inicial e continuada de professores de línguas vão ao encontro das áreas de pesquisa do DME - Depto de Metodologia de Ensino. Ao colaborar com a melhoria do ensino por meio do trabalho com professores pré e em serviço, e com o aperfeiçoamento da comunidade acadêmica, o programa cumpre um papel social relevante.

PALAVRAS-CHAVE língua estrangeira: inglês; língua estrangeira: espanhol; língua materna: português; educação; educação profissional 


\section{Tíruı Gestão da Informação e do Conhecimento}

COORDENAÇÃo Wanda Aparecida Machado Hoffmann

SETOR Departamento de Ciência da Informação

CONTATO dci@ufscar.br

RESUMO O objetivo do programa é atender organizações, pesquisadores, profissionais e a população em geral, envolvidos com pesquisa, geração, organização e gestão da informação e do conhecimento.

PALAVRAS-CHAVE gestão; informação; educação; educação profissional

DATA INÍCIO 16/8/1999




\section{Educacẫo}

Gestão e Planejamento Ambiental -
Conservação de Recursos Naturais para um
Desenvolvimento Sustentado

\begin{tabular}{ll} 
COORDENAÇÃO & Jose Eduardo Dos Santos \\
\hline SETOR & Departamento de Ciências Ambientais \\
\hline CONTATO & dcam@ufscar.br \\
\hline RESUMO & $\begin{array}{l}\text { O programa busca o aperfeiçoamento de metodologias de análise e planejamento } \\
\text { ambiental e o treinamento de alunos de graduação, pós-graduação e técnicos da } \\
\text { esfera governamental, além da melhoria e aprimoramento da pesquisa relacionada à } \\
\text { estes assuntos e de aulas em disciplinas afins. }\end{array}$
\end{tabular}

PALAVRAS-CHAVE ambiental; desenvolvimento; educação; educação ambiental

DATA INÍCIO 6/7/2001




\section{Educacã̃o}

\section{título Grupo de Estudos do Agronegócio (GEAgro)}

COORDENAÇÃo Marta Cristina Marjotta Maistro

SETOR Departamento de Tecnologia Agroindustrial e Socioeconomia

Rural

CONTATO secdtai@cca.ufscar.br

RESUMO Os cursos de graduação da UFSCar no Centro de Ciências Agrárias, em Araras, têm, na área de Socioeconomia, um conteúdo obrigatório mínimo e algumas disciplinas optativas que abrangem um conteúdo razoável na área. Porém, sempre ocorre o fato de alguns alunos demonstrarem interesse em avançar mais na área voltada para os aspectos econômicos do agronegócio, combinando autodidatismo e orientação de professores, em número bastante reduzido e lotados no Departamento de Tecnologia Agroindustrial e Socioeconomia Rural. Reuniões iniciais com um grupo desses alunos indicaram a possibilidade de criar um Grupo de Estudos com objetivos específicos. A atuação nesse grupo permitirá que o aluno participante avance no conhecimento e na prática de análise econômica. Os resultados desses estudos a serem desenvolvidos têm um bom potencial para serem divulgados na comunidade, como podem evoluir até para apresentação em congressos e seminários e para publicação em periódicos de divulgação.

PALAVRAS-CHAVE agronegócio; economia aplicada; grupo de estudos; educação; desenvolvimento rural 
TíTULO

\section{Identificação e Intervenção Precoce Domiciliar de Crianças com TGD (Transtorno Global Do Desenvolvimento)}

\begin{tabular}{ll} 
COORDENAÇÃO & Ana Lucia Rossito Aiello \\
\hline SETOR & Departamento de Psicologia \\
\hline CONTATO & dpsic@ufscar.br
\end{tabular}

RESUMO Vários estudos (por exemplo, Filipek et al., 1999) têm apontado para a necessidade premente de detecção precoce dos transtornos globais de desenvolvimento (TGD) a fim de que as famílias possam acessar serviços apropriados de intervenção. Resultados de pesquisas sobre a inclusão da criança e da família em serviços de intervenção o mais precocemente possível têm demonstrado que esse é um dos fatores fundamentais na maximização dos resultados com a criança (por exemplo, Lovaas, 1987; Dawson \& Osterling, 1997). Atualmente, triagem e diagnóstico de TGD são baseados em características comportamentais, não existindo exames biológicos para seu diagnóstico (Filipek et al., 1999; Johnson \& Myers, 2007). Independente da severidade das características comportamentais do TGD e da percepção dos pais de que há algo errado com seu filho por volta dos dois anos de idade (Young et al., 2003), a idade média para diagnóstico é tardia, geralmente quando a criança está em idade escolar (Mandell et al., 2005), perdendo-se assim, o período ótimo para intervenção precoce.

Os objetivos desse programa são:

1. Identificar o mais cedo possível atrasos no desenvolvimento infantil relacionados ao TGD de crianças de zero a seis anos;

2. Promover o desenvolvimento infantil de crianças em risco para atraso de desenvolvimento ou TGD;

3. Intervir junto com os pais dessas crianças e de forma multidisciplinar favorecendo o desenvolvimento infantil e o bem estar da família, além de promover relações intra-familiares positivas;

4. Fortalecer as potencialidades e recursos que a família tem em si mesma e no ambiente para lidar com adversidades;

5. Promover redes sociais de apoio na família e na comunidade;

6. Realizar pesquisas sobre triagem do desenvolvimento infantil e intervenção com famílias

7. Contribuir para a prevenção de deficiências;

8. Desenvolver materiais didáticos para capacitar famílias.

9. Capacitar alunos-estagiários na avaliação do desenvolvimento infantil e na intervenção com famílias. 


\section{Educacã̃o}

Tíuıo Inclusão Social do Deficiente Mental Através do Trabalho

\begin{tabular}{ll} 
COORDENAÇÃo & Antonio Celso de Noronha Goyos \\
\hline SETOR & Departamento de Psicologia \\
\hline CONTATO & dpsic@ufscar.br \\
\hline RESUMO & $\begin{array}{l}\text { O programa tem como meta principal, no âmbito acadêmico, criar e tornar } \\
\text { disponível o conhecimento que possa ser incorporado pela população individual e } \\
\text { institucional envolvida no atendimento da pessoa com deficiência mental, através } \\
\text { de pesquisas e consultorias. }\end{array}$ \\
\hline PALAVRAS-CHAVE & $\begin{array}{l}\text { formação; trabalho; deficiência; educação; } \\
\text { atenção a grupos de pessoas com necessidades especiais }\end{array}$ \\
\hline DATA INÍ́CIO & $1 / 1 / 2006$ \\
\hline
\end{tabular}




\section{Educațão}

Tírulo Informação para Educação

$\begin{array}{ll}\text { COORDENAÇÃo } & \text { Luciana de Souza Gracioso } \\ \text { SETOR } & \text { Departamento de Ciência da Informação }\end{array}$

CONTATO dci@ufscar.br

RESUMO Contribuir para a formação qualificada de professores, especialistas em educação, pessoal de apoio técnico e pedagógico e bibliotecários, no desenvolvimento de práticas educativas inovadoras, no que diz respeito às atividades de acesso e uso da informação, de promoção da leitura e da pesquisa escolar.

PALAVRAS-CHAVE Informação; educação; educação; cultura e memória social

DATA INÍCIO $\quad 1 / 1 / 1999$




\section{Educațão}

Títuı Informação, Tecnologia e Sociedade

COORDENAÇÃo Rogerio Aparecido Sa Ramalho

SETOR Departamento de Ciência da Informação

CONTATO dci@ufscar.br

RESUMO O presente programa de extensão busca contribuir para o ensino e desenvolvimento de novas Tecnologias da Informação e Comunicação (TIC), analisando os impactos de tais tecnologias na sociedade contemporânea. A relevância social e acadêmica do programa relaciona-se à necessidade de oferecer às comunidades internas e externas, elementos conceituais que favoreçam o estudo da inegável influência exercida pelas tecnologias, estimulando a troca de experiências entre a comunidade acadêmica e profissional, a fim de desenvolver a capacidade crítica, responsável e construtiva enquanto ser humano.

PALAVRAS-CHAVE informação; tecnologia; sociedade; educação; educação continuada 


\section{Educațão}

Tíulo Intervenção Precoce e Educação Inclusiva

COORDENAÇÃo Fabiana Cia

SETOR Departamento de Psicologia

CONTATO dpsic@ufscar.br

RESUMO Nos primeiros anos de vida ocorrem importantes e rápidas mudanças no processo de desenvolvimento, assim a escola e a família precisam oferecer estimulação necessária para que a criança desenvolva o máximo de suas potencialidades. Quando trata-se de crianças com necessidades educacionais especiais (NEE), pais e professores não se sentem preparados para promover esse ambiente estimulador. Assim, o programa tem por objetivos: empoderar as famílias de crianças préescolare com NEE; trabalhar na formação de professores, quanto a adaptação de materiais pedagógicos, desenvolvimento infantil e intervenção precoce e estimular crianças pré-escolares com NEE.

PALAVRAS-CHAVE intervenção precoce; pré-escolares; professores; educação; educação especial 


\section{Educacã̃o}

Tiтulo Laboratório de Bioensaios e Modelagem Matemática

\begin{tabular}{ll} 
COORDENAÇÃO & Irineu Bianchini Junior \\
\hline SETOR & Departamento de Hidrobiologia \\
\hline CONTATO & secdhb@ufscar.br \\
\hline RESUMO & $\begin{array}{l}\text { O programa objetiva escrever e discutir aspectos relacionados ao funcionamento } \\
\text { dos ciclos biogeoquímicos dos sistemas aquáticos naturais e artificiais (rios, lagos, } \\
\text { grandes reservatórios, represas etc); gestão de recursos hídricos e a atenuaça de } \\
\text { impactos negativos gerados a partir de pressões antrópicas sobre esses ambientes. }\end{array}$
\end{tabular}

PALAVRAS-CHAVE bioensaios; medelagem; educação; educação ambiental

DATA INÍCIO 16/9/1999




\section{Educațão}

\section{Tiтulo Lazer, Educação Desportiva e Humanização}

COORDENAÇÃo Waldemar Marques Junior

SETOR Departamento de Educação Física e Motricidade Humana

CONTATO defmh@ufscar.br

RESUMO Orientar os projetos de Extensão que tematizam o Lazer e a Educação Desportiva, numa perspectiva da indissociabilidade ensino-pesquisa-extensão, tendo como referencial teórico-metodológico a teoria histórico-social da formação do indivíduo, estabelecendo uma relação de compromisso técnico e político da Universidade com a sociedade, na direção de transformá-la.

PALAVRAS-CHAVE lazer; educação; humanização; educação; esporte, lazer e saúde 


\section{Educacã̃o}

\section{Tíruı Lingüística Aplicada: Português para Estrangeiros}

\begin{tabular}{ll} 
COORDENAÇÃO & Nelson Viana \\
\hline SETOR & Departamento de Letras
\end{tabular}

CONTATO dl@ufscar.br

RESUMO Possibilitar o desenvolviemnto de pesquisa na área de ensino / aprendizagem de Segunda língua e, possivelmente, a elaboração e publicação de material teórico e material didático relevantes para a área, para utilização interna e externa.

PALAVRAS-CHAVE português; estrangeiros; educação; educação profissional

DATA INÍCIO $\quad 1 / 1 / 2000$




\section{Educațão}

\section{TítuLo \\ Modelagem Estatística Aplicada e Levantamento De Dados}

\begin{tabular}{|c|c|}
\hline COORDEN & Cecilia Candolo \\
\hline SETOR & Departamento de Estatística \\
\hline CONTATO & deschefe@ufscar.br \\
\hline RESUMO & $\begin{array}{l}\text { A proposta deste programa é viabilizar ferramentas e instrumentos envolvendo } \\
\text { a aplicação e a disseminação da modelagem estatística e do levantamento de } \\
\text { dados relacionados às áreas de análise de regressão (regressão linear, logística, de } \\
\text { Poisson, modelo de Cox, entre outras), modelos lineares generalizados, modelos } \\
\text { mistos (lineares ou não), incluindo dados longitudinais. As atividades podem } \\
\text { envolver trabalho interativo e cooperativo para desenvolvimento científico, cursos e } \\
\text { mini-cursos de técnicas de modelagem estatística específicas ou gerais, capacitação } \\
\text { em softwares estatísticos, reciclagem de profissionais, projetos relacionados } \\
\text { ao levantamento de informações e de prestação de serviços de assessoria e de } \\
\text { consultoria, além da divulgação do conhecimento científico gerado. }\end{array}$ \\
\hline
\end{tabular}

PALAVRAS-CHAVE análise de regressão; modelos lineares generalizados; levantamento de dados; educação; cooperação interinstitucional 


\section{Educacã̃o}

\section{Título Observatório do Turismo do Estado de São Paulo - OTURESP}

\begin{tabular}{ll} 
COORDENAÇÃo & Telma Darn \\
\hline SETOR & Departamento de Geografia, Turismo e Humanidades \\
\hline CONTATO & dgth@ufscar.br
\end{tabular}

RESUMO A missão do Observatório será a de ser um instrumento social, facilitador de gestão e debate, que deverá servir de elemento técnico, catalisador, polifuncional e descentralizado, planejado e administrado de forma participativa, com estabilidade e autonomia, com visão estratégica, observando a situação atual e analisado as perspectivas futuras da atividade turística no Estado de São Paulo, fundamentalmente através da conformação de uma rede multidisciplinar de pesquisadores compostas pelos docentes da UFSCar e demais participantes externos, bem como, da sistematização, estruturação, avaliação, discussão, apartação, participação, estimulo a produção e divulgação do conhecimento na área do turismo, sempre buscando a objetividade e a credibilidade 


\section{Educacã̃o}

\section{TítuLo \\ PEGASUS - Programa de Educação e Gestão para o Acesso à Sustentabilidade}

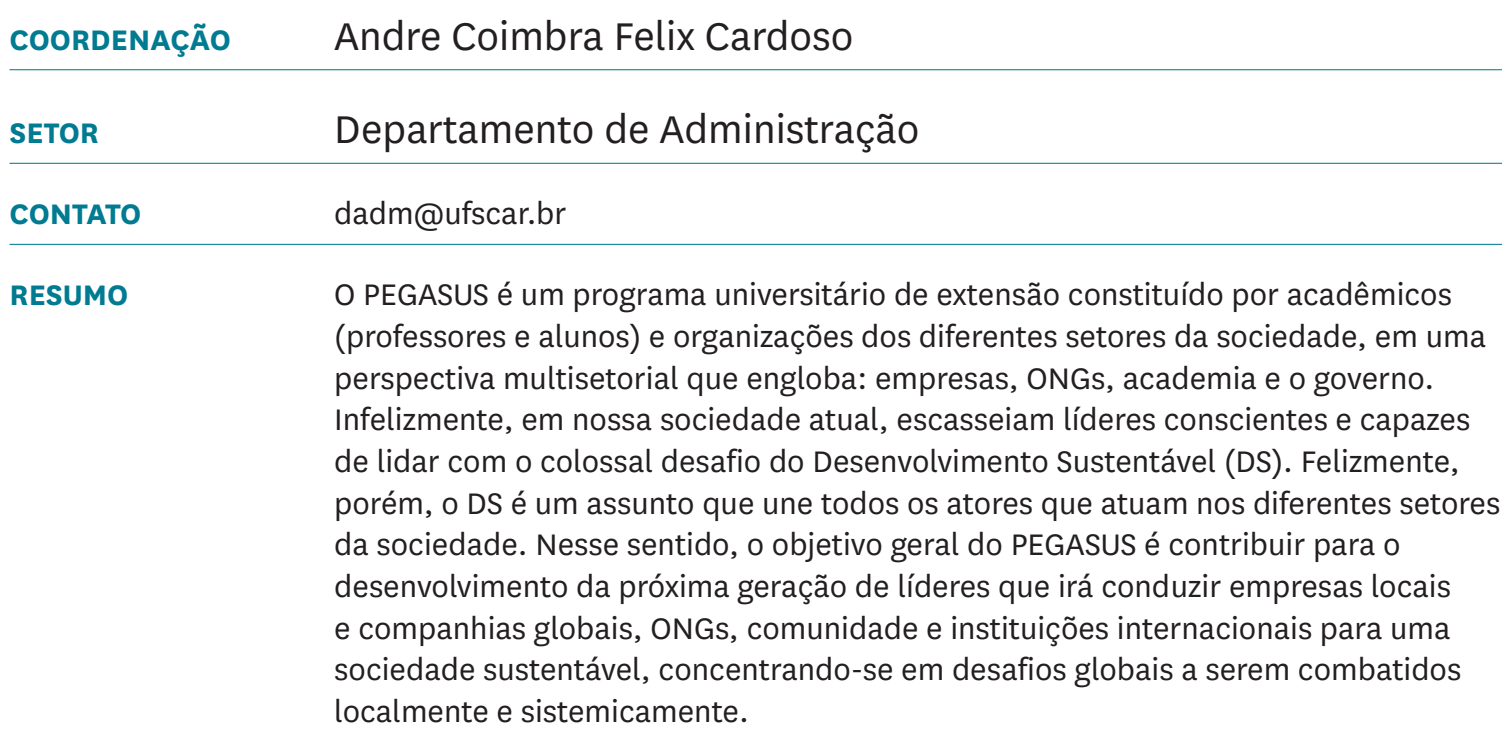

PALAVRAS-CHAVE Sustentabilidade; educação; gestão; educação; empreendorismo 


\section{TíTULO \\ PIBID-UFSCar: Espaço de Formação Compartilhada entre Professores da Educação Básica e Licenciandos}

\begin{tabular}{ll} 
COORDENAÇÃO & Maria do Carmo de Sousa \\
\hline SETOR & Departamento de Metodologia de Ensino \\
\hline CONTATO & deme@ufscar.br \\
\hline RESUMO & O PIBID/UFSCar tem por objetivos: articular e coordenar atividades de prática de \\
& ensino, Estágio Supervisionado, conteúdos curriculares e extracurriculares com \\
& ações colaborativas junto aos professores de escolas públicas estaduais de São \\
& Carlos e Sorocaba, bem como, escolas municipais de Araras e São Carlos e seus \\
& alunos, tendo em vista: a Iniciação à Docência dos licenciandos da UFSCar; a \\
& formação continuada dos professores em serviço na Escola Pública; a promoção da \\
& melhoria do ensino e da aprendizagem na Educação Básica, por meio de ações que \\
& contemplam os objetivos do edital PIBID/CAPES e as Propostas Curriculares Estadual \\
& e/ou Municipal, em vigor.
\end{tabular}

PALAVRAS-CHAVE iniciação à docência; formação de professores; espaço compartilhado; educação; educação continuada 


\section{Educațão}

Tiтulo Planejamento Florestal

COORDENAÇÃo Claudio Roberto Thiersch

SETOR Departamento de Ciências Ambientais - Sorocaba

CONTATO dca@ufscar.br

RESUMO Para qualquer atividade de base florestal, seja para fins produtivos ou conservacionistas, é primordial o uso de ferramentas eficientes nas áreas de apoio aos processos de tomada de decisão. Por sua vez, estas dependem do conhecimento quantitativo e qualitativo do dado recurso, bem como, do entendimento do padrão de variação deste ao longo do tempo. Por ser uma área na qual normalmente grandes massas de dados são manipuladas e analisadas, este programa tem como objetivo desenvolver/aprimorar metodologias, ferramentas e sistemas computacionais, bem como, capacitar alunos e profissionais na gestão dos recursos florestais.

PALAVRAS-CHAVE biometria; inventário; planejamento; educação; educação continuada

DATA INÍ́CIO 29/4/2011




\section{Educacã̃o}

\begin{tabular}{ll} 
TítUlo & Políticas Públicas e Gestão da Educação \\
\hline COORDENAÇÃo & Celso Luiz Aparecido Conti \\
\hline SETOR & Departamento de Educação \\
\hline CONTATO & secded@ufscar.br \\
\hline RESUMo & $\begin{array}{l}\text { O programa tem por objetivo realizar estudos sobre políticas e gestão em educação; } \\
\text { subsidiar educadores na formulação, implementação e avaliação de políticas } \\
\text { educacionais; formação continuada de educadores no trabalho de gestão de } \\
\text { unidades de ensino. }\end{array}$ \\
\hline PALAVRAS-CHAVE & políticas; educação; educação; educação profissional \\
\hline DATA INíCIO & 1/1/2002 \\
\hline
\end{tabular}




\section{Educacã̃o}

\section{Tírulo Popularização da Educação em Ciências}

COORDENAÇÃo Denise de Freitas

SETOR Departamento de Metodologia de Ensino

CONTATO deme@ufscar.br

RESUMO A informação científica está presente no cotidiano da sociedade atual, entretanto, essa divulgação não acontece de forma problematizada e contextualizada para contribuir com a alfabetização crítica e o entendimento da ciência que resulte em uma incorporação desses saberes. Daí a necessidade de se investir em uma popularização da ciência que possibilite a formação de uma cidadania científica. Objetivo: promover a alfabetização científica em diferentes instâncias (universidades, escolas de ensino fundamental e médio, comunidades) e integrar docentes e alunos das universidades às comunidades escolares, buscando uma troca de saberes. 


\section{Educacẫo}

TítuLo

\section{Práticas Pedagógicas e Processos}

Formativos na Educação Escolar e Não

Escolar: Estudo, Produção e Divulgação de

\section{Conhecimentos e Saberes}

\begin{tabular}{ll} 
COORDENAÇÃo & Fernando Donizete Alves \\
\hline SETOR & Departamento de Educação Física e Motricidade Humana \\
\hline CONTATO & defmh@ufscar.br \\
\hline RESUMO & $\begin{array}{l}\text { O presente programa de extensão configura-se como espaço de estudo, pesquisa e } \\
\text { consequente produção de conhecimentos e saberes inerentes a prática educativo- } \\
\text { pedagógica e a formação profissional em contextos escolares e não escolares e } \\
\text { que possam corroborar com a melhoria da qualidade do processo de ensino e de } \\
\text { aprendizagem. }\end{array}$
\end{tabular}

PALAVRAS-CHAVE práticas pedagógicas; processos formativos; educação escolar e não escolar; educação; educação continuada 


\section{Educacã̃o}

TíTULo

\section{Programa de Avaliação e Acompanhamento de Políticas para a População Negra}

\begin{tabular}{ll} 
COORDENAÇÃo & Valter Roberto Silverio \\
\hline SETOR & Departamento de Sociologia \\
\hline CONTATO & ds@ufscar.br \\
\hline RESUMO & O Programa tem por objetivo central mapear, acompanhar, analisar e avaliar o \\
& desenvolvimento de políticas/projetos de ação afirmativa (tanto na modalidade \\
& reserva de vagas, ou de cotas para negros e indígenas, quanto na modalidade \\
& preferência) com especial atenção àqueles voltados para o acesso à educação \\
& superior. Configurar e acompanhar o debate de políticas sobre o ensino superior, \\
& em relação às políticas afirmativas, desde o governo FHC e o primeiro governo de \\
& Lula, compreendendo as linhas e as dimensões sociológicas, econômicas, políticas e \\
& jurídicas que atravessam e (re)desenham esse debate, compondo a genealogia das \\
& ações afirmativas é o que tal pesquisa pretende realizar.
\end{tabular}




\section{Educațão}

\section{Título Programa de Educação Continuada em}

\section{Saúde}

\begin{tabular}{ll} 
COORDENAÇÃo & Ana Claudia de Oliveira \\
\hline SETOR & Departamento de Medicina \\
\hline CONTATO & dmed@ufscar.br \\
\hline RESUMO & $\begin{array}{l}\text { O desenvolvimento de habilidades e competências em medicina está diretamente } \\
\text { vinculada ao acesso atualizado às informações, as quais estão em constante } \\
\text { mudança frente às tecnologias e conhecimentos rapidamente desenvolvidos. Um } \\
\text { dos objetivos desse programa é propiciar o acesso à informação médica atualizada } \\
\text { visando a formação de excelência em Medicina. Para tal, serão desenvolvidas } \\
\text { atividades de caráter prático e teórico voltado aos estudantes de graduação, } \\
\text { pós-graduação e profissionais da saúde, na forma de seminários, aulas, oficinas e } \\
\text { discussão reflexiva de temas em medicina e demais áreas da saúde. }\end{array}$
\end{tabular}

PALAVRAS-CHAVE $\quad$ educação continuada; saúde; medicina; educação; educação continuada

DATA INÍCIO 24/4/2013




\section{Equcacã̃o}

\section{TíTULO \\ Programa de Educação das Relações Étnico- Raciais da UFSCar}

\begin{tabular}{ll} 
COORDENAÇÃO & Petronilha Beatriz Gonçalves e Silva \\
\hline SETOR & Departamento de Teoria e Práticas Pedagógicas \\
\hline CONTATO & dtpp@ufscar.br
\end{tabular}

RESUMO O presente programa se desenvolve no quadro do Programa de Ações Afirmativas da UFSCar, nos termos da Portaria UFSCar 695/2007 que prevê o desenvolvimento de ações, nos diferentes âmbitos da vida universitária, conduzidas por servidores docentes e técnico-administrativos -, por estudantes, em colaboração com sistemas de ensino - municipal, estadual, federal -, bem como com entidades do movimento social, entre elas, Movimento Negro, Movimento Indígena, agremiações como Associação dos Estudantes Africanos em São Carlos.

A principal atividade desse programa diz respeito à difusão da educação das relações étnico-raciais na educação básica e superior, em estabelecimentos dos diferentes níveis de ensino tanto da rede pública como privada, junto a grupos que se empenham em iniciativas para promover igualdade social, étnico-racial, garantias de direito à cultura, história, identidade próprias. As ações que ocorrerem fora da comunidade universitária prioritariamente serão desenvolvidas em bairros situados à margem dos centros urbanos, mas não unicamente.

PALAVRAS-CHAVE educação; relações étnico-raciais; igualdade de direitos; educação; direitos de grupos sociais 


\section{Educacṭ̃o}

Tírulo Programa de Educação Especial: Formação e Inclusão

\begin{tabular}{ll} 
COORDENAÇÃo & Rosemeire de Araujo Rangni \\
\hline SETOR & Departamento de Psicologia
\end{tabular}

CONTATO dpsic@ufscar.br

RESUMO A inclusão de estudantes com necessidades educacionais especiais (NEE) em escolas regulares tem evidenciado um paradigma de educação - uma escola que eduque a todos. Apesar do trabalho apresentado pela Educação Especial, observase que há necessidade de se efetivar a formação inicial e continuada dos educadores para garantir respostas educativas aos estudantes, como também, apoio aos seus familiares ou responsáveis. Para essas garantias, o objetivo do Programa de Educação Especial: Formação e Inclusão - PEEFI - é atuar junto à comunidade institucional e extrainstitucional para contribuir que os indivíduos com NEE tenham sua educação e inclusão. 


\section{TítULo \\ Programa de Educação Superior UAB- UFSCar (Universidade Aberta do Brasil)}

\begin{tabular}{ll} 
COORDENAÇÃo & Denise de Paula Martins de Abreu e Lima \\
\hline SETOR & Gabinete da Reitoria \\
\hline CONTATO & reitoria@ufscar.br \\
\hline
\end{tabular}

RESUMO O projeto UAB-UFSCar (universidade Aberta do Brasil) tem como principal objetivo levar a educação superior pública, gratuita e de qualidade a muitos egressos do ensino médio que não apresentam condições de frequentar a universidade de forma presencial. Na busca por esse objetivo, o verdadeiro desafio da EaD continua sendo o seu sentido democratizante e a qualidade da proposta pedagógica e de seus materiais. A característica de complementaridade entre educação presencial e educação a distância deixa clara a necessidade de busca por qualidade em ambas as modalidades, embora possuam peculiaridades. Será necessário, portanto, buscar compreender as implicações que esta extensão espaço-temporal da universidade traz efetivamente à comunidade. A compreensão desses fatores passa pela clara explanação de, no mínimo, quatro aspectos componentes da estrutura organizacional da educação: a gestão, a docência, a aprendizagem e a mediação tecnológica dos processos educacionais. No caso da educação a distância, o conjunto de atividades envolvendo esses quatro aspectos é realizado numa logística diferenciada do que fomos acostumados na educação tradicional. Por isso, para que a UFSCar mantenha seu padrão de qualidade também nos cursos a distância, serão necessárias algumas iniciativas de formação docente visando a reelaboração das concepções de gestão, docência, aprendizagem e de mediação tecnológica dos processos educacionais. Dessa forma, este programa de extensão tem como objetivos: auxiliar os docentes da UFSCar a organizar, selecionar, gerir e elaborar cursos e disciplinas a serem oferecidas na modalidade de EaD; formar tutores (a distância e presenciais) para atuarem nos cursos oferecidos na UAB; auxiliar servidores da UFSCar (docentes e técnico-administrativos) no desenvolvimento e utilização de TICs; criar condições para o desenvolvimento de uma cultura de qualidade na EaD; estimular a formação de uma equipe de apoio técnicoadministrativo para o oferecimento de cursos pela modalidade de EaD.

PALAVRAS-CHAVE educação a distancia; tecnologia educacional; tutoria; educação; educação à distância 


\section{Educațão}

TítuLo

Programa de Estudos Avançados em Desenvolvimento e Economia - PEADE

\begin{tabular}{|c|c|}
\hline COORDEN & Alexandre Lopes Gomes \\
\hline SETOR & Departamento de Economia \\
\hline CONTATO & deco@ufscar.br \\
\hline RESUMO & $\begin{array}{l}\text { O PEADE é um programa de extensão com o objetivo de criar atividades de } \\
\text { extensão no Departamento de Economia da UFSCAR. Sabe-se que o município } \\
\text { de Sorocaba carece deste tipo de atividade, portanto o programa se justifica no } \\
\text { sentido de oferecer cursos de extensão de curta e longa duração para a comunidade } \\
\text { universitária e do município de Sorocaba. Além disso, o programa abrange } \\
\text { atividades de assessoria, estudos e análise econômica para empresas e municípios } \\
\text { da região. }\end{array}$ \\
\hline
\end{tabular}

PALAVRAS-CHAVE educação; economia; desenvolvimento; educação; educação continuada

DATA INÍCIO

$19 / 4 / 2012$ 
TÍTULO

\section{Programa de Extensão para a Democratização do Conhecimento: Comunicação entre Universidade, Comunidade e Escola}

COORDENAÇÃo Estefano Vizconde Veraszto

CONTATO

dcnme@cca.ufscar.br

RESUMO

O Departamento de Ciências da Natureza, Matemática e Educação (DCNME) da UFSCar, campus Araras, congrega hoje vários professores que possuem, apesar de suas diferentes áreas de formação, um eixo temático que é a Educação. Esse eixo, por si só, tem uma forte conexão com a extensão, ponto da tríade tão importante que, muitas vezes, é negligenciada na universidade. A educação e seu poder transformador constituem a base do programa de extensão proposto, que abrigará projetos, eventos e cursos que visem à divulgação de ações universitárias, à construção de conhecimentos relacionados a processos educativos e desenvolvimento social e à produção de materiais didáticos. 0 Programa de Extensão para a Democratização do Conhecimento: comunicação entre Universidade, Comunidade e Escola, buscará articular projetos de extensão de caráter multidisciplinar às atividades de pesquisa e ensino, de maneira a evidenciar estes elementos indissociáveis que caracterizam a universidade. O principal intuito desta proposta é contribuir para o oferecimento de oportunidades de aprendizagem a todas e todos os envolvidos, permitindo possibilidades de estudos e uma formação mais ampla e sólida dos acadêmicos da UFSCar fundamentada no diálogo para intervir na realidade das escolas de educação básica e pública, ao mesmo tempo em que pode possibilitar o acesso de diferentes segmentos da sociedade à universidade e às atividades por ela e nela desenvolvidas. Desta forma, serão empregados esforços do corpo docente da instituição no sentido de orientar os alunos em formação para que busquem meios colaborativos para superar os problemas reais dos processos de ensino, aprendizagem e de disseminação do saber, democratizando o conhecimento. 
TíTULO

\section{Programa de Formação Continuada em Educação Especial a Profissionais de Redes Municipais de Ensino}

\begin{tabular}{|c|c|}
\hline SETOR & Departamento de Psicologia \\
\hline CONTATO & dpsic@ufscar.br \\
\hline RESUMO & $\begin{array}{l}\text { A política educacional vigente indica a inclusão de toda a criança na escola } \\
\text { regular, respeitando suas necessidades, todavia tais cuidados nem sempre lhe } \\
\text { são proporcionados. Este é o caso da inclusão escolar de crianças e jovens com } \\
\text { deficiências perceptuais, intelectuais e/ou físicas, que por sua dificuldade de acesso } \\
\text { aos conteúdos escolares trabalhados (por questões linguísticas, pedagógicas, } \\
\text { metodológicas, de configuração do espaço físico e materiais de apoio) ficam } \\
\text { alijados dos processos de ensino-aprendizagem. Tornam-se urgente desenvolver, } \\
\text { na educação básica, práticas pedagógicas atentas às necessidades destes sujeitos } \\
\text { em consonância com a legislação atual. Este programa pretende realizar ações de } \\
\text { implementação, acompanhamento e pesquisa vinculadas a propostas de inclusão } \\
\text { de alunos com deficiência junto a Escolas Municipais de Educação Infantil, Ensino } \\
\text { Fundamental e Educação de Jovens e Adultos. }\end{array}$ \\
\hline
\end{tabular}

PALAVRAS-CHAVE educação inclusiva; educação básica; formação continuada; educação; educação especial 


\section{Educacã̃o}

\section{TítuLo \\ Programa de Formação em Educação Infantil da UAC}

\begin{tabular}{ll} 
COORDENAÇÃo & Andrea Braga Moruzzi \\
\hline SETOR & Unidade de Atendimento a Criança \\
\hline CONTATO & uac@ufscar.br \\
\hline RESUMO & Este Programa tem por objetivo centralizar e sistematizar os processos formativos \\
& que ocorrem na Unidade de Atendimento a Criança da UFSCar por meio da \\
& realização de diferentes cursos de extensão promovidos pela Unidade, ACIEPES, \\
& Estágios Curriculares e Remunerados, Encontros de Educação Infantil etc. \\
& Considera-se que a Unidade, desde sua inauguração em 1992, vem promovendo \\
& parcerias entre Unidades e Departamentos no sentido de ser um lócus de estágio \\
& para diferentes cursos de graduação - educação musical, pedagogia, enfermagem, \\
& educação especial, bem como, no sentido de ser um lócus constantemente \\
& procurado para realização de pesquisas de diferentes áreas, além das citadas acima, \\
& a psicologia, a terapia ocupacional, educação ambiental, entre outras. Constituir \\
& um Programa para a Unidade de Atendimento a Criança vai também ao encontro da \\
& necessidade de consolidar a UAC enquanto uma Unidade Educacional regida pelo \\
& tripé Ensino, Pesquisa e Extensão (Resolução de Março do CNE/CEB 2011).
\end{tabular}




\section{TítuLo \\ Programa de Inovação em Educação, Tecnologias e Linguagens (EaD-UFSCar)}

\begin{tabular}{ll} 
COORDENAÇÃo & Daniel Ribeiro Silva Mill \\
\hline SETOR & Secretaria Geral de Educação a Distância \\
\hline CONTATO & sead@ufscar.br \\
\hline
\end{tabular}

RESUMO O presente Programa busca atender atividades inovadoras que articulem educação, tecnologias e linguagens em iniciativas envolvendo a universidade e outras instâncias públicas (governamentais, administrativas, de ensino superior, de educação básica etc). Em especial, esse Programa busca atender às demandas do Sistema UAB (Universidade Aberta do Brasil) na Universidade Federal de São Carlos (UFSCar) e outras iniciativas de formação pela Educação a Distância e de investigação pelo Grupo de Estudos e Pesquisas sobre Inovação em Educação, Tecnologias e Linguagens (HORIZONTE). Frente ao grande desafio da EaD e da incorporação de tecnologias digitais nos processos de ensino e de aprendizagem presenciais ou virtuais, busca-se constituir propostas educacionais em seu sentido democratizante, com qualidade da proposta pedagógica e de seus materiais. A dissolução das fronteiras entre educação a distância e presencial deixa clara a necessidade de busca por qualidade em ambas as modalidades, de modo complementar entre si, resguardando as peculiaridades de cada modalidade. A compreensão desses fatores passa pela clara explanação de, no mínimo, quatro aspectos componentes da estrutura organizacional da educação: a gestão, a docência, a aprendizagem e a mediação tecnológica dos processos educacionais. De modo transversal, tem-se a flexibilidade curricular e a perspectiva de democratização da educação. Assim, para que a UFSCar mantenha seu padrão de qualidade também em iniciativas de inovação educacional e tecnológica, são necessárias algumas iniciativas de formação e reelaboração das concepções de currículo, gestão, docência, aprendizagem e de mediação tecnológica dos processos educacionais. A busca por novas formas de ensino-aprendizagem e pela incorporação de outras tecnologias no processo pedagógico ganha importância nesse cenário.

PALAVRAS-CHAVE educação a distancia; tecnologia educacional; linguagens e aprendizagem; educação; educação à distância 


\section{Educacã̃o}

\section{Tíruı Programa de Revitalização Geriátrica}

COORDENAÇÃo Jose Rubens Rebelatto

SETOR Departamento de Fisioterapia

CONTATO dfisio@ufscar.br

RESUMO Este programa tem como objetivo principal proporcionar à população da terceira idade uma oportunidade de convívio social, esportivo e acadêmico visando melhora da qualidade de vida destes indivíduos. Aos idosos participantes são oferecidas aulas com temas diversos, prática de atividade física supervisionada por professores de educação física e fisioterapeutas, avaliações periódicas realizada por equipe competente e treinada para este fim, resposta à participação no programa, entre outros. O programa de Revitalização Geriátrica também tem como objetivo a produção de conhecimento científico, pois assim, pode proporcionar informações relevantes e recentes para os alunos e profissionais interessados nesta temática.

PALAVRAS-CHAVE revitalização geriátrica; idoso; fisioterapia geriátrica; educação; atenção integral à terceira idade 


\section{Educacã̃o}

TíTULo

Programa em Socioeconomia e Estatística Aplicada

\begin{tabular}{ll} 
COORDENAÇÃo & Adriana Estela Sanjuan Montebello \\
\hline SETOR & $\begin{array}{l}\text { Departamento de Tecnologia Agroindustrial e Socioeconomia } \\
\text { Rural }\end{array}$
\end{tabular}

CONTATO

secdtai@cca.ufscar.br

RESUMO

O presente programa pretende reunir as linhas de pesquisa (Economia, Sociologia Rural e Meio Ambiente, Estatística aplicada a Economia, Estatística Experimental e Multivariada) trabalhadas pelos Professores da área de Socioeconomia Rural do DTAISER, a fim de proporcionar a interrelação entre suas áreas de pesquisas, disseminando o ferramental da Teoria Econômica, da Sociologia e da análise Estatística. Como objetivos deste programa podem-se destacar: oferecer ao aluno participante oportunidade de ampliar conhecimentos nas áreas citadas; permitir que os alunos desenvolvam estudos e trabalhos nas linhas de pesquisa relacionadas ao programa, ampliando a possibilidade de cumprimento de créditos extra-classe. 


\section{Educațão}

Título Programa Futuro Cientista (PFC)

COORDENAÇÃo Fabio de Lima Leite

SETOR Departamento de Física, Química e Matemática

CONTATO dfqm@ufscar.br

RESUMO O Programa Futuro Cientista (PFC) é uma iniciativa que tem como objetivo principal descobrir futuros talentos para a ciência. O PFC será constituído, inicialmente, na região de Sorocaba e, posteriormente, em todo o território nacional, através de uma Rede de Pesquisadores, que visará à divulgação científica e tecnológica, o resgate do espírito científico junto do grande público e a criação de contextos adequados à formação de futuros cientistas. o Programa prevê o apoio às escolas, à colaboração entre instituições científicas, empresas, e instituições educativas, e o desenvolvimento e produção de recursos e conteúdos para a educação formal e não formal.

PALAVRAS-CHAVE cientista; ensino fundamental; ciência; educação; ensino fundamental

DATA INÍCIO 23/11/2009


TítuLo

\section{PRO-INFÂNCIA: Programa de Promoção do Desenvolvimento Infantil}

\begin{tabular}{ll} 
COORDENAÇÃo & Maria Stella Coutinho de Alcantara Gil \\
\hline SETOR & Departamento de Psicologia \\
\hline CONTATO & dpsic@ufscar.br \\
\hline
\end{tabular}

RESUMO No desenvolvimento das crianças ressalta-se o papel fundamental dos pais e professores na proposição, condução e manutenção de situações interativas significativas com as crianças, pois são eles que podem ajustar a natureza e o grau de dificuldade da situação interativa proposta aos progressos e dificuldades manifestados pelas crianças. Dado o valor das interações sociais na vida infantil, há que se considerar uma importante alteração no cotidiano da criança a partir do momento em que ela passa a frequentar a creche/pré-escola. Nesse novo ambiente, ela convive com outros adultos e compartilha o mesmo espaço e brinquedos com outras crianças, experimenta ritmos diferentes do seu e participa de um outro universo de objetos, ações e relações (Oliveira, 1992). A partir do ingresso do bebê na creche, a família, os professores e outros bebês ou crianças constituem-se nas principais fontes de interação das crianças. Ninguém como eles têm a possibilidade de manter uma relação tão próxima, íntima e permanente com a criança nem compartilha tantas experiências e vivências na interação diária.

Considera-se fundamental, portanto, que os adultos responsáveis pelos bebês ampliem a consciência e o conhecimento do quão decisiva pode ser a sua atuação para propiciar o pleno desenvolvimento das potencialidades e capacidades dos pequenos. Diante da realidade atual da educação infantil é imprescindível que se realize a orientação contínua de pais, de professores e de outros profissionais e, também que se formem profissionais psicólogos, pedagogos e outros capacitados a orientá-los.

PALAVRAS-CHAVE desenvolvimento infantil; prevenção; promoção do desenvolvimento; educação; educação infantil 


\section{Equcacã̃o}

\section{TítuLo \\ Rede Colaborativa de Práticas Educativas em Matemática}

\begin{tabular}{ll} 
COORDENAÇÃO & Renata Prenstteter Gama \\
\hline SETOR & Departamento de Metodologia de Ensino \\
\hline CONTATO & deme@ufscar.br \\
\hline RESUMO & Esse programa busca compartilhar as atividades de ensino, pesquisa e extensão \\
& realizadas no programa observatório da educação em rede das universidades \\
& UFSCar, PUC-SP e UFABC. A rede parte do pressuposto da relevância dos múltiplos \\
& olhares e contextos trazidos pelos formadores, professores em serviço e futuros \\
& professores, enquanto dialogam e problematizam sobre as diferentes práticas \\
& docentes para melhorar o ensino de matemática, as práticas de inserção \\
& e sustentabilidade na docência. O objetivo principal é viabilizar atividades \\
& compartilhdas para a constituição de uma rede colaborativa de práticas educativas \\
& do professor que ensina matemática. Essas atividades se constituem em pesquisas, \\
& atividades de extensão, oficinas, mini-cursos, palestras e eventos acadêmicos \\
& voltados a articulação dessas diferentes práticas nas quais possibilitam práticas \\
& investigativas, teórico-metodológico, análise e elaboração de recursos didáticos e \\
& produção de narrativas educativas.
\end{tabular}

PALAVRAS-CHAVE universidade-escola; colaboração; práticas educativas; educação; educação continuada 


\section{Educacã̃o}

\section{тіт́то Reflexões Geográficas}

COORDEnAÇão Neusa de Fatima Mariano

SETOR Departamento de Geografia, Turismo e Humanidades

CONTATO dgth@ufscar.br

RESUMO A proposta do presente Programa vem sanear uma lacuna existente, que satisfaça às necessidades dos trabalhos e atividades desenvolvidas no âmbito da Geografia. Objetiva-se, desta forma, acolher atividades de extensão cujos temas envolvam não só o ensino de Geografia (fundamental e médio), de forma mais geral, mas também, as especificidades da Geografia: geografia agrária e urbana, geomorfologia, climatologia, hidrografia, geografia cultural, epistemologia da geografia, cartografia, geografia econômica e política etc. Tais temas, uma vez inseridos nas atividades, poderão contribuir para a formação e atualização do professor de Geografia a partir da aplicação de seus conteúdos trabalhados em sala de aula. Faz-se pertinente, portanto, promover o diálogo entre estudantes (geografia, turismo, economia, e outros) da UFSCar e de outras universidades, e professores (público externo) sob a perspectiva da ciência geográfica, já que o campus de Sorocaba conta com um curso de Licenciatura em Geografia. geografia; natureza; sociedade; educação; educação continuada 


\section{Educațão}

título Tecnologias para Acessibilidade

\begin{tabular}{ll} 
COORDENAÇÃo & Murillo Rodrigo Petrucelli Homem \\
\hline SETOR & Departamento de Computação \\
\hline RENTATO & dcomp@ufscar.br \\
\hline O programa se destina ao estudo, desenvolvimento e disseminação, através de um \\
conjunto de atividades como mini-cursos, seminários, palestras, integração entre \\
projetos de mestrado e de disciplinas de graduação dos cursos de Bacharelado em \\
Ciência da Computação - Sorocaba e do Programa de Pós-graduação em Ciência da \\
Computação de Sorocaba (podendo incluir outros), de novos métodos e inovaçães \\
tecnológicas, voltados para acessibilidade de pessoas com deficiências físicas \\
ou cognitivas por meio de mecânicas que estimulem o engajamento destas na \\
sociedade.
\end{tabular}

PALAVRAS-CHAVE acessibilidade; gameficação; interfaces homem-máquina; educação; atenção a grupos de pessoas com necessidades especiais 


\section{Educațão}

\section{Título Temas em Antropologia e Ciência Política}

COORDENAÇÃo Vera Alves Cepeda

SETOR Departamento de Ciências Sociais

CONTATO d-dcso@ufscar.br

RESUMO A constituição do campo das ciências sociais funciona como um laboratório reflexivo entre a origem no contexto social e sua posterior influência/impacto nesse meio. Este Programa tem como objetivo facilitar e sistematizar os momentos e movimentos de interlocução e diálogo das pesquisas e atividades acadêmicas produzidas pelo corpo discente e docente da Ciências Sociais (graduação e pósgraduação em Ciência Política e Antropologia da UFSCar) com o entorno social, utilizando a extensão como ferramenta de produção de conhecimento, diálogo social e combustível da contínua reciclagem necessária ao campo das Ciências Sociais - em especial a dimensão da organização e representações políticas e as questões culturais ligadas à antropologia.

PALAVRAS-CHAVE ação e representações política; cultura e identidade; ciências sociais; educação; organizações populares

DATA INÍCIO $\quad 5 / 11 / 2012$ 
TítuLo

\section{Transferência de Conhecimento, Tecnologia e Equipamentos para o Ensino de Engenharia Química}

\begin{tabular}{ll} 
COORDENAÇÃo & Jose Mansur Assaf \\
\hline SETOR & Departamento de Engenharia Química \\
\hline CONTATO & deqchefe@ufscar.br \\
\hline RESUMO & $\begin{array}{l}\text { O objetivo do programa é promover melhoria na infra-estrutura de ensino de } \\
\text { engenharia, fornecendo tecnologia e equipamentos, através de cursos, treinamentos } \\
\text { de docentes e fornecimento de unidades experimentais. }\end{array}$
\end{tabular}

PALAVRAS-CHAVE transferência; tecnologia; educação; inovação tecnológica

DATA INÍCIO 21/6/2000 
TíTULo

\section{Unidade de Iniciação à Leitura para Atendimento a Escolares de Risco}

\begin{tabular}{ll} 
COORDENAÇÃo & Deisy Das Gracas de Souza \\
\hline SETOR & Departamento de Psicologia \\
\hline CONTATO & dpsic@ufscar.br \\
\hline RESUMO & $\begin{array}{l}\text { Um considerável conjunto de estudos na área de Leitura e Escrita tem sido } \\
\text { empreendido por docentes e alunos do curso de Graduação em Psicologia e do } \\
\text { programa de Pós-Graduação em Educação Especial da UFSCar . Parte substancial } \\
\text { destes estudos tem sido desenvolvida no contexto dos projetos de extensão Unidade } \\
\text { de Iniciação à Leitura para Atendimento a Escolares de Risco sob responsabilidade } \\
\text { dos proponentes deste projeto. A Unidade foi concebida como um laboratório para } \\
\text { investigação, prestação de serviços e transferência de conhecimento sobre ensino } \\
\text { de leitura, escrita e matemática. O presente projeto visa colocar à disposição } \\
\text { de alunos do ensino fundamental, que estejam apresentando dificuldades de } \\
\text { aprendizagem de leitura e escrita, um currículo básico para o ensino dessas } \\
\text { habilidades. O programa proposto tem características de suplementação, no sentido } \\
\text { de que deve ser acrescentado à exposição do aluno à escola e não em lugar dela. O } \\
\text { projeto consiste no oferecimento de uma série de três módulos de ensino de Leitura } \\
\text { e Escrita para aplicação individualizada. }\end{array}$ \\
\hline
\end{tabular}

PALAVRAS-CHAVE aquisição de leitura; alfabetização; ensino informatizado; educação; incentivo à leitura 


\section{Meio Ambiente}

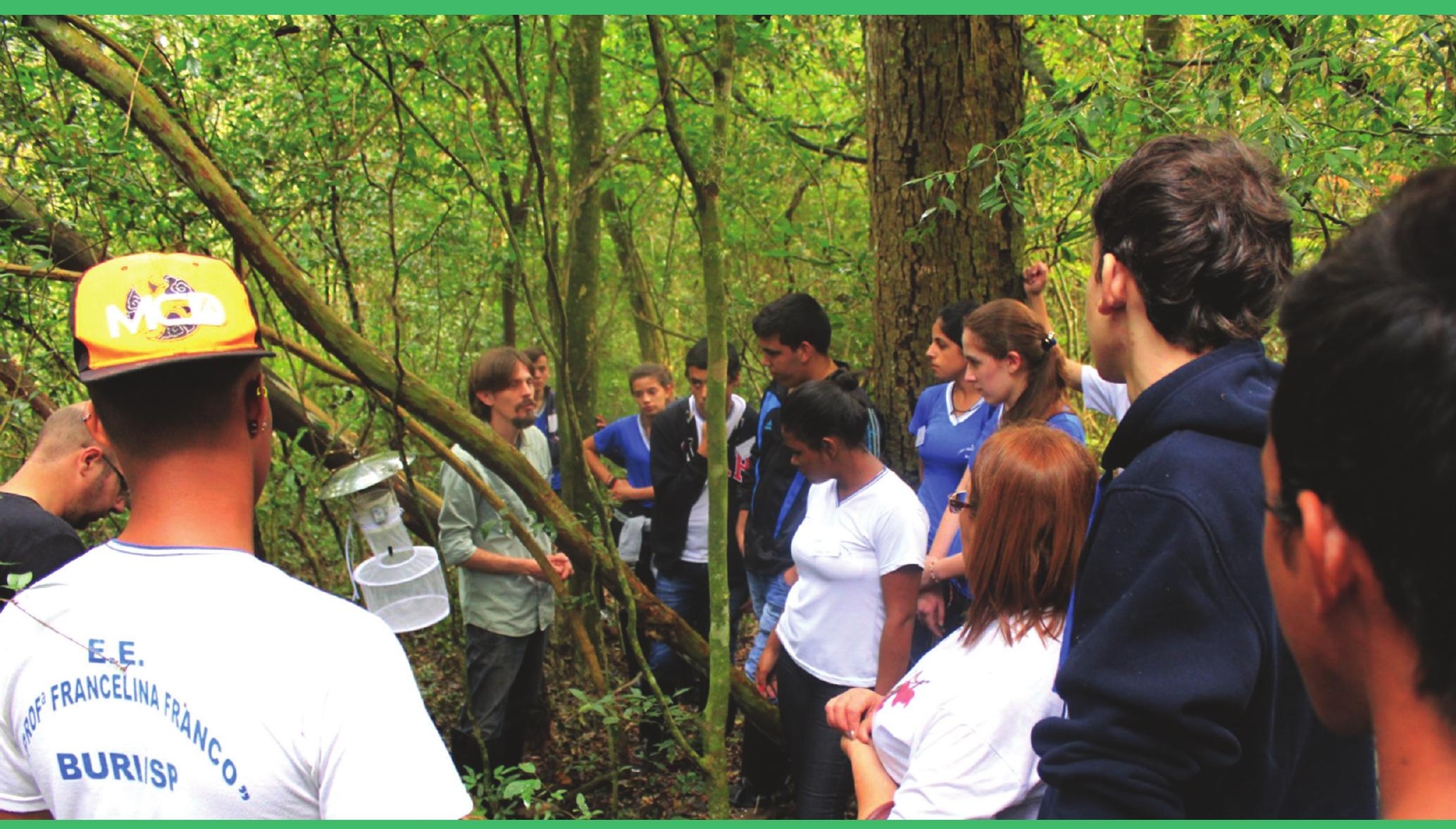

Atividade Dia de Campo na Fazenda Floresta - Campus Lagoa do Sino.

Foto: Tiago Santi. 
Título

\section{A Bacia Hidrográfica como Unidade de Planejamento}

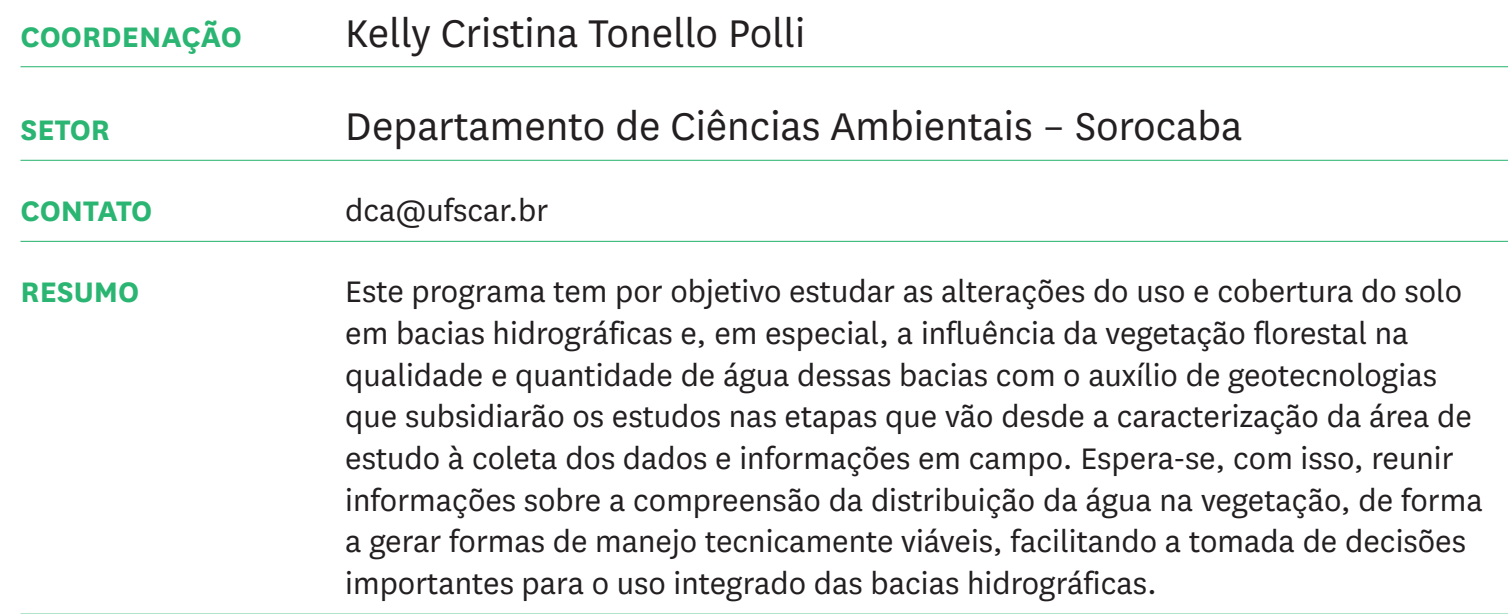

PALAVRAS-CHAVE nascentes; meio ambiente; bacias hidrográficas; meio ambiente; gestão de recursos naturais 
TíTULO

\section{Agroecologia, Desenvolvimento Rural e Meio Ambiente}

\begin{tabular}{ll} 
COORDENAÇÃo & Renata Evangelista de Oliveira \\
\hline SETOR & Departamento de Desenvolvimento Rural \\
\hline CONTATO & ddr@cca.ufscar.br \\
\hline RESUMO & O objetivo deste Programa é realizar atividades de extensão na área de Agroecologia \\
& e Desenvolvimento Rural, mais precisamente no fortalecimento das formas de \\
& transição para sistemas produtivos agroecológicos e sua interação com processos \\
& de desenvolvimento rural, tais como organização do trabalho, a produção de \\
& alimentos orgânicos e em base ecológica, o desenvolvimento de canais alternativas \\
& de comercialização, a promoção de formas de processamento de produtos, a \\
& interação com atividades não-agrícolas e a promoção de iniciativas no campo da \\
& cultura e da educação ambiental e a análise, proteção e recuperação ambiental. \\
& O Programa tem como premissa a articulação dos diferentes aspectos sociais, \\
& culturais, tecnológicos, econômicos e políticos das transformações no meio rural, \\
& bem como a perspectiva de realizar atividades em colaboração com diversos \\
& atores sociais a agências governamentais em uma abordagem participativa e com \\
& a articulação de conhecimentos, sobretudo das áreas disciplinares de Agronomia, \\
& Agroecologia, Economia, Educação Ambiental, Sociologia, Biologia, Química \\
& Ambiental e Física.
\end{tabular}

PALAVRAS-CHAVE agroecologia; desenvolvimento rural; meio ambiente; meio ambiente; desenvolvimento rural 


\begin{tabular}{|c|c|}
\hline Título & As Abelhas e os Serviços Ambientais \\
\hline COORDENAÇÃO & Roberta Cornelio Ferreira Nocelli \\
\hline SETOR & Departamento de Ciências da Natureza, Matemática e Educação \\
\hline CONTATO & dcnme@cca.ufscar.br \\
\hline RESUMO & $\begin{array}{l}\text { As abelhas são os principais agentes polinizadores, porém o número de espécies } \\
\text { e de indivíduos por colmeia vem diminuindo, o que pode estar relacionado à ação } \\
\text { antrópica. Para diminuir esse impacto é importante a dissemiação de técnicas de } \\
\text { manejo mais seguras, tanto das abelhas quanto das culturas onde eleas vivem e/ } \\
\text { ou visitam. Um melhor manejo pode garantir a preservação dessas espécies, assim } \\
\text { como uma maior produção para os agricultores, apicultores e meliponicultores. } \\
\text { Assim, os objetivos desse programa são: avaliar os impactos dessas ações; } \\
\text { disseminar técnicas de manejo mais favoráveis ao processo de polinização; fazer } \\
\text { levantamentos da disponibilidade de polinizadores nos agroecossistemas. }\end{array}$ \\
\hline
\end{tabular}

PALAVRAS-CHAVE polinização; produção agrícola; agrotóxicos; meio ambiente; gestão de recursos naturais 


\section{тітицо $\quad$ Atividades em Biotecnologia Ambiental}

COORDENAÇÃo Vadim Viviani

SETOR Departamento de Física, Química e Matemática

CONTATO dfqm@ufscar.br

RESUMO O centro de Biotecnologia Ambiental preve a realização de atividades de divulgação de tecnologias e prestação de serviços na área de biotecnologia voltada ao meio ambiente. A biotecnologia está tendo crescente impacto na sociedade moderna, e acredita-se que irá desempenhar papel fundamental nas áreas de saúde, agricultua e meio ambiente. Em países emergentes e megadiversos como o Brasil, a biotecnologia terá um papel fundamental no desenvolvimento científico e tecnológico de suas sociedades. Entretanto, estes crescentes avanços tem de ser constantemente acompanhados por novas tecnologias voltadas à avaliação de seus impactos no meio ambiente. Existe a necessidade urgente de se utilizar e aprimorar as novas tecnologias necessárias à monitoração dos impactos ambientais a nos níveis físico, químico e biológico. Assim sendo, o centro aqui proposto prevê a realização de atividades formativas e de divulgação destas novas tecnologias, de forma multidisciplinar, e de prestação de serviços educativos à comunidade de Sorocaba e região, permitindo que estas atividades se reflitam na melhoria da qualidade ambiental.

PALAVRAS-CHAVE biotecnologia; bioindicadores; biosensores; meio ambiente; inovação tecnológica

DATA INÍCIO 23/8/2012


TíTULO

\section{Avaliações de Impactos em Populações de} Peixes

$\begin{array}{ll}\text { COORDENAÇÃO } & \text { Alberto Carvalho Peret } \\ \text { SETOR } & \text { Departamento de Hidrobiologia }\end{array}$

CONTATO

secdhb@ufscar.br

RESUMO Defender o interesse geral da população nas questões relacionadas ao ambiente e, no nosso caso, relacionadas às questões sobre os peixes, especialmente os de interesse comercial. 


\section{tírulo Cavernas Brasileiras - Conservação e} Diversidade

\begin{tabular}{ll} 
COORDENAÇÃo & Maria Elina Bichuette \\
\hline SETOR & Departamento de Ecologia e Biologia Evolutiva \\
\hline CONTATO & secdebe@ufscar.br \\
\hline RESUMO & $\begin{array}{l}\text { O Programa visa interagir com parques estaduais, municipais e nacionais nas } \\
\text { propostas de programas de monitoramento e educação ambiental, além de propor } \\
\text { medidas mitigatórias ao ambiente subterrâneo. }\end{array}$ \\
\hline PALAVRAS-CHAVE & cavernas; conservação; educação ambiental; meio ambiente; educação ambiental \\
\hline DATA INÍCIO & 21/9/2011
\end{tabular}


TíTULO

\section{Conservação, Biologia e Manejo de Animais} Silvestres

\begin{tabular}{ll} 
COORDENAÇÃO & Vlamir Jose Rocha \\
\hline SETOR & Departamento de Ciências da Natureza, Matemática e Educação \\
\hline CONTATO & denme@cca.ufscar.br
\end{tabular}

RESUMO Devido ao efeito devastador que o Estado de São Paulo sofreu em sua vegetação nativa para dar espaço a áreas agrícolas ao longo dos séculos, restam hoje apenas pequenos fragmentos da vegetação original e como consequência ocorre um impacto na fauna que depende destas áreas para manterem as populações. Dois tipos de impactos são observados nas populações da fauna silvestre: para as espécies que se adaptam, o que se observa é um aumento populacional devido a nova situação ambiental que favorece espécies oportunistas como por exemplo populações de capivaras (Hydrochaeris hidrochaeris). O outro impacto conduz ao extremo oposto onde as espécie diminuem sua população chegando muitas vezes a extinção local justamente devido às alterações do ambiente. Seja qual for o tipo de impacto é de fundamental importância que se realize o manejo adequado dos animais silvestres tanto para controle populacional quanto para aumento populacional. Em função disto se justifica criar um programa em conservação e manejo de fauna silvestre com os seguintes objetivos: formar mão de obra qualificada de alunos de graduação e pós-graduação que possa atuar na área de conservação e manejo de animais silvestres; fornecer assistência a produtores rurais que possuam problemas de danos agrícolas causado por animais silvestres; fornecer assistência de manejo de animais silvestres a entidades como zoológicos, criadouros conservacionista, criadouros científicos; executar projetos de educação ambiental em escolas da rede pública e privada; montar um museu da fauna com exemplares taxidermizados para serem utilizados em feiras de ciências e educação ambiental.

PALAVRAS-CHAVE fauna; manejo; educação ambiental; meio ambiente; gestão de recursos naturais 
TíTULO

\section{Conservação da Natureza e Gestão} Ambiental

\begin{tabular}{ll} 
COORDENAÇÃo & Eliana Cardoso Leite \\
\hline SETOR & Departamento de Ciências Ambientais \\
\hline CONTATO & dca@ufscar.br \\
\hline RESUMO & Nos últimos anos tem crescido a demanda por profissionais qualificados que atuem \\
& em órgãos de licenciamento, fiscalização e proteção ambiental. Estes, geralmente \\
& são graduados e não recebem treinamento específico em suas funções. Na região \\
& de Sorocaba existem dicotomias como a existência de cidades economicamente \\
& bem desenvolvidas mas que preservam a integridade dos ecossistemas naturais. \\
& Assim, faz-se necessário capacitar profissionais de nível médio e superior para a \\
& busca de caminhos entre o desenvolvimento e a conservação ambiental, ou seja, \\
& o desenvolvimento sustentável. Isto será possível com implantação de atividades \\
& de extensão desse programa, o que facilitará a democratização do conhecimento \\
& científico e tecnológico da UFSCar para com a comunidade da região, e possibilitará \\
& que alunos de graduação da UFSCar - Sorocaba vivenciem na prática questões \\
& ambientais trabalhadas nas grandes curriculares de seus cursos.
\end{tabular}




\section{Título Conservação de Ecossistemas}

COORDENAÇÃo Marcel Okamoto Tanaka

SETOR Departamento de Ciências Ambientais

CONTATO dcam@ufscar.br

RESUMO Ecossistemas naturais têm grande importância para as atividades humanas, fornecendo serviços inestimáveis do ponto de vista social e também para a manutenção da diversidade e integridade do ambiente. Estes sistemas estão sendo rapidamente degradados, sendo necessárias ações urgentes de monitoramento e recuperação, que dependem fortemente da colaboração de setores da sociedade civil. Neste programa pretende-se integrar os resultados da pesquisa acadêmica com atividades de extensão, facilitando o acesso do conhecimento pela sociedade civil e propondo novas formas de disseminação deste conhecimento.

PALAVRAS-CHAVE ecossistemas; macroinvertebrados; uso da terra; meio ambiente; gestão de recursos naturais 
Título Desenvolvimento Urbano e Regional e Habitação Social

\begin{tabular}{ll} 
COORDENAÇÃo & Carolina Maria Pozzi de Castro \\
\hline SETOR & Departamento de Engenharia Civil \\
\hline CONTATO & deciv@ufscar.br \\
\hline RESUMO & $\begin{array}{l}\text { São objetivos deste programa: formar pessoal técnico governamental e não } \\
\text { governamental e atender demandas de problemas e solicitações de prestação de } \\
\text { serviço, organização de eventos e cooperação interinstitucional que desenvolvam, } \\
\text { discutam e difundam o conhecimento sobre a gestão municipal e o desenvolvimento } \\
\text { urbano e regional, especialmente no estado de são Paulo. }\end{array}$ \\
\hline
\end{tabular}

PALAVRAS-CHAVE desenvolvimento; urbano; meio ambiente; desenvolvimento urbano

DATA INÍCIO 14/1/2000




\section{5}

Título

\section{Diversificação de Atividades para Sistemas de Produção de Base Agroecológica - Implantação de uma Unidade Modelo}

\begin{tabular}{ll} 
COORDENAÇÃO & Jean Carlos Cardoso \\
\hline SETOR & Departamento de Desenvolvimento Rural \\
\hline CONTATO & ddr@cca.ufscar.br \\
\hline RESUMO & $\begin{array}{l}\text { A diversificação de atividades dentro de unidades de produção agropecuárias são } \\
\text { alternativas para a viabilização de pequenos agronegócios, como os objetivos de } \\
\text { fornecer um modelo de produção que objetive a sustentabilidade consorciada } \\
\text { à viabilidade econômica necessária. A instalação de uma unidade modelo de } \\
\text { sistema de produção diversificado serve à comunidade acadêmica, pois se embasa } \\
\text { num sistema de produção ativo e funcional, do qual os alunos são os maiores } \\
\text { beneficiários, mas também transpassa os portões da universidade, podendo servir } \\
\text { de modelo para viabilização de cursos, palestras e principalmente um local onde o } \\
\text { produtor possa buscar informações e tecnologias. }\end{array}$
\end{tabular}




\section{5}

Tírulo Ecologia da Paisagem e Conservação

COORDENAÇÃO Rogerio Hartung Toppa

SETOR Departamento de Ciências Ambientais

CONTATO dca@ufscar.br

RESUMO O Programa Ecologia da Paisagem e Conservação tem como finalidade realizar módulos de estudo aplicados ao uso de Geotecnologias voltadas a formação profissional na temática ambiental. O desenvolvimento terá como propósito subsidiar o meio acadêmico e profissional para estimular e potencializar a elaboração de pesquisas e atividades voltadas a sociedade, por meio de aplicações envolvendo fundamentações teóricas e prática da Ecologia, Biologia da Conservação, Cartografia e Geoprocessamento.

PALAVRAS-CHAVE geoprocessamento; planejamento ambiental; ecologia da paisagem; meio ambiente; educação profissional 
Título Ecologia e Conservação

COORDENAÇÃo Dalva Maria da Silva Matos

SETOR Departamento de Hidrobiologia

CONTATO secdhb@ufscar.br

RESUMO Estamos propondo este programa para incluir as atvidades de extensão que já são realizadas por docentes juntamente coms seus alunos do PPGERN, entre as quais o curso de verão em Ecologia, que anualmente tem sido oferecido e em cada edição recebemos alunos de diversas partes do Brasil. o Simpósio de ecologia é mais uma atividade e além de outros eventos e mini-cursos.

PALAVRAS-CHAVE cursos; eventos; ecologia; meio ambiente; educação ambiental

DATA INÍCIO 16/11/2011 


\section{5}

Tíruı Educação Ambiental

COORDENAÇÃo Haydee Torres de Oliveira

SETOR Departamento de Ciências Ambientais

CONTATO dcam@ufscar.br

RESUMO O presente Programa com foco em Educação Ambiental reflete a consolidação do laboratório de EA do DHb e do GEPEA - Grupo de Estudos e Pesquisa em Educação. Privilegia-se uma perspectiva de formação de práxis, fundamentada em escolhas pedagógicas que favorecem a integração entre ensino, pesquisa, extensão e gestão ambiental e a construção de sujeitos que possam tomar em suas mãos a construção de sociedades mais justas e sustentáveis.

PALAVRAS-CHAVE educação ambiental; sustentabilidade; educadoras; meio ambiente; educação ambiental 
Tíruıo Entomologia Aquática

COORDENAÇÃo Livia Maria Fusari

SETOR Departamento de Hidrobiologia

CONTATO secdhb@ufscar.br

RESUMO O Programa tem por objetivo prestar assessoria e treinamento a profissionais e estudantes da área biológica no conhecimento e identificação dos Insetos Aquáticos, bem como no reconhecimento de seu papel nos vários sistemas aquáticos continentais e na avaliação e no monitoramento ambiental.

PALAVRAS-CHAVE insetos aquáticos; taxonomia; ecologia; meio ambiente; educação profissional DATA INÍCIO $\quad 28 / 5 / 2010$ 


\section{Estudos, Pesquisas, Ensino, Consultoria, Assessoria e Divulgação em Geociências, Geotecnia e Meio Ambiente}

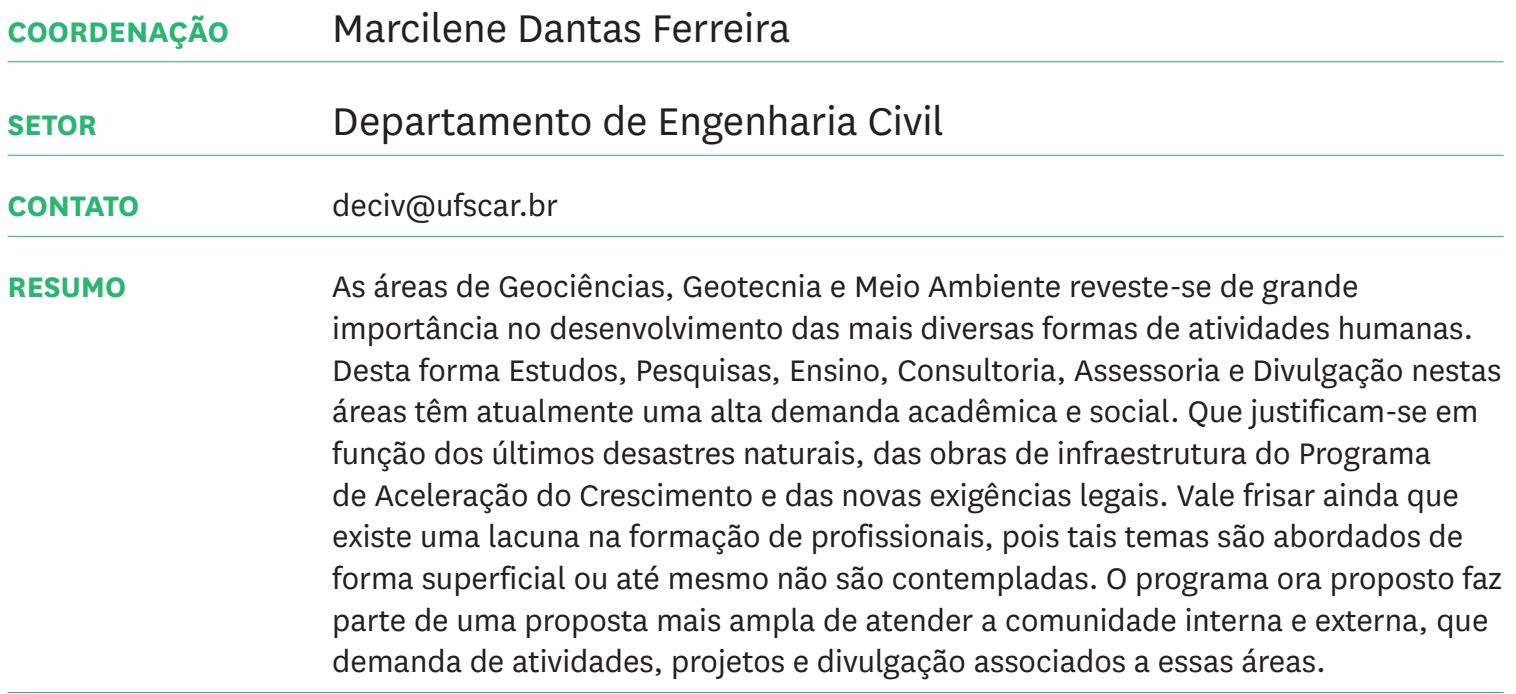


TítULO

\section{Formação Profissional Inicial, Continuada, Treinamento e Prestação de Serviço na Área de Ciências Naturais}

\begin{tabular}{ll} 
COORDENAÇÃO & Maria Virginia UrSo Guimaraes \\
\hline SETOR & Departamento de Biologia \\
\hline RONTATO & dbio@ufscar.br \\
\hline RESUMO & $\begin{array}{l}\text { Formação e aperfeiçoamento de profissionais que atuam na área de Ciências } \\
\text { Naturais em âmbito regional, nacional e internacional que resulte na melhoria } \\
\text { de qualidade dos profissionais formados nesta instituição e na qualificação de } \\
\text { profissionais em atividade no mercado. Através da realização de cursos, palestras, } \\
\text { ciclo de debates, atuação em consultorias ambientais, entre outras atividades a } \\
\text { serem desenvolvidas com a participação dos estudantes dos cursos de Ciências } \\
\text { Biológicas da UFSCar, servidores docentes e técnico-administrativos, pretende-se } \\
\text { atingir o tripé Ensino-Pesquisa-Extensão, além da aproximação com a comunidade } \\
\text { regional. }\end{array}$
\end{tabular}

PALAVRAS-CHAVE biologia; formação continuada; ensino; meio ambiente; educação continuada 
Título Genética Aplicada à Conservação Animal

COORDENAÇÃo Patricia Domingues de Freitas

SETOR Departamento de Genética e Evolução

CONTATO dge@ufscar.br

RESUMO O programa integra metodologias da genética clássica e molecular para fornecer subsídios para auxiliar na resolução de problemas relativos a conservação da biodiversidade e seu uso sustentável, podendo ressaltar abordagens relacionadas à genética forense e monitoramento e manejo de populações in situ e ex situ.

PALAVRAS-CHAVE genética da conservação; genética forense; aquicultura sustentável; meio ambiente; gestão de recursos naturais

DATA INÍCIO 3 3/10/2014 
TíTULO

\section{Geotecnologias Aplicadas ao Planejamento e Conservação de Paisagens}

\begin{tabular}{ll} 
COORDENAÇÃO & Roberta Averna Valente Botezelli Tolini \\
\hline SETOR & Departamento de Ciências Ambientais \\
\hline CONTATO & dca@ufscar.br
\end{tabular}

RESUMO O programa tem por objetivo o desenvolvimento de atividades de extensão que estejam relacionadas às geotecnologias e também à topografia, aplicadas ao planejamento e conservação de paisagem. Atividades relacionadas ao treinamento/ aprendizado de geotecnologias (Sistema de Informação Geográfica, Sensoriamento Remoto e GNSS), bem como a aplicação prática e disseminação à comunidade destas técnicas. Um objetivo especifico do Programa será a disseminação das Geotecnologias sempre por meio da Técnica Participatória.

PALAVRAS-CHAVE geoprocessamento; ecologia da paisagem; técnica participatória; meio ambiente; desenvolvimento rural 
TíTULO

Gestão e Análise Ambiental: PET AMBIENTAL

\begin{tabular}{ll} 
COORDENAÇÃo & Juliano Costa Goncalves \\
\hline SETOR & Departamento de Ciências Ambientais \\
\hline CONTATO & dcam@ufscar.br \\
\hline RESUMO & O Programa de Educação Tutorial Ambiental (PET Ambiental) é uma programa \\
& de ensino, pesquisa e extensão. A criação deste Programa de Extensão está de \\
& acordo com as necessidades do PET Ambiental, tendo em vista as atividades de \\
& extensão que deve desenvolver. Os objetivos deste Programa de Extensão estão \\
& alinhados com os objetivos do PET Ambiental e são, de forma resumida: promover \\
& uma formação ampla e de qualidade aos alunos do Curso de Gestão e Análise \\
& Ambiental; diversificar as atividades curriculares dos estudantes da UFSCar; \\
& estimular a integração da formação acadêmica da UFSCar com as futuras atividades \\
& profissionais.
\end{tabular}

PALAVRAS-CHAVE gestão ambiental; sustentabilidade; desenvolvimento sustentável; meio ambiente; gestão de recursos naturais 
TÍTULO

\section{Grupo de Estudos em Ecologia da Restauração (GEER): Proposta de Criação de um Grupo de Estudos Ligado à Área de Ecologia Vegetal}

\begin{tabular}{ll} 
COORDENAÇÃo & Alessandra dos Santos Penha \\
\hline SETOR & Departamento de Biotecnologia e Produção Vegetal e Animal \\
\hline CONTATO & stela@cca.ufscar.br \\
\hline RESUMO & objetivo do programa é capacitar o corpo discente do Centro de Ciências \\
& Agrárias da UFSCar em atividades teóricas e práticas direta e indiretamente \\
& outros materiais acadêmicos para discutirem sobre a temática que subsidia e que \\
& se relaciona à ecologia da restauração, como o paradigma da sustentabilidade \\
& no âmbito da restauração de ecossistemas naturais degradados, a dinâmica de \\
& sucessão secundária, os mecanismos de regeneração natural em comunidades \\
& vegetais nativas brasileiras, os impactos de atividades antrópicas sob atributos \\
& ecossistêmicos, técnicas de manejo e de adequação ambiental de áreas-alvo \\
& da restauração ecológica, legislação ambiental, entre outros temas ligados à \\
& conservação e manejo de recursos naturais no interior de propriedades rurais. \\
& Pretende-se realizar projetos de pesquisa e extensão universitária relacionados a \\
& esses temas.
\end{tabular}

PALAVRAS-CHAVE restauração ecológica; manejo; áreas degradadas; meio ambiente; gestão de recursos naturais 
TíTULO

\section{Inovação, Formação e Atuação de Profissionais no Licenciamento Ambiental}

\begin{tabular}{ll} 
COORDENAÇÃO & Alberto Luciano Carmassi \\
SETOR & Centro de Ciências da Natureza \\
\hline CONTATO & diretorccn@ufscar.br
\end{tabular}

RESUMO O programa tem por objetivo o desenvolvimento de protocolos e metodologias a serem utilizadas por Engenheiros Ambientais e Biólogos em processos de Licenciamento Ambiental. Atualmente as empresas públicas e privadas, bem como órgãos ambientais, apresentam dificuldades em encontrar profissionais que atendam as demandas e expectativas do mercado e, principalmente, que tenham condição de realizar um trabalho que realmente avalie os impactos ambientais que os pequenos, médios e grandes empreendimentos causam sobre o meio ambiente. Esse programa, além formar mão de obra qualificada para atuar nos setores público e privado, prestará assessoria técnica e buscará estágios e bolsas de estudo para os alunos da UFSCar que pretendem atuar nessa área.

PALAVRAS-CHAVE protocolos de avaliação; impacto ambiental; monitoramento ambiental; meio ambiente; gestão de recursos naturais 


\section{TíTULO \\ Integrando Ações em Ensino-Pesquisa- Extensão: Coletivo de Estudos e Práticas em Permacultura - Pés Vermelhos (CPPV)}

\begin{tabular}{ll} 
COORDENAÇÃO & Ana Paula de Oliveira Amaral Mello \\
\hline SETOR & Departamento de Desenvolvimento Rural \\
\hline CONTATO & ddr@cca.ufscar.br \\
\hline RESUMO & O coletivo foi formado por alunos do curso de Bacharelado em Agroecologia \\
& com o intuito de colocar em prática o aprendizado construído em sala de aula e, \\
principalmente, com experiências adquiridas fora da universidade no diálogo com & \\
& os produtores rurais, assentados da reforma agrária da região. A premissa maior \\
& do coletivo é de que ao aplicar os conceitos de forma participativa construindo \\
& o conhecimento junto com docente, o aluno sente-se mais motivado a se manter \\
& no curso, bem como a transmitir o conhecimento prático/teórico para fora dos \\
& domínios da universidade. Ensinar é aprender. Essa justificativa vem sustentada \\
pelo Plano de Desenvolvimento Institucional da UFSCar e pelos Projetos Político- \\
pedagógicos dos diferentes cursos oferecidos no Centro de Ciências Agrárias \\
da UFSCar. Atualmente o coletivo é coordenado pela docente proponente desse \\
projeto.
\end{tabular}

PALAVRAS-CHAVE permacultura; integração de sistemas; agroecologia; meio ambiente; desenvolvimento rural 
Título Laboratório de Plâncton DHb

COORDEnAçÃo Maria da Graca Gama Melão

SETOR Departamento de Hidrobiologia

CONTATO secdhb@ufscar.br

RESUMO O objetivo do programa é desenvolver atividades (cursos, palestras, assessorias, análises laboratoriais e de campo) que disponibilizem à comunidade, o conhecimento científico na área de limnologia. 
TíTULO

Observatório do Comitê de Bacia do Rio Sorocaba e Médio Tietê

\begin{tabular}{ll} 
COORDENAÇÃO & Andre Cordeiro Alves dos Santos \\
SETOR & Departamento de Biologia \\
\hline CONTATO & dbio@ufscar.br
\end{tabular}

RESUMO O programa tem como objetivo assessorar o comitê de bacia na proposição de politicas públicas para a gestão dos recursos hidrícos. O Comitê de Bacia é formado por integrantes de três segmentos, Estado, Municípios e Sociedade Civil, principlamente para estes dois últimos a Universidade pode ser parceira na elaboração de projetos, na formação de técnicos e na definição de metas e ações. As atividades previstas para este programa incluem cursos e treinamentos e apoio técnico em projetos e planos sobre conservação de recursos hídricos para os integrantes do Colegiado do CBH-SMT.

PALAVRAS-CHAVE recursos hidricos; gestão ambiental; políticas públicas; meio ambiente; capacitação de gestores de políticas públicas 
Título

Pesquisa e Desenvolvimento em Alternativas de Manejo de Solos Tropicais

\begin{tabular}{ll} 
COORDENAÇÃO & Maria Leonor Ribeiro Casimiro Lopes Assad \\
\hline SETOR & Departamento de Recursos Naturais e Proteção Ambiental \\
\hline RESUMO & secdrnpa@cca.ufscar.br \\
& Os solos constituem a base para a produção de alimentos, fibras e matérias- \\
& primas diversas e o conhecimento de seu comportamento e de sua distribuição e \\
& variação no espaço é de grande importância nos estudos ambientais (zoneamentos, \\
& avaliações de impactos) visando o desenvolviemnto rural (planejamentos, \\
& alternativas de manejo). A disponibilidade de informação sobre solos é fundamental \\
& para a tomada de decisão no agronegócio. O Programa tem por objetivo produzir \\
& informaçães sobre a distribuição e o funcionamento de solos brasileiros bem \\
& como fornecer alternativas para seu manejo. Visa também organizar cursos de \\
& curta duração, para graduandos e técnicos que atuam com produção agrícola, \\
& e desenvolver atividades de divulgação do conhecimento científico sobre solos \\
& brasileiros.
\end{tabular}




\section{5}

TÍTULO

Pesquisa, Ensino e Consultoria em Microbiologia Ambiental

\begin{tabular}{ll} 
COORDENAÇÃO & Iolanda Cristina Silveira Duarte \\
\hline SETOR & Departamento de Biologia \\
\hline CONTATO & dbio@ufscar.br \\
\hline
\end{tabular}

RESUMO O presente programa pretende estudar, pesquisar e dar consultoria na área de microbiologia ambiental. Serão desenvolvidos projetos relacionados com análises da biodiversidade microbiana e biorremediação de áreas contaminadas e tratamento de águas residuárias.

O principal objetivo desse programa é envolver discentes da UFSCar em projetos de biorremediação e controle ambiental atuando de forma efetiva junto à comunidade.

PALAVRAS-CHAVE microbiologia; saneamento; bioprocessos; meio ambiente; inovação tecnológica 
Título

\section{Pesquisa, Ensino, Consultoria e Análises de Solo, Gases do Efeito Estufa e Biogeoquímica de Ecossistemas Tropicais}

\begin{tabular}{ll} 
COORDENAÇÃO & Janaina Braga do Carmo \\
SETOR & Departamento de Ciências Ambientais - Sorocaba \\
\hline CONTATO & dca@ufscar.br \\
\hline RESUMO & $\begin{array}{l}\text { As justificativas para a criação do programa é firmar parcerias com empresas e } \\
\text { instituições de pesquisa nacional e internacional bem como a prestação de serviços } \\
\end{array}$ \\
& $\begin{array}{l}\text { à comunidade, através de análises rotineiras e mais específicas no que diz respeito à } \\
\text { fertilidade, microbiologia e emissão de gases (CO2, N2O e CH4) do solo. } \\
\text { Os principais objetivos são: prestação de serviço à comunidade regional; ensino e } \\
\text { pesquisa; consultoria e parceria com empresas privadas. }\end{array}$
\end{tabular}

PALAVRAS-CHAVE ecossistemas tropicais; emissão de gases; solo agrícola e florestal; meio ambiente; cooperação interinstitucional 
Plano de Monitoramento da Ictiofauna

e Avifauna dos Ambientes Aquáticos e Fragmentos Vegetais da Área do Centro Experimental de Aramar

COORDENAÇÃo Julio Cesar Garavello

SETOR Departamento de Ecologia e Biologia Evolutiva

CONTATO secdebe@ufscar.br

RESUMO Inventário das espécies de peixes dos ribeirões e riachos afluentes dos rios Ipanema e Sorocaba e aves nos fragmentos vegetais contidos na área sob influência do Centro Tecnológico de Aramar em Iperó.

PALAVRAS-CHAVE ictiofauna; avifauna; aramar; meio ambiente; gestão de recursos naturais

DATA INÍCIO $\quad$ 4/1/2013 


\section{TíTULO \\ Programa de Atividades de Extensão da Secretaria Geral de Gestão Ambiental e Sustentabilidade (SGAS)}

\begin{tabular}{ll} 
COORDENAÇÃO & Erica Pugliesi \\
\hline SETOR & Departamento de Ciências Ambientais \\
\hline RESUMO & dcam@ufscar.br \\
& O programa de extensão proposto terá como escopo o desenvolvimento e \\
& implantação de projetos em áreas ligadas ao meio ambiente, tais como gestão \\
& de resíduos sólidos recicláveis comuns e perigosos, educação ambiental e \\
& agroecologia. Pretende-se estabelecer parceiros e oferecer assessoria na \\
& implementação de atividades de coleta seletiva de resíduos recicláveis e manejo e \\
& recuperação dos diversos resíduos perigosos gerados nas mais diversas atividades \\
& industriais, semi-industriais e de saúde, com o objetivo de permitir destinação \\
& segura e ambientalmente correta, buscar a otimização dos processos nas unidades \\
& geradoras, a redução de custos de implantação e operação do gerenciamento de \\
& resíduos, além do incremento constante da conscientização ambiental das pessoas \\
& envolvidas.
\end{tabular}

PALAVRAS-CHAVE gestão de resíduos; educação ambiental; agroecologia; meio ambiente; gestão de recursos naturais 


\section{Tírulo Programa de Extensão em Biologia Vegetal}

COORDENAÇÃo Marcos Arduin

SETOR Departamento de Botânica

CONTATO db@ufscar.br

RESUMO O objetivo principal deste programa é desenvolver atividades extensionistas, serviços e produtos, nas áreas temáticas discriminadas. Estas atividades estão diretamente associadas às atividades de ensino e pesquisa dos docentes do Departamento de Botânica e afins.

PALAVRAS-CHAVE biologia vegetal; capacitação; recuperação; meio ambiente; educação ambiental DATA INÍCIO $\quad 11 / 8 / 2005$ 
Tíruıo Programa de Extensão em Direito Ambiental

COORDENAÇÃo Celso Maran de Oliveira

SETOR Departamento de Ciências Ambientais

CONTATO dcam@ufscar.br

RESUMO O presente Programa procura responder demandas da sociedade no sentido de promover o necessário suporte as atividades do Poder Público e da iniciativa privada através da elaboração de laudos, estudos, pareceres e auditorias em Direito Ambiental e em áreas afins. Pretende, igualmente, capacitar estudantes de graduação e de pós graduação no campo do Direito Ambiental. Pretende ainda promover cursos diversos (especialização, atualização, treinamento e qualificação profissional e capacitação) na Área do Direito Ambiental e outras áreas correlatas.

PALAVRAS-CHAVE direito ambiental; gestão ambiental; desenvolvimento sustentável; meio ambiente; gestão de recursos naturais 


\section{5}

TíTULO

\section{Programa de Extensão em Perícias e} Sustentabilidade Ambiental

\begin{tabular}{ll} 
COORDENAÇÃo & Carlos Augusto de Sousa Martins Filho \\
\hline SETOR & Departamento de Ciências Ambientais \\
\hline CONTATO & dcam@ufscar.br
\end{tabular}

RESUMO O presente Programa procura responder demandas da Justiça Estadual de São Paulo e da Justiça Federal no sentido de promover o necessário suporte as atividades do Poder Judiciário através da elaboração de Laudos Periciais em diversas áreas. Simultaneamente pretende capacitar estudantes de graduação e de pós-graduação no campo das perícias judiciais. Pretende ainda promover cursos diversos (especialização, atualização,treinamento e qualificação profissional capacitação) na Área de Perícias e outras áreas correlatas.

PALAVRAS-CHAVE perícias ambientais; gestão ambiental; sustentabilidade ambiental; meio ambiente; gestão de recursos naturais 


\section{Título Rede de Sementes Florestais}

\begin{tabular}{|c|c|}
\hline COORDEN/ & Fatima Conceicao Marquez Pina Rodrigues \\
\hline SETOR & Departamento de Ciências Ambientais - Sorocaba \\
\hline CONTATO & dca@ufscar.br \\
\hline RESUMO & $\begin{array}{l}\text { A demanda por sementes florestais tanto para a produção de mudas quanto para } \\
\text { o artesanato é crescente no mercado. A maioria das áreas potenciais de produção } \\
\text { de sementes está localizada nas áreas de entorno das Unidades de Conservação } \\
\text { e em assentamentos ou pequenas propriedades rurais, demandando a parceria } \\
\text { com órgãos públicos e a sociedade civil para viabilizar a produção sustentável de } \\
\text { sementes. O programa tem como objetivo geral contribuir para a estruturação } \\
\text { da produção de sementes florestais a partir parcerias e ações em andamento no } \\
\text { âmbito em da Rede Mata Atlântica de Sementes Florestais e das Redes de Sementes } \\
\text { Florestais. }\end{array}$ \\
\hline
\end{tabular}

sementes florestais; rede de sementes florestais; produto florestal não-madeireiro; meio ambiente; educação ambiental 


\section{Títuı $\quad$ Sustentabilidade e Gestão Ambiental}

COORDENAÇÃo Frederico Yuri Hanai

SETOR Departamento de Ciências Ambientais

CONTATO dcam@ufscar.br

RESUMO Este programa de extensão possui objetivo principal de viabilizar a realização de projetos, ações e atividades no sentido de colaborar com estudos, proposições e aplicações de instrumentos, ferramentas, indicadores e procedimentos para análise da sustentabilidade e para a gestão ambiental. Novos instrumentos, ferramentas, indicadores e procedimentos adequados e confiáveis são necessários para enfrentar a fragmentação e as dificuldades de integração dos conhecimentos relacionados à complexidade da sustentabilidade e seu desenvolvimento nos processos de gestão ambiental. As atividades programadas visam propiciar a integração e o compartilhamento de saberes, conhecimentos e tecnologias, buscando assegurar a equidade de acesso dos usuários, a fim de tornar úteis os resultados obtidos aos usuários envolvidos. 
Tітицо Zoofisiologia e Bioquímica Comparativa

COORDENAÇÃo Marisa Narciso Fernandes

SETOR Departamento de Ciências Fisiológicas

CONTATO dcf@ufscar.br

RESUMO O programa tem como pressuposto a divulgação e uso do conhecimento para Instituições de ensino ou tecnológicas, públicas ou privadas, produtores rurais e empresas, com vistas ao manejo adequado de ambientes aquáticos de forma a manter a saúde dos peixes e outros animais aquáticos, incentivar o aumento da produtividade e a preservação da qualidade da água.

PALAVRAS-CHAVE bioindicadores; morfologia; fisiologia; meio ambiente; inovação tecnológica 
Frame do vídeo USE - 10 anos de história. Direção: Débora Burini.

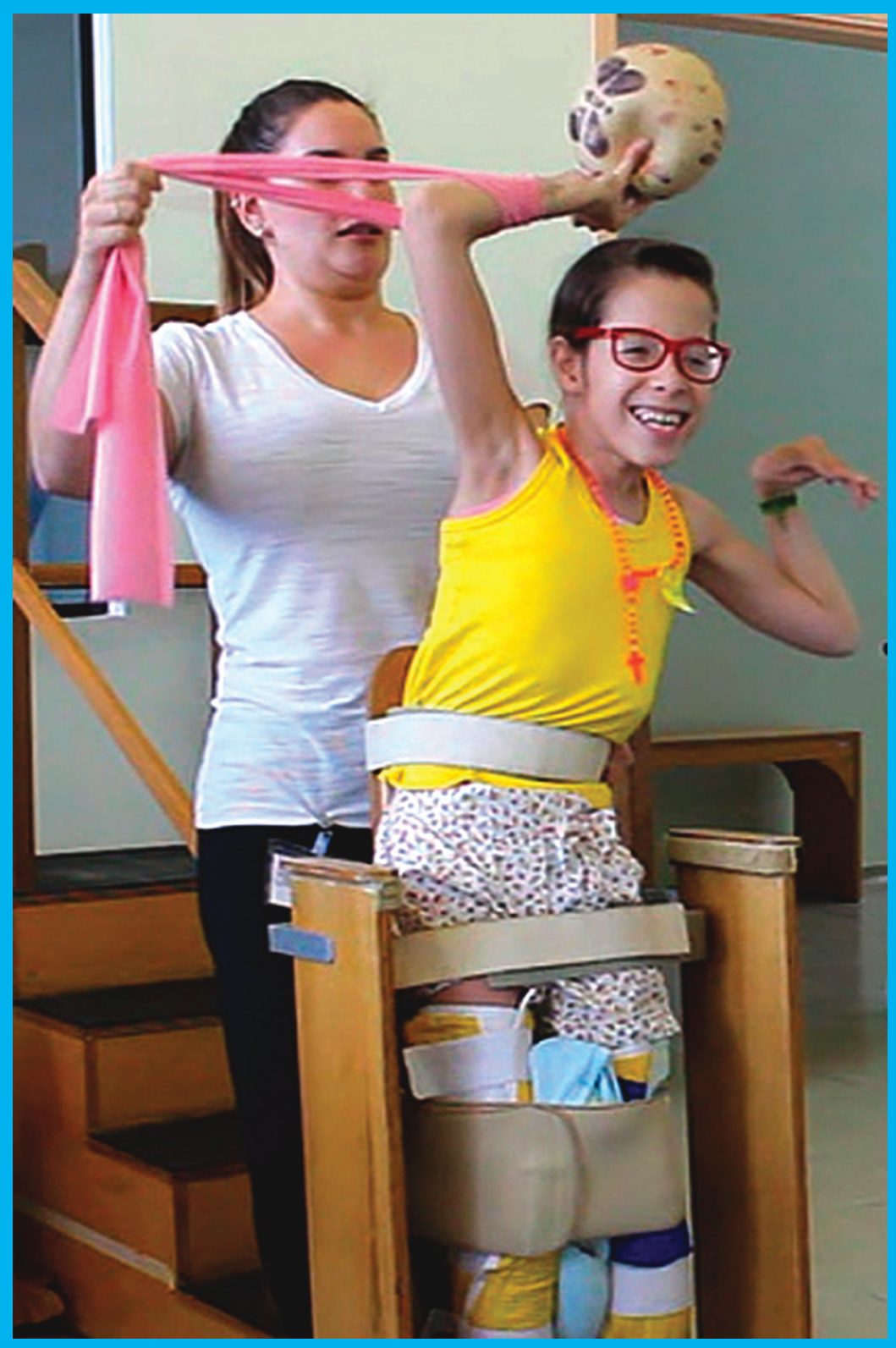

OUTUBRO 2016 
A Avaliação Psicológica como Recurso Técnico da Psicologia Aplicada: instrumentação, Diagnóstico e Intervenção

\begin{tabular}{ll} 
COORDENAÇÃO & Marilia Goncalves \\
\hline SETOR & Departamento de Psicologia \\
\hline CONTATO & dpsic@ufscar.br \\
\hline RESUMO & $\begin{array}{l}\text { São objetivos deste programa a construção de instrumentos específicos para cada } \\
\text { situação; o ecaminhamento dos casos para os serviços existentes na comunidade; } \\
\text { a publicação na imprensa não especializada e nos meios acadêmicos os resultados } \\
\text { das análises dos dados obtidos nas atividades do programa. }\end{array}$
\end{tabular}




\begin{tabular}{ll} 
TíTULO & Abordagem Interdisciplinar em Cardiologia \\
\hline COORDENAÇÃo & Sergio Luiz Brasileiro Lopes \\
\hline SETOR & Departamento de Medicina \\
\hline CONTATO & dmed@ufscar.br \\
\hline RESUMO & $\begin{array}{l}\text { As doenças cardiovasculares são altamente prevalentes na população adulta, } \\
\text { acometendo principalmente indivíduos em idade produtiva. Carreiam grande } \\
\text { morbidade e são a primeira causa de mortalidade entre os adultos acima de 39 } \\
\text { anos, constituindo-se, assim, em um ônus individual, coletivo e social. A abordagem } \\
\text { interdisciplinar é capaz de prover uma atenção integral aos seus portadores, } \\
\text { favorecendo a resolutividade do cuidado e a melhoria da qualidade de vida dos } \\
\text { usuários. }\end{array}$ \\
\hline PALAVRAS-CHAVE & $\begin{array}{l}\text { integralidade; interdisciplinar; cardiologia; saúde; } \\
\text { atenção integral à saúde de adultos }\end{array}$ \\
\hline DATA INÍCIO & 5/11/2012
\end{tabular}


Título

\section{Ações de Integração em Gestão, Formação, Saúde e Trabalho}

\begin{tabular}{ll} 
COORDENAÇÃO & Vivian Aline Mininel \\
\hline SETOR & Departamento de Enfermagem \\
\hline CONTATO & denf@ufscar.br \\
\hline
\end{tabular}

RESUMO Este programa visa integrar ações desenvolvidas em ensino, pesquisa e extensão, sobre as relações entre trabalho e gestão em saúde, considerando as repercussões na saúde dos trabalhadores e na formação profissional. Parte-se do pressuposto de que as mudanças ocorridas no cenário da saúde e no contexto macrossocial de trabalho refletem nas práticas de gestão, nos princípios da formação e nos processos de trabalho nas esferas microssociais.

O programa de extensão está vinculado ao Grupo de Ensino, Pesquisa e Extensão “Gestão, Formação, Saúde e Trabalho”, desenvolvido com o intuito de fortalecer o tripé ensino, pesquisa e extensão, fomentando a construção de conhecimentos que subsidiem a prática profissional qualificada.

É relevante, do ponto de vista acadêmico, por proporcionar aos estudantes possibilidades de inserção em atividades voltadas para a construção de conhecimentos e práticas de gestão, trabalho e saúde, com base na formação. Do ponto de vista social, vislumbra-se contribuir com a qualificação dos serviços de saúde, das práticas de cuidado e do desenvolvimento dos trabalhadores, com foco na integralidade e humanização da assistência ao usuário.

PALAVRAS-CHAVE Saúde; trabalho; gestão; saúde; desenvolvimento do sistema de saúde

DATA INÍ́CIO 9 9/9/2016


TÍTULO

Ações e Investigações em Processos Psicanalíticos

\begin{tabular}{ll} 
COORDENAÇÃO & Cassia Regina Rodrigues \\
\hline SETOR & Departamento de Medicina \\
\hline CONTATO & dmed@ufscar.br \\
\hline RESUMO & $\begin{array}{l}\text { A contemporaneidade tem se caracterizado pelo aumento do sofrimento mental, } \\
\text { fruto da precariedade das condições concretas e afetivas da humanidade. Em } \\
\text { consequência desse panorama, tem sido crescente o número de pessoas que } \\
\text { buscam auxílio psicoterápico em instituições de saúde. Partindo da perspectiva pós- } \\
\text { moderna de que o aparecimento da patologia nas pessoas é fortemente influenciado } \\
\text { pela cultura, esse programa tem como objetivo analisar o campo que compõe os } \\
\text { processos psicoterápicos psicanalíticos desenvolvidos na Sus. } \\
\text { Através dessa análise, vislumbra-se a possibilidade de implementar e implantar } \\
\text { práticas clínicas psicoterápicas resolutivas às necessidades de saúde da população } \\
\text { que tem buscado auxílio nos serviços de Atenção Básica à saúde. }\end{array}$
\end{tabular}

PALAVRAS-CHAVE psicanálise; psicoterapia; cuidado em saúde; saúde; atenção integral à saúde de adultos 
Tíruı $\quad$ Ações em Saúde Coletiva

COORDENAÇÃo Geovani Gurgel Aciole da Silva

SETOR Departamento de Medicina

CONTATO dmed@ufscar.br

RESUMO O presente programa busca levar estudantes de graduação na área da saúde, profissionais de saúde, usuários, gestores etc, numa perspectiva interdisciplinar, a vivenciar ações de saúde coletiva nosa vários níveis de atenção e nos diversos cenários de produção do cuidado, como forma de contribuir para o desenvolvimento da tríada ensino-pesquisa-extensão. o programa espera, além disso, estimular os estudantes e profissionais a desenvolverem pequenos projetos de intervenção, no sentido de vivenciarem de modo teórico-prático as relações entre o mundo das necessidades sociais de saúde e a formação na graduação com as práticas profissionais interagindo com os diversos grupos e organizações sociais e a comunidade em geral.

PALAVRAS-CHAVE cuidado em saúde; educação em saúde; saúde coletiva; saúde; desenvolvimento do sistema de saúde 

em Bebês de Risco nos Dois Primeiros Anos de Vida

\begin{tabular}{ll} 
COORDENAÇÃO & Eloisa Tudella \\
\hline SETOR & Departamento de Fisioterapia \\
\hline CONTATO & dfisio@ufscar.br \\
\hline RESUMO & $\begin{array}{l}\text { São objetivos deste programa: proporcionar atendimento especializado à } \\
\text { população; estimular a constituição de equipes interdepartamentais que viessem a } \\
\text { estruturar projetos de extensão interdisciplinares com temáticas do Programa. }\end{array}$ \\
\hline PALAVRAS-CHAVE & acompanhamento; bebês; infância; saúde; atenção integral à criança \\
\hline DATA INÍCIO & $29 / 6 / 2000$
\end{tabular}




\begin{tabular}{ll} 
TÍTULO & Ambulatório de Dermatologia Clínica \\
\hline COORDENAÇÃo & Maristela Schiabel Adler \\
\hline SETOR & Departamento de Medicina \\
\hline CONTATO & dmed@ufscar.br \\
\hline RESUMO & $\begin{array}{l}\text { O programa visa o atendimento e tratamento clínico de usuários da rede pública de } \\
\text { saúde da cidade de São Carlos, portadores de patologias dermatológicas crônicas } \\
\text { e agudas, auxiliando dessa forma no atendimento da atenção básica dessas } \\
\text { patologias. }\end{array}$ \\
\hline PALAVRAS-CHAVE & dermatologia; atendimento; tratamento clinico; saúde; saúde da família \\
\hline DATA INÍCIO & 24/4/2013
\end{tabular}


TÍTULO

Análise de Alimentos Voltada à Educação Nutricional

\begin{tabular}{ll} 
COORDENAÇÃO & Lucia Helena Seron \\
\hline SETOR & Departamento de Química \\
\hline CONTATO & dqchefe@ufscar.br \\
\hline RESUMO & O programa abrangerá várias atividades tais como a determinação analítica de \\
& vários nutrientes de interesse em alimentos (frutas e hortaliças)quais sejam: \\
& vitamina C, vitamina A, vitamina E e sais minerais como ferro, cálcio, fósforo, cobre, \\
& zinco, etc. Esses nutrientes são indispensáveis ao ser humano, principalmente \\
& a crianças em idade escolar. Além disso, buscará apresentar às crianças do \\
& ensino fundamental esses conhecimentos para nelas desenvolver uma educação \\
& nutricional, para que passem a ter uma alimentação balanceada e saudável. Buscará \\
& ainda determinar os teores de compostos tóxicos presentes em alimentos naturais \\
& e industrializados, a fim de que as crianças evitem a ingestão de alimentos com alto \\
& teor de sódio, alimentos contendo nitratos e oxalatos, altamente prejudiciais e que \\
& podem desencadear graves problemas de saúde ao ser humano.
\end{tabular}

PALAVRAS-CHAVE $\quad$ alimentos; vitaminas e minerais; educação nutricional; saúde; atenção integral à criança 
TítuLo

Apoio à Rede Escola de Cuidados à Saúde do Município de São Carlos

$\begin{array}{ll}\text { COORDENAÇÃo } & \text { Bernardino Geraldo Alves Souto } \\ \text { SETOR } & \text { Departamento de Medicina }\end{array}$

CONTATO dmed@ufscar.br

RESUMO O presente programa tem como propósito contribuir nos processos de formação, educação permanente, participar ativamente da construção das práticas de cuidado e gestão e ampliar a relevância de suas linhas de pesquisa e de produção tecnológica, direcionando-as para o enfrentamento dos problemas prevalentes de saúde das pessoas, famílias e da sociedade.

saúde; práticas; formação; saúde; educação continuada 


\section{Tíruı Apoio Matricial em Atenção à Saúde da Criança e do Adolescente}

\begin{tabular}{|c|c|}
\hline COORDEN & Bento Vidal de Moura Negrini \\
\hline SETOR & Departamento de Medicina \\
\hline CONTATO & dmed@ufscar.br \\
\hline RESUMO & $\begin{array}{l}\text { A Área da saúde da Criança e do adolescente (ASCRA) do Departamento de } \\
\text { Medicina da UFSCar, através de seu corpo docente, desenvolve atividades } \\
\text { assistenciais, de intervenção coletiva e processos de educação para a saúde e } \\
\text { vigilância epidemiológica e ambiental tendo como alvo crianças, pré-adolescentes } \\
\text { e adolescentes (0 a } 18 \text { anos), e profissionais de saúde envolvidos com esta } \\
\text { população, incluindo o trabalho em creches e escolas - integração do sistema de } \\
\text { saúde/sistema de educação. Com base nos princípios do SUS, o cuidado integral à } \\
\text { criança envolve a promoção da saúde, a prevenção e o tratamento de problemas } \\
\text { prevalentes na infância, buscando a melhoria da qualidade de vida individual e } \\
\text { coletiva. Entende-se que a Universidade deve e pode participar da transformação } \\
\text { das práticas profissionais e do cuidado, atuando em parceria com a rede escola, } \\
\text { que é parte integrante da estrutura do curso de medicina da UFSCar. Esta atividade } \\
\text { proposta está em consonância com o Programa de Apoio à Rede Escola de Cuidados } \\
\text { à Saúde do Município de São Carlos e tem por objetivo promover a melhoria das } \\
\text { condições de vida da população de crianças e adolescentes deste município, através } \\
\text { da formação de um grupo técnico com caráter interinstitucional, contando com } \\
\text { participação multiprofissional, visando apoiar de forma matricial a construção e } \\
\text { execução de políticas de atenção à integral à saúde da criança. Pretende-se compor } \\
\text { o grupo técnico de Saúde da Criança do município de São Carlos, participando das } \\
\text { reuniões semanais do mesmo e das demais atividades que forem demandadas. }\end{array}$ \\
\hline
\end{tabular}

PALAVRAS-CHAVE Saúde da criança; saúde adolescente; apoio matricial; saúde; atenção integral à criança 


\section{Título \\ Assessoria Técnica Junto ao Hospital Escola Municipal (HEM)}

$\begin{array}{ll}\text { COORDENAÇÃo } & \text { Bento Vidal de Moura Negrini } \\ \text { SETOR } & \text { Departamento de Medicina }\end{array}$

CONTATO dmed@ufscar.br

RESUMO Tendo em vista a necessidade de inserção do corpo docente médico no Hospital Escola Municipal, atendendo os anseios de todos os atores envolvidos na rede de parceria; a insociabilidade ensino, pesquisa e extensão/assistência; a necessidade de docentes e preceptores capacitados para a supervisão de alunos e residentes; a necessidade de atualização constante dos profissionais médicos e não médicos que atuam num ambiente universitário, a presença do corpo docente do DMed possibilitará a implementação de um serviço médico com a qualidade técnica exigida e esperada pela UFSCar. 
TÍTULO

\section{Assistência, Ensino e Pesquisa em Moléstias Infecciosas e Parasitárias}

\begin{tabular}{ll} 
COORDENAÇÃO & Sigrid de Sousa Dos Santos \\
SETOR & Departamento de Medicina \\
\hline
\end{tabular}

CONTATO_dmed@ufscar.br

RESUMO Uma vez que a universidade deve estar intimamente ligada à realidade que a cerca e a interação entre universidade-sociedade gera benefícios mútuos, propõe-se a integração de docente infectologista do Departamento de Medicina da UFSCar no cenário do Hospital Escola Municipal (HEM) com atividades de assistência especializada, consultoria, ensino e pesquisa em Moléstias Infecciosas e Parasitárias. O objetivo é o aprimoramento da assistência hospitalar e a integração entre a universidade e o Hospital Escola Municipal.

PALAVRAS-CHAVE infectologia; interdisciplinar; saúde; saúde; hospitais e clínicas universitárias 


\section{Saúde}

TíTULO

\section{Atenção à Saúde da Criança com Patologias Gastroenterológicas, Hepáticas e Nutricionais}

\begin{tabular}{ll} 
COORDENAÇÃO & Andrea Aparecida Contini \\
\hline SETOR & Departamento de Medicina \\
\hline CONTATO & dmed@ufscar.br \\
\hline RESUMO & Em 2011 foi iniciado o Ambulatório de Gastroenterologia, Hepatologia e Nutrição \\
& realizado no Centro Municipal de Especialidades em Saúde (CEME) do município. \\
& Neste período, o Ambulatório já proporcionou atendimentos de cerca de 200 \\
& pacientes, buscando o cuidado integral dos pacientes pediátricos com patologias \\
& gastrointestinais, hepáticas e nutricionais e das suas famílias, de acordo com as \\
& melhores evidências científicas, segundo as normas do Sistema Único de Saúde \\
& (SUS). O grande desenvolvimento científico da gastroenterologia e hepatologia \\
& pediátrica observado na atualidade proporcionou diagnósticos mais precisos, mais \\
& precoces e atendimento médico com maior resolução e menor custo final associado \\
& a melhor qualidade de vida para o paciente e seus familiares. Nas últimas décadas, \\
& tanto a gastroenterologia como a hepatologia apresentaram enorme crescimento \\
& como especialidade pediátrica, tornando-se componente essencial em todos \\
& os centros acadêmicos de formação. Desta forma esse ambulatório envolverá \\
atendimento médico, investigação diagnóstica, avaliação e acompanhamento \\
especializado para as patologias encaminhadas; servirá para aprendizagem da \\
graduação e pós-graduação; poderá vir a contribuir no desenvolvimento de \\
pesquisas éticas e relevantes ao saber e à prática médica.
\end{tabular}




\section{Tírulo Atenção à Saúde em Genética Médica}

\section{COORDENAÇÃo Debora Gusmão Melo}

SETOR Departamento de Medicina

CONTATO dmed@ufscar.br

RESUMO Embora individualmente raras, em conjunto, as doenças genéticas não são raras, afetando 3 a 7\% da população geral. Além disso, junto com as anomalias congênitas, as doenças genéticas representam a segunda causa de mortalidade infantil no Brasil e em São Carlos. O objetivo geral desse Programa de Extensão é colaborar com a implantação da Política Nacional de Atenção Integral em Genética Clínica no Sistema Único de Saúde no município de São Carlos e região. Para isso, serão desenvolvidas atividades para o atendimento de demandas individuais e coletivas relacionadas às doenças genéticas e anomalias congênitas, compreendendo três grandes campos: (I) assistência, (II) educação em saúde e (III) políticas públicas. O eixo das ações assistenciais do Programa é o Ambulatório de Genética Médica. A principal atividade de extensão relacionada à educação em saúde é a ACIEPE Tópicos de Genética Médica. No campo de políticas públicas, são desenvolvidas ações de apoio e avaliação de políticas já existentes na área e de investigação da aplicação da tecnologia genômica na saúde.

PALAVRAS-CHAVE genética médica; atenção à saúde; aconselhamento genético; saúde; atenção a grupos de pessoas com necessidades especiais 
Tíuıo Atenção em Educação e Saúde Cardiovascular na Cidade de São Carlos

\begin{tabular}{ll}
\hline COORDENAÇÃo & Meliza Goi Roscani \\
\hline SETOR & Departamento de Medicina \\
\hline CONTATO & dmed@ufscar.br \\
\hline RESUMO & $\begin{array}{l}\text { O objetivo do programa de extensão na cidade de São Carlos, visa a atenção } \\
\text { primária e secundária em saúde e educação cardiovascular. }\end{array}$ \\
& As ações para a promoção da saúde e educação contam principalmente com: \\
& campanhas para a conscientização da população; atividades de extensão que visem \\
& estudantes de medicina, enfermagem , residentes e profissionais médicos formados \\
nas diversas áreas de atuação; Liga de Cardiologia; \\
participação dos alunos de medicina da Liga nos plantões clínicos do Hospital \\
Escola para melhorar o aprendizado e a promoção da saúde cardiovascular junto à \\
população.
\end{tabular}

prevenção; conscientização; ensino; saúde; atenção integral à saúde de adultos 


\section{TíTULO \\ Atenção Integral à Saúde do Adulto - Ações Educativas, Cuidativas, Gerenciais e de Pesquisa}

\begin{tabular}{ll} 
COORDENAÇÃo & Rosely Moralez de Figueiredo \\
\hline SETOR & Departamento de Enfermagem \\
\hline CONTATO & denf@ufscar.br \\
\hline RESUMO & $\begin{array}{l}\text { São objetivos deste programa desenvolver ações de ensino, pesquisa, extensão e } \\
\text { gerenciais junto a indivíduos e famílias adultos, profissionais da área da saúde e } \\
\text { instituições de saúde visando a melhoria da assistência e a qualidade de vida. }\end{array}$ \\
\hline PALAVRAS-CHAVE & saúde; adulto; saúde; desenvolvimento do sistema de saúde \\
\hline DATA INÍCIO & $1 / 1 / 2003$
\end{tabular}




\section{Saúde}

TÍTULO

\section{Atendimento Integral ao Portador de Hepatite Viral a partir da Implantação do Programa Nacional de Hepatites Virais (PNHV SUS/2002)}

\begin{tabular}{ll} 
COORDENAÇÃo & Ana Claudia de Oliveira \\
SETOR & Departamento de Medicina \\
\hline CONTATO & dmed@ufscar.br \\
\hline RESUMO & O SUS prevê o atendimento integral dos indivíduos portadores das hepatites \\
& virais no Brasil, de acordo com o Programa Nacional de Prevenção e Controle \\
& das Hepatites Virais. Esse programa foi instituído pelo Ministério da Saúde, em \\
& fevereiro de 2002, com os objetivos principais de: desenvolver ações de promoção \\
& da saúde, prevenção e assistência aos pacientes com hepatites virais, promover a \\
& vigilância epidemiológica e sanitária, ampliar o acesso e incrementar a qualidade e \\
& a capacidade instalada dos serviços de saúde em todos os níveis de complexidade, \\
& além de organizar, regulamentar, acompanhar e avaliar o conjunto das ações de \\
& saúde. O objetivo do presente programa é desenvolver condições para a adequada \\
& implantação do PNHV em nosso município, nos níveis primários e secundários de \\
& atenção, através de uma abordagem multi e interdisciplinar do portador de hepatite \\
& viral.
\end{tabular}

PALAVRAS-CHAVE hepatite viral; prevenção e tratamento; programa nacional hepatite; saúde; atenção integral à saúde de adultos 


\section{Título Avaliação e Intervenção Fisioterapêtica}

COORDENAÇÃo Patricia DriusSo

SETOR Departamento de Fisioterapia

CONTATO dfisio@ufscar.br

RESUMO O objetivo desta atividade é realizar avaliação e tratamento fisioterapêutico à comunidade de São Carlos e promover atividades acadêmicas e eventos científicos (palestras, congressos, minicursos, simpósios etc) de forma a contribuir com a produção e divulgação do conhecimento científico na área. Serão realizadas avaliações e intervenções fisioterapêuticas relacionadas às diversas áreas de atuação da Fisioterapia, tais como: Saúde Materno-Infantil, Saúde do Trabalhador, Saúde do Idoso etc. Eventos científicos também estão previstos, tais como Simpósio de Fisioterapia, palestras e cursos de capacitação. Estas atividades envolverão estudantes, profissionais e docentes da UFSCar e externos à instituição.

PALAVRAS-CHAVE fisioterapia; reabilitação; prevenção; saúde; desenvolvimento do sistema de saúde 
Título Change Pain

COORDENAÇÃo Rodrigo Bezerra de Menezes Reiff

SETOR Departamento de Medicina

CONTATO dmed@ufscar.br

RESUMO CHANGE PAIN é um programa que objetiva conscientizar os profissionais de saúde sobre as necessidades médicas ainda não atendidas para o tratamento da dor, e desenvolver soluções que melhorem a qualidade de vida dos pacientes, tendo como metas: facilitar a comunicação entre médico e paciente; facilitar o diagnóstico correto e evitar que a dor se torne crônica; buscar o equilíbrio entre tolerabilidade e confiabilidade; avaliar os mecanismos de dor; fornecer atualização constante sobre as diversas formas de dor; aprender a utilizar corretamente os analgésicos opiodes.

PALAVRAS-CHAVE dor; analgesia; educação médica; saúde; hospitais e clínicas universitárias 
Tíтu $\quad$ Clínica Psicanalítica Contemporânea

COORDENAÇÃo Joao Angelo Fantini

SETOR Departamento de Psicologia

CONTATO dpsic@ufscar.br

RESUMO São objetivos deste programa: oferecer atendimento psicoterápico continuado à comunidade da UFSCar e de São Carlos; produzir e publicar artigos científicos; organizar eventos científicos; promover cursos de extensão, aperfeiçoamento e especialização.

PALAVRAS-CHAVE psicoterapia; psicanálise; extensão; saúde; saúde da família

DATA INÍCIO $\quad 1 / 1 / 2006$ 


\section{тítulo Comportamento e Saúde - Prevenção e Promoção em Saúde Mental e Qualidade de Vida}

\begin{tabular}{ll} 
COORDENAÇÃO & Maria de Jesus Dutra dos Reis \\
\hline SETOR & Departamento de Psicologia \\
\hline CONTATO & dpsic@ufscar.br \\
\hline RESUMO & Os quadros crônicos cobram um alto preço ao seu portador e sua família. \\
& Transtornos de ansiedade e do humor, estresse e perda na qualidade de vida são \\
& algumas das condições diariamente associadas à cronicidade. O presente programa \\
& tem como objetivo promover projetos relativos a intervenções e pesquisas sobre a \\
& prevenção e tratamento de quadros crônicos, visando particularmente promover \\
& comportamentos que desenvolvam bem estar psicológico, cognitivo e emocional. \\
& Para tanto, buscará promover ações direcionadas aos diversos atores envolvidos \\
& no cuidado destes quadros (pacientes, familiares, profissionais de saúde, agentes \\
& comunitários, professores, entre outros) e também ações para prevenção e \\
& promoção da saúde e da qualidade de vida.
\end{tabular}

PALAVRAS-CHAVE Saúde mental; qualidade de vida; cronicidade; saúde; atenção integral à saúde de adultos 


\section{Saíde}

título Cuidado ao Paciente Portador de Doenças Crônicas não Transmissíveis

\begin{tabular}{ll} 
COORDENAÇÃo & Lucimar Retto da Silva de Avo \\
\hline SETOR & Departamento de Medicina \\
\hline CONTATO & dmed@ufscar.br \\
\hline RESUMO & No âmbito social, este programa se justifica uma vez as doenças crônicas são \\
& extremamente prevalentes (75\% dos idosos no Brasil); representam um problema \\
& de saúde pública (60\% da mortalidade no mundo); afetam a qualidade de vida \\
& dos indivíduos afetados; causam morte prematura; e geram efeitos econômicos \\
& adversos. Em termos acadêmicos, o programa representa uma oportunidade para os \\
& estudantes de graduação e pós-graduação desenvolverem habilidades assistenciais, \\
& de intervenção individual e coletiva, processos de educação em saúde e vigilância \\
epidemiológica, tendo como alvo o paciente portador de doenças crônicas em um \\
contexto multidisciplinar de trabalho em equipe.
\end{tabular}

PALAVRAS-CHAVE doenças crônicas; prevenção; promoção de saúde; saúde; atenção a grupos de pessoas com necessidades especiais 


\section{ті́тьо Diabetes Mellitus e Metabologia}

COORDENAÇÃo Angela Merice de Oliveira Leal

SETOR Departamento de Medicina

CONTATO dmed@ufscar.br

RESUMO O Diabetes Mellitus (DM) e as doenças metabólicas correlatas são doenças crônicas, de proporções epidêmicas e importante problema de saúde pública, especialmente nos países em desenvolvimento. Suas consequências, a médio e longo prazos, incorrem em elevado custo social e econômico. As evidências são unânimes em demonstrar que o prognóstico do Diabetes Mellitus depende do controle metabólico, que só é atingido através de intervenções múltiplas, tanto medicamentosas como não-medicamentosas. Estas últimas concentram-se na abordagem nutricional, exercício físico e educação e são a base fundamental do cuidado ao portador de Diabetes Mellitus. Este cuidado requer trabalho multidisciplinar integrado e educação continuada dos profissionais de saúde.

PALAVRAS-CHAVE diabetes mellitus; metabologia; multiprofissional; saúde; atenção integral à saúde de adultos 


\section{Título Divulgação e Atualização na Área de Motricidade Humana}

\begin{tabular}{ll} 
COORDENAÇÃO & Luiz Goncalves Junior \\
SETOR & Departamento de Educação Física e Motricidade Humana \\
\hline CONTATO & defmh@ufscar.br \\
\hline RESUMO & $\begin{array}{l}\text { São objetivos deste programa: fornecer conhecimentos necessários à capacitação } \\
\text { de profissionais para atuarem no âmbito da Motricidade Humana; oferecer métodos } \\
\text { e Técnicas que permitam a realização de diagnósticos, intervenções e avaliações na } \\
\text { área da Motricidade Humana. }\end{array}$
\end{tabular}

PALAVRAS-CHAVE motricidade humana; saúde; saúde da família

DATA INÍCIO 1/2/2005


Título Educação em Saúde

COORDENAÇÃo Maria Waldenez de Oliveira

SETOR Departamento de Metodologia de Ensino

CONTATO deme@ufscar.br

RESUMO Desenvolver ações educativas, no sentido da melhoria da qualidade de vida das comunidades a partir de uma visão integral do processo saúde-doença. Públicoalvo: São Carlos e região; crianças adolescentes, internos ou não de casas de abrigo e orfanatos; grupos de idosos; clientes de postos de saúde; profissionais do sexo; clientes das unidades básicas de saúde; trabalhadores da indústria e comércio; profissionais da área de saúde que trabalham em unidades básicas de saúde e hospitais.

PALAVRAS-CHAVE educação; saúde; saúde; desenvolvimento do sistema de saúde

DATA INÍCIO $\quad 1 / 1 / 1999$




\section{Tíruıo Esporte para a Cidadania}

COORDENAÇÃo Luiz Goncalves Junior

SETOR Departamento de Educação Física e Motricidade Humana

CONTATO defmh@ufscar.br

RESUMO São objetivos deste programa: subsidiar os conteúdos das disciplinas como medidas e avaliação para EFMH; Tópicos em nutrição relacionados ao exercício; fundamentos da capoeira; pesquisa fenomenológica em educação física; laboratório e estágio em Educação Física.

PALAVRAS-CHAVE esporte; cidadania; saúde; saúde da família

DATA INÍCIO 16/9/1999 
Tíruıo Fisiologia do Exercício

COORDENAÇ̃̃o Sergio Eduardo de Andrade Perez

SETOR Departamento de Ciências Fisiológicas

CONTATO dcf@ufscar.br

RESUMO São objetivos deste programa: promover um conjunto de atividades voltadas à comunidade interna e externa à Universidade, as quais resultarão em importante ação formadora e geradora de pesquisas científicas aplicadas.

PALAVRAS-CHAVE fisiologia; exercício; saúde; esporte, lazer e saúde

DATA INIÍCIO $\quad 1 / 1 / 2001$


Tíтьо Fisioterapia Cardiovascular

\begin{tabular}{ll} 
COORDENAÇÃO & Aparecida Maria Catai \\
\hline SETOR & Departamento de Fisioterapia \\
\hline CONTATO & dfisio@ufscar.br \\
\hline RESUMO & $\begin{array}{l}\text { É objetivo deste programa a capacitação de profissionais da área da saúde para } \\
\text { intervir em nível preventivo e curativo de doenças cardiovasculares, visando a } \\
\text { ampliação do serviço assistencial em fisioterapia cardiovascular. }\end{array}$ \\
\hline
\end{tabular}

PALAVRAS-CHAVE fisioterapia; cardiovascular; saúde; desenvolvimento do sistema de saúde

DATA INÍ́CIO 28/1/2000




\section{Título Gerontologia: Gestão da Velhice Saudável}

COORDEnAÇÃo Wilson Jose Alves Pedro

SETOR Departamento de Gerontologia

CONTATO dgero.secretaria@ufscar.br

RESUMO O aumento significativo do número de idosos, a ampliação da expectativa de vida, a prevenção de doenças crônicas e degenerativas, as mudanças no mundo do trabalho e nas políticas sociais, bem como os novos arranjos familiares desafiam continuamente o campo emergente da Gerontologia. O envelhecimento ativo e saudável, prioridade da ONU e da OMS, deve ser priorizado nas políticas e práticas de saúde, especialmente ao nível local e regional, visando a participação social, a promoção da saúde e a segurança. É nesta perspectiva que o presente programa de extensão se estrutura, visando subsidiar um dos maiores desafios da contemporaneidade: o envelhecimento ativo e saudável.

PALAVRAS-CHAVE gerontologia; gestão; envelhecimento ativo-saudável; saúde; atenção integral à terceira idade 


\section{ті́тицо Hepatites Virais em São Carlos}

\section{COORDENAÇão Silvana Gama Florencio Chacha}

SETOR Departamento de Medicina

CONTATO dmed@ufscar.br

RESUMO Para o seguimento de portadores de hepatites virais o Ministério da Saúde desenvolve o Programa de Combate às Hepatites Virais, que estabelece centrais estaduais e pólos regionais de tratamento, os quais devem ser estruturados de forma a garantir o cuidado de pacientes com hepatites virais. Este programa de extensão tem por finalidade: promover ações de educação continuada junto aos profissionais da rede primária de atenção à saúde, no que dia respeito a prevenção e detecção precoce das hepatites virais; a re-estruturação do Ambulatório de Hepatites Virais municipal de Saúde São Carlos, a fim de adequa-lo ao cuidado integral de pacientes portadores de hepatites virais em São Carlos, promovendo ações para capacitação e atualização; a realização do cuidado integral a pacientes portadores de hepatites virais em seguimento no Ambulatório de Hepatites do Programa DST/AIDS municipal de São Carlos, pertencente à rede SUS.

PALAVRAS-CHAVE hepatite $c$; hepatite b; hepatites virais; saúde; atenção integral à saúde de adultos

DATA INÍCIO 29/4/2016


TíTULO

Integração de Ações Educativas e Assistenciais à Mulher e à Criança

$\begin{array}{ll}\text { COORDENAÇÃo } & \text { Jamile Claro de Castro Bussadori } \\ \text { SETOR } & \text { Departamento de Enfermagem }\end{array}$

CONTATO denf@ufscar.br

RESUMO São objetivos do programa: diagnosticar situações do processo saúde-doença da população atendida pelo programa; realizar atividades educativas e cuidativas junto às mulheres da comunidade universitária e externa, sobre sexualidade, gravidez, parto, puerpério, aleitamento maternos, cuidades com recém-nascido e criança etc. recém-nascido; criança; saúde; atenção integral à mulher 


\section{Saúde}

\section{Tíruı Integração de Ações Educativas e de Pesquisa em Urgências e Emergências, Cuidados Críticos e Cardiovasculares}

\begin{tabular}{ll} 
COORDENAÇÃO & Regimar Carla Machado Ranzani \\
\hline SETOR & Departamento de Enfermagem \\
\hline CONTATO & denf@ufscar.br
\end{tabular}

RESUMO

A atenção à saúde em Unidades de Emergência prevê a chegada de pacientes com
diferentes perfis clínicos, nas mais diversas prioridades de atendimento (de imediato
a não urgente). As características clínicas do paciente, assim como o seu risco de
morte, requerem um acolhimento eficaz e adequada avaliação da classificação
de risco, bem como, o reconhecimento da parada cardiorrespiratória (PCR), a
realização das manobras básicas de reanimação cardiopulmonar (RCP) e o manuseio
do desfibrilador externo automático (DEA), que caracterizam como habilidades
importantes para proporcionar um atendimento rápido e eficaz na emergência.
Contudo, as situações de urgência/emergência podem apresentar-se em qualquer
local e momento, fundamentando a relevância de treinamentos, programa de
educação continuada não somente de profissionais de saúde, mas também da
população. Este projeto apresenta como eixo norteador capacitar profissionais da
saúde quanto a urgências e emergências, cuidados críticos, doenças e emergências
cardiovasculares, além de, proporcionar treinamentos a leigos quanto ao
atendimento básico de emergência, objetivando realizar atividades teórico-práticas
por meio da estratégia de simulação, estimular a participação ativa dos alunos de
enfermagem da Liga de Urgências e Emergências na educação profissional e busca
do conhecimento mediante as atividades práticas desenvolvidas; incentivar ações
de aprimoramento, tendo como princípio a indissociabilidade entre ensino, pesquisa
e extensão, bem como estimular a pesquisa e subsidiar a produção científica da
temática abordada. Atividades de extensão para o desenvolvimento da educação
continuada: curso de atualização em cuidados críticos, cardiologia e emergências
visando os estudantes de enfermagem, medicina, fisioterapia, educação física,
terapia ocupacional, nutrição, biomedicina, gerontologia.

PALAVRAS-CHAVE

capacitação; tecnologia; simulação; saúde; educação continuada 
TíTULO

Interdisciplinar de Pesquisa e Extensão na Maturidade

$\begin{array}{ll}\text { COORDENAÇÃO } & \text { Sofia Cristina lost Pavarini } \\ \text { SETOR } & \text { Departamento de Gerontologia }\end{array}$

CONTATO dgero.secretaria@ufscar.br

RESUMO É objetivo deste programa desenvolver projetos de extensão em parceria com diversos setores da comunidade e com diversos departamentos da UFSCar.

PALAVRAS-CHAVE interdisciplinar; maturidade; saúde; educação profissional

1/1/1999 


\section{TítULo \\ Intervenção Fisioterapêutica no Paciente Pneumopata}

\begin{tabular}{ll} 
COORDENAÇÃO & Valeria Amorim Pires di Lorenzo \\
\hline SETOR & Departamento de Fisioterapia \\
\hline CONTATO & dfisio@ufscar.br \\
\hline
\end{tabular}

RESUMO O Setor de Fisioterapia Respiratória da UFSCar desenvolve assistência fisioterapêutica a pacientes com doenças pulmonares agudas e crônicas de São Carlos e região. Estas atividades são muito procuradas por alunos da graduação em fisioterapia e profissionais da área de saúde pela utilização de técnicas de avaliações e intervenções fisioterapêuticas na área de fisioterapia respiratória. o propósito do programa de extensão é melhorar a qualidade do serviço oferecido à comunidade, capacitar e atualizar alunos da graduação e profissionais que atuam ou desejam atuar nesta área.

PALAVRAS-CHAVE fisioterapia respiratória; reabilitação pulmonar; avaliação respiratória; saúde; atenção integral à saúde de adultos 
Laboratório de Atividades e
Desenvolvimento - LAD/DTO

COORDENAÇÃo Regina Helena Vitale Torkomian Joaquim

SETOR Departamento de Terapia Ocupacional

CONTATO chdto@ufscar.br

RESUMO Pretende-se contribuir para a formação, investigação e disseminação de conhecimentos relativos à atividade humana / desenvolvimento, focalizada para população infantil e adolescente de forma direta; objetiva-se alcançar através de diferentes práticas com profissionais inseridos em sistemas de saúde e educação que atuam junto à comunidade etc.

PALAVRAS-CHAVE laboratório; desenvolvimento; saúde; educação profissional

DATA INÍCIO $\quad 1 / 8 / 1999$




\section{Título LAEP - Liga Acadêmica de Atividades} Pediátricas

\begin{tabular}{ll} 
COORDENAÇÃO & Ieda Regina Lopes Del Ciampo \\
SETOR & Departamento de Medicina \\
\hline CONTATO & dmed@ufscar.br \\
\hline
\end{tabular}

RESUMO A Liga Acadêmica de Especialidades Pediátricas (LAEP) é uma entidade vinculada ao Departamento de Medicina da UFSCar e ao Centro Acadêmico de Medicina Sérgio Arouca. Segue as diretrizes da ABLAM (Associação Brasileira de Ligas Acadêmicas de Medicina) e é constituída por alunos (ligantes) do terceiro e quarto anos do Curso de Medicina da UFSCar. Objetiva aprofundar e difundir conhecimentos, realizar ações educativas e atender às demandas populacionais pediátricas, por meio de atividades de ensino, pesquisa e extensão, demandadas pelos ligantes e supervisionadas pelo corpo docente vinculado ao programa.

PALAVRAS-CHAVE liga; pediatria; criança; saúde; atenção integral à criança

DATA INÍCIO 31/5/2016




\section{Título Liga Acadêmica de Especialidades de Especialidades Pediátricas}

\begin{tabular}{ll} 
COORDENAÇÃO & Carla Maria Ramos Germano \\
\hline SETOR & Departamento de Medicina \\
\hline CONTATO & dmed@ufscar.br \\
\hline
\end{tabular}

RESUMO A LAEP tem como objetivos aprofundar de forma teórico-prática os conhecimentos preventivos, semiológicos, diagnósticos e terapêuticos em Pediatria, através de reuniões quinzenais com temas vivenciados pelos ligantes durante atendimento nos ambulatórios de especialidades pediátricas, com apresentação de seminários, palestras, eventos, entre outras atividades, sob supervisão dos docentes relacionados à área em discussão; aplicar o conhecimento mais atual em Pediatria na rede de saúde do município, através de palestras, ações preventivas, distribuição de panfletos e manuais, criando um vínculo entre Universidade e Comunidade; estimular projetos científicos de interesse acadêmico e social que contribuam para o conhecimento científico na área; apoiar e estimular projetos que, através da identificação de demandas do município, possam contribuir para a melhoria das ações desenvolvidas na Comunidade; contribuir efetivamente para a formação de um indivíduo saudável desde a infância, em suas áreas biológica, psicológica e social, para que este possa crescer apto a desenvolver todo o seu potencial.

PALAVRAS-CHAVE Saúde da criança; assistência integral à saúde; educação; saúde; atenção integral à criança 


\section{Tírulo Liga Acadêmica de Medicina de Família e Comunidade}

\begin{tabular}{ll} 
COORDENAÇÃo & Mariana de Almeida Prado Faga \\
\hline SETOR & Departamento de Medicina \\
\hline RESUMO & dmed@ufscar.br \\
\hline & $\begin{array}{l}\text { Promover o ensino da Medicina de Família e Comunidade (MFC), apoiar a vivência } \\
\text { e integração dos alunos junto aos serviços de atenção primária à saúde (APS), } \\
\text { manter e promover intercâmbio de experiências entre os alunos, profissionais e } \\
\text { usuários dos serviços; refletir sobre situações problemas vivenciadas nos serviços e } \\
\text { na comunidade; realizar revisões de estudos da área da atenção primária à saúde; } \\
\text { auxiliar a elaboração e execução de protocolos assistenciais; promover atividades } \\
\text { de educação permanente em saúde; participar de projetos de pesquisa que possam } \\
\text { contribuir com desenvolvimento científico; realizar projetos de educação em saúde, } \\
\text { de caráter interdisciplinar, que envolvam os trabalhadores e usuários dos serviços } \\
\text { de saúde. }\end{array}$
\end{tabular}

PALAVRAS-CHAVE Saúde da família e comunidade; atenção primária à saúde; educação em saúde; Saúde; saúde da família 
Tírulo Liga Acadêmica de Saúde Mental

\begin{tabular}{ll} 
COORDENAÇÃO & Jair Borges Barbosa Neto \\
\hline SETOR & Departamento de Medicina \\
\hline CONTATO & dmed@ufscar.br \\
\hline RESUMO & A Liga Acadêmica de Saúde Mental (LASM) é uma entidade que possui duração \\
& ilimitada e caráter multidisciplinar. Vinculada ao Departamento de Medicina da \\
& UFSCar, é organizada pelos alunos de medicina. A liga visa cumprir objetivos de \\
& ensino, pesquisa e extensão, de forma integrada, contando com atendimentos na \\
& Unidade Saúde Escola (USE), reflexão da prática e seminários em saúde mental, com \\
& enfoque na clínica centrada no sujeito de forma multidisciplinar, irá também realizar \\
& simpósios. Será importante para os alunos dos cursos envolvidos, pois aprofundará \\
& nas questões de saúde mental, e para a comunidade, pois irá disponibilizar \\
& atendimentos multidisciplinares.
\end{tabular}

PALAVRAS-CHAVE liga acadêmica; saúde mental; multidisciplinar; saúde;

hospitais e clínicas universitárias 


\section{Título Liga Acadêmica de Terapia Antálgica e Cuidados Paliativos (LATACP)}

\begin{tabular}{ll} 
COORDENAÇÃO & Esther Angelica Luiz Ferreira \\
\hline SETOR & Departamento de Medicina \\
\hline CONTATO & dmed@ufscar.br \\
\hline
\end{tabular}

RESUMO A LATACP é uma entidade formada por alunos da Medicina UFSCar, médicos colaboradores e um professor orientador, sem fins lucrativos, com os objetivos de: mobilizar e orientar, contribuindo para sua formação acadêmica, estudantes da UFSCar; atuar na prevenção e na promoção de saúde na comunidade, através de atividades realizadas em campanhas, acompanhamentos ambulatoriais, préhospitalares e hospitalares, entre outros; desenvolver, promover e difundir estudos na área de Terapia Antálgica e Cuidados Paliativos.

PALAVRAS-CHAVE dor; cuidados paliativos; assistência terminal; saúde; atenção a grupos de pessoas com necessidades especiais 


\section{Tí́to Liga de Infectologia da UFSCar}

\section{COORDENAÇÃo Sigrid de Sousa Dos Santos}

SETOR Departamento de Medicina

CONTATO dmed@ufscar.br

RESUMO A Liga de Infectologia da Universidade Federal de São Carlos (LINFU), é composta por estudantes de graduação dos $1^{\circ}$ e $2^{\circ}$ Ciclos do Curso de Medicina ( $1^{\circ}$ ao $4^{\circ}$ ano). Inicialmente as ações da liga eram enquadradas como Atividade de Extensão e vinculadas apenas ao Departamento de Medicina. No entanto, com a ampliação e diversificação de suas ações, englobando diferentes atividades de extensão e realizando parcerias com o Programa Municipal de DST/AIDS; com outras unidades da UFSCar, particularmente o Departamento Médicos e Odontológico, a Unidade de Simulação da Prática Profissional em Saúde e com docentes e estudantes de outras áreas da saúde, passou a ser Programa de Extensão. A liga visa cumprir de forma integrada objetivos de ensino, pesquisa e extensão na área de infectologia. Todas as atividades da liga são orientadas e supervisionadas por docente infectologista doutora em Doenças Infecciosas e Parasitárias. As ações da liga incluem atendimento supervisionado de pacientes com doenças infecciosas e parasitárias em cenário ambulatorial, de urgência e de internação; organização de encontros mensais para discussões de caso, seminários e palestras; simpósios de infectologia; campanhas de prevenção contra DST; campanhas de aconselhamento e testagem para HIV, hepatite $B$, hepatite $C$ e sífilis; projetos de pesquisa em doenças infecciosas e parasitárias; oficinas de microbiologia; manutenção de blog para orientação em doenças infecciosas e parasitárias, divulgação de eventos, divulgação de dados epidemiológicos, de normas técnicas e de dados científicos de interesse.

PALAVRAS-CHAVE Infectologia; cuidado; educação; saúde; atenção a grupos de pessoas com necessidades especiais 


\section{Título Natação para Servidores e Alunos da} UFSCar

COORDENAÇÃo Corinne Arrouvel

SETOR Departamento de Física, Química e Matemática

CONTATO dfqm@ufscar.br

RESUMO A natação é um esporte muito importante para a saúde e para facilitar o lazer e a pratica de esporte aquático no mar, rio e lagoas, com segurança. A inexistência de piscinas municipais em Sorocaba e no campus da UFSCar-Sorocaba não permite aos alunos da UFSCar de ter acesso às aulas de natação a baixo custo.

Para facilitar a pratica dessa atividade, a possibilidade é de usar os recursos de clubes privados e ter a ajuda de um técnico local. A piscina semi-olímpica será dividida em diferentes grupos, de nível iniciante ate avançado.

PALAVRAS-CHAVE natação; saude; educação; saúde; esporte, lazer e saúde

DATA INÍCIO 28 28/6/2013




\section{Título Núcleo de Apoio Tecnológico e Educacional em Gerontologia (NATEG)}

$\begin{array}{ll}\text { COORDENAÇÃo } & \text { Tiago da Silva Alexandre } \\ \text { SETOR } & \text { Departamento de Gerontologia }\end{array}$

CONTATO_dgero.secretaria@ufscar.br

RESUMO O Brasil vêm enfrentando um rápido processo de envelhecimento populacional que pode resultar, em algumas situações, em maior vulnerabilidade e maior carga de morbidade sobre a população idosa. Tal fenômeno traz consigo grandes demandas de cuidado em saúde de longa duração, específicas e altamente onerosas que obrigam os sistemas de saúde a se prepararem para atendê-las. Dessa forma, o objetivo da proposta é auxiliar no manejo dessas demandas com atividades de formação e aprimoramento profissional, assim como no desenvolvimento, aprimoramento e divulgação de tecnologias que possam ser incorporadas na gestão dos serviços de saúde.

PALAVRAS-CHAVE tecnologia; educação; gerontologia; saúde; desenvolvimento do sistema de saúde 


\section{тітuঃ $\quad$ Políticas e Práticas em Saúde}

\begin{tabular}{ll} 
COOORDENAÇÃO & Maria Lucia Teixeira Machado \\
\hline SETOR & Departamento de Enfermagem \\
\hline CONTATO & denf@ufscar.br \\
\hline RESUMO & $\begin{array}{l}\text { Este programa tem por objetivos: articular atividades de ensino, pesquisa e } \\
\text { extensão; promover cursos de capacitação técnico-política para trabalhadores, } \\
\text { gestores e conselheiros da saúde; prestar assessorias a gestores e órgãos públicos } \\
\text { de saúde; desenvolver ações de promoção e educação em saúde. }\end{array}$ \\
\hline PALAVRAS-CHAVE & políticas; saúde; saúde; desenvolvimento do sistema de saúde \\
\hline DATA INÍCIO & $1 / 1 / 2003$ \\
\hline
\end{tabular}


Título

PRO-GERONTO: Processos e Produtos em Gerontologia

$\begin{array}{ll}\text { COORDENAÇÃO } & \text { Vania Aparecida Gurian Varoto } \\ \text { SETOR } & \text { Departamento de Gerontologia }\end{array}$

CONTATO dgero.secretaria@ufscar.br

RESUMO O fenômeno do envelhecimento populacional global está transformando diversos aspectos da sociedade. A tecnologia médica mais eficente tem contribuído no controle de muitas doenças. Em contrapartida o avanço tecnológico e de processos de melhoria da vida frente à heterogeneidade da população ainda não acompanha as suas necessidades, observando-se espaços e procedimentos não adequados a trabalhar o potencial e as limitações de pessoas e do coletivo. A tecnologia se propõe a facilitar a vida das pessoas independentemente da faixa etária e de onde e como estejam. Para tanto, a compreensão e o desenvolvimento de processos inovadores do cuidar, de produtos e diretrizes inter e multidisciplinares em busca do bem-estar pessoal e do coletivo, frente as novas organizações familiares e sociais, se faz necessária, ampliando a possibilidade de inserir pessoas e comunidade, respeitando potencial e limites de cada um nas diferentes fases da vida.

PALAVRAS-CHAVE gerontologia; gestão; tecnologia; saúde; cooperação interinstitucional

DATA INÍCIO 28/4/2011




\section{Saúde}

TíTULO

Programa de Ação e Investigação em Terapia Ocupacional na Disfunção Física do Adulto

\begin{tabular}{ll} 
COORDENAÇÃOO & Daniel Marinho Cezar da Cruz \\
\hline SETOR & Departamento de Terapia Ocupacional \\
\hline CONTATO & chdto@ufscar.br \\
\hline RESUMO & A atuação clínica com portadores de disfunções físicas é um campo consolidado \\
& e historicamente vinculado à formação do profissional como um dos pilares do \\
& corpo teórico e aplicado que constituem as bases da Terapia Ocupacional. É uma \\
& área em pleno desenvolvimento técnico-científico em nosso país. A demanda \\
& pela Reabilitação é significativa em nosso meio, no qual 14,5\% da população é \\
& portadora de algum tipo de deficiência (IBGE-2002). Na idade adulta observa- \\
& se maior número de acidentes, exposição a situações de riscos ocupacionais e \\
& outros agravos advindos da aquisição de doenças, que necessitam de tratamento \\
& de recuperação ou de reabilitação, dependendo das sequelas ou evolução das \\
& patologias. O programa propõe atividades em parceria com a Unidade Saúde Escola \\
& (USE) e com a rede municipal de saúde, já conveniada com a UFSCar. Atividades de \\
& difusão, de formação continuada para profissionais da área, pesquisas, assessorias, \\
& consultorias e publicações, serão contempladas neste programa.
\end{tabular}


Título Programa de Apoio ao Parto Saudável

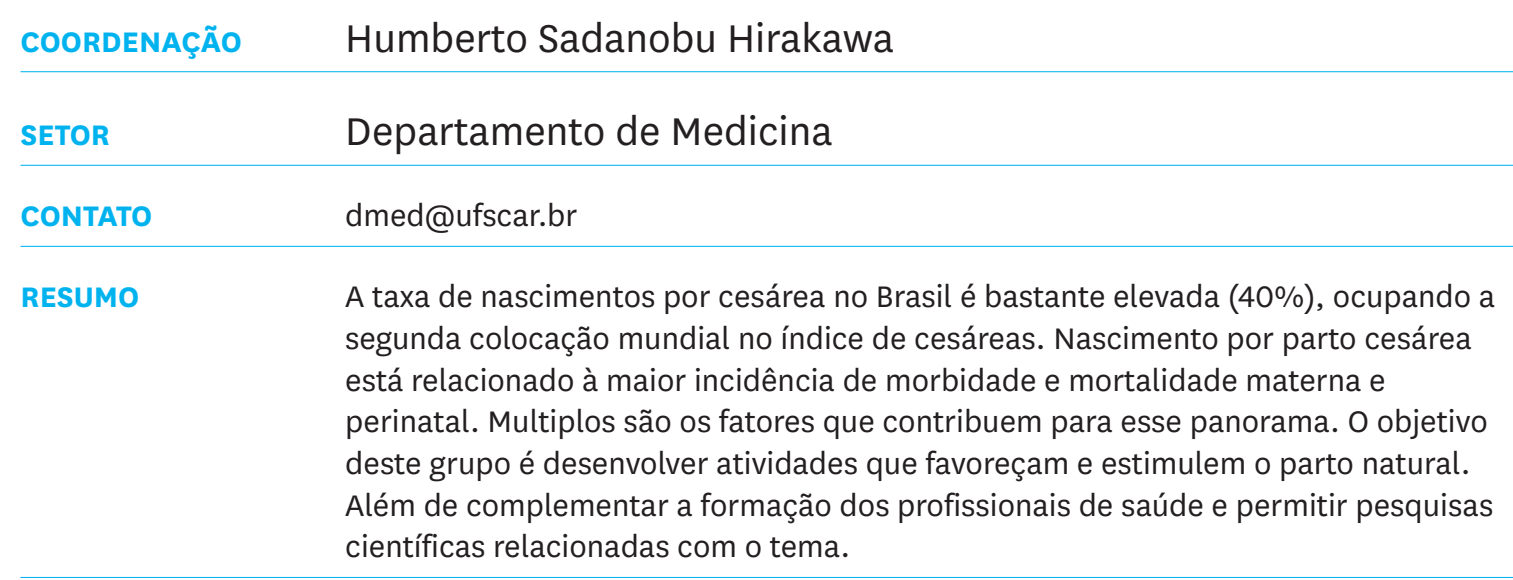


Título

Programa de Assistência Fisioterapêutica Hospitalar

\begin{tabular}{ll} 
COORDENAÇÃO & Adriana Sanches Garcia de Araujo \\
SETOR & Departamento de Fisioterapia \\
\hline CONTATO & dfisio@ufscar.br
\end{tabular}

RESUMO Este projeto tem como justificativa acadêmica fornecer condições ao aluno de atuar no campo profissional dentro do ambiente hospitalar, buscando atenção a saúde da criança, do adulto e do idoso; estabelecer e aplicar estratégias de avaliação e intervenção em unidade de emergência e enfermarias e futuramente em Unidade de terapia Intensiva, apresentando alternativas para os problemas individuais e sociais, podendo atuar nos níveis de assistência preventiva, curativa e de promoção da saúde; bem como, proporcionar ao aluno experiência do seu exercício profissional individual, inter e multiprofissional que envolve a atuação do fisioterapeuta no ambiente hospitalar.

PALAVRAS-CHAVE fisioterapia; atenção hospitalar; ciclos de vida; saúde; hospitais e clínicas universitárias 
Título

Programa de Atendimento em Endocrinologia e Metabologia da Unidade de Saúde-Escola

\begin{tabular}{ll} 
COORDENAÇÃO & Joyce do Rosario Martins \\
SETOR & Departamento de Medicina \\
\hline CONTATO & dmed@ufscar.br \\
\hline RESUMO & $\begin{array}{l}\text { Os hormônios atuam em todo o nosso organismo e são considerados cruciais para o } \\
\text { seu bom funcionamento. A área de Endocrinologia e Metabologia abrange diversas } \\
\text { patologias extremanete prevalentes na população em geral como as tiroidopatias, } \\
\text { diabetes mellitus, obesidade entre outras. O atendimento de pacientes na área de } \\
\text { Endocrinologia visa a excelência em serviço integrado as demais áreas de saúde da } \\
\text { UFSCar e à rede de saúde-escola de São Carlos. }\end{array}$
\end{tabular}

endocrinologia; metabologia; hormônios; saúde; atenção integral à saúde de adultos 


\section{TítULo \\ Programa de Atendimento Integral ao Portador de Hepatopatia Crônica}

\begin{tabular}{|c|c|}
\hline COORDEN & Ana Claudia de Oliveira \\
\hline SETOR & Departamento de Medicina \\
\hline CONTATO & dmed@ufscar.br \\
\hline RESUMO & $\begin{array}{l}\text { Estima-se que existam cerca de } 3 \text { milhões de infectados cronicamente pelos vírus } \\
\text { hepatotrópicos B e C. São doenças que frequentemente evoluem para a cronicidade, } \\
\text { chegando à cirrose e maior risco de câncer do fígado. Crescente interesse tem } \\
\text { surgido com os conhecimentos a cerca da doença hepática gordurosa não-alcoólica } \\
\text { (esteatose). Atualmente várias são as evidências do risco, de tal distúrbio hepático, } \\
\text { de também evoluir para cirrose hepática e para o carcinoma hepatocelular. Dessa } \\
\text { forma, o presente programa busca desenvolver e integrar atividades de pesquisa, } \\
\text { ensino e extensão relacionadas às doenças hepáticas mais prevalentes no município } \\
\text { de São Carlos. }\end{array}$ \\
\hline
\end{tabular}

PALAVRAS-CHAVE hepatites virais; doença hepática gordurosa; cirrose hepática; saúde; atenção integral à saúde de adultos 


\section{Programa de Combate e Prevenção} de Violência Doméstica - Pesquisa e Intervenção

\begin{tabular}{ll} 
COORDENAÇÃo & Rachel de Faria Brino \\
\hline SETOR & Departamento de Psicologia \\
\hline CONTATO & dpsic@ufscar.br \\
\hline RESUMO & $\begin{array}{l}\text { São objetivos do programa: tender vítimas de violência doméstica, seja em situação } \\
\text { de crise/emergência ou oferecendo psicoterapia a casos pertinentes; produzir } \\
\text { pesquisa na área; contribuir para a prevenção da violência. }\end{array}$ \\
\hline PALAVRAS-CHAVE & violência; doméstica; saúde; saúde da família \\
\hline DATA INÍCIO & 1/8/1999
\end{tabular}




\section{TítULo \\ Programa de Extensão em Medicina de Urgência}

COORDENAÇÃo Fabio Fernandes Neves

SETOR Departamento de Medicina

CONTATO dmed@ufscar.br

RESUMO A Medicina de Urgência é uma área ampla, interdisciplinar, complexa e desafiadora, requerendo um treinamento contínuo nos diferentes níveis de atenção. As urgências médicas são tradicionalmente atendidas em diferentes tipos de serviços: unidades básicas de saúde (atendimento pré-hospitalar fixo), hospitais de média e alta complexidade (atendimento hospitalar) e pelo serviço de atendimento móvel de urgência (SAMU - atendimento pré-hospitalar móvel). Neste modelo, a atuação dos profissionais de saúde permeia todos os níveis de atenção. Este programa prevê a realização de atividades de prevenção, assistência e reabilitação nos diferentes níveis de atenção da Medicina de Urgência.

PALAVRAS-CHAVE urgência; atendimento; prevenção; saúde; cooperação interinstitucional 
TÍTULO

Programa de Extensão Psicanálise e Disfunções Físicas

\begin{tabular}{ll} 
COORDENAÇÃO & Rosana Mattioli \\
\hline SETOR & Departamento de Fisioterapia \\
\hline CONTATO & dfisio@ufscar.br \\
\hline RESUMO & $\begin{array}{l}\text { Este projeto visa, através de atividades teóricas e prática clínica: contribuir na } \\
\text { formação estudantes e profissionais da saúde através de grupo de estudos de } \\
\text { Psicanálise e disfunções físicas; oferecer atendimento psicanalítico com supervisão } \\
\text { para população de renda baixa através da Clínica Social do núcleo Tavola - Instituto } \\
\text { de Educação e pesquisa em Psicanálise. }\end{array}$
\end{tabular}

PALAVRAS-CHAVE psicanálise; disfunções físicas; plasticidade do sistema nervoso central; saúde; cooperação interinstitucional 


\section{Tíтulo Programa de Neurologia Cognitiva e Comportamental da UFSCar}

\begin{tabular}{ll} 
COORDENAÇÃo & Francisco de Assis Carvalho do Vale \\
\hline SETOR & Departamento de Medicina \\
\hline RONTATO & dmed@ufscar.br \\
\hline RESUMO & A área de Neurologia Cognitiva e Comportamental trata de transtornos cognitivos \\
& e comportamentais associados a doenças neurológicas e não neurológicas, \\
& destacando-se as síndromes demenciais. As demências destacam-se em \\
& decorrência de sua alta prevalência, afetando cerca de 5\% da população acima \\
& de 65 anos, e do seu alto custo socioeconômico. Embora o clínico geral seja capaz \\
& de referenciar pacientes para os serviços especializados, na maioria das vezes \\
& não é capaz de diagnosticar a síndrome demencial. Cada vez mais, ambulatórios \\
& multidisciplinares especializados para o atendimento de pacientes com transtornos \\
& cognitivos-comportamentais e demências são a regra em ambiente universitário. \\
& Os objetivos do presente programa são: produção de conhecimentos por meio \\
& de pesquisas e sua divulgação através de ensino e extensão; atenção integral \\
& e interdisciplinar de adultos e idosos com transtornos cognitivos e demências, \\
& incluindo diagnósticos, tratamentos, reabilitação mental e prevenção; capacitação \\
& e aprimoramento dos alunos e profissionais para o atendimento de pessoas com \\
& aqueles problemas de saúde.
\end{tabular}

PALAVRAS-CHAVE neurologia comportamental; demências; transtornos cognitivos; saúde; atenção integral à terceira idade 


\section{Saíde}

Tírulo Promoção à Saúde do Idoso: a Busca pelo Envelhecimento Saudável na Atenção Básica

\begin{tabular}{ll} 
COORDENAÇÃo & Silvia Carla da Silva Andre \\
\hline SETOR & Departamento de Enfermagem \\
\hline CONTATO & denf@ufscar.br \\
\hline RESUMO & O processo normal de envelhecimento proporciona ao idoso algumas alterações \\
& que merecem ser identificadas pelos serviços de saúde. O objetivo desta atividade \\
& será implementar um programa de ações de promoção da saúde aos idosos \\
& cadastrados e acompanhados pela Unidade de Saúde da Família (USF) Jardim \\
& Munique em consonância com a Política Nacional de Atenção ao Idoso (Lei 8842/94) \\
& e a Política Nacional de Saúde do Idoso (1999), buscando educar a comunidade para \\
& a melhora das condições físicas e emocionais em temas relacionados à assistência \\
& de enfermagem. O método a ser empregado será por meio da criação de um grupo \\
& de idosos, com encontros quinzenais de duas horas e meia de duração e por meio \\
da realização de visitas domiciliares quinzenais com a finalidade de acompanhar os & \\
& idosos cadastrados na USF.
\end{tabular}




\section{Tírulo Promoção, Prevenção, Reabilitação e Recuperação da Saúde Reprodutiva e Sexual da Mulher}

COORDENAÇÃo Rodrigo Alves Ferreira

SETOR Departamento de Medicina

CONTATO dmed@ufscar.br

RESUMO Uma série de cuidados e atitudes de promoção, prevenção, reabilitação e recuperação é necessária para a manutenção da saúde da mulher em diferentes fases da vida como adolescência, menacme, climatério e senilidade. As mulheres têm sua própria história com característica individuais e familiares, crenças, mitos, medos, dúvidas que exigem uma complexa rede de cuidados para propiciar uma vida saudável e sem surpresas. O objetivo geral deste programa é desenvolver atividades que possibilitam qualificação, aprimoramento e treinamento de estudantes de graduação e pós-graduação da área da saúde e psicologia, profissionais da saúde, psicologia e educação e médicos residentes em ginecologia e obstetrícia na abordagem integral à saúde da mulher com vistas à assistência individual e coletiva, ação educativa individual e coletiva, gestão do cuidado, atividades de extensão e desenvolvimento de pesquisas básicas e clínicas na área da saúde da mulher.

PALAVRAS-CHAVE Saúde da mulher; saúde reprodutiva; educação; saúde; atenção integral à mulher 


\section{ті́ти $\quad$ ProViVe - Programa Viva bem a Velhice}

COORDENAÇÃo Marcos Hortes Nisihara Chagas

SETOR Departamento de Gerontologia

CONTATO dgero.secretaria@ufscar.br

RESUMO Com o envelhecimento populacional, o aumento do número de idosos com doenças crônicas é significativo, devendo-se destacar as demências e demais transtornos mentais. Sabe-se que grande parte dos fatores de risco para declínio cognitivo são modificáveis, ressaltando a importância de programas de promoção da velhice saudável, prevenção de doenças, reconhecimento de demência e tratamento farmacológico e não-farmacológico. O objetivo é atuar nesta área através de treinamento de profissionais da saúde para reconhecimento, realização de campanhas de conscientização de fatores de risco, atuar no seguimento através de um ambulatório de Psicogeriatria, entre outras ações.

PALAVRAS-CHAVE envelhecimento saudável; cognição; prevenção e promoção de saúde; saúde; atenção integral à terceira idade 
ті́ть- Saúde Mental e Cidadania

COORDENAÇÃo Georgina Carolina de Oliveira Faneco Maniakas

SETOR Departamento de Psicologia

CONTATO dpsic@ufscar.br

RESUMO Viabilizar o processo de desinstitucionalização do usuário de saúde mental por meio: do incremento de serviços comunitários que venham a se responsabilizar pela assistência aos pacientes psiquiátricos, a fim de evitar as frequentes reinternações hospitalares; da diminuição dos leitos hospitalares e da conscientização dos usuários, familiares, acompanhantes e da comunidade em geral, a partir de um constante processo de construção de cidadania. 
TÍTULO

\section{Saúde Mental no Contexto da Reforma Psiquiátrica}

\begin{tabular}{ll} 
COORDENAÇÃO & Sonia Regina Zerbetto \\
\hline SETOR & Departamento de Enfermagem \\
\hline CONTATO & denf@ufscar.br
\end{tabular}

RESUMO São objetivos deste programa: capacitar trabalhadores da saúde, principalmente enfermeiros, comprometidos com a construção de uma nova forma de conceber e tratar as pessoas em sofrimento psíquico; oferecer oportunidade ao aluno, principalmente de enfermagem, de vivenciar a construção de uma nova prática em saúde mental pautada nos princípios da Reforma Psiquiátrica, portanto, da reabilitação psicossocial; promover a reflexão/debate na comunidade sobre novas formas de enfrentamento do sofrimento psíquico; produzir e divulgar conhecimento na área integrando ensino, pesquisa e extensão. 
Título Saúde Psicossomática

COORDENAÇÃo Doris Lieth Nunes Peçanha

SETOR Departamento de Psicologia

CONTATO dpsic@ufscar.br

RESUMO São objetivos deste programa: intervir na comunidade como agente promotor da saúde integral; promover a saúde de crianças com asma e câncer no contexto familiar; intervir preventivamente no caso de crianças em risco psicossocial, meninos de rua da cidade de São Carlos etc.

PALAVRAS-CHAVE saúde; psicossomática; saúde; desenvolvimento do sistema de saúde DATA INÍCIO $\quad 1 / 1 / 2001$ 


\section{Laboratório de Saúde Mental do DTO}

\begin{tabular}{ll} 
COORDENAÇÃo & Thelma Simoes Matsukura \\
\hline SETOR & Departamento de Terapia Ocupacional \\
\hline CONTATO & chdto@ufscar.br \\
\hline RESUMO & $\begin{array}{l}\text { O programa objetiva contribuir para a implementação, investigação e transmissão } \\
\text { das ações realizadas em Psiquiatria e Saúde Mental, buscando alcançar a melhoria } \\
\text { da qualidade de vida da população. }\end{array}$
\end{tabular}

PALAVRAS-CHAVE psiquiatria; saúde mental; terapia ocupacional; saúde; saúde da família 
Tíruıo Unidade Saúde Escola

COORDENAÇÃo Marcia Niituma Ogata

SETOR Departamento de Enfermagem

CONTATO denf@ufscar.br

RESUMO A Unidade Saúde Escola tem como missão: prestar assistência qualificada e gratuita a todo cidadão dentro dos princípios do Sistema Único de Saúde, de forma articulada com a rede pública de saúde; formar e qualificar profissionais na área de saúde, desenvolvendo pesquisa científica e gerando tecnologia; divulgar o conhecimento produzido, tornando-o acessível a quem de interesse. Seus objetivos são: atuar na perspectiva de atendimento integral ao usuário, da promoção de saúde à reabilitação; contribuir para o equacionamento de problemas sociais que determinam e condicionam o nível de saúde da população, interagindo de forma permanente e integrada com o sistema loco/regional de saúde.

PALAVRAS-CHAVE Sistema único de saúde; linhas de cuidado em saúde; trabalho em equipe; saúde; atenção integral à saúde de adultos

DATA INÍCIO $\quad 6 / 4 / 2010$ 


\section{Tennologjae}

\section{Produpão}

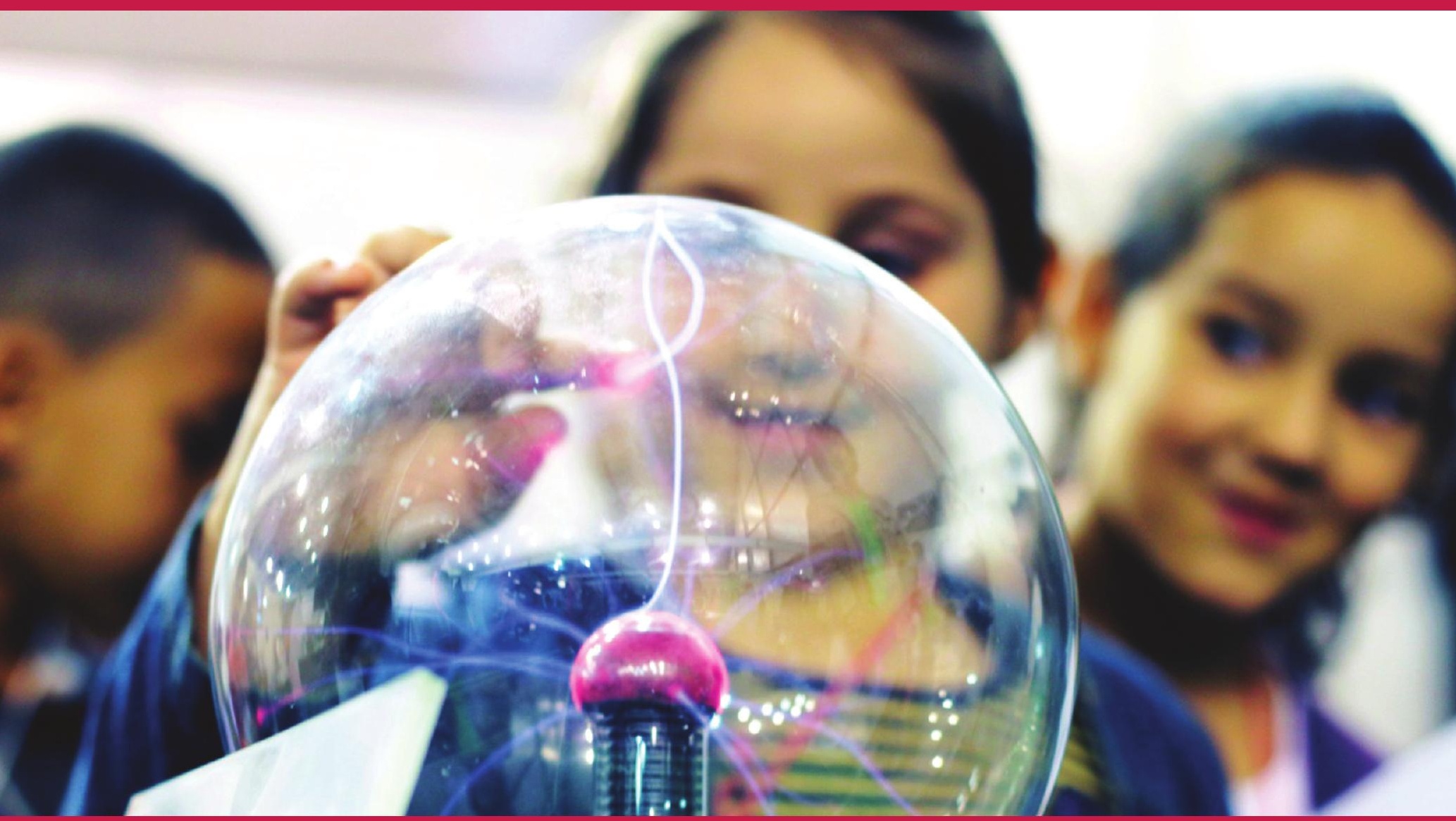

$67^{a}$ Reunião Anual da SBPC - Campus São Carlos.

Foto: Rogério Gianlorenzo. 


\section{Teenologia e Produção}

TítULo

\section{Ações Educacionais e Tecnológicas para o Desenvolvimento da Região de Leme}

\begin{tabular}{ll} 
COORDENAÇÃo & Jozivaldo Prudencio Gomes de Morais \\
\hline SETOR & Departamento de Biotecnologia e Produção Vegetal e Animal \\
\hline CONTATO & stela@cca.ufscar.br \\
\hline RESUMO & $\begin{array}{l}\text { Objetivo fundamental deste programa é formar parceria com a iniciativa privada } \\
\text { de moda a fomentar o setor agroindustrial da região de Leme no estado de São } \\
\text { Paulo com as tecnologias e informações geradas pela UFSCar e, ao mesmo tempo, } \\
\text { abrir áreas de pesquisa para acadêmicos e oportunidades práticas para os nossos } \\
\text { estudantes e egressos. }\end{array}$
\end{tabular}




\section{Tecnologia e Produção}

\section{ті́тu $\quad$ Ambientes de Computação Ubíqua na Saúde (ACUS)}

\begin{tabular}{|c|c|}
\hline COORDEN & Wanderley Lopes de Souza \\
\hline SETOR & Departamento de Computação \\
\hline CONTATO & dc@ufscar.br \\
\hline RESUMO & $\begin{array}{l}\text { Computação Ubíqua refere-se a ambientes saturados de dispositivos } \\
\text { computacionais fixos e móveis e redes de comunicação com e sem fio, que se } \\
\text { integram naturalmente à atividade humana. Na Saúde, o emprego da Computação } \\
\text { Ubíqua, na educação, comunidades, lares e hospitais, tem sido útil na construção } \\
\text { de modelos de Cuidado de Saúde centrados no paciente. Para tal, é necessária uma } \\
\text { troca de informações entre os diversos profissionais responsáveis pelo Cuidado de } \\
\text { Saúde ágil, eficiente e segura. Esse programa de extensão visa o desenvolvimento } \\
\text { de ambientes de Computação Ubíqua para a Saúde, que permita aos seus usuários a } \\
\text { troca de informações quando, onde e como melhor lhes aprouver. }\end{array}$ \\
\hline
\end{tabular}

PALAVRAS-CHAVE computação ubíqua; educação em saúde; cuidado de saúde; tecnologia e produção; inovação tecnológica 


\section{Tecnologia e Producẵo}

\section{Título Análise, Modelagem, Simulação, Projeto e Controle de Sistemas Dinâmicos}

\begin{tabular}{ll} 
COORDENAÇÃo & Osmar Ogashawara \\
\hline SETOR & Centro de Ciências Exatas e de Tecnologia \\
\hline RESUMO & ccetdir@ufscar.br \\
\hline O Curso de Graduação em Engenharia Elétrica da UFSCar, desde o início de sua \\
implantação em 2009, tem vivenciado ações e experiências inovadoras nas áreas \\
de ensino, pesquisa e extensão, por iniciativa dos professores do curso, com a \\
finalidade principal de estimular os estudantes a se envolverem em atividades \\
acadêmicas e complementares. O presente programa tem como objetivo principal \\
contribuir com o fortalecimento e reconhecimento do Curso de Engenharia Elétrica \\
por intermédio da ampliação das possibilidades de planejamento e realização de \\
atividades de extensão junto às comunidades acadêmica interna e acadêmica/ \\
profissional externa de instituições públicas e privadas. O programa abrange \\
um espectro bastante amplo de atividades, mas com enfoque nas áreas de \\
conhecimento relacionado ao Grupo de Pesquisa “Modelagem, simulação e controle \\
de sistemas dinâmicos” cadastrado no CNPq, com aprovação da UFSCar, sempre \\
buscando promover a integração de conhecimentos abordados em atividades de \\
ensino e pesquisa, e contribuir com o processo de formação acadêmica, tecnológica \\
e social dos públicos-alvos e da comunidade acadêmica envolvida.
\end{tabular}

PALAVRAS-CHAVE engenharia elétrica; atividades complementares; difusão do conhecimento; tecnologia e produção; educação continuada 


\section{Tecnologia e Producẵo}

\section{TíTULO \\ Aplicação, Aprimoramento e Difusão de Técnicas Avançadas de Engenharia de Software}

\begin{tabular}{|c|c|}
\hline SETOR & Departamento de Computação \\
\hline CONTATO & dc@ufscar.br \\
\hline RESUMO & $\begin{array}{l}\text { Técnicas avançadas de desenvolvimento e manutenção de software permitem que } \\
\text { sistemas sejam desenvolvidos com mais qualidade e com mais produtividade. } \\
\text { Entretanto, a maior parte dessas técnicas fica restrita aos muros das universidades } \\
\text { e contextos de pesquisa. Neste programa de extensão, o objetivo é agrupar um } \\
\text { conjunto de atividades cujo escopo é disseminar e transferir o conhecimento gerado } \\
\text { em nosso grupo de pesquisa para empresas públicas e privadas que possam se } \\
\text { beneficiar com tais técnicas avançadas. Essa experiência refletirá positivamente nos } \\
\text { cursos de graduação e pós-graduação. }\end{array}$ \\
\hline
\end{tabular}

PALAVRAS-CHAVE desenvolvimento de software; manutenção de software; evolução de software; tecnologia e produção; inovação tecnológica

DATA INÍCIO

$17 / 10 / 2011$ 


\section{Tecnologia e Producẵo}

\section{TítuLo \\ Aplicações de Mineração, Visualização e Gerenciamento de Dados}

\begin{tabular}{|c|c|}
\hline DORDE & Marcela Xavier Ribeiro \\
\hline SETOR & Departamento de Computação \\
\hline CONTATO & dc@ufscar.br \\
\hline RESUMO & $\begin{array}{l}\text { O progresso da tecnologia de informação fez com que a quantidade de dados } \\
\text { coletados e produzidos diariamente crescesse exponencialmente. No entanto, para } \\
\text { que esses dados sejam úteis para a sociedade é necessário que os mesmos sejam } \\
\text { analisados. A análise computacional desses dados via ferramentas de mineração e } \\
\text { visualização tende a revelar padrões que podem ser usados para beneficiar diversos } \\
\text { setores da sociedade. O objetivo desse programa é fornecer mecanismos para } \\
\text { aplicar técnicas de mineração, análise e visualização de dados em problemas reais } \\
\text { da sociedade atual. Neste programa de extensão, pretende-se promover acordos de } \\
\text { cooperação com empresas e centros de pesquisas, bem como dar suporte a eventos } \\
\text { que integrem pesquisas e suas aplicações na indústria, trazendo retorno para a } \\
\text { sociedade. }\end{array}$ \\
\hline
\end{tabular}

PALAVRAS-CHAVE banco de dados; visualização; mineração; tecnologia e produção; cooperação interinstitucional 


\section{Teenologia e Produção}

\begin{tabular}{ll} 
Título & Apoio ao Desenvolvimento de Produtos, \\
& Processos e à Formação de Pessoal para a \\
& Indústria Química e Áreas Correlatas \\
\hline COORDENAÇÃo & Paulo Waldir Tardioli \\
\hline SETOR & Departamento de Engenharia Química \\
\hline CONTATO & deqchefe@ufscar.br \\
\hline RESUMO & $\begin{array}{l}\text { O objetivo do programa é participar do desenvolvimento de produtos e processos, } \\
\text { bem como a formação de pessoal para a indústria química e áreas correlatas. }\end{array}$ \\
\hline PALAVRAS-CHAVE & produtos; indústria; tecnologia e produção; educação profissional \\
\hline DATA INíCIO & 1/10/2001
\end{tabular}




\section{Teenologia e Produção}

\section{ті́тио $\quad$ Apoio ao Uso de Software Livre}

COORDENAÇão Tiemi Christine Sakata

SETOR Departamento de Computação

CONTATO dcomp@ufscar.br

RESUMO O presente programa visa incentivar a comunidade do campus a utilização de software livre e contribuir para a disseminação do uso de software livre na comunidade em geral. Para isso, o programa será composto de cursos, palestras e atividades voltadas à qualificação e/ou aperfeiçoamento das habilidades de utilização do computador utilizando software livre. Além disso, pretende-se desenvolver material de apoio apropriado para os cursos/atividades oferecidos. 


\section{Tecnologia e Produção}

Aṕíto $\quad$ Apoio Tecnológico e Educacional ao
Desenvolvimento de Projetos Mecânicos

COORDENAÇÃo Sergio Henrique Evangelista

SETOR Departamento de Engenharia Mecânica

CONTATO demec@ufscar.br

RESUMO As técnicas de projeto e fabricação mecânica empregadas com ferramentas de análise computacional permitem ampliar o horizonte de atividades em Engenharia Mecânica, em comparação às atividades tradicionais, muitas vezes baseadas somente na experiência do engenheiro projetista e em métodos por tentativa-eerro. Este programa visa desenvolver a integração entre as práticas tradicionais de projeto, de fabricação e de experimentação em associação aos processos computacionais aplicados em Engenharia Mecânica, como meio de subsidiar a capacitação técnica de profissionais e alunos. Esta capacitação dar-se-á por intermédio de cursos, da aplicação das tecnologias e conhecimentos gerados na resolução de problemas da indústria, além de projetos de pesquisa, consultorias e assessorias a serem realizadas.

PALAVRAS-CHAVE projetos mecânicos; desenvolvimento de produtos; simulação computacional; tecnologia e produção; inovação tecnológica 


\section{Teenologia e Produção}

TítULo

Apoio Tecnológico e Educacional em Vidros e Materiais Afins

\begin{tabular}{ll} 
COORDENAÇÕO & Edgar Dutra Zanotto \\
\hline SETOR & Departamento de Engenharia de Materiais \\
\hline CONTATO & demachef@ufscar.br \\
\hline RESUMO & $\begin{array}{l}\text { O objetivo do programa é oferecer atividades de extensão, projetos nas áreas de } \\
\text { síntese e desenvolvimento de novos vidros e materiais correlatos, análises técnicas, } \\
\text { laudos, consultoria e formação profissional. }\end{array}$ \\
\hline PALAVRAS-CHAVE & apoio tecnológico; vidros; tecnologia e produção; inovação tecnológica \\
\hline DATA INÍcIO & 8/8/2000
\end{tabular}




\section{Teenologia e Produção}

TÍTULO

\section{Assessoria e Consultoria a Pessoas ou Instituições Públicas ou Privadas em Estudos Relacionados à Engenharia de Transportes}

\begin{tabular}{ll} 
COORDENAÇÃO & Marcos Antonio Garcia Ferreira \\
\hline SETOR & Departamento de Engenharia Civil \\
\hline RESUMO & deciv@ufscar.br \\
\hline $\begin{array}{l}\text { Constituem temas pertinentes a este programa de extensão: plano de transportes; } \\
\text { sistemas viários; sistemas de transportes coletivos; projetos para rodovias e vias } \\
\text { urbanas ; controle e fiscalização da educação de obras afins; ensaios realizados } \\
\text { pelos laboratórios (solo, agregado e asfalto). Projetos de roteirização do transporte } \\
\text { de alunos da zona rural, execução de ensaios de laboratório e desenvolvimento de } \\
\text { banco de dados de acidentes de trânsito. }\end{array}$
\end{tabular}




\section{Tecnologia e Producạ̃o}

\section{TíTULO \\ Atividades Agrícolas e Agroindustriais para o Desenvolvimento Sustentável do Território Lagoa do Sino}

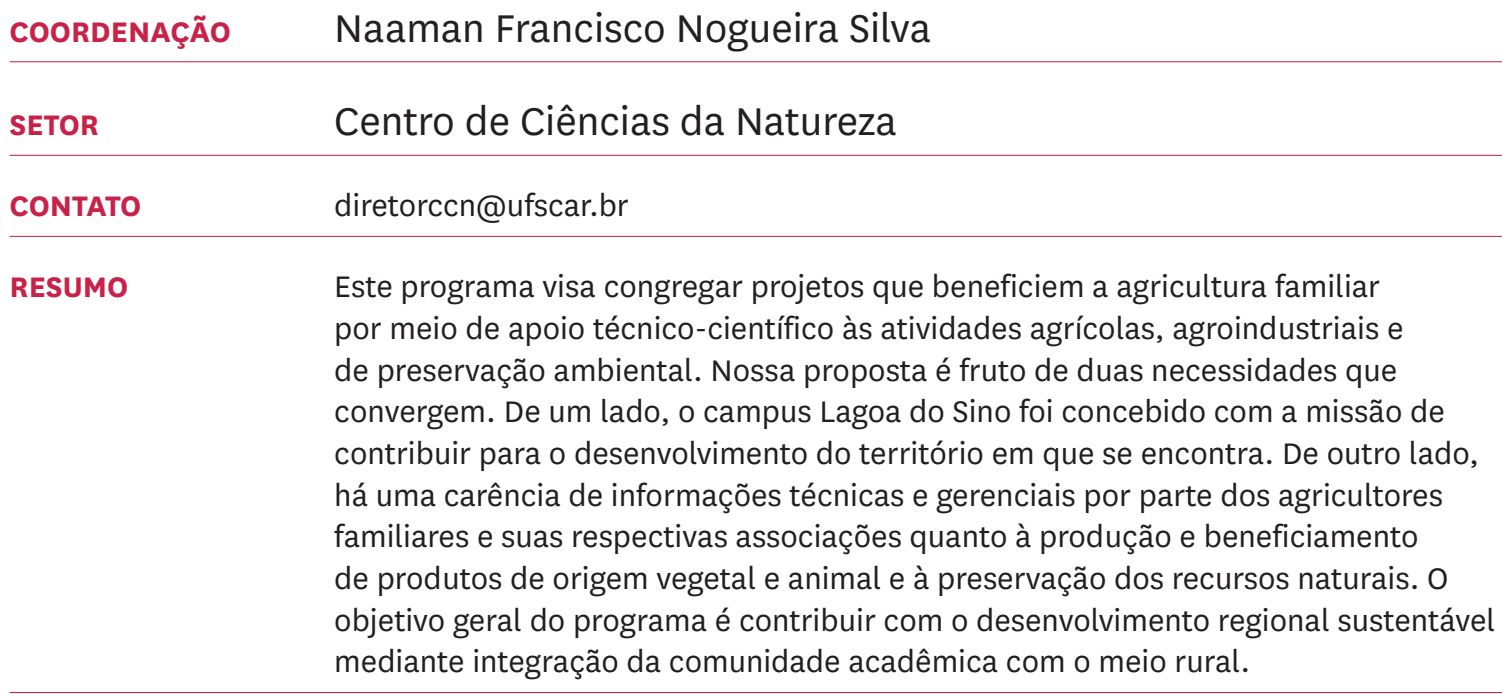




\section{Tecnologia e Produção}

\section{TítULo \\ Atividades de Divulgação de Ciência e Tecnologia na Química}

\begin{tabular}{ll} 
COORDENAÇÃo & Elton Fabiano Sitta \\
\hline SETOR & Departamento de Química \\
\hline CONTATO & dqchefe@ufscar.br \\
\hline RESUMO & $\begin{array}{l}\text { O programa buscará o desenvolvimento de atividades que auxiliem os alunos a } \\
\text { conhecer melhor a pesquisa de ponta desenvolvida dentro e fora da universidade, } \\
\text { bem como o papel do químico dentro da indústria. Acolherá ainda a já consolidada } \\
\text { Semana da Química. Neste contexto, durante a semana vários profissionais da } \\
\text { indústria bem como professores universitário apresentam palestras e mini cursos } \\
\text { que contemplam várias áreas da química, buscando atender pontos previamente } \\
\text { escolhidos pelos alunos do bacharelado e licenciatura em química. Os alunos que } \\
\text { participam da organização da semana, ainda adquirem experiência na organização } \\
\text { de eventos. }\end{array}$
\end{tabular}

PALAVRAS-CHAVE graduação em química; perspectivas profissionais; formação continuada; tecnologia e produção; educação profissional 


\section{Teenologia e Produção}

\begin{tabular}{ll} 
Título & Atividades Integradas de Extensão do \\
& GEPEQ - Grupo de Estudo e Pesquisa em \\
& Qualidade \\
\hline COORDENAÇÃo & Roberto Antonio Martins \\
\hline SETOR & Departamento de Engenharia de Produção \\
\hline CONTATO & dep@ufscar.br \\
\hline RESUMO & $\begin{array}{l}\text { O programa visa contribuir para a geração e difusão de novos conhecimentos que } \\
\text { permitam o aumento da produtividade e da qualidade das empresas brasileiras. }\end{array}$ \\
\hline PALAVRAS-CHAVE & atividades; integradas; tecnologia e produção; inovação tecnológica \\
\hline DATA INÍCIO & 14/1/2000
\end{tabular}




\section{Teenologia e Produção}

\begin{tabular}{ll} 
TÍTULO & Avaliação da Fertilidade do Solo \\
\hline COORDENAÇÃo & Jose Carlos Casagrande \\
\hline SETOR & Departamento de Recursos Naturais e Proteção Ambiental \\
\hline CONTATO & secdrnpa@cca.ufscar.br \\
\hline RESUMO & $\begin{array}{l}\text { São objetivos do programa: efetuar análises químicas; diagnosticar problemas de } \\
\text { fertilidade do solo e efetuar recomendações quantitativas de adubação e calagem, } \\
\text { assim como indicar o manejo da fertilidade do solo para os produtores rurais etc. }\end{array}$ \\
\hline PALAVRAS-CHAVE & fertilidade; solo; tecnologia e produção; desenvolvimento rural \\
\hline DATA INÍCIO & 1/1/1999
\end{tabular}




\section{Tecnologia e Producạ̃o}

\section{ті́тulo Avaliação de Herbicidas em Plantas e no Ambiente}

\begin{tabular}{ll} 
COORDENAÇÃo & Patricia Andrea Monquero \\
\hline SETOR & Departamento de Recursos Naturais e Proteção Ambiental \\
\hline RENTATO & secdrnpa@cca.ufscar.br \\
\hline A utilização de herbicidas no manejo de plantas daninhas é uma prática comum \\
em condições agrícolas e não agrícolas, sendo um dos métodos mais eficientes e, \\
em muitos casos, o mais econômico e o único utilizado. O programa apresentará os \\
seguintes objetivos principais: avaliação de herbicidas em plantas e no ambiente, \\
recomendações técnicas no uso de herbicidas, estudos de biologia das plantas \\
daninhas e estudos de tecnologia de aplicação.
\end{tabular}

PALAVRAS-CHAVE herbicidas; seletividade; ambiente; tecnologia e produção; desenvolvimento rural

DATA INÍCIO 6/4/2006




\section{Tecnologia e Produção}

Bítulo Buímica e Biologia Molecular Aplicadas à
Biotecnologia

\begin{tabular}{ll} 
COORDENAÇÃo & Flavio Henrique da Silva \\
\hline SETOR & Departamento de Genética e Evolução \\
\hline CONTATO & dge@ufscar.br \\
\hline
\end{tabular}

RESUMO Este programa tem por objetivo principal disponibilizar os conhecimentos do laboratório de Biologia Molecular do Departamento de Genética e Evolução da UFSCar para o setor produtivo e Instituições de pesquisa no desenvolvimento de projetos na área de Biotecnologia. O Programa prevê o oferecimento de serviços na área de Biologia Molecular tais como clonagem, sequenciamento e manipulação de DNA, produção de proteínas recombinantes, diagnóstico de doenças, análises genéticas, análise de biodiversidade etc.

PALAVRAS-CHAVE bioquímica; biologia molecular; biotecnologia; tecnologia e produção; educação ambiental 


\section{Tecnologia e Producẵo}

\section{тітuго Bioquímica e Biologia Molecular de Microorganismos}

\begin{tabular}{|c|c|}
\hline COORDE & Anderson Ferreira da Cunha \\
\hline SETOR & Departamento de Genética e Evolução \\
\hline CONTATO & dge@ufscar.br \\
\hline RESUMO & $\begin{array}{l}\text { Os microorganismos tem se mostrado como elementos experimentais excelentes } \\
\text { para a produção de proteínas heterólogas que podem ser aplicadas nos mais } \\
\text { diversos campos da ciência e da indústria. A facilidade de manipulação de genes } \\
\text { através de ferramentas de biologia molecular, aliada a crescente demanda nas } \\
\text { indústrias por melhorias em processos ou produção de produtos vêm colaborando } \\
\text { de maneira crescente no aprimoramento de diversos processos biotecnológicos. } \\
\text { Nesse sentido torna-se cada vez mais importante a integração indústria- } \\
\text { universidade. Este programa tem o objetivo de promover esta integração através da } \\
\text { execução de projetos que visem a identificação e manipulação de sistemas genéticos }\end{array}$ \\
\hline
\end{tabular}




\section{Tecnologia e Produção}

\section{Título Bovinocultura}

COORDENAÇÃo Jozivaldo Prudencio Gomes de Morais

SETOR Departamento de Biotecnologia e Produção Vegetal e Animal

CONTATO $\quad$ stela@cca.ufscar.br

RESUMO Objetivos: dar suporte a atividades de Ensino, Pesquisa e Extensão relacionada à produção de leite, treinamento de técnicos qualificados para atuação na bovinocultura leiteira nacional, promover difusão de tecnologia pelo treinamento de alunos, técnicos e produtores, melhoria de índices zootécnicos de produtores com consequente aumento de produtividade e redução de custos.

PALAVRAS-CHAVE bovinocultura; leite; atividades; tecnologia e produção; desenvolvimento rural

DATA INÍCIO 6/6/2006




\section{Teenologia e Produção}

\section{Título Capacitação Tecnológica de Estudantes e Profissionais para a Utilização e Desenvolvimento de Software Aplicado à Área de Processamento, Análise e Manipulação de Imagens e Vídeos Biomédicos}

\begin{tabular}{ll} 
COORDENAÇÃO & Ricardo Jose Ferrari \\
\hline SETOR & Departamento de Computação \\
\hline RESUMO & dc@ufscar.br \\
& $\begin{array}{l}\text { Com o crescente mercado de novas tecnologias na área de equipamentos e } \\
\text { software para o processamento, análise e manipulação de imagens e vídeos } \\
\text { biomédicos existe uma demanda muito grande em relação à formação (treinamento } \\
\text { e aprimoramento) de profissionais para atuar no desenvolvimento e uso de } \\
\text { software voltado para a finalidade descrita acima. Neste contexto, esse programa } \\
\text { de extensão visa suprir tais necessidades através de atividades de consultoria, } \\
\text { treinamento de estudantes e profissionais de engenharia e computação e também } \\
\text { no desenvolvimento de software voltado para a solução de problemas dessa área do } \\
\text { conhecimento. }\end{array}$
\end{tabular}

PALAVRAS-CHAVE imagens e vídeos biomédicos; software para a área médica; sinais biomédicos; tecnologia e produção; inovação tecnológica 


\section{Teenologia e Produção}

Título Capacitação Tecnológica

COORDENAÇÃo Sandra Abib

SETOR Departamento de Computação

CONTATO dc@ufscar.br

RESUMO O programa visa atender a demanda de pessoal especializado para trabalhar em pesquisa e desenvolvimento na área de telecomunicações.

PALAVRAS-CHAVE capacitação; tecnológica; tecnologia e produção; inovação tecnológica 


\section{Teenologia e Produção}

Tiтulo Caracterização Estrutural dos Materiais

COORDENAÇÃo Walter Jose Botta Filho

SETOR Departamento de Engenharia de Materiais

CONTATO demachef@ufscar.br

RESUMO O Programa tem como objetivo disseminar informações com relação às técnicas de caracterização estrutural dos materiais, através de cursos voltados para usuários das diversas técnicas. São previstas também atividades de média e longa duração com relação à assessoria e consultoria nas diversas técnicas de análise.

PALAVRAS-CHAVE caracterização; estrutural; tecnologia e produção; educação ambiental DATA INÍCIO $\quad 1 / 1 / 2005$ 


\section{Teenologia e Produção}

Título Centro de Caracterização e
Desenvolvimento de Materiais (CCDM)

\begin{tabular}{ll} 
COORDENAÇÃo & Nelson Guedes de Alcantara \\
\hline SETOR & Departamento de Engenharia de Materiais \\
\hline CONTATO & demachef@ufscar.br \\
\hline RESUMO & $\begin{array}{l}\text { É objetivo do programa: contribuir para soluções integradas na área de materiais } \\
\text { e áreas afins, com atendimento diferenciado, através da capacitação tecnológica e } \\
\text { excelência operacional. }\end{array}$ \\
\hline PALAVRAS-CHAVE & materiais; desenvolvimento; tecnologia e produção; inovação tecnológica \\
\hline DATA INÍcIO & \begin{tabular}{l}
$1 / 1 / 2000$ \\
\hline
\end{tabular}
\end{tabular}




\section{Teenologia e Produção}

TítuLo

Cooperação Técnico-Científica na Área de Melhoramento Genético da Cana-de-Açúcar

\begin{tabular}{ll} 
COORDENAÇÃo & Hermann Paulo Hoffmann \\
\hline SETOR & Departamento de Biotecnologia e Produção Vegetal e Animal \\
\hline CONTATO & stela@cca.ufscar.br \\
\hline
\end{tabular}

RESUMO O programa visa estabelecer parcerias com empresas ou associações de produtores do setor sucroalcooleiro para o desenvolvimento de tecnologia, especialmente novas variedades de cana-de-açúcar, para posterior transferência aos produtores. Participam da equipe de trabalho 12 profissionais externos de outras instituições. Há convênio com 128 unidades. 


\section{Teenologia e Produção}

\section{título Cultura de Tecidos de Plantas}

COORDENAÇão Lee Tseng Sheng Gerald

SETOR Departamento de Biotecnologia e Produção Vegetal e Animal

CONTATO $\quad$ stela@cca.ufscar.br

RESUMO São objetivos do programa: desenvolver pesquisa sobre a produção de plantas in vitro; divulgar os resultados de pesquisas; treinar alunos de graduação e pósgraduação através do desenvolvimento de pesquisa; assessorar instituições a implantarem projetos de produção comercial das plantas in vitro; fornecer mudas in vitro para produtores e empresas.

PALAVRAS-CHAVE in vitro; graduação; tecnologia e produção; desenvolvimento rural 
Título

Desenvolvimento de Atividades

Relacionadas a Materiais Compósitos, Híbridos e Tecnologias Aplicáveis nas Áreas Aeronáutica, Náutica e de Geração de Energia a partir de Fontes Alternativas

COORDENAÇÃO

SETOR

CONTATO

RESUMO
Jane Maria Faulstich de Paiva

Departamento de Engenharia de Produção - Sorocaba

deps@ufscar.br

Atualmente é grande o interesse na aplicação de materiais compósitos e híbridos nas áreas aeronáutica, náutica e de energia alternativa (eólica, solar, de marés etc), visando o desenvolvimento de tecnologias aplicáveis e a melhoria de dispositivos, peças ou componentes. Neste programa serão abordados o estudo, a aplicação e o aprimoramento destes materiais e de tecnologias relacionadas, incluindo o aproveitamento de resíduos e materiais descartados durante o processo de fabricação ou de utilização dos mesmos. Particularmente, a aplicação dos materiais compósitos na fabricação de pás eólicas de aerogeradores é interessante porque trata de tecnologia relacionada á área de Energia Limpa. Portanto, este programa está relacionado á proposta do tema Sustentabiidade, incentivando o Campus de Sorocaba e envolve a participação de discentes e de docentes com experiência nas áreas de tecnologias, materiais, qualidade, controle e planejamento da produção.

PALAVRAS-CHAVE Tecnologia; compósitos; híbridos; tecnologia e produção; inovação tecnológica $30 / 5 / 2007$ 


\section{Tecnologia e Produção}

\section{tiтulo Desenvolvimento de Materiais e Dispositivos (Sensores, Ataudores e Transdutores) Piezoelétricos}

\begin{tabular}{ll} 
COORDENAÇÃO & Jose Antonio Eiras \\
\hline SETOR & Departamento de Física \\
\hline RESUMO & dfchefe@ufscar.br \\
\hline $\begin{array}{l}\text { Este programa visa desenvolver materiais e dispositivos, baseados em materiais } \\
\text { piezoelétricos, para aplicações em Medicina e em Energias Renováveis. Para } \\
\text { aplicações em medicina prevê-se o desenvolvimento (construção, caracterização } \\
\text { e otimização) de transdutores ultrassônicos, na forma de arranjos lineares ou } \\
\text { matriciais, para aplicações em diagnose. Para aplicações em energias renováveis } \\
\text { prevê-se o desenvolvimento (construção, caracterização e adequação) de elementos } \\
\text { piezoelétricos para a captação e conversão de energia mecânica em elétrica. }\end{array}$ \\
\hline
\end{tabular}

PALAVRAS-CHAVE piezoelétricos; transdutores ultrassonicos; conversores de energia; tecnologia e produção; pólos tecnológicos

DATA INÍCIO 19/4/2012 


\section{Teenologia e Produção}

\begin{tabular}{|c|c|}
\hline TítULo & $\begin{array}{l}\text { Desenvolvimento de Processos, Produtos } \\
\text { e Controles Químico, Microbiológico, } \\
\text { Matéria-Prima e de Qualidade, Aplicado à } \\
\text { Agroindústria de Fermentações }\end{array}$ \\
\hline COORDENAÇÃO & Jorge José Correa Lopes \\
\hline SETOR & $\begin{array}{l}\text { Departamento de Tecnologia Agroindustrial e Socioeconomia } \\
\text { Rural }\end{array}$ \\
\hline CONTATO & secdtai@cca.ufscar.br \\
\hline RESUMO & $\begin{array}{l}\text { É objetivo do programa a capacitação de gerentes industriais e técnicos das } \\
\text { indústrias de fermentações de novas tecnologias utilizadas nos diferentes setores } \\
\text { produtivos, visando diminuir custos, aumentar eficiências e rendimentos, minimizar } \\
\text { perdas, utilizar e tratar os resíduos gerados de forma racional, sempre com o } \\
\text { objetivo de proteger o meio ambiente. }\end{array}$ \\
\hline PALAVRAS-CHAVE & fermentações; microbiológico; tecnologia e produção; inovação tecnológica \\
\hline TTA INÍCIO & /2004 \\
\hline
\end{tabular}




\section{Teenologia e Produção}

\section{тітulo Desenvolvimento de Técnicas, Produtos e Serviços para o Controle Fitossanitário e Cultural em Cana-de-Açúcar}

\begin{tabular}{ll} 
COORDENAÇÃo & Marcos Antonio Sanches Vieira \\
\hline SETOR & Departamento de Biotecnologia e Produção Vegetal e Animal \\
\hline CONTATO & stela@cca.ufscar.br \\
\hline RESUMO & $\begin{array}{l}\text { É objetivo do programa: colocar à disposição dos produtores canavieiros, produtos } \\
\text { e serviços tecnológicos oriundos do trabalho de investigação científica composto } \\
\text { de: mudas de cana-de-açúcar com alta qualidade genética, cultural e sanitária; } \\
\text { orientações para o controle de doenças da cana-de-açúcar e diagnóstico das } \\
\text { mesmas; análise e desenvolvimento de pesquisas que propiciem melhorias ao } \\
\text { sistema de produção de mudas e produção agroindustrial do setor sucroalcooleiro. }\end{array}$ \\
\hline PALAVRAS-CHAVE & cana-de-açúcar; citrus; tecnologia e produção; desenvolvimento rural \\
\hline DATA INÍcıo & 21/6/2000
\end{tabular}




\section{Teenologia e Produção}

\begin{tabular}{|c|c|}
\hline Título & $\begin{array}{l}\text { Desenvolvimento de Técnicas, Produtos e } \\
\text { Serviços para o Manejo da Água no Sistema } \\
\text { Solo Planta }\end{array}$ \\
\hline COORDENAÇÃO & Jose Geanini Peres \\
\hline SETOR & Departamento de Recursos Naturais e Proteção Ambiental \\
\hline CONTATO & secdrnpa@cca.ufscar.br \\
\hline RESUMO & $\begin{array}{l}\text { São objetivos do programa: realizar análises físico-hídricas de solos e realizar } \\
\text { estudos sobre o consumo de água para cultivos em condições de campos. }\end{array}$ \\
\hline PALAVRAS-CHAVE & manejo; solo; tecnologia e produção; desenvolvimento rural \\
\hline TA INÍ́cıo & $1 / 9 / 2000$ \\
\hline
\end{tabular}




\section{Teenologia e Produção}

Tiтulo Desenvolvimento de Tecnologia em Materiais e Processos

\begin{tabular}{ll} 
COORDENAÇÃo & Ernesto Antonio Urquieta Gonzalez \\
\hline SETOR & Departamento de Engenharia Química \\
\hline CONTATO & deqchefe@ufscar.br \\
\hline RESUMO & $\begin{array}{l}\text { Este programa objetiva o desenvolvimento de ciência e tecnologia em materiais e } \\
\text { processos assim como a formação de recursos humanos para os diversos setores da } \\
\text { sociedade. }\end{array}$ \\
\hline PALAVRAS-CHAVE & materiais; processos; formação; tecnologia e produção; inovação tecnológica \\
\hline DATA INÍcIO & 30/8/2006
\end{tabular}




\section{Teenologia e Produção}

\section{тітицо Desenvolvimento e Controle da Qualidade na Agroindústria Canavieira (DCQAC)}

\begin{tabular}{ll} 
COORDENAÇÃo & Maria Teresa Mendes Ribeiro Borges \\
\hline SETOR & $\begin{array}{l}\text { Departamento de Tecnologia Agroindustrial e Socioeconomia } \\
\text { Rural }\end{array}$
\end{tabular}

CONTATO

secdtai@cca.ufscar.br

RESUMO Este programa busca a capacitação de técnicos de nível médio (técnicos de laboratório) na utilização do conhecimento tecnológico disponível, além da elaboração e execução de projetos de pesquisa voltados para controle de qualidade da matéria-prima de processos e de produtos. 


\section{Teenologia e Produção}

Desenvolvimento, Análise, Produção e
Divulgação de Ferramentas para Projetos de
Sistemas Estruturais de Concreto Armado e
Protendido

\begin{tabular}{ll} 
COORDENAÇÃO & Roberto Chust Carvalho \\
\hline SETOR & Departamento de Engenharia Civil \\
\hline RENTATO & deciv@ufscar.br \\
\hline São objetivos do programa: contribuir para impelmentação de um núcleo de \\
desenvolvimento de novas técnicas de projeto, análise e novas ferramentas \\
computacionais que permitam ao projetista de sistema em concreto armado e \\
protendido atuar com conhecimento de teorias de ponta; capacitar os profissionais \\
atuantes nas áreas abrangidas pelo programa; criar um programa livre de sistema \\
estruturais em concreto armado e protendido.
\end{tabular}

PALAVRAS-CHAVE Sistemas estruturais; concreto armado; computação; tecnologia e produção; desenvolvimento urbano 


\section{Tecnologia e Produção}

\section{título Diagnose e Controle de Doenças de Plantas}

\begin{tabular}{ll} 
COORDENAÇÃo & Alfredo Seiiti Urashima \\
\hline SETOR & Departamento de Biotecnologia e Produção Vegetal e Animal \\
\hline CONTATO & stela@cca.ufscar.br \\
\hline RESUMO & $\begin{array}{l}\text { Os principais objetivos do programa incluem o treinamento dos alunos do curso } \\
\text { de Engenharia agronômica do Centro de Ciências Agrárias de Araras na diagnose } \\
\text { e controle de doenças de plantas. No nível social o programa visa atender os } \\
\text { produtores rurais da região que carecem de assessoria e um serviço especializado } \\
\text { em diagnose e controle de doenças de plantas. }\end{array}$
\end{tabular}

PALAVRAS-CHAVE diagnose; doenças de plantas; controle; tecnologia e produção;

desenvolvimento rural 


\section{Tecnologia e Produção}

\section{ті́тu Difusão do Conhecimento e Formação Educacional na área de Engenharia de Materiais}

\begin{tabular}{ll} 
COORDENAÇÃo & Tomaz Toshimi Ishikawa \\
\hline SETOR & Departamento de Engenharia de Materiais \\
\hline RESUMO & demachef@ufscar.br \\
& $\begin{array}{l}\text { A necessidade contínua de aperfeiçoamento dos profissionais na área de ciência } \\
\text { e engenharia de materiais, faz com que os professores e pesquisadores sejam } \\
\text { solicitados a ministrarem cursos de curta duração e outras atividades relativas à } \\
\text { área de educação. Os principais objetivos do programa são: atender a sociedade } \\
\text { nas suas necessidades no conhecimento dos materiais e sua importância para a } \\
\text { resolução dos problemas tecnológicos. Deve-se ressaltar também que a promoção } \\
\text { da carreira de engenharia de materiais é um dos objetivos dentro de atividades } \\
\text { específicas. }\end{array}$
\end{tabular}

PALAVRAS-CHAVE I I educação; cursos de curta duração; disseminação dos conhecimentos; tecnologia e produção; educação profissional 


\section{Tecnologia e Produção}

\section{título Difusão e Aplicação de Métodos Quantitativos}

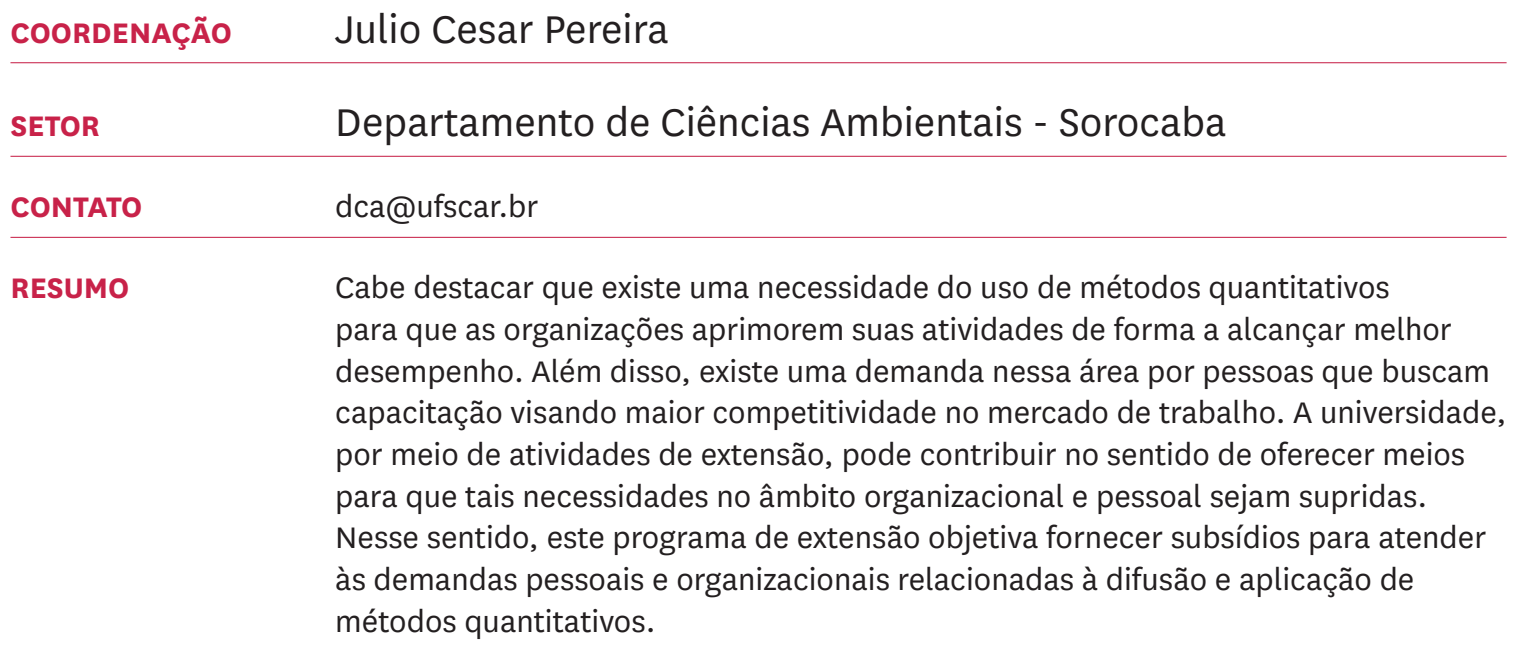

PALAVRAS-CHAVE métodos quantitativos; capacitação; operações; tecnologia e produção; educação continuada 


\section{títuı Difusão e Aplicações de Métodos para Gestão e Melhoria da Produtividade e da Qualidade de Sistemas de Produção}

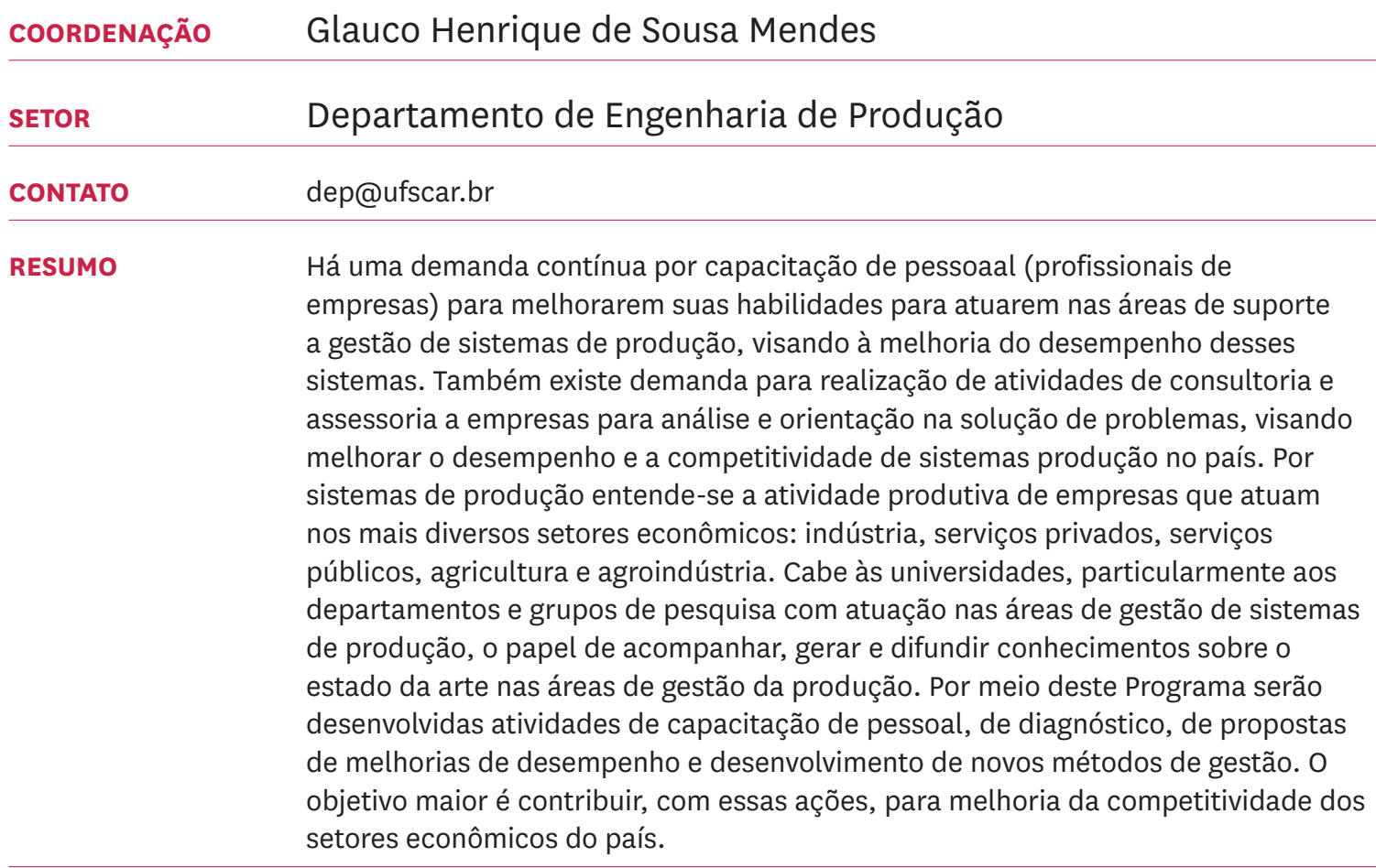

PALAVRAS-CHAVE Sistemas de produção; capacitação; produtividade e qualidade; tecnologia e produção; educação continuada 


\section{Tecnologia e Produção}

\section{ті́тuо Do DNA à Biologia Sintética}

COORDENAÇão Francis de Morais Franco Nunes

SETOR Departamento de Genética e Evolução

CONTATO dge@ufscar.br

RESUMO A Genética é uma ciência que faz parte do cotidiano da sociedade, seja na medicina, nos conflitos de natureza ética e religiosa, na agricultura, nos tribunais de justiça, no legislativo, entre outros. É uma área do conhecimento em constante avanço, desde a compreensão da regulação da expressão gênica em procariotos e eucariotos, o isolamento de genes de interesse, até as aplicações em larga escala como os Projetos Genomas, a Biologia de Sistemas e a Biologia Sintética. O Programa tem como principal objetivo criar e executar atividades que aliem a produção do conhecimento, parcerias público-privadas e popularização da ciência, de forma a integrar as interfaces clássicas e modernas da Genética.

PALAVRAS-CHAVE genética; genômica; biologia sintética; tecnologia e produção; pólos tecnológicos 


\section{Tecnologia e Producạ̃o}

\begin{tabular}{|c|c|}
\hline Título & Engenharia de Microestrutura de Materiais \\
\hline COORDENAÇÃO & José de Anchieta Rodrigues \\
\hline SETOR & Departamento de Engenharia de Materiais \\
\hline CONTATO & demachef@ufscar.br \\
\hline RESUMO & $\begin{array}{l}\text { São objetivos deste programa disponibilizar para as comunidades interna e externa } \\
\text { várias atividades que serão canais de comunicação, de troca de experiência, de } \\
\text { ensino e de aprendizado e de consultoria, na área de Engenharia de Microestrutura } \\
\text { de Materiais refratários e cerâmicas técnicas. O Grupo de Engenharia de } \\
\text { Microestrutura de Materiais disponibilizará os mais diversos serviços, dentro da sua } \\
\text { capacidade de recursos humanos, de modo que o estudante e o profissional possam } \\
\text { ser servidos técnica e cientificamente para desenvolvimento da Engenharia de } \\
\text { Materiais no Brasil. }\end{array}$ \\
\hline
\end{tabular}

microestrutura; engenharia; tecnologia e produção; inovação tecnológica 


\section{Teenologia e Produção}

\begin{tabular}{ll} 
Título & Engenharia para a Web: Metodologias, \\
& Técnicas e Processos para o \\
& Desenvolvimento de Sistemas de Software \\
& para a Web com Qualidade \\
\hline COORDENAÇÃo & Sergio Donizetti Zorzo \\
\hline SETOR & Departamento de Computação \\
\hline CONTATO & dc@ufscar.br \\
\hline RESUMO & $\begin{array}{l}\text { O objetivo do programa é dar continuidade às atividades já desenvolvidas pelo grupo } \\
\text { Simucad no campo do Projeto de Unidades Industriais e de Negócios. }\end{array}$ \\
\hline DALAVRAS-CHAVE & tecnologia; computação; tecnologia e produção; inovação tecnológica \\
\hline DATA Inícıo & 1/5/2000
\end{tabular}




\section{Tecnologia e Produção}

\section{TítuLo \\ Estudo de Linguagens de Programação de Computadores}

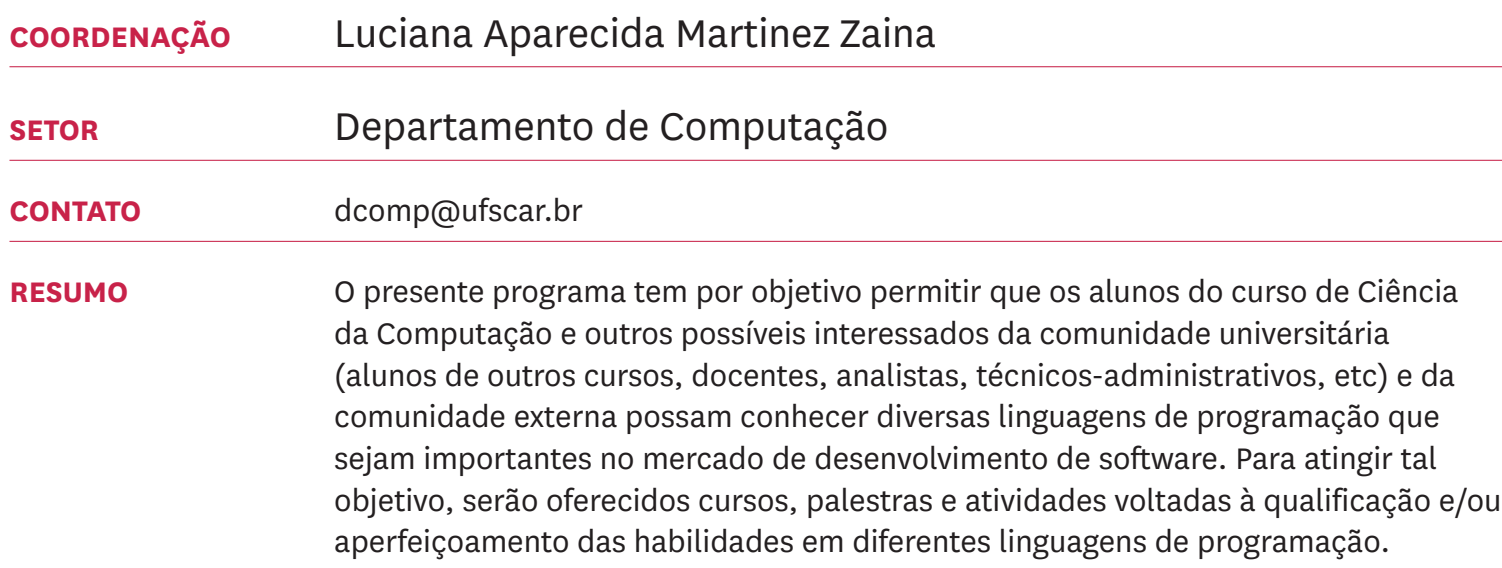

PALAVRAS-CHAVE linguagens de programação; desenvolvimento de software; estilos de linguagens; tecnologia e produção; educação profissional 


\section{Tecnologia e Producẵo}

\begin{tabular}{|c|c|}
\hline TítuLo & Estudos do Setor Sucroenergético \\
\hline COORDENAÇÃO & Octavio Antonio Valsechi \\
\hline SETOR & $\begin{array}{l}\text { Departamento de Tecnologia Agroindustrial e Socioeconomia } \\
\text { Rural }\end{array}$ \\
\hline CONTATO & secdtai@cca.ufscar.br \\
\hline RESUMO & $\begin{array}{l}\text { O setor sucroenergético brasileiro é referência mundial para países que visam obter } \\
\text { energia a partir de biomassa renovável, que no caso é a cana-de-açúcar. } \\
\text { Desde 1975, com a criação do Programa Nacional do Álcool (PROALCOOL) o país } \\
\text { vêm utilizando o etanol oriundo da cana-de-açúcar como substituto da gasolina em } \\
\text { veículos leves e mais recentemente estudos e testes vêm sendo desenvolvidos em } \\
\text { veículos de grande porte como caminhões, ônibus e tratores. A UFSCar, se destaca } \\
\text { neste âmbito em função de que em } 1990 \text { incorporou no quadro de seus servidores, } \\
\text { o corpo técnico e também as dependências físicas do extinto Programa Nacional } \\
\text { de melhoramento de Cana vinculado ao Instituto do Açúcar e do Álcool (IAA/ } \\
\text { PLANALSUCAR), berço de área de pesquisa sucroenergética que deu suporte técnico } \\
\text { ao PROALCOOL. Atualmente a UFSCar é solicitada para atender demandas nacionais } \\
\text { e internacionais referentes ao setor. Desta forma e como até o presente momento } \\
\text { não existe na UFSCar um programa que abranja desde a geração de conhecimento, } \\
\text { pesquisa e divulgação desta área e como este departamento está intimamente } \\
\text { vinculado às atividades do setor, houve-se por bem oferecer este programa para } \\
\text { em primeira instância proporcionar aos alunos desta instituição um relacionamento } \\
\text { mais próximo ao setor, alé de colocá-los diretamente em contato com o setor } \\
\text { produtivo através de palestras, conferencias, reuniões etc. }\end{array}$ \\
\hline
\end{tabular}




\section{Tecnologia e Produção}

TítuLo

Estudos, Desenvolvimentos e

Caracterização de Materiais Geotécnicos

\begin{tabular}{ll} 
COORDENAÇÃO & Fernando Henrique Martins Portelinha \\
\hline SETOR & Departamento de Engenharia Civil \\
\hline RENTATO & deciv@ufscar.br \\
\hline \multirow{2}{*}{ O programa de extensão agrupa atividades de pesquisas tecnológicas, } \\
desenvolvimentos e ensaios de caracterização física, hidráulica e mecânica de \\
materiais geotécnicos aplicados a engenharia civil. O objetivo do programa é colocar \\
o laboratório de Geotecnia da UFSCar (LabGEO/UFSCar) à disposição de institutos, \\
universidades e empresas para colaborações no desenvolvimento tecnológico, bem \\
como para prestação de serviços de ensaios laboratoriais para empresas no ramo \\
de engenharia geotécnica. Objetiva-se proporcionar a integração das atividades \\
de extensão com os alunos de graduação e pós-graduação do departamento de \\
engenharia civil da UFSCar (DECiv/UFSCar).
\end{tabular}

PALAVRAS-CHAVE

geotecnia; estudos; tecnologia; tecnologia e produção; inovação tecnológica 


\section{Teenologia e Produção}

\section{Título Estudos, Pesquisas, Ensino, Consultoria e Assessoria em Engenharia e Segurança de Tráfego}

\begin{tabular}{ll} 
COORDENAÇÃo & Archimedes Azevedo Raia Junior \\
\hline SETOR & Departamento de Engenharia Civil \\
\hline CONTATO & deciv@ufscar.br \\
\hline RESUMO & $\begin{array}{l}\text { A Engenharia e Segurança de Tráfego se relaciona com o planejamento, geometria, } \\
\text { operações de tráfego, suas redes, terminais, pólos geradores de viagens, inclusive } \\
\text { com a integração de todos os modos e tipos de transportes, proporcionando } \\
\text { movimentação segura, eficiente, visando a sutentabilidade ambiental e melhoria } \\
\text { da qualidade de vida das pessoas. No Brasil morrem, anualmente, cerca de } 30 \text { mil } \\
\text { pessoas, enquanto que mais de } 300 \text { mil sofrem lesões nos acidentes de trânsito, que } \\
\text { têm custos de cerca de } \mathbf{R} \text { \$ } 30 \text { bilhões/ano. O objetivo precípuo é estudar, pesquisar, } \\
\text { ensinar, prestar consultoria e assessoria em Engenharia e Segurança de Tráfego. }\end{array}$ \\
\hline
\end{tabular}

PALAVRAS-CHAVE trânsito; tráfego; segurança; tecnologia e produção; desenvolvimento urbano

DATA INÍCIO 18/7/2007




\section{Tecnologia e Producẵo}

\section{titulo Formação de Profissionais em Gestão de Negócios}

$\begin{array}{ll}\text { COORDENAÇÃo } & \text { Danilo Rolim Dias de Aguiar } \\ \text { SETOR } & \text { Departamento de Economia }\end{array}$

CONTATO deco@ufscar.br

RESUMO Existe, atualmente uma grande procura por cursos de especialização em gestão de negócios, tanto por parte de profissionais de administração, como principalmente, por profissionais de outras áreas. Diante desta demanda, a UFSCar-Sorocaba, que possui em seu corpo docente um grupo professores altamente capacitado, muito tem a contribuir, tanto na região de Sorocaba, como em outras partes do País. Para as atividades acadêmicas desenvolvidas na UFSCar, a grande vantagem decorrente do presente programa de extensão é que os professores terão contato mais próximo com os problemas reais defrontados pelas empresas, o que lhes permitirá enriquecer suas aulas de graduação, apresentando casos reais, e definir problemas de pesquisa que sejam realmente relevantes para a sociedade brasileira. Dessa Forma, o programa incentivará a integração entre extensão, ensino e pesquisa. 


\section{Teenologia e Produção}

ті́тuцo Geoprocessamento

COORDENAÇão Sergio Antonio Rohm

SETOR Departamento de Engenharia Civil

CONTATO deciv@ufscar.br

RESUMO É objetivo deste programa disponibilizar os conceitos, as metodologias, as técnicas, os equipamentos e os serviços do NGEO, com fim de disseminar o geoprocessamento. 


\section{Teenologia e Produção}

Gestão da Criação, Treinamento, Incubação,
Pesquisa e Desenvolvimento e Inovação
(PeDel) e Transferência de Tecnologia de
Empreendimentos de Base Tecnológica

\begin{tabular}{ll} 
COORDENAÇÃO & Alexandre Alvaro \\
\hline SETOR & Departamento de Computação \\
\hline CONTATO & dcomp@ufscar.br \\
\hline RESUMO & $\begin{array}{l}\text { As Instituições de Ciência de Tecnologia (ICTs) necessitam cada vez mais trabalhar } \\
\text { próximos aos problemas reais da indústria visando retornar o conhecimento, de } \\
\text { forma sustentável, para a sociedade. Durante os projetos de P\&D\&l diversas idéias } \\
\text { podem se transformar em negócios (seja projetos de ICTs, da indústria ou de } \\
\text { empreendedores do mercado), necessitando de suporte (das ICTs e de parceiros } \\
\text { da indústria) para a criação, treinamento e capacitação dos empreendedores, } \\
\text { incubação das startups, busca de investimento no mercado (venture capital, seed } \\
\text { money, etc), parceiros e networking, amadurecimento e transferência de tecnologia } \\
\text { para a sociedade. }\end{array}$ \\
\hline
\end{tabular}




\section{Teenologia e Produção}

Título

Gestão Empresarial e Estudos Econômicos Aplicados aos Sistemas Agroindustriais

$\begin{array}{ll}\text { COORDENAÇÃo } & \text { Mario Otavio Batalha } \\ \text { SETOR } & \text { Departamento de Engenharia de Produção }\end{array}$

contato dep@ufscar.br

RESUMO São objetivos deste programa: realizar diagnósticos; desenvolver ações de planejamento; controlar processos de gerenciamento de sistemas de produtos e serviços; gerar conhecimento; pesquisar, propor, implementar políticas públicas e privadas de desenvolvimento. 


\section{título IAHoMaq: Interfaces Avançadas entre Homens e Máquinas}

\begin{tabular}{ll} 
COORDENAÇÃo & Ednaldo Brigante Pizzolato \\
\hline SETOR & Departamento de Computação \\
\hline CONTATO & dc@ufscar.br \\
\hline
\end{tabular}

RESUMO São objetivos deste programa: desenvolver interfaces mais inteligentes e com "comportamento" mais natural. Para os sistemas presenciais, gestos, toques e reconhecimento de fala poderão integrar soluções de interfaces multimodais que permitam um nível de diálogo mais natural com os sistemas computacionais; para os sistemas remotos (como, por exemplo, call centers), utilização de conceitos de reconhecimento de fala ou DTMF combinados com conceitos de humanização para fazer com que os diálogos sejam mais naturais ou similares àqueles entre humanos. Justificativa acadêmica: as interfaces multimodais (gestos, toques e fala) estão cada vez mais presentes no dia a dia das pessoas, mas os princípios e conceitos de IHC e de Processamento de Sinais envolvidos ainda não estão consolidados na grade curricular. Muitos alunos de graduação se formam sem saber projetar uma interface multimodal simples. Para interfaces remotas, o conceito de humanização envolve aspectos de psicologia e de linguística, enquanto que os algoritmos de tratamento das respostas dos usuários envolvem aspectos lógicos. Pretende-se promover a integração de alunos de letras e psicologia com alunos de computação de forma a trazer ganhos acadêmicos (com visões/perspectivas distintas sobre o mesmo problema) para todos os envolvidos. Além do envolvimento em projetos de extensão, os alunos também poderão participar de atividades como ciclos de palestras, mini-cursos ou elaboração de artigos científicos. Justificativa social: os resultados obtidos podem gerar ganhos para as empresas que, por sua vez poderão contratar mais pessoas e gerar mais satisfação para os clientes. Além disso, profissionais de mercado poderão solicitar projetos específicos de cursos de curta duração que promovam o aperfeiçoamento técnico relativo a conceitos de interfaces multimodais (gestos, toques, reconhecimento de fala, teclado, mouse), interface humano-computador, programação de realidade virtual, programação de realidade aumentada; programação em voicexml dentre outras.

PALAVRAS-CHAVE humanização; atendimento eletrônico; interface humano computador; tecnologia e produção; cooperação interinstitucional 


\section{Tecnologia e Producạ̃o}

Título Informação, Ciência e Tecnologia

\begin{tabular}{ll} 
COORDENAÇÃo & Leandro Innocentini Lopes de Faria \\
\hline CENOR & Departamento de Ciência da Informação \\
\hline RESUMO & dci@ufscar.br \\
& $\begin{array}{l}\text { O programa dedica-se à compreensão dos avanços científicos e mudanças } \\
\text { tecnológicas, além de seus impactos para as organizações e a sociedade. } \\
\text { O objetivo é desenvolver, aplicar e disseminar metodologias e ferramentas para } \\
\text { análise de informação científica e tecnológica, por meio de treinamentos e cursos, } \\
\text { bem como a realização de estudos de prospecção tecnológica, mapeamento } \\
\text { científico e tecnológico, gestão do conhecimento, gestão da inovação e inteligência } \\
\text { competitiva. }\end{array}$
\end{tabular}

PALAVRAS-CHAVE indicadores de c\&t; inteligência competitiva; bibliometria; tecnologia e produção; inovação tecnológica 


\section{Teenologia e Produção}

TítuLo

\section{Inovação Tecnológica e Capacitação de} Pessoal em Processos Biotecnológicos

\begin{tabular}{ll} 
COORDENAÇÃo & Raquel de Lima Camargo Giordano \\
\hline SETOR & Departamento de Engenharia Química
\end{tabular}

CONTATO deqchefe@ufscar.br

RESUMO São objetivos deste programa: transferência de tecnologia, incluindo o aumento de escala até o nível industrial, na área dos processos biotecnológicos; treinamento de pessoal técnico em tópicos de relevância para o desenvolvimento tecnológico.

PALAVRAS-CHAVE tecnologia; capacitação; tecnologia e produção; inovação tecnológica 


\section{Tecnologia e Produção}

\section{Título Internet das Coisas}

COORDENAÇÃo Helio Crestana Guardia

SETOR Departamento de Computação

CONTATO dc@ufscar.br

RESUMO Com a miniaturização de dispositivos computacionais, tornou-se possível incorporar capacidade de processamento e comunicação a diferentes tipos de objetos e ambientes. Usando tecnologias de transmissão sem fio é possível coletar dados remotamente e eventualmente controlar objetos interligados em redes. Nesse sentido, este programa está relacionado à incorporação de dispositivos computacionais em objetos e ambientes, tratando da identificação e localização de objetos interligados e da utilização desta tecnologia para diferentes cenários de aplicação. Como resultado, busca-se criar mecanismos que apoiem aspectos de nossas vidas cotidianas utilizando recursos computacionais.

PALAVRAS-CHAVE internet das coisas; smart cities; desenvolvimento de software; tecnologia e produção; inovação tecnológica 


\section{Teenologia e Produção}

$\begin{array}{ll}\text { Iítulo } & \text { Investigação de Novos Paradigmas de } \\ \text { Interação Considerando NUI (Natural User } \\ \text { Interfaces) }\end{array}$

\begin{tabular}{ll} 
COORDENAÇÃo & Junia Coutinho Anacleto \\
\hline SETOR & Departamento de Computação \\
\hline CONTATO & dc@ufscar.br
\end{tabular}

RESUMO O programa visa fomentar a discussão das novas formas de interação humanocomputador por voz, visão, gestos, toque, entre outros, com o objetivo de colaborar com a definição do estado da arte considerando essas novas formas de interação, estabelecendo novas fronteiras de conhecimentos em parceria com pesqusadores brasileiros, internacionais, e com empresas de abrangência mundial, principalmente no que se refere a uma sociedade mais conectada e ativa através de tecnologias de apoio a redes sociais, com atenção especial ao design para gerenciamento e visualização de grandes quantidades de dados em diferentes contextos, na área que hoje esta sendo chamada de Visual analitics. 


\section{Tecnologia e Producẵo}

\section{тітиц Laboratório de Caracterização de Fármacos e Quimiometria Aplicada}

\begin{tabular}{|c|c|}
\hline COORDEN & Renato Lajarim Carneiro \\
\hline SETOR & Departamento de Química \\
\hline CONTATO & dqchefe@ufscar.br \\
\hline RESUMO & $\begin{array}{l}\text { O controle de qualidade de fármacos, tanto do ponto de vista de atividade } \\
\text { terapêutica como da própria matéria prima é de grande importância para produção } \\
\text { de medicamentos competitivos no cenário nacional e mundial. O Brasil vive uma } \\
\text { expansão na produção de medicamentos principalmente desde os anos } 2000 \text {, com } \\
\text { a comercialização dos genéricos, o que torna importante análises químicas de } \\
\text { ponta para agregar valor a tais produtos possibilitando a exportação dos mesmos. } \\
\text { Assim, os objetivos deste programa de extensão é atender à comunidade quanto } \\
\text { a necessidade de análises específicas de caracterização ou quantificação de } \\
\text { fármacos e auxiliar na implementação de métodos de calibração multivariados e de } \\
\text { otimização de processos. }\end{array}$ \\
\hline
\end{tabular}

PALAVRAS-CHAVE quimiometria; análise de fármacos; espectroscopia raman; tecnologia e produção; cooperação interinstitucional 


\section{Tecnologia e Producẵo}

\section{Tírulo Laboratório de Espectroanalítica, Preparo de Amostras e Quimiometria}

\begin{tabular}{ll} 
COORDENAÇÃO & Edenir Rodrigues Pereira Filho \\
\hline SETOR & Departamento de Química \\
\hline CONTATO & dqchefe@ufscar.br \\
\hline RESUMO & A espectroanalítica tem proporcionado a resolução de diversos problemas de ordem \\
& social, econômica e tecnológica, oferecendo técnicas e métodos analíticos capazes \\
& de determinar diversos tipos de analitos (metais e contaminantes, principalmente) \\
& em diferentes amostras. Juntamente com medidas espectroanalíticas também \\
& é necessária a proposição de procedimentos de preparo de amostras capazes \\
& de converter amostras sólidas, por exemplo, em soluções representativas. \\
& Essa combinação de tecnologias analíticas possibilita a obtenção de conjuntos \\
& de dados cada vez maiores e complexos que, em muitos casos, requerem a \\
utilização de ferramentas matemáticas/estatísticas (quimiometria) para a sua \\
correta análise e interpretação. Assim, os principais objetivos deste programa são \\
atender a comunidade com análises e treinamentos específicos na determinação \\
de constituintes e caracterização de diversos tipos de amostras (alimentos, \\
tecnológicas e ambientais).
\end{tabular}

PALAVRAS-CHAVE espectroanalítica; preparo de amostras; quimiometria; tecnologia e produção; cooperação interinstitucional 


\section{Tecnologia e Producẵo}

\section{ті́тьо Laboratório de Polímeros - Soluções para a Comunidade de Polímeros}

\begin{tabular}{ll} 
COORDENAÇÃO & Caio Marcio Paranhos da Silva \\
\hline SETOR & Departamento de Química \\
\hline CONTATO & dqchefe@ufscar.br
\end{tabular}

RESUMO Nos últimos anos, a produção científica e tecnológica tem possibilitado o desenvolvimento de novos materiais, com superiores propriedades mecânicas, térmicas, químicas, de transporte e elétricas, dentre outras. Neste contexto, há a agregação de valor aos produtos com melhor desempenho. Para tal, as empresas brasileiras de base tecnológica ainda se ressentem da ausência tanto de mão de obra especializada na área de polímeros, quanto de assessoria técnica para a resolução de problemas internos. A presente proposta tem por objetivo o oferecimento de assessoria e consultoria na área de materiais poliméricos, através da realização de ensaios técnicos normatizados, formação de recursos humanos qualificados para a área de polímeros e mecanismos de transferência de tecnologia. A metodologia do programa proposto baseia-se na utilização dos recursos existentes no Laboratório de Polímeros do Departamento de Química, oferecimento de treinamento técnico ao público requerente e emissão de pareceres técnicos.

PALAVRAS-CHAVE materiais polímericos; consultoria; caracterização de materiais; tecnologia e produção; inovação tecnológica 


\section{Tecnologia e Produção}

\section{ті́тuıo Mecanização Agrícola no Manejo Solo-Planta}

\begin{tabular}{|c|c|}
\hline COORDEN & Rubismar Stolf \\
\hline SETOR & Departamento de Recursos Naturais e Proteção Ambiental \\
\hline CONTATO & secdrnpa@cca.ufscar.br \\
\hline RESUMO & $\begin{array}{l}\text { São objetivos deste programa: desenvolver e testar equipamentos agrícolas; } \\
\text { estudar e desenvolver técnicas de avaliação da compactação do solo pelo tráfego } \\
\text { de máquinas e a influência do tipo de solo; desenvolver técnicas alternativas que } \\
\text { minimizam o impacto ambiental por uso indevido de máquinas agrícolas, tais como, } \\
\text { plantio direto, cultivo mínimo e técnicas de conservação do solo; recuperar áreas } \\
\text { degradadas; estender tecnologia a empresas agrícolas e a produtores rurais na } \\
\text { área do programa e propiciar treinamento a alunos da UFSCar; promover Cursos } \\
\text { de Extensão; propiciar um apoio ao desenvolvimento da mecanização agrícola no } \\
\text { Centro de Ciências Agrárias da UFSCar em ensino, pesquisa e extensão. }\end{array}$ \\
\hline
\end{tabular}




\section{Tecnologia e Produção}

\begin{tabular}{|c|c|}
\hline Título & Melhoramento Genético de Hortaliças \\
\hline COORDENAÇÃO & Fernando Cesar Sala \\
\hline SETOR & Departamento de Biotecnologia e Produção Vegetal e Animal \\
\hline CONTATO & stela@cca.ufscar.br \\
\hline RESUMO & $\begin{array}{l}\text { A produção das principais espécies de hortaliças no Brasil é frequentemente } \\
\text { limitada pela falta de adaptação das atuais cultivares às regiões tropicais, pois, com } \\
\text { poucas exceções, são espécies exóticas e oriundas de regiões de clima temperado. } \\
\text { O desenvolvimento de novos cultivares/híbridos adaptados as condições tropicais } \\
\text { de cultivo se faz necessário para atender a demanda crescente do mercado } \\
\text { consumidor e produtor. Recentemente, fomos surpreendidos com a doação para à } \\
\text { UFSCar de um Banco de Germoplasma composto de oito espécies (alface, pimenta, } \\
\text { pimentão, coentro, maxixe, feijão-vagem, abóbora e abobrinha) de hortaliças e } \\
\text { com várias centenas de linhagens e populações segregantes. Com isso, esse banco } \\
\text { genético será utilizado como matéria-prima principal para o desenvolvimento de } \\
\text { novos cultivares e híbridos com resistência aos principais fatores bióticos e abióticos } \\
\text { para as espécies citadas acima. }\end{array}$ \\
\hline
\end{tabular}

PALAVRAS-CHAVE variedades; produção; resistência à fitopatógenos; tecnologia e produção; inovação tecnológica 


\section{Teenologia e Produção}

Tíruı Minimização e Reciclagem de Resíduos

\begin{tabular}{ll} 
COORDENAÇÃo & Bernardo Arantes do Nascimento Teixeira \\
\hline SETOR & Departamento de Engenharia Civil \\
\hline CONTATO & deciv@ufscar.br \\
\hline RESUMO & $\begin{array}{l}\text { O programa visa contribuir para o melhoramento do potencial de aplicação dos } \\
\text { materiais recuperados dos resíduos sólidos urbanos e industriais. }\end{array}$ \\
\hline
\end{tabular}

PALAVRAS-CHAVE

minimização; reciclagem; tecnologia e produção; educação ambiental 


\section{Teenologia e Produção}

\section{Título \\ Núcleo de Reologia e Processamento de Polímeros do DEMa/NRPP/DEMa}

\begin{tabular}{ll} 
COORDENAÇÃo & Luiz Antonio Pessan \\
\hline SETOR & Departamento de Engenharia de Materiais \\
\hline CONTATO & demachef@ufscar.br \\
\hline RESUMO & $\begin{array}{l}\text { O programa visa a transferência de conhecimento científico e tecnológico para a } \\
\text { comunidade e a obtenção de uma visão prática dos problemas tecnológicos da } \\
\text { indústrias. }\end{array}$ \\
\hline PALAVRAS-CHAVE & núcleo; processamento; tecnologia e produção; inovação tecnológica \\
\hline DATA INÍCIO & 18/11/1999
\end{tabular}




\section{Tecnologia e Produção}

\section{TítULo \\ Pesquisa e Desenvolvimento em Microbiologia Agrícola e Molecular}

\begin{tabular}{ll} 
COORDENAÇÃo & Sandra Regina Ceccato Antonini \\
\hline SETOR & $\begin{array}{l}\text { Departamento de Tecnologia Agroindustrial e Socioeconomia } \\
\text { Rural }\end{array}$
\end{tabular}

CONTATO

secdtai@cca.ufscar.br

RESUMO Esse programa tem o objetivo de atender a demanda tanto da área industrial quanto do setor rural no âmbito da microbiologia agrícola e industrial, propondo e desenvolvendo atividades de pesquisa, treinamento e prestação de serviços. Contamos com um laboratório inter-departamental (LAMAM - Laboratório de Microbiologia Agrícola e Molecular), multidisciplinar, apto a desenvolver tais atividades, que apoiarão sobremaneira as atividades de pesquisa/ensino dos professores envolvidos nesse programa. 


\section{Teenologia e Produção}

TítuLo

\section{Pesquisa e Tecnologia em Sistemas} Multimidia Distribuídos

\begin{tabular}{ll} 
COORDENAÇÃo & Luis Carlos Trevelin \\
\hline SETOR & Departamento de Computação \\
\hline CONTATO & dc@ufscar.br \\
\hline RESUMO & $\begin{array}{l}\text { Este programa visa envolver pesquisadores e alunos do Departamento de } \\
\text { Computação em atividades de Pesquisa e Desenvolvimento de projetos na área de } \\
\text { Sistema de Multimídia Distribuídos, através de parcerias com empresas, escolas, } \\
\text { órgãos do governo e agências de fomento. Transferência de conhecimento e troca de } \\
\text { experiências entre pesquisadores e alunos. }\end{array}$
\end{tabular}




\section{Teenologia e Produção}

Título Pesquisa Operacional Aplicada

COORDENAÇÃo Reinaldo Morabito Neto

SETOR Departamento de Engenharia de Produção

CONTATO dep@ufscar.br

RESUMO O programa tem por objetivos: promover e discutir o conhecimento e a aplicação da Pesquisa Operacional em sistemas de produção; estimular pesquisa aplicada, gerando conhecimento teórico e produtos tecnológicos. 


\section{Tecnologia e Produção}

\section{тітицо Pesquisas e Análises Cromatográficas}

COORDENAÇÃo Quezia Bezerra Cass

SETOR Departamento de Química

CONTATO dqchefe@ufscar.br

RESUMO Ainda hoje no Brasil, um grande desafio a ser enfrentado é compartilhar o conhecimento produzido no meio acadêmico com as empresas. Tais parcerias certamente enriquecem a formação dos alunos com as demandas trazidas pelas empresas e geram recursos para o financiamento de pesquisas nas Universidades. Neste sentido, o objetivo deste programa de extensão é estabelecer cooperação tecnológica entre os pesquisadores do Separare - Núcleo de Pesquisas em Cromatografia, situado no Departamento de Química, e Centros de Pesquisa de Indústrias Químicas e Farmacêuticas.

PALAVRAS-CHAVE desenvolvimento de métodos; análises cromatográficas; desenvolvimento de projetos; tecnologia e produção; inovação tecnológica 


\section{Teenologia e Produção}

Título

Planejamento e Gerenciamento de Sistemas Hidráulicos, Sanitários e Ambientais

\begin{tabular}{ll} 
COORDENAÇÃO & Erich Kellner \\
\hline SETOR & Departamento de Engenharia Civil \\
\hline CONTATO & deciv@ufscar.br \\
\hline RESUMO & $\begin{array}{l}\text { O objetivo deste programa é buscar a reciclagem de conhecimentos práticos por } \\
\text { parte dos docentes e técnicos envolvidos; e também o fornecimento de dados e } \\
\text { informações para os programas e disciplinas de graduação e pós. }\end{array}$ \\
\hline PALAVRAS-CHAVE & planejamento; gerenciamento; tecnologia e produção; inovação tecnológica \\
\hline DATA INÍCIO & $2 / 8 / 1999$ \\
\hline
\end{tabular}




\section{Tecnologia e Producẵo}

\section{тітицо Programa de Apoio Tecnológico e Educacional em Metais Vítreos e Nano-Estruturados}

\begin{tabular}{ll} 
COORDENAÇÃo & Claudio Shyinti Kiminami \\
\hline SETOR & Departamento de Engenharia de Materiais \\
\hline RESUMO & demachef@ufscar.br \\
\hline & $\begin{array}{l}\text { Os metais vítreos e os nano-estruturados se constituem numa nova classe de } \\
\text { materiais com propriedades inovadoras devido à estrutura distinta dos tradicionais. } \\
\text { Grande desenvolvimento científico e tecnológico tem sido realizado na última } \\
\text { década nessa nova classe de materiais e o grupo de pesquisa do DEMa-UFSCar } \\
\text { vem atuando fortemente em pesquisa científica e tecnológica nesse tema, sendo } \\
\text { hoje um dos grupos de destaque em nível mundial. A presente proposta visa a } \\
\text { contribuição do DEMa na inovação tecnológica que essa nova classe de material } \\
\text { pode trazer à indústria nacional e assim como a difusão no meio estudantil e técnico } \\
\text { desse tema. Assim o presente programa visa englobar todas as atividades do grupo } \\
\text { no desenvolvimento de metais vítreos e metais nano-estruturados, entre os quais } \\
\text { podem ser destacados ensaios específicos, preparação de corridas experimentais, } \\
\text { caracterização física e estrutural e cursos voltados para o entendimento e aplicação } \\
\text { assim como na difusão de conhecimento no tema. }\end{array}$
\end{tabular}




\section{Teenologia e Produção}

Programa de Apoio Tecnológico e
Educacional em Simulação Computacional
Aplicada aos Materiais de Engenharia e seus
Processos de Transformação

COORDENAÇÃo Rodrigo Bresciani Canto

SETOR Departamento de Engenharia de Materiais

CONTATO demachef@ufscar.br

RESUMO A simulação computacional é uma ferramenta imprescindível para a resolução de problemas avançados de engenharia e pode contribuir sobremaneira na formação intelectual de alunos de engenharia. Este programa objetiva desenvolver subsídios para a aplicação eficiente da simulação computacional e desenvolver/realizar experimentos úteis para a identificação dos modelos computacionais capazes de representar os materiais de engenharia e seus processos de transformação. Com isso, propiciar a capacitação de profissionais e alunos, por intermédio de cursos, bem como aplicar as tecnologias e conhecimentos gerados na resolução de problemas da indústria, por intermédio de projetos de pesquisa, consultorias e assessorias.

PALAVRAS-CHAVE Simulação computacional; materiais; modelagem; tecnologia e produção; inovação tecnológica 


\section{Teenologia e Produção}

\section{TítuLo \\ Programa de Desenvolvimento e \\ Transferência de Tecnologia para o \\ Aperfeiçoamento de Setores Produtivos}

\begin{tabular}{ll} 
COORDENAÇÃo & Miguel Angel Aires Borras \\
\hline SETOR & Departamento de Engenharia de Produção - Sorocaba \\
\hline RESUMO & deps@ufscar.br \\
\hline & $\begin{array}{l}\text { O desenvolvimento e transferência de tecnologia entre as universidades e o setor } \\
\text { produtivo tem se tornado cada vez mais importante para o desenvolvimento sócio- } \\
\text { econômico da sociedade. O intuito deste programa é o de promover trabalhos que } \\
\text { tratem do desenvolvimento e transferência de tecnologias de produtos, processos e } \\
\text { de gestão, seja por meio de projetos executados em parceria com o setor produtivo, } \\
\text { acadêmico ou governamental para instalação de infra-estrutura e desenvolvimento } \\
\text { de produtos e processos de estímulo à inovação tecnológica como ferramenta } \\
\text { de incremento competitivo, seja através de projetos que visem a divulgação, } \\
\text { capacitação e aperfeiçoamento de tecnologias por meio de cursos de curta ou longa } \\
\text { duração. }\end{array}$
\end{tabular}

PALAVRAS-CHAVE inovação tecnológica; transferência de tecnologia; treinamento e capacitação; tecnologia e produção; pólos tecnológicos 


\section{Programa de Ensino, Pesquisa e Extensão do Laboratório de Ergonomia, Simulação e Projeto de Situações Produtivas - PSPLab/ DEP/UFSCar}

COORDEnAção Nilton Luiz Menegon

SETOR

Departamento de Engenharia de Produção

CONTATO

dep@ufscar.br

RESUMO

Este programa articula as ações desenvolvidas desde 1995 pelos grupos ergo\&ação e Simucad do DEP/UFSCar e seus respectivos programas de extensão a partir dos quais foi viabilizada a implantação do Laboratório de Ergonomia, Simulação e Projeto de Situações Produtivas (PSPLab/DEP/UFSCar) no ano de 2010. O programa justifica-se a partir da seguintes considerações: a extensão univiersitária praticada de forma continuada e perene é dependente de forte articulação com as atividades de ensino e pesquisa e só se viabiliza de forma independente quando é produtora de infraestrutura autônoma (nos seus diferentes matizes); a pesquisa é dependente de articulações e respaldo social que transcende os limites das fontes de finaciamento institucional, fortemente associadas às temáticas pré-definidas e enviesadas pelo interesses técno-científicos dominantes (nos seus diferentes matizes); a sólida formação de graduandos e pós-graduandos em campos de conhecimento voltados para a ação e transformação dos status quo (nos seus diferentes matizes) exigem transcendência dos limetes estabelecidos pelas estruturas curriculares. Assim sendo, os interesses acadêmicos e sociais estão ancorados num mesmo ponto de sustentação: pensandoagindo ou agindopensando. Trata-se de uma perspectiva epistemológica, antes de tudo.

PALAVRAS-CHAVE Situações produtivas; simulação; ergonomia; tecnologia e produção; inovação tecnológica 


\section{Teenologia e Produção}

TítuLo

\section{Programa de Extensão do Grupo de Eletroquímica e Polímeros DQ-UFSCar}

\begin{tabular}{ll} 
COORDENAÇÃo & Carlos Ventura D Alkaine \\
\hline SETOR & Departamento de Química \\
\hline CONTATO & dqchefe@ufscar.br \\
\hline RESUMO & $\begin{array}{l}\text { O objetivo do programa é o desenvolvimento de trabalhos nas áreas de atuação } \\
\text { acadêmicas do GEP em relação a setores industriais, com projetos específicos } \\
\text { por eles demandados. Áreas de atuação possíveis serão, por exemplo, corrosão, } \\
\text { baterias industriais, tintas anticorrosivas, galvanoplastia, polímeros, sistemas } \\
\text { dinâmicos, gestão da tecnologia etc. A filosofia será a de realizar trabalhos nas áreas } \\
\text { em que se publica academicamente. }\end{array}$
\end{tabular}




\section{Tecnologia e Producẵo}

\section{ті́тuı Programa de Extensão em Adequação Ambiental}

\begin{tabular}{|c|c|}
\hline COORDEN & Carlos Augusto de Sousa Martins Filho \\
\hline SETOR & Departamento de Ciências Ambientais \\
\hline CONTATO & dcam@ufscar.br \\
\hline RESUMO & $\begin{array}{l}\text { O presente programa pretende realizar ações de restauração florestal no campus de } \\
\text { São Carlos da UFSCar, em imóveis rurais e empreendimentos diversos (loteamentos, } \\
\text { mineradoras, etc.) principalmente relacionados a Áreas de Preservação Permanente } \\
\text { (APP) e Áreas de Reserva Legal (ARL) e Projetos de Recuperação de Áreas } \\
\text { Degradadas (PRAD). Atualização das práticas de conservação dos recursos naturais } \\
\text { e dos processos legais para adequação ambiental. O Programa através do Núcleo } \\
\text { de Perícias, Engenharia de Avaliações e Sustentabilidade Ambiental (NUPEASA) do } \\
\text { Departamento de Ciências Ambientais pretende, com apoio de órgãos de classe e } \\
\text { da Policia Militar Ambiental do Estado de São Paulo, desenvolver todo um conjunto } \\
\text { de atividades com o objetivo maior de promover a recuperação florestal nas áreas } \\
\text { sobre influência da UFSCar. }\end{array}$ \\
\hline
\end{tabular}




\section{Tecnologia e Producẵo}

\section{Tíruı Programa de Extensão em Produção e Restauração Florestal}

\begin{tabular}{ll} 
COORDENAÇÃo & Ricardo Augusto Gorne Viani \\
\hline SETOR & Departamento de Biotecnologia e Produção Vegetal e Animal \\
\hline RENTATO & stela@cca.ufscar.br \\
\hline As cadeias de produção florestal de espécies nativas e de restauração florestal \\
precisam ser fortalecidas como geradoras de emprego e renda por meio da geração \\
de pesquisas e disseminação dos resultados aos setores da sociedade envolvidos \\
com estas atividades. O objetivo central do programa é a disseminação do \\
conhecimento em restauração e produção florestal gerado em pesquisas, por alunos \\
de graduação e professores do Centro de Ciências Agrárias da UFSCar, a agricultores \\
e técnicos. Com o programa esperamos contribuir para que as cadeias de produção \\
de árvores nativas e de restauração florestal sejam fortalecidas como geradoras de \\
trabalho e renda e disseminar tecnologias que facilitem o atendimento, por parte \\
dos produtores rurais, às novas exigências do Código Florestal brasileiro.
\end{tabular}

PALAVRAS-CHAVE produção florestal; restauração florestal; código florestal; tecnologia e produção; desenvolvimento rural 


\section{Tecnologia e Producẵo}

\section{ті́тu $\quad$ Programa de Gestão em Operações e Logística}

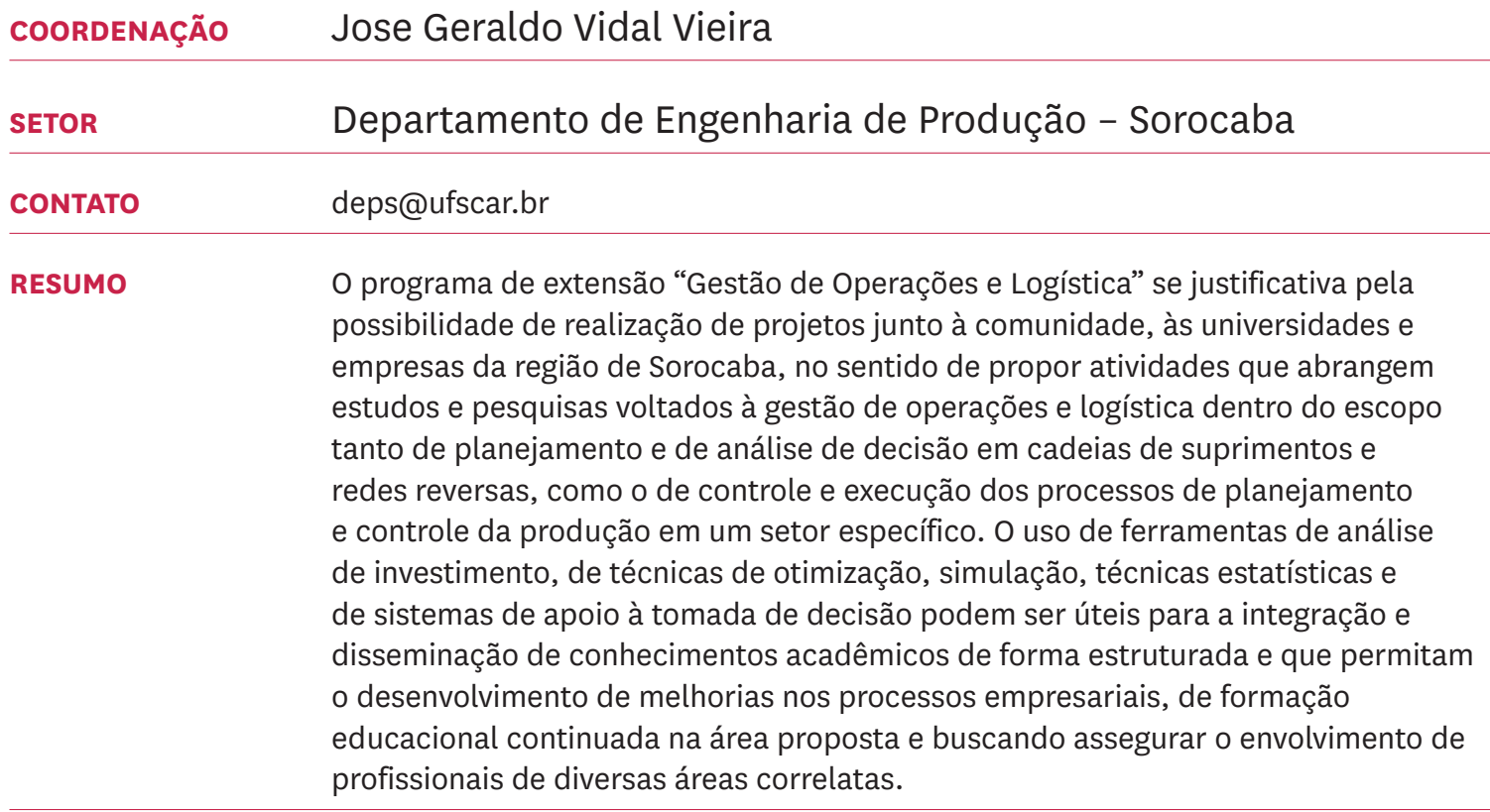

PALAVRAS-CHAVE logística; operações; sistema de apoio à decisão; tecnologia e produção; cooperação interinstitucional 


\section{Tíuıo Programa de Inovação Tecnológica, Propriedade Intelectual e Transferência de Tecnologia da Agência de Inovação da UFSCar}

\begin{tabular}{ll} 
COORDENAÇÃo & Ana Lucia Vitale Torkomian \\
\hline SETOR & Agência de Inovação da UFSCar \\
\hline CONTATO & inovacao@ufscar.br \\
\hline RESUMO & A Agência de Inovação da UFSCar, órgão vinculado diretamente à Reitoria, foi \\
& $\begin{array}{l}\text { instituída por meio da Portaria GR no 823/08 (02/01/2008), tem como finalidade } \\
\text { principal gerir a política de inovação da Universidade e dar celeridade à tramitação } \\
\text { de procedimentos e iniciativas que visem à inovação tecnológica, à proteção da } \\
\text { propriedade intelectual e à transferência de tecnologia no âmbito institucional. } \\
\text { Além disso, nas áreas de atuação da Agência de Inovação da UFSCar, destacam- } \\
\text { se o apoio e suporte a comunidade acadêmica na promoção da proteção de } \\
\text { ativos de propriedade intelectual (patentes, marcas, programas de computador, } \\
\text { desenho industrial, cultivares, entre outros), além da busca de parceiros industriais } \\
\text { para promover o transbordamento do conhecimento gerado na universidade } \\
\text { para a sociedade, por meio do desenvolvimento conjunto ou de transferência de } \\
\text { tecnologia. Este programa visa consolidar as ações da Agência, dando visibilidade a } \\
\text { toda a comunidade da UFSCar. }\end{array}$
\end{tabular}

PALAVRAS-CHAVE inovação tecnológica; propriedade intelectual; transferência de tecnologia; tecnologia e produção; inovação tecnológica 


\section{Tecnologia e Produção}

\section{Título Programa de Melhoria Tecnica da Área de Sistemas Estruturais e Construtivos}

\begin{tabular}{ll} 
COORDENAÇÃo & Guilherme Aris Parsekian \\
\hline SETOR & Departamento de Engenharia Civil \\
\hline RENTATO & deciv@ufscar.br \\
\hline O setor de construção civil é carente de profissionais capacitados, com reflexo na \\
qualidade das edificações, seja no produto final que muitas vezes contém falhas, \\
seja no processo de produção lento, dispendioso e gerador de desperdício de \\
materiais e de entulho. O objetivo do programa é contribuir para a melhoria da \\
qualidade de construçães, através da difusão de conhecimentos técnicos e de \\
experiências no desenvolvimento de projetos e de racionalizaçao da construção. \\
São objeto desse programa: o desenvolvimento de material técnico (normas, \\
manuais, livros), a realizaçao de cursos de extensão e treinamentos, assessoria no \\
desenvolvimento de projetos, realização de ensaios de laboratório.
\end{tabular}

PALAVRAS-CHAVE estruturas; construção civil; racionalização; tecnologia e produção; inovação tecnológica 
Título

\section{Programa do NETPRE para Integração \\ Pesquisa-Projeto-Produção no \\ Desenvolvimento da Construção \\ Industrializada de Concreto no Brasil}

\begin{tabular}{ll} 
COORDENAÇÃo & Marcelo de Araujo Ferreira \\
\hline SETOR & Departamento de Engenharia Civil \\
\hline CONTATO & deciv@ufscar.br \\
\hline RESUMO & O NETPRE - Núcleo de Estudo e Tecnologia em Pré-Moldados de Concreto da UFSCar \\
& atua em três áreas de pesquisa: estudo teórico-experimental do comportamento \\
& de elementos em concreto pré-moldado (através do Laboratório NETPRE); \\
& análise e projeto de estruturas pré-moldadas; estudo de processos produtivos \\
& industrializados. Este grupo possui interação com pesquisadores da UFG e UNESP- \\
& Ilha Solteira e com a University of Nottingham, do Reino Unido. Além disto, possui \\
& forte interação com o setor produtivo, através da cooperação entre a UFSCar e \\
& a ABCiC (Associação Brasileira de Construção Industrializada de Concreto). O \\
& principal objetivo deste programa é a consolidação do NETPRE como um Centro de \\
& Referência para o Setor de Estruturas Pré-Fabricadas no Brasil. Dentre os objetivos \\
& específicos tem-se: pesquisa aplicada; normalização técnica; procedimentos de \\
& projeto estrutural; processos Industrializados de Concreto; dissemição tecnológica \\
& através de seminários e cursos (graduação, pós-graduação e extensão); formação \\
& de profissionais técnicos para a área; publicações de materiais técnicos e científicos.
\end{tabular}

PALAVRAS-CHAVE concreto pré-moldado; estruturas pré-fabricadas; construção industrializada; tecnologia e produção; inovação tecnológica 


\section{Teenologia e Produção}

\section{TíTULO \\ Programa em Desenvolvimento, Inovação e Difusão em Tecnologias da Informação e Comunicação (TIC)}

\begin{tabular}{ll} 
COORDENAÇÃo & Cesar Augusto Cavalheiro Marcondes \\
\hline CONTATO & Departamento de Computação \\
\hline RESUMO & dc@ufscar.br \\
& $\begin{array}{l}\text { O programa visa assessorar a formação e/ou atualização tecnológica aos } \\
\text { profissionais que atuam na área de computação, para atender a demanda de } \\
\text { pessoal especializado para trabalhar em pesquisa e desenvolvimento de recursos } \\
\text { computacionais a serem aplicados na área de Tecnologia da Informação e } \\
\text { Comunicação (TIC). }\end{array}$
\end{tabular}

PALAVRAS-CHAVE inovação tecnológica; tecnologia da informação; apoio a consultas e análises g; tecnologia e produção; inovação tecnológica 


\section{Teenologia e Produção}

tíuıo Programa Produção em Monogástricos

COORDENAÇÃo Luciana Thie Seki Dias

SETOR Departamento de Biotecnologia e Produção Vegetal e Animal

CONTATO stela@cca.ufscar.br

RESUMO O objetvo do programa é dar suporte às pesquisas que podem vir a ser desenvolvidas em nosso campus para auxiliar na formação intelectual e profissional dos alunos de graduação e pós-graduação além de gerar informações a pesquisadores e técnicos de áreas correlatas, produtores e fabricantes de insumo utilizados na produção animal.

PALAVRAS-CHAVE aves; peixes; nutrição; tecnologia e produção; desenvolvimento rural

DATA INÍCIO $\quad 5 / 11 / 2012$




\section{Teenologia e Produção}

TíTULO

Projeto PROMUS - Promovendo Mudanças

- "Mentes Pensantes, Criativas e de Boa

Vontade, Unidas no Desenvolvimento

de Projeto Inovador e Auto-Sustentável Aplicado a Sociedades Desfavorecidas"

\begin{tabular}{ll} 
COORDENAÇÃo & Yeda Regina Venturini \\
\hline SETOR & Departamento de Computação \\
\hline RESUMO & dcomp@ufscar.br \\
& $\begin{array}{l}\text { Projeto multidisciplinar com o objetivo de promover mudanças tanto nas } \\
\text { comunidades alvo quanto nos participantes diretamente envolvidos. Almeja ser uma } \\
\text { experiência enriquecedora para os participantes, promovendo a conscientização } \\
\text { social, a criatividade e o trabalho de equipe. Tem como foco promover mudanças } \\
\text { em comunidades desfavorecidas, através da aplicação e disseminação de } \\
\text { soluções criativas e autosustentáveis para resolver problemas relevantes para esta } \\
\text { comunidade. Estas soluções podem ser técnicas ou não, em todas as áreas (ciência, } \\
\text { engenharia, biologia, humana, etc.). Sempre utilizando materiais disponíveis na } \\
\text { comunidade, tal que a comunidade possa dar continuidade. }\end{array}$ \\
\hline
\end{tabular}

social; sustentável; multidisciplinar; tecnologia e produção; desenvolvimento urbano 


\section{Tecnologia e Producẵo}

\section{ті́тьо Projeto, Modelagem e Simulação de}

Sistemas Mecânicos

\begin{tabular}{ll}
\hline COORDENAÇÃo & Flavio Yukio Watanabe \\
\hline SETOR & Centro de Ciências Exatas e de Tecnologia \\
\hline RENTATO & ccetdir@ufscar.br \\
\hline O objetivo principal deste Programa de Extensão é contribuir com o fortalecimento \\
e reconhecimento do Curso de Engenharia Mecânica da UFSCar por intermédio \\
da ampliação das possibilidades de planejamento e realização de atividades de \\
extensão junto às comunidades acadêmica interna e acadêmica/profissional externa \\
de instituições públicas e privadas. O programa abrange um espectro bastante \\
amplo de atividades, mas com enfoque na área de Projeto Mecânico, que engloba \\
os processos de projeto, modelagem, simulação, ensaios, análise e otimização \\
de sistemas mecânicos, utilizando métodos de solução analítica, numérica e \\
computacional; sempre buscando promover a integração de conhecimentos \\
abordados em atividades de ensino e pesquisa, e contribuir com o processo de \\
formação acadêmica, tecnológica e social dos públicos-alvos e da comunidade \\
acadêmica envolvida.
\end{tabular}




\section{Teenologia e Produção}

Título

Projetos de Unidades Industriais e de Negócios

$\begin{array}{ll}\text { COORDENAÇÃo JOaO Alberto Camarotto } \\ \text { SETOR } & \text { Departamento de Engenharia de Produção }\end{array}$

CONTATO dep@ufscar.br

RESUMO O objetivo do programa é dar continuidade às atividades já desenvolvidas pelo grupo Simucad no campo do Projeto de Unidades Industriais e de Negócios.

PALAVRAS-CHAVE Unidades; negócios; tecnologia e produção; inovação tecnológica

DATA INÍCIO 21/6/2000




\section{Teenologia e Produção}

Química e Biogeoquímica Ambiental do
Laboratório de Biogeoquímica Ambiental do
Departamento de Química da UFSCar

\begin{tabular}{ll} 
COORDENAÇÃo & Antonio Aparecido Mozeto \\
\hline SETOR & Departamento de Química \\
\hline CONTATO & dqchefe@ufscar.br \\
\hline
\end{tabular}

RESUMO São objetivos deste programa: qualificar o Laboratório que apresenta as atividades desenvolvidas e experiência na área de concentração das Ciências da Terra; oferecer uma oportunidade extra para formação de estudantes de Graduação e Pós-graduação; constituir-se num elemento regularizador destas atividades desenvolvidas pelo Laboratório de Biogeoquímica Ambiental do DQ, dentro do escopo de atuação da FAI. 


\section{Tecnologia e Produção}

Título Robótica

\begin{tabular}{ll} 
COORDENAÇÃo & Tatiana de Figueiredo Pereira Alves Taveira Pazelli \\
\hline SETOR & Departamento de Engenharia Elétrica \\
\hline RENTATO & dee@ufscar.br \\
\hline Este programa de extensão visa a divulgação, o desenvolvimento e o ensino de \\
atividades relacionadas, direta ou indiretamente, ao campo da robótica. São \\
constituintes deste programa, projetos e atividades de desenvolvimento e aplicação \\
de sistemas robóticos, ressaltando a característica multidisciplinar dessa tecnologia \\
e ilustrando a modificação social envolvida nos diversos setores de aplicação.
\end{tabular}

PALAVRAS-CHAVE robótica; educação; aplicação; tecnologia e produção; cooperação interinstitucional

DATA INÍCIO 29/4/2016




\section{Tecnologia e Producẵo}

\section{Título Route UFSCar}

COORDENAÇÃo Jose Benaque Rubert

SETOR Departamento de Engenharia Mecânica

CONTATO demec@ufscar.br

RESUMO Trata-se do desenvolvimento e construção de uma veículo automotor de competição na categoria Fórmula SAE, que incorpora gestão, desenvolvimento e inovação tecnológica. Para o desenvolvimento dessas atividades existe um grupo de estudantes em formação que deverá participar de eventos e competições onde o veículo produzido submete-se a uma série de testes competitivos de desempenho. Trata-se de uma atividade complementar de formação dos estudantes de engenharia da universidade reconhecida dentro de muitos projetos pedagógicos e é também uma atividade de extensão, pois além de participação em competições e eventos universitários, o grupo em formação se propõem a levar este trabalho ao conhecimento de estudantes do ensino médio, como forma de despertar interesse desses alunos para os cursos de engenharia. O grupo jé fez contatos preliminares com a Secretaria de Educação do Estado e houve a manifestação de interesse nesta iniciativa. O projeto do veículo e algumas peças que já foram obtidas foram apresentadas no evento Circo da Ciência, realizado pela UFSCar em 2011.

PALAVRAS-CHAVE fórmula sae; veículos automotores; veículos de competição; tecnologia e produção; inovação tecnológica 


\section{Títuıo Serviço de Análise do Laboratório de Ressonância Magnética Nuclear do DQ-UFSCar}

$\begin{array}{ll}\text { COORDENAÇÃo } & \text { Antonio Gilberto Ferreira } \\ \text { SETOR } & \text { Departamento de Química }\end{array}$

CONTATO dqchefe@ufscar.br

RESUMO O Laboratório de Ressonância Magnética Nuclear (RMN) localizado no Departamento de Química da UFSCar, teve o seu início em 1994 e a partir dessa data passou a prestar serviços de análises de: RMN, Infravermelho, Ultravioleta e CHN para o departamento de Química da UFSCar e também para a indústria químico farmacêutica da região e de outros estados. O principal objetivo do laboratório sempre foi a formação de recursos humanos na área de RMN e, para isso, temos orientado alunos nos níveis de mestrado, doutorado e pós-doutorado focando essas técnicas. Porém, com a crescente demanda da indústria químico farmacêutica por estas análises, passou-se também a fazer prestação de serviços. Esses serviços são basicamente de três naturezas: simples obtenção de medidas espectroscópicas; interpretação de resultados com emissão de relatórios (para ANVISA e/ou FDA); desenvolvimento de análises para elucidação estrutural de compostos orgânicos, principalmente os minoritários, presentes em produtos químico farmacêuticos. Essas análises são requisitadas em regime de urgência e normalmente enviamos os resultados em menos de 72 horas depois da chegada da(s) amostra(s) no laboratório de RMN. Entendemos que ao prestarmos esses serviços para as indústrias, geramos receita para o laboratório, departamento e a Universidade, mas, principalmente, acabam gerando uma demanda na qual conseguimos inserir os nossos profissionais nessas indústrias. Não só isso, mas também, com essa demanda estamos criando um ambiente para que no futuro essa prestação de serviço seja feita por uma empresa junior (spin-off), por exemplo. É importante esclarecer que a técnica de RMN é tão carente no meio industrial brasileiro, que não temos nenhum empresa privada que faça essa prestação de serviço. Esses serviços são realizados por empresas estrangeiras e/ou por laboratórios de RMN localizados nas Instituições de Ensino Superior.

PALAVRAS-CHAVE rmn; infravermelho; ultravioleta; tecnologia e produção; inovação tecnológica 


\section{Tecnologia e Producạ̃o}

\section{ті́те $\quad$ Silvicultura e Recursos Florestais}

COORDENAÇÃo Jose Mauro Santana da Silva

SETOR Departamento de Ciências Ambientais - Sorocaba

CONTATO dca@ufscar.br

RESUMO A atividade florestal no curso de engenharia florestal da Universidade Federal de São Carlos atende não só à demanda atual por proteção dos recursos, energia, produção e crescimento, como também pela redução dos impactos no ambiente.

Da área profissionalizante são desenvolvidas habilidades e competências para a produção sustentável, geração de novos produtos, monitoramento, manejo dos recursos hídricos e florestais, bem como sua conservação. Com o aumento da procura ao curso de Engenharia Florestal por parceiros externos, como ONGs, prefeituras e empresas privadas, surge a necessidade de criação de um programa da grande área denominada silvicultura.

PALAVRAS-CHAVE florestas; biomassa; recursos ambientais; tecnologia e produção; gestão de recursos naturais 


\section{Tecnologia e Produção}

\section{tíruı $\quad$ Síntese e Avaliação da Atividade Biológica de Produtos Naturais e Análogos}

\begin{tabular}{ll} 
COORDENAÇÃo & Arlene Goncalves Correa \\
\hline SETOR & Departamento de Química \\
\hline CONTATO & dqchefe@ufscar.br \\
\hline \multirow{2}{*}{ RESUMO } & O Laboratório de Síntese de Produtos Naturais do Departamento de Química \\
& da UFSCar tem como principal linha de pesquisa a síntese de produtos naturais \\
& bioativos e análogos, empregando tecnologias combinatórias, visando a otimização \\
& da atividade biológica e a determinação da relação estrutura-atividade. \\
& O presente trabalho tem como objetivos: sintetizar alcalóides 4-quinolinônicos \\
& (1) e acridônicos (2), xantonas (3), neoligananas (4), cumarinas (5), entre outros, \\
& através de métodos descritos na literatura e/ou de novas rotas sintéticas; realizar os \\
bioensaios in vitro e/ou in vivo para verificar a atividade inibitória destes compostos \\
frente a enzimas, tais como gGAPDH de T. cruzi, APRT de Leishmania tarentolae e \\
PNP de Schistosoma mansoni; a partir da identificação de um composto de partida \\
que apresente atividade frente à enzima, estudar possíveis modificações estruturais \\
para a preparação de análogos; preparar coleções combinatórias, utilizando- \\
se tanto síntese em fase sólida como em solução, e avaliar os componentes das \\
mesmas com relação à atividade inibitória da enzima.
\end{tabular}

PALAVRAS-CHAVE síntese; produtos naturais; doenças tropicais; tecnologia e produção; inovação tecnológica 


\section{Tecnologia e Producạ̃o}

\section{тітио $\quad$ Sistemas Computacionais Inteligentes}

COORDENAÇÃo Estevam Rafael Hruschka Junior

SETOR Departamento de Computação

CONTATO dc@ufscar.br

RESUMO Sistemas computacionais tradicionais estão presentes no dia-a-dia das empresas, organizações e pessoas em geral. Entretanto, a capacidade de executar tarefas que exigem algum tipo de inteligência (aprendizado, tomada de decisão etc.) ainda não é uma realidade em muitos sistemas computacionais. O objetivo desse programa é aproximar as descobertas científicas e tecnológicas (vinculadas à inteligência artificial) e a sociedade. Assim, pretende-se promover acordos de cooperação com empresas e centros de pesquisas, bem como dar suporte a eventos que tenham como meta integrar resultados de pesquisa (científica e tecnológica) com aplicações reais que tragam retorno para a sociedade. 


\section{Tecnologia e Producẵo}

TítuLo

Sistemas Computacionais Inteligentes Aplicados para Obtenção de Conhecimento Online

\begin{tabular}{ll} 
COORDENAÇÃo & Helena de Medeiros Caseli \\
\hline SETOR & Departamento de Computação \\
\hline CONTATO & dc@ufscar.br
\end{tabular}

RESUMO A quantidade de informação produzida e disponibilizada de modo online em páginas da Internet cresce a cada dia. Essas informações geralmente são veiculadas em língua natural (português, inglês, espanhol etc.) e vêm acompanhadas de informação visual (imagens e vídeos, por exemplo). Trata-se, portanto, de uma fonte rica de conhecimento útil para aplicações e sistemas computacionais inteligentes. Sistemas inteligentes são capazes de aprender a partir de informações e utilizar o conteúdo aprendido para desempenhar uma tarefa ou produzir conhecimento que servirá para o desenvolvimento de uma aplicação computacional. Eles são uma demanda para instituições de pesquisa, empresas e a sociedade de modo geral. O objetivo desse programa é, portanto, aproximar a sociedade das descobertas científicas e tecnológicas vinculadas às áreas de inteligência artificial, processamento de língua natural e de imagem. Assim, pretende-se promover acordos de cooperação com empresas e centros de pesquisas, bem como dar suporte a eventos que tenham como meta integrar resultados de pesquisa (científica e tecnológica) com aplicações reais que tragam retorno para a sociedade.

PALAVRAS-CHAVE inteligência artificial; processamento língua natural; processamento de imagem; tecnologia e produção; inovação tecnológica 


\section{Tecnologia e Produção}

Título Suporte Tecnológico em Educação a

Distância

\begin{tabular}{ll} 
COORDENAÇÃo & Cesar Augusto Camillo Teixeira \\
\hline SETOR & Departamento de Computação \\
\hline CONTATO & dc@ufscar.br \\
\hline RESUMO & $\begin{array}{l}\text { São objetivos do programa: dar uma formação aos profissionais que atuam na } \\
\text { área de computação, para atuarem no desenvolvimento de ambientes de EAD. } \\
\text { Para atingir tais objetivos poderão ser realizados assessorias, cursos de extensão } \\
\text { isolados, cursos de especialização ou de aperfeiçoamento, ou outras atividades que } \\
\text { propiciam atualização tecnológica em Educação a distância para nossos alunos. }\end{array}$
\end{tabular}

PALAVRAS-CHAVE tecnológico; educação; tecnologia e produção; educação à distância

DATA INÍCIO 14/3/2001




\section{Tecnologia e Produção}

TítuLo

\section{Técnicas de Análise, Diagnóstico e Projetos para Sistemas Elétricos de Potência}

\begin{tabular}{ll} 
COORDENAÇÃo & Ricardo Augusto Souza Fernandes \\
\hline SETOR & Centro de Ciências Exatas e de Tecnologia \\
\hline CONTATO & ccetdir@ufscar.br
\end{tabular}

RESUMO Este Programa de Extensão visa a realização de atividades junto às empresas do setor de energia elétrica. Destaca-se que tais atividades poderão ser desenvolvidas na forma de P\&D ANEEL, consultorias e/ou cursos de extensão. Por meio do estabelecimento deste vínculo universidade-empresa, será possível trazer aos alunos de graduação os problemas vivenciados pelas empresas. Portanto, vislumbra-se também o aprimoramento das atividades relacionadas ao ensino. É importante comentar que este Projeto de Extensão foi idealizado com base nas atividades de pesquisa desenvolvidas pelo Grupo de Pesquisa "Smart Grids e Qualidade da Energia Elétrica”, o qual encontra-se nos diretórios do CNPq e é certificado pela UFSCar. Assim, nota-se que este Projeto de Extensão busca garantir a interação entre ensino, pesquisa e extensão. 


\section{Teenologia e Produção}

TítuLo

\section{Tecnologia de Informação, Programação de Operações e Cadeia de Suprimento}

\begin{tabular}{ll} 
COORDENAÇÃo & Fabio Molina da Silva \\
\hline SETOR & Departamento de Engenharia de Produção \\
\hline CONTATO & dep@ufscar.br \\
\hline RESUMO & $\begin{array}{l}\text { São objetivos deste programa: disseminar modelos e procedimentos relativos ao } \\
\text { planejamento, à programação e ao controle da produção, buscando um melhor } \\
\text { desempenho operacional e financeiro; fomentar a pesquisa aplicada, propiciando a } \\
\text { geração de conhecimento em programação de operações e em gestão de cadeias de } \\
\text { suprimentos. }\end{array}$
\end{tabular}




\section{Tecnologia e Produção}

\section{Título Tecnologia e Desenvolvimento de Materiais}

COORDENAÇão Tomaz Toshimi Ishikawa

SETOR Departamento de Engenharia de Materiais

CONTATO demachef@ufscar.br

RESUMO A comunidade tecnológica e científica das empresas necessita sempre de uma análise ou uma investigação mais detalhada para a tomada de decisões. Para tanto requerem que estudos sejam realizados a médio prazo, com pesquisa, ensaios etc. Neste aspecto, o DEMa mantém uma relação de interação universidade-empresa de forma positiva e tenta na medida do possível, responder às solicitações da demanda. Os principais objetivos são: manter atualização de novas tendências em termos de tecnologia; ter uma interação com problemas tecnológicos, que servem de exemplos em salas de aula durante a exposição teórica; dar aos alunos a oportunidade de fazer estágio, fazer visitas às empresas como parte do aprendizado juntamente com os alunos em disciplinas específicas, entre outros.

PALAVRAS-CHAVE consultoria; desenvolvimento de materiais; prestacao de serviços; tecnologia e produção; inovação tecnológica 


\section{Tecnologia e Producạ̃o}

\section{TíTULO \\ Tecnologias e Aplicações de Automação Industrial}

\begin{tabular}{ll} 
COORDENAÇÃo & Edilson Reis Rodrigues Kato \\
\hline SETOR & Departamento de Computação \\
\hline RESUMO & dc@ufscar.br \\
& $\begin{array}{l}\text { A Automação Industrial está presente na realidade do Brasil, a qual necessita } \\
\text { desenvolvimento em pesquisa e qualificação de mão de obra capaz de permitir seu } \\
\text { crescimento. Abrange várias áreas do conhecimento, tais como engenharia elétrica, } \\
\text { mecânica, de computação, de produção, civil, além das ciências básicas. O objetivo } \\
\text { desse programa é criar meios para transferência de conhecimento gerado no âmbito } \\
\text { da UFSCar, especificamente no campo de Automação Industrial para a sociedade de } \\
\text { forma geral, promovendo a capacitação de recursos humanos e de empresas dos } \\
\text { setores industrial e serviços que atuam ou fazem uso de técnicas de Automação. }\end{array}$
\end{tabular}

PALAVRAS-CHAVE automação; sistemas computacionais; sistemas de controle; tecnologia e produção; inovação tecnológica 


\section{Tecnologia e Produção}

\section{TítULo \\ Tecnologias e Aplicações de Inteligência Computacional}

\begin{tabular}{ll} 
COORDENAÇÃo & Heloisa de Arruda Camargo \\
\hline SETOR & Departamento de Computação \\
\hline RONTATO & dc@ufscar.br \\
\hline RESUMO & $\begin{array}{l}\text { A inteligência computacional permeia todas as áreas do conhecimento, a medida } \\
\text { que visa a aquisição, representação e processamento do conhecimento na solução } \\
\text { de problemas. O objetivo desse programa é criar meios para transferência de } \\
\text { conhecimento gerado no âmbito do DC -UFSCar, especificamente no campo de } \\
\text { Inteligência Computacional para a sociedade de forma geral. }\end{array}$
\end{tabular}

PALAVRAS-CHAVE inteligência computacional; conhecimento impreciso; raciocínio; tecnologia e produção; inovação tecnológica 


\section{Teenologia e Produção}

Tírulo Tecnologias e Estratégias de Automação

\begin{tabular}{ll} 
COORDENAÇÃo & Orides Morandin Junior \\
\hline SETOR & Departamento de Computação \\
\hline CONTATO & dc@ufscar.br \\
\hline RESUMO & $\begin{array}{l}\text { O objetivo do programa é tornar acessível à sociedade o conhecimento de domínio } \\
\text { da Universidade promovendo a capacitação de recursos humanos } \\
\text { e de empresas dos setores industrial e serviços que atuam ou fazem uso de técnicas } \\
\text { de Automação. }\end{array}$ \\
\hline
\end{tabular}

PALAVRAS-CHAVE estratégia; automação; tecnologias; tecnologia e produção; inovação tecnológica

DATA INÍ́CIO 27/10/2006 


\section{Tecnologia e Produção}

Título

\section{Tecnologias, Treinamentos e Aplicações em Telecomunicações}

\begin{tabular}{ll} 
COORDENAÇÃo & Jose Carlos Pizolato Junior \\
\hline SETOR & Centro de Ciências Exatas e de Tecnologia \\
\hline CONTATO & ccetdir@ufscar.br
\end{tabular}

RESUMO

A Engenharia Elétrica está presente na realidade do Brasil, a qual necessita de desenvolvimento em pesquisa e qualificação de mão de obra capaz de permitir seu crescimento. Dentre as várias áreas de conhecimento da Engenharia Elétrica destaca-se a especialidade de telecomunicações. O objetivo desse programa é criar meios para transferência de conhecimento gerado no âmbito da UFSCar, especificamente no campo de telecomunicações para a sociedade de forma geral, promovendo a capacitação de recursos humanos e de empresas dos setores industrial e serviços que atuam em telecomunicações.

PALAVRAS-CHAVE treinamento; tecnologia; sistemas de telecomunicações; tecnologia e produção; educação continuada 


\section{Teenologia e Produção}

TítuLo

TEC-SHARE: Transferência de Tecnologia no Ensino de Computação

\begin{tabular}{ll} 
COORDENAÇÃo & Antonio Carlos dos Santos \\
\hline SETOR & Departamento de Computação \\
\hline CONTATO & dc@ufscar.br \\
\hline RESUMO & $\begin{array}{l}\text { São objetivos deste programa: disponibilizar à sociedade conhecimentos, técnicas e } \\
\text { recursos referentes ao ensino de computação; compartilhar a excelência no ensino } \\
\text { de computação com outras instituiçães de ensino, visando sua capacitação gradual, } \\
\text { o aprimoramento de seus serviços à sociedade e, consequentemente, um maior } \\
\text { alcance social dos conhecimentos produzidos, sistematizados e difundidos através } \\
\text { do DC/UFSCar. }\end{array}$
\end{tabular}

transferência; tecnologia; tecnologia e produção; inovação tecnológica 


\section{Teenologia e Produção}

TítuLo

\section{Testes e Análises Técnicas, Físico-Químicas e Analíticas de Materiais e seus Componentes}

\begin{tabular}{ll} 
COORDENAÇÃo & Elson Longo da Silva \\
\hline SETOR & Departamento de Química \\
\hline CONTATO & dqchefe@ufscar.br
\end{tabular}

RESUMO O Centro de Desenvolvimento de Materiais Funcionais (CDMF - CEPID - FAPESP) tem como um dos objetivos principais os projetos de inovação. Assim, o CDMF relacionase com empresas de alta tecnologia como também outros Centros e Departamentos que procuram parceria de desenvolvimento ou caracterizações únicas e especializadas. Devido à grande variedade e alto padrão dos equipamentos do CDMF esse centro tem capacidade de fornecer serviço especializado em medidas físicoquímicas tanto para Empresas do setor tecnológico, bem como para comunidade acadêmica.

PALAVRAS-CHAVE caracterização; físico-química; tecnologia; tecnologia e produção; inovação tecnológica 
8

\section{Trabalho}

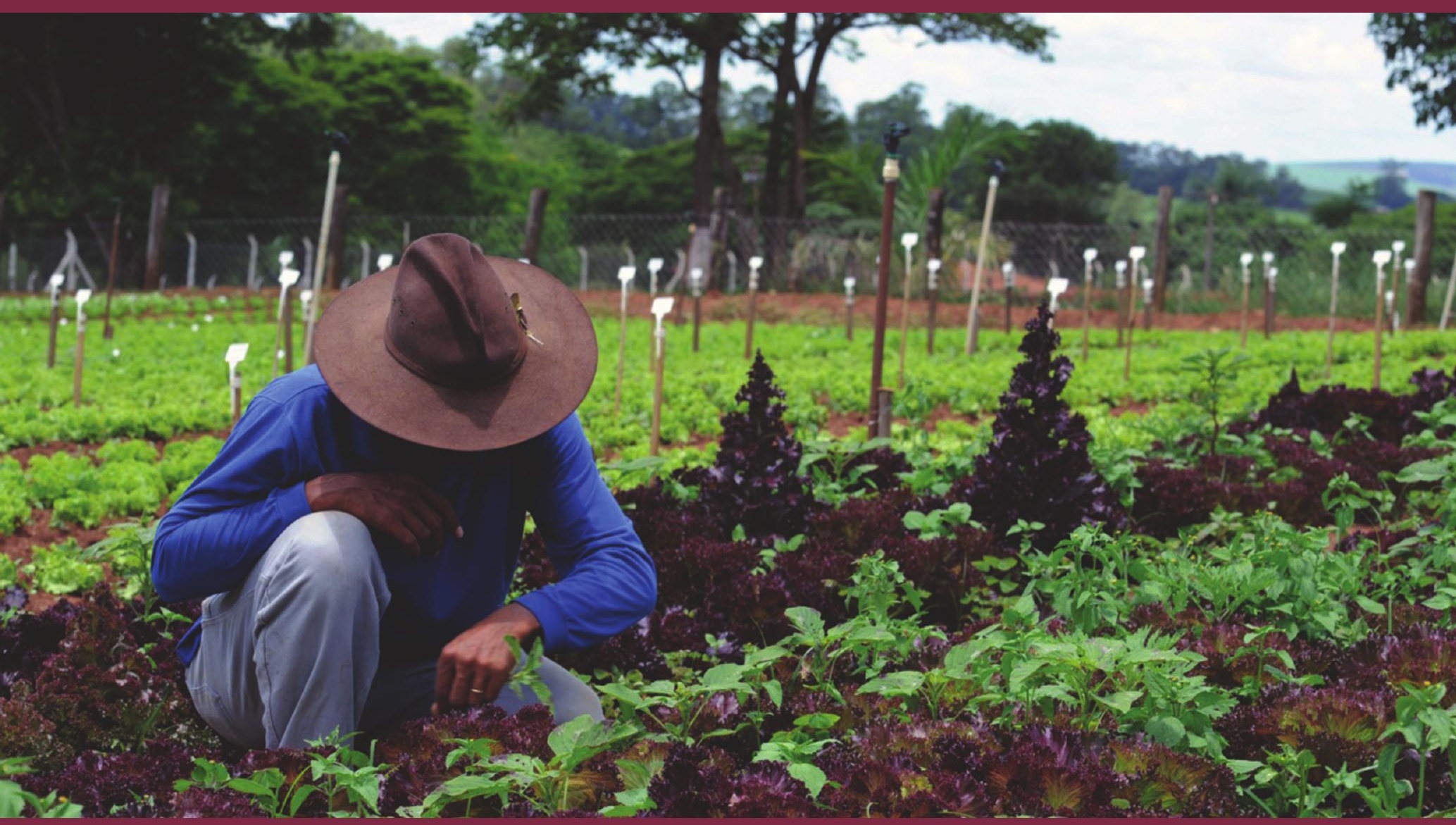

UFSCar Campus Araras, 2012.

Foto: Cain Rodrigues. 
TítuLo

\section{Agricultura Sustentável (Antes Denominado Tecnologia Apropriada para Agricultura Familiar)}

\begin{tabular}{ll} 
COORDENAÇÃo & Luiz Antonio Correia Margarido \\
\hline SETOR & $\begin{array}{l}\text { Departamento de Tecnologia Agroindustrial e Socioeconomia } \\
\text { Rural }\end{array}$ \\
\hline CONTATO & secdtai@cca.ufscar.br \\
\hline RESUMO & $\begin{array}{l}\text { Os objetivos do programa são analisar e selecionar sob a prisma da sustentabilidade } \\
\text { (econômica, social e ecológica), técnicas apropriadas para produtores rurais que } \\
\text { não dispõem de recursos econômicos para grandes investimentos e, fazer com que } \\
\text { estas técnicas cheguem aos agricultores de modo a que passem a tirar proveito das } \\
\text { mesmas. }\end{array}$
\end{tabular}

PALAVRAS-CHAVE agricultura; sustentável; trabalho; questão agrária

DATA INÍCIO

$1 / 5 / 1999$ 
TÍTULO

\section{Ergonomia, Segurança, Higiene e Projeto do Trabalho. Ergo-e-Ação: Grupo de Ensino, Pesquisa e Extensão em Ergonomia e Projetação do Trabalho}

COORDENAÇÃo Nilton Luiz Menegon

SETOR Departamento de Engenharia de Produção

CONTATO dep@ufscar.br

RESUMO São objetivos deste programa a utilização da base conceitual, dos métodos e das técnicas apresentadas na concepção de situações de trabalho contextualizadas em estratégias operacionais específicas; geração de conhecimento acerca da realidade das situações de trabalho e dos processos de introdução de mudanças positivas neste campo. 
TíTULo

Incubadora Regional de Cooperativas Populares - INCOOP

\begin{tabular}{ll} 
COORDENAÇÃo & Ana Lucia Cortegoso \\
\hline SETOR & Departamento de Psicologia \\
\hline CONTATO & dpsic@ufscar.br \\
\hline RESUMO & $\begin{array}{l}\text { É objetivo deste programa estimular constituição de equipes interdepartamentais } \\
\text { que venham a estruturar projetos de extensão interdisciplinares que enfoquem a } \\
\text { temática da Economia Solidária. }\end{array}$ \\
\hline PALAVRAS-CHAVE & incubadora; cooperativas; trabalho; organizações populares \\
\hline DATA INÍCIO & $10 / 3 / 2000$ \\
\hline
\end{tabular}


TíTULo

\section{Processo Organizativo e Gestão de Assentamentos Rurais e Comunidades Tradicionais}

\begin{tabular}{ll} 
COORDENAÇÃo & Rosemeire Aparecida Scopinho \\
\hline SETOR & Departamento de Psicologia \\
\hline CONTATO & dpsic@ufscar.br \\
\hline RESUMO & $\begin{array}{l}\text { As transformações em curso no mundo do trabalho rural brasileiro tornam a } \\
\text { organização econômica e social nos assentamentos de reforma agrária e outros tipos } \\
\text { de comunidades rurais tradicionais objeto de preocupações de vários segmentos } \\
\\
\text { e agentes sociais, governamentais ou não. Essas comunidades são tidas como } \\
\text { fenômenos sociais importantes a partir da década de 1990, pela potencialidade } \\
\text { que possuem de contribuir para gerar trabalho e renda e solucionar os problemas } \\
\text { relacionados à pobreza e à degradação ambiental, tornando-se espaços de } \\
\text { enraizamento e de reconstrução de relações sociais. O programa objetiva } \\
\text { aprofundar estudos e sistematizar e divulgar experiências vividas no processo } \\
\text { organizativo dessas comunidades. }\end{array}$ \\
\hline
\end{tabular}


TíTULo

Psi-Sistemas: Serviço em Psicologia Organizacional

\begin{tabular}{ll} 
COORDENAÇÃo & Elizabeth Joan Barham \\
\hline SETOR & Departamento de Psicologia \\
\hline CONTATO & dpsic@ufscar.br \\
\hline RESUMO & $\begin{array}{l}\text { É objetivo deste programa apoiar iniciativas relacionadas à proposição, } \\
\text { planejamento, implantação, implementação e aperfeiçoamento de organizações e } \\
\text { serviços de forma que estes, constituam adequados ambientes de trabalho capazes } \\
\text { de cumprir a função social para a qual foram propostos. }\end{array}$
\end{tabular}


título Qualidade de Vida na UFSCar

COORDENAÇão Eliane da Silva Grazziano

SETOR Departamento de Terapia Ocupacional

CONTATO denf@ufscar.br

RESUMO O Programa proposto surgiu como um dos objetivos traçados pelo Plano de Desenvolvimento Institucional (PDI) da UFSCar, que tem entre suas diretrizes específica, a valorização dos servidores por meio do aperfeiçoamento das políticas que promovam a qualidade de vida e tem como eixo norteador propor ações que contemplem a promoção da qualidade de vida dos servidores dentro e fora do trabalho, envolvendo seus familiares. Pretende-se que o programa proposto identifique fatores protetivos da saúde destes trabalhadores.

PALAVRAS-CHAVE qualidade de vida; saúde do trabalhador; equilíbrio emocional; trabalho; saúde e segurança no trabalho 


\section{MINISTÉRIO DA}

EDUCACÃO

Universidade Federal de São Carlos Pró-Reitoria de Extensão

Rodovia Washington Luís, km 235

Monjolinho, São Carlos-SP

CEP 13565-905

+55 16 3351-8112

proex@ufscar.br

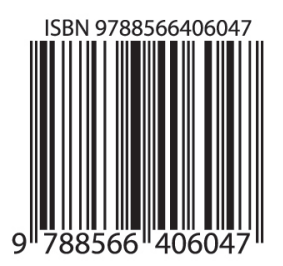

